\title{
INTERIM DESIGN STATUS AND OPERATIONAL REPORT FOR REMOTE HANDLING FIXTURES: PRIMARY AND SECONDARY BURNERS
}

\author{
by \\ R. M. BURGOYNE \\ Prepared under \\ Contract EY-76-C-03-0167 \\ Project Agreement No. 53 \\ for the San Francisco Operations Office \\ U.S. Energy Research and Development Administration
}




\section{DISCLAIMER}

This report was prepared as an account of work sponsored by an agency of the United States Government. Neither the United States Government nor any agency Thereof, nor any of their employees, makes any warranty, express or implied, or assumes any legal liability or responsibility for the accuracy, completeness, or usefulness of any information, apparatus, product, or process disclosed, or represents that its use would not infringe privately owned rights. Reference herein to any specific commercial product, process, or service by trade name, trademark, manufacturer, or otherwise does not necessarily constitute or imply its endorsement, recommendation, or favoring by the United States Government or any agency thereof. The views and opinions of authors expressed herein do not necessarily state or reflect those of the United States Government or any agency thereof. 


\section{DISCLAIMER}

Portions of this document may be illegible in electronic image products. Images are produced from the best available original document. 


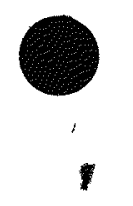

4

*

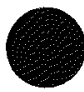




\begin{abstract}
The HTGR reprocessing flowsheet consists of two basic process elements: (1) spent fuel crushing and burning and (2) solvent extraction.

Fundamental to these elements is the design and development of specialized process equipment and support facilities. A major consideration of this design and development program is equipment maintenance: specifically, the design and demonstration of selected remote maintenance capabilities and the integration of these into process equipment design.

This report documents the current status of the development of remote handling and maintenance fixtures for the primary and secondary burners.
\end{abstract}


•

$y$

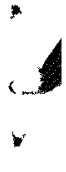


CONTENTS

ABSTRACT . . . . . . . . . . . . . . . . . . . . . iii

1. INTRODUCTION. . . . . . . . . . . . . . . . . 1-1

2. SUMMARY . . . . . . . . . . . . . . . . . 2-1

2.1. Tilt-Down Fixture - Primary and Secondary Burners. . . 2-2

2.2. Tri-Beam Lift Hook Assembly. . . . . . . . . . 2-3

2.3. Lift Fixture - Secondary Burner. . . . . . . . . 2-4

2.4. Susceptor and Ceramic Holding and Trunnion Fixture . . 2-4

2.5. Susceptor and Ceramic Removal Fixture......... 2-5

2.6. Heater and Shroud Handling Fixture . . . . . . . 2-7

3. SEMIREMOTE HANDLING FIXTURES. . . . . . . . . . . . . 3-1

3.1. Tilt-Down Fixture - Primary and Secondary Burners. . . 3-1

3.1.1. Design Requirements ... . . . . . . . 3-1

3.1.2. Fixture Description . . . . . . . . . 3-8

3.1.3. Operational Description ........ 3-16

3.1.4. Control System ........... 3-19

3.1.5. Reliability ........... . 3-20

3.1.6. Maintenance ........... 3-20

3.1.7. Availability. . . . . . . . . 3-20

3.1.8. Safety.............. . . 3-21

3.1.9. Testing ............ . . 3-22

3.1.10. Performance Evaluation. . . . . . . . 3-25

3.1.11. Recommendations .......... 3-25

3.2. Tri-Beam Lift Hook Assembly - Primary Burner . . . . 3-26

3.2.1. Design Requirements .......... 3-26

3.2.2. Fixture Description . . . . . . . . 3-26

3.2.3. Operational Description ......... 3-28

3.2.4. Contro1 System. . . . . . . . . . . 3-31

3.2.5. Reliability ............ 3-31

3.2.6. Maintenance ............ . 3-32

3.2.7. Availability. . . ....... . 3-32 
3.2.8. Safety. . . . . . . . . . . 3-32

3.2.9. Testing.............. . 3-33

3.2.10. Performance Evaluation. . . . . . . . 3-34

3.2.11. Recommendations . . . . . . . . 3-36

3.3. Lift Fixture - Secondary Burner. . . . . . . . . 3-37

3.3.1. Design Requirements . . . . . . . . . 3-37

3.3.2. Fixture Description . . . . . . . . . 3-38

3.3.3. Operational Description . . . . . . . 3-38

3.3.4. Control Systems . . . . . . . . . 3-38

3.3.5. Reliability ........... 3-41

3.3.6. Maintenance ........... 3-41

3.3.7. Availability. . . . . . . . . . 3-41

3.3.8. Safety ............. 3-42

3.3.9. Testing. . . . . . . . . . . . 3-42

3.3.10. Performance Evaluation. . . . . . . . 3-43

3.3.11. Recommendations . . . . . . . . . 3-43

3.4. Susceptor and Ceramic Holding and Trunnion Fixture -

Primary Burner ............. . . 3-43

3.4.1. Design Requirements ......... 3-43

3.4.2. Fixture Description . . . . . . . . 3-45

3.4.3. Operational Description . . . . . . . 3-49

3.4.4. Control Systems . . . . . . . . . . 3-49

3.4.5. Reliability ............ . 3-49

3.4.6. Maintenance ............ . 3-51

3.4.7. Availability........... . 3-51

3.4.8. Safety............. . . 3-51

3.4.9. Testing............ 3-51

3.4.10. Performance Evaluation. . . . . . . . 3-54

3.4.11. Recommendations . . . . . . . . . 3-55

3.5. Susceptor and Ceramic Removal Fixture - Primary
Burner . . . . . . . . . . 3-55

3.5.1. Design Requirements .......... 3-55

3.5.2. Fixture Description ......... 3-57

3.5.3. Operational Description . . . . . . . 3-58

3.5.4. Reliability........... 3-62

3.5.5. Maintenance .......... 3-62 
3.5.6. Availability............ 3-62

3.5.7. Safety. . . . . . . . . . . 3-63

3.5.8. Testing . . . . . . . . . . . 3-63

3.5.9. Performance Evaluation. . . . . . . . 3-64

3.5.10. Recommendations . . . . . . . . 3-66

3.6. Susceptor and Ceramic Holding Fixture - Secondary

Burner . . . . . . . . . . . . . 3-67

3.6.1. Design Requirements .......... 3-67

3.6.2. Fixture Description . . . . . . . . 3-67

3.6.3. Operational Description ........ 3-69

3.6.4. Control Systems ............ 3-69

3.6.5. Reliability ............ 3-69

3.6.6. Maintenance ........... 3-69

3.6.7. Availability. ............ 3-70

3.6.8. Safety................ 3-70

3.6.9. Testing .............. 3-70

3.6.10. Performance Evaluation. ........ 3-70

3.6.11. Recommendations . . . . . . . . 3-71

3.7. Heater and Shroud Handling Fixture - Primary Burner. • 3-71

3.7.1. Design Requirements . . . . . . . . 3-71

3.7.2. Fixture Description ......... 3-73

3.7.3. Operationa1 Description ........ 3-76

3.7.4. Control Systems . . . . . . . . 3-78

3.7.5. Reliability ............ 3-78

3.7.6. Maintenance ............ 3-79

3.7.7. Availability. . . . . . . . . . 3-79

3.7.8. Safety............... 3-79

3.7.9. Testing. . . . . . . . . . . . 3-80

3.7.10. Performance Evaluation. ........ 3-80

3.7.11. Recommendations . . . . . . . . . 3-81

3.8. Remote Carts - Primary and Secondary Burners . . . . 3-81

4. ACKNOWLEDGMENTS .................... . . 4-1

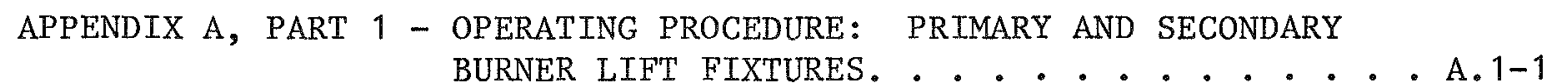

APPENDIX A, PART 2 - OPERATING PROCEDURE: PRIMARY BURNER SUSCEPTOR

AND CERAMIC REMOVAL TOOL. . . . . . . . A.2-1 
APPENDIX A, PART 3 - OPERATING PROCEDURE: PRIMARY AND SECONDARY BURNER TRUNNION FIXTURE . . . . . . . A. A-1

APPENDIX A, PART 4 - OPERATING PROCEDURE: TILT-DOWN FIXTURE FOR PRIMARY AND SECONDARY BURNERS ...... . A.4-1

APPENDIX A, PART 5 - OPERATING PROCEDURE: PRIMARY BURNER HEATER AND SHROUD HANDLING FIXIURE . . . . . . A.5-1

APPENDIX B - MANUFACTURING DRAWINGS. . . . . . . . . . . . B B-1

FIGURES

Frontispiece. Reprocessing facility . . . . . . . . . . . . xi

1. Primary burner assembly . . . . . . . . . . . . 3-3

2. Primary burner tube assembly. . . . . . . . . . . . 3-5

3. Primary burner heater and lower shroud assembly . . . . . . 3-6

4. Primary burner susceptor and ceramic assembly . . . . . . . 3-7

5. Secondary burner assembly . . . . . . . . . . . . 3-9

6. Secondary burner tube assemb1y. . . . . . . . . . . 3-11

7. Secondary burner susceptor and ceramic assembly . . . . . . 3-12

8. Tilt-down fixture - primary and secondary burners . . . . . 3-13

9. Tilt-down fixture with trunnion horizontal. . . . . . . . . 3-14

10. Tilt-down fixture with trunnion erect . . . . . . . . 3-14

11. Tilt-down fixture - trunnion blocks . . . . . . . . . 3-15

12. Tilt-down fixture - swive1 support roller for top end of burner. ................. 3-15

13. Tilt-down fixture - secondary burner; roller assembly in operating position. . . . . . . . . . . . 3-17

14. Tilt-down fixture - secondary burner; roller assembly in retracted position. . . . . . . . . . . . . 3-17

15. Tilt-down fixture - motor and drive assembly. . . . . . . 3-18

16. Tilt-down fixture - control box . . . . . . . . . . 3-18

17. Tilt-down fixture - structural proof test . . . . . . . 3-23

18. Tilt-down fixture - structura1 proof test . . . . . . . 3-23

19. Tilt-down fixture - execting primary burner . . . . . . . 3-24

20. Tilt-down fixture - removing primary burner . . . . . . . 3-24

21. Tri-beam lift fixture . . . . . . . . . . . . 3-27

22. Tri-beam lift fixture - center hub adjustment and lift lugs . . 3-29

23. Tri-beam lift fixture - center hub assembly . . . . . . . 3-29 


\section{FIGURES (Continued)}

24. Tri-beam lift fixture - 1ifting primary burner . . . . . . 3-30

25. Tri-beam lift fixture - adjusting center hub . . . . . . . 3-35

26. Secondary burner lift fixture. . . . . . . . . . . 3-39

27. Secondary burner lift fixture - lift hook. . . . . . . . . 3-39

28. Secondary burner lift fixture - lifting burner tube. . . . . 3-40

29. Secondary burner lift fixture - lifting burner tube. . . . . 3-40

30a. Susceptor and ceramic holding and trunnion fixture (upright). . . . . . . . . . . . . . . 3-44

$30 \mathrm{~b}$. Susceptor and ceramic holding and trunnion fixture (extended) ................ . . 3444

31. Susceptor and ceramic holding fixture - secondary burner; support lugs retracted . . . . . . . . . . . . 3-47

32. Susceptor and ceramic holding fixture - secondary fixture; support lugs extended............... 3-47

33a. Susceptor and ceramic holding fixture - bearing pillow blocks and lock arrangement . . . . . . . . . . . . . 3-48

33b. Susceptor and ceramic holding fixture - lock pin withdrawn . . 3-48

34. Installation of ceramic/susceptor into holding and trunnion fixture................ 3-50

35. Sequence for assembly of 16 -in. $(40 \mathrm{~cm})$ primary burner heater section................ 3-52

36. Susceptor and ceramic removal tool . . . . . . . . 3-56

37a. Susceptor and ceramic removal tool - support lugs

"retracted". . . . . . . . . . . . . . . 3-59

37b. Susceptor and ceramic removal tool - support lugs

"extended" . . . . . . . . . . . . . . 3-59

38. Installation of susceptor/ceramic into trunnion holding fixture sleeve................ . 3-60

39. Susceptor and ceramic holding fixture - secondary burner "upright". . . . . . . . . . . . . . . . 3-68

40. Susceptor and ceramic holding fixture - secondary burner "inverted" . . . . . . . . . . . . . . . 3-68

41. Heater and shroud handling fixture - primary burner. . . . . 3-72

42. Heater and shroud handling fixture - upper shroud and lower plenum in position . . . . . . . . . . . . . . . 3-72

43a. Right carrier assembly . . . . . . . . . . . 3-74

43b. Right carrier assembly ............. . . 3-74 


\section{FIGURES (Continued)}

43c. Left carrier assembly. . . . . . . . . . . . 3-75

44. Primary burner heater and shroud removal fixture - upper and lower shroud assemblies in position. . . . . . . . . . 3-77

45. Primary burner heater and shroud removal fixture - upper and lower shroud assemblies in position. . . . . . . . . . 3-77

46. Secondary burner plenum remote cart. . . . . . . . . 3-82

47. Primary burner plenum remote cart. . . . . . . . . . . . 3-83 


\section{INTRODUCTION}

This report covers a portion of the work performed by General Atomic Company under U.S. Energy Research and Development Administration Contract E(04-3)-167, Project Agreement No. 53. This project agreement is part of the program for development of recycle technology for High-Temperature GasCooled Reactor (HTGR) fuels described in the "National HTGR Fuel Recycle Development Program" (ORNL-4702).

The objectives of the specific work scope covered by this report (Publication No. 6 of 189 sU012 dated 5/21/75) are to provide the necessary technology, development, engineering, and demonstration of remote handling and maintenance equipment.

The report addresses specific fixture criteria, descriptions, operational checkout, and performance evaluations. References to figures are made throughout the report by two numbers in parentheses designating the figure number and part number; e.g., (2-8) refers to Figure 2, part number 8 .

This report documents the design activities associated with the eight remote handling fixtures for the primary and secondary burners. Specific fixture selection for this phase of the remote handling program was based on the following basic parameters:

\section{Pilot Plant Hnadling Requirements}

Existing facility constraints placed restrictions on plant handling capabilities. Process equipment handling requirements were reviewed against those constraints, and specific fixtures and associated design criteria were identified. 
2. Process Equipment Configuration

Pilot plant constraints and specific features desirable from an experimental point of view, combined with process requirements, were the major determining factors for equipment configuration. Although remote handling considerations were incorporated into the process equipment design, convenience of assembly and disassembly within the existing facility was the controlling factor. Handling fixtures were then provided to suit these configurations, since it was not considered reasonable to impose additional handling restrictions on non-prototypical equipment.

3. Remote Hand1ing Demonstration

Where it was feasible within the established constraints, selected fixtures were designed to demonstrate remote operations or techniques that had not been previously demonstrated. Within the concept of remote fixture design, a "semiremote" handling philosophy was adopted whereby manual assistance could be employed to locate, align, or actuate the fixture. This approach was utilized where it was judged that the manual operations required could be accomplished with the aid of conventional remote technology.

The remote fixture design program to date has addressed those handing capabilities necessary to accommodate assembly and disassembly of the main burner components within the constraints of existing facility and equipment restrictions. This work has included definition of remote equipment interfaces and specific equipment features necessary to accommodate remote assembly and disassembly. Included are such items as:

1. Remotely activated vessel clamps.

2. Remotely activated shroud assemblies.

3. Removable burner vessel tubes.

4. Removable support structure for secondary burner assembly.

5. Remote cart assemblies. 
Detail design and operating reports covering these items will be provided later in the program.

It can be seen from the above that the design of the fixtures and associated equipment interfaces presented in this report represents the first phase of a program which will now be directed toward development of an integrated remote maintenance system. Each section of the report contains specific recommendations for future design activities. These are associated with the existing fixture designs.

Future work on process equipment maintenance will begin with detailed studies of the existing equipment to determine maintenance requirements. These will include identification of high maintenance items, maintainability of these items, and possible design improvements, necessary to reduce maintenance requirements. The results of this study will be used as the basis for establishing remote maintenance equipment requirements. 


\section{SUMMARY}

The objectives of the work described in this report are to provide the necessary technology, development, engineering, and demonstration of remote handling and maintenance equipment for the HTGR fuel recycle cold pilot plant.

This report documents the equipment design associated with the eight fixtures selected for the primary and secondary burners. Fixture selection for this program was based on:

1. Pilot plant handling requirements.

2. Process equipment configurations.

3. Remote handing demonstration requirements.

In addition to the design of selected fixtures, the program included the definition of remote equipment interfaces and specific features necessary to accommodate remote handling, assembly, and disassembly. These features include:

1. Remotely activated vessel clamps.

2. Remotely activated shroud assemblies.

3. Removable burner tubes.

4. A removable support structure for the secondary burner assembly.

5. Remote cart assemblies.

These pilot plant remote design activities represent the first phase of a program which is directed toward an integrated remote maintenance system for the HRDF. The pilot plant program is now being structured to define prototypical equipment, determine specific maintenance requirements, and identify remote maintenance equipment and facilities. 
The report is organized into sections covering each of the eight remote fixtures. Each section discusses the fixture design requirements, operation, controls, reliability, maintenance, availability, safety, testing, checkout, and performance and includes recommendations for further design if required.

\subsection{TILT-DOWN FIXTURE - PRIMARY AND SECONDARY BURNERS}

Specific facility handling requirements established the requirement for this fixture. It was decided to provide a fixture which could handle both burners since their basic handling requirements were similar. These included:

1. Rotational capability (erection).

2. Axia1 rotation.

3. In-plant transport.

The design chosen consisted of a base called the support assembly and a movable cradle called the trunnion assembly. The support is provided with four casters and four outriggers and houses the motor drive and controls. The trunnion assembly cradles and supports the burner tubes and is rotated (erected) to the vertical position by a drive system and trunnion bearing assemblies. The trunnion assembly clamps are provided with rollers which permit axial rotation of the burner tube.

During burner tube removal, the fixture is placed adjacent to the burner and the trunnion assembly is erected to the vertical position. After withdrawal of the burner tube from the burner assembly, the tube is placed vertically into the erect trunnion assembly. Clamps are closed to secure the tube and the trunnion is lowered to the horizontal position, carrying the burner tube with it.

A control box which houses the motor controls and limit switch interlocks is provided on the support assembly. 
Fixture reliability, maintenance, and availability are not fully determined since sufficient operation has not been carried out to date. Final determinations will be made in these areas later in the program.

The tilt-down fixture performance was functionally demonstrated during initial installation of the primary burner. The fixture performed satisfactorily, and no significant problems were noted.

Recommendations resulting from the initial demonstration include the addition of electrical interlocks to the outriggers and redesign of the secondary burner clamp assembly to improve safety.

\subsection{TRI-BEAM LIFT HOOK ASSEMBLY}

Critical control of the burner tube during insertion and withdrawal from the burner assembly established the need for a special lift fixture.

The fixture design adopted consists of a center hub assembly with three radial arms, each of which is provided with a hook for engaging a primary burner lift lug. The center hub assembly is provided with a lift attachment and is adjustable so that the center of lift effort can be aligned with the burner tube center of gravity, causing the burner tube to hang plumb.

Aside from the adjustment of the center hub, operation of the fixture is similar to that of a conventional lift yoke.

As with the tilt-down fixture, final determinations of fixture reliability, maintenance, and availability will be made later in the program.

Operational checkout of the fixture was successfully completed during initial installation of the primary burner. The fixture performance was satisfactory. However, three problems were encountered which will require further design and corrective action. The problems involved: 
1. Difficulty in center hub adjustment.

2. Lack of adjustable counterweight.

3. Burner lug/1ift hook interface engagement.

Further activities will be directed toward resolution of these problems and determination of maintenance, reliability, and availability.

\subsection{LIFT FIXTURE - SECONDARY BURNER}

This lift fixture was supplied to provide the lifting interface between the pilot plant crane and the secondary burner.

The fixture is a basic two-legged yoke with a center lift attachment and two lift hooks. Owing to conflicts between primary and secondary burner installation, no performance tests were completed for this fixture. Current activity plans include demonstration tests in April 1977.

\subsection{SUSCEPTOR AND CERAMIC HOLDING AND TRUNNION FIXTURE}

A special purpose fixture was identified for restraining and supporting the susceptor and ceramic assembly and providing the capability to withdraw the susceptor for inspection, repair, or replacement. The fixture was designed to accommodate both the primary and secondary susceptors since the basic handling requirements were the same for both.

The fixture was designed with two basic assemblies, the support trunnion and the sleeve. The support trunnion is common to both primary and secondary burners and consists of a pipe structure with a rectangular base and two side supports. The side supports house the rotating bearing pillow blocks, which in turn interface with the sleeve assembly trunnions.

Two sleeve assemblies are provided, one for each burner. They consist of an aluminum tube with center trunnions for mounting on the support base. Four latches are provided on each end of the tube which slide radially inward to support the ends of the susceptor and ceramic. 
In operation the sleeve assembly is rotated to a vertical position and locked. The top four lathes are retracted, and the susceptor and ceramic assembly is inserted into the sleeve. The top latches are engaged and the sleeve is rotated $180^{\circ}$. The other four latches are disengaged and the susceptor is withdrawn from the ceramic, which remains supported in the sleeve.

Fixture reliability, maintenance, and availability are not fully determined and are included in future work scopes.

The fixture operation was checked during initial assembly of the primary burner. Although the operations were successfully completed, a few problems were noted for future corrective action. These included:

1. The fit between the ceramic and sleeve was unsatisfactory.

2. The locking action of the top latches was difficult.

These items reflected dimensional interferences which require resolution with the ceramic assembly.

\subsection{SUSCEPTOR AND CERAMIC REMOVAL FIXTURE}

Unique handling and interface requirements for removing the primary burner susceptor and ceramic established the need for this special fixture. Fixture design was closely coordinated with the basic burner design so that proper equipment configuration would be provided to permit susceptor removal.

The fixture design consists of a cylindrical aluminum frame with two sets of support lugs and a center lifting bail. Each set of lugs consists of four lugs which independently capture and support the susceptor flange or ceramic insulator.

During operation the fixture is lowered into the lower shroud assembly and is centered in the susceptor liner. One set of four lugs is engaged 
and contacts the susceptor flange. The ceramic is supported by the flange, and therefore as the susceptor is withdrawn it carries the ceramic along with it. These two components are then placed into the trunnion fixture (see Section 2.4). The removal fixture is withdrawn, and the assembly is inverted by rotating the trunnion assembly sleeve $180^{\circ}$. The removal fixture is then reinstalled, and the second set of four lugs is engaged to support the susceptor tube on its edge with the lugs not contacting the ceramic. This permits withdrawal of the susceptor while the ceramic remains with the trunnion sleeve.

Fixture reliability, maintenance, and availability determinations are included in future workscope and will be completed as additional operational experience is gained.

Operational checkout was performed during initial assembly of the primary burner lower shroud assembly. Although the operations were completed, serious problems were encountered with the fixture operations and significant reevaluation of overall suitability will be required. The problems encountered can be categorized as follows:

1. Interface equipment dimensions.

2. Fixture manufacturing deviations.

3. Operational problems.

Future design activities will be directed toward resolution of the above problems by:

1. Recommending interface envelopes for the burner and shroud equipment.

2. Recommending corrective action to redesign the fixture to meet equipment envelope and/or remote operation needs. 


\subsection{HEATER AND SHROUD HANDLING FIXTURE}

The requirements for this fixture resulted from unique pilot plant handling requirements, combined with a requirement to remove the susceptor and ceramic from the primary burner lower shroud. The fixture basic function includes translation of the lower shroud from its operating position to a position adjacent to the pit wall, thus permitting overhead access for introduction of the susceptor and ceramic removal tool (see Section 2.5).

The fixture consists of six basic assemblies: the front and rear supports, two rail assemblies, and two trolly assemblies. When assembled, they form a bridge arrangement which spans the area between the burner structural supports and the pit wall. When the fixture is positioned with the trolly assemblies attached to the shroud, the shroud can be rolled outward as required to provide vertical access.

When removal of the lower shroud or susceptor ceramic is required, the fixture supports and rail assemblies are installed in the pit area. The trolly assemblies are then connected to the brackets furnished on the lower shroud exhaust plenum. The trollies contain adjusting screws for raising the shroud off its support plate. Once this is accomplished, the shroud assemb1y can be moved to the pit wall by activating a drive unit located in the right rail assembly.

Operation of the fixture was verified during assembly of the primary burner. No major problems were noted, and all assembly operations were completed without incident. Some minor problems were noted, correction of which would improve operation and simplify assembly of the fixture. Corrective actions are included in future scope of work. 


\section{SEMIREMOTE HANDLING FIXTURES}

The fixtures described in this report are used in conjunction with the primary and secondary burners during various handling and maintenance operations. The process equipment components involved include the following:

- Primary burner (Fig. 1).

- Burner tube assembly (Fig. 2).

- Heater and lower shroud assembly (Fig. 3).

- Susceptor and ceramic assembly (Fig. 4).

- Secondary burner (Fig. 5)

- Burner tube assembly (Fig. 6).

- Susceptor and ceramic assembly (Fig. 7).

Figures 1 and 5 are cross sections of the burners which show the relationships of the selected process components when assembled in their operating configuration. Figures 2 through 4 and Figs. 6 and 7 identify individual component overall envelopes and weights for the primary and secondary burners, respectively.

3.1. TILT-DOWN FIXTURE - PRIMARY AND SECONDARY BURNERS (FIGS. 8a, 8b)

\subsubsection{Design Requirements}

A review of burner tube handling requirements indicated that a special fixture was needed during initial installation and subsequent maintenance or inspection operations. Figures 2 and 6 show the envelope of the primary and secondary burner tube assemblies. 
Four basic criteria were identified:

1. The fixture shall interface with both primary and secondary burner tubes. This is desirable since basic handling operations are similar and the envelopes are compatible for both burners. Also, only one fixture would be required.

2. The fixture shall be capable of rotating the burner tubes from a horizontal to a vertical attitude. The burner tubes are mounted in a vertical attitude during operation. Due to their length, particularly the primary burner tube, and the handling restrictions this imposed, placement of the tubes horizontally was required to permit handling within the confines of the pilot plant facility. This also aided maintenance and inspection operations by eliminating the need for special work platforms and tube supports. For future in-cell handling, it was considered desirable to demonstrate this capability.

3. The fixture shall be capable of rotating the burner tube about its longitudinal axis. This feature aids in inspection of both interior and exterior tube surfaces and permits accurate dimensional surveys to determine distortions. In addition, this feature simplifies installation and maintenance of thermocouple leads.

4. The fixture shall provide the capability to transport the burner tubes in a horizontal position within the pilot plant area. This requirement aids in pilot plant handling by minimizing crane tie-up and also allows outside loading and unloading of burner tubes and movement to maintenance areas not serviced by overhead cranes. 


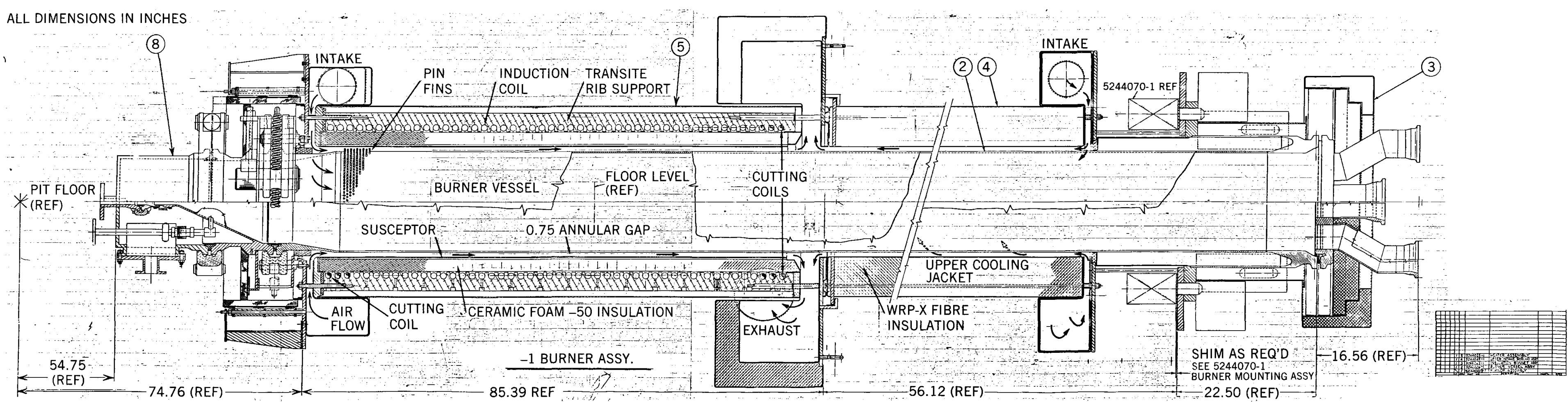





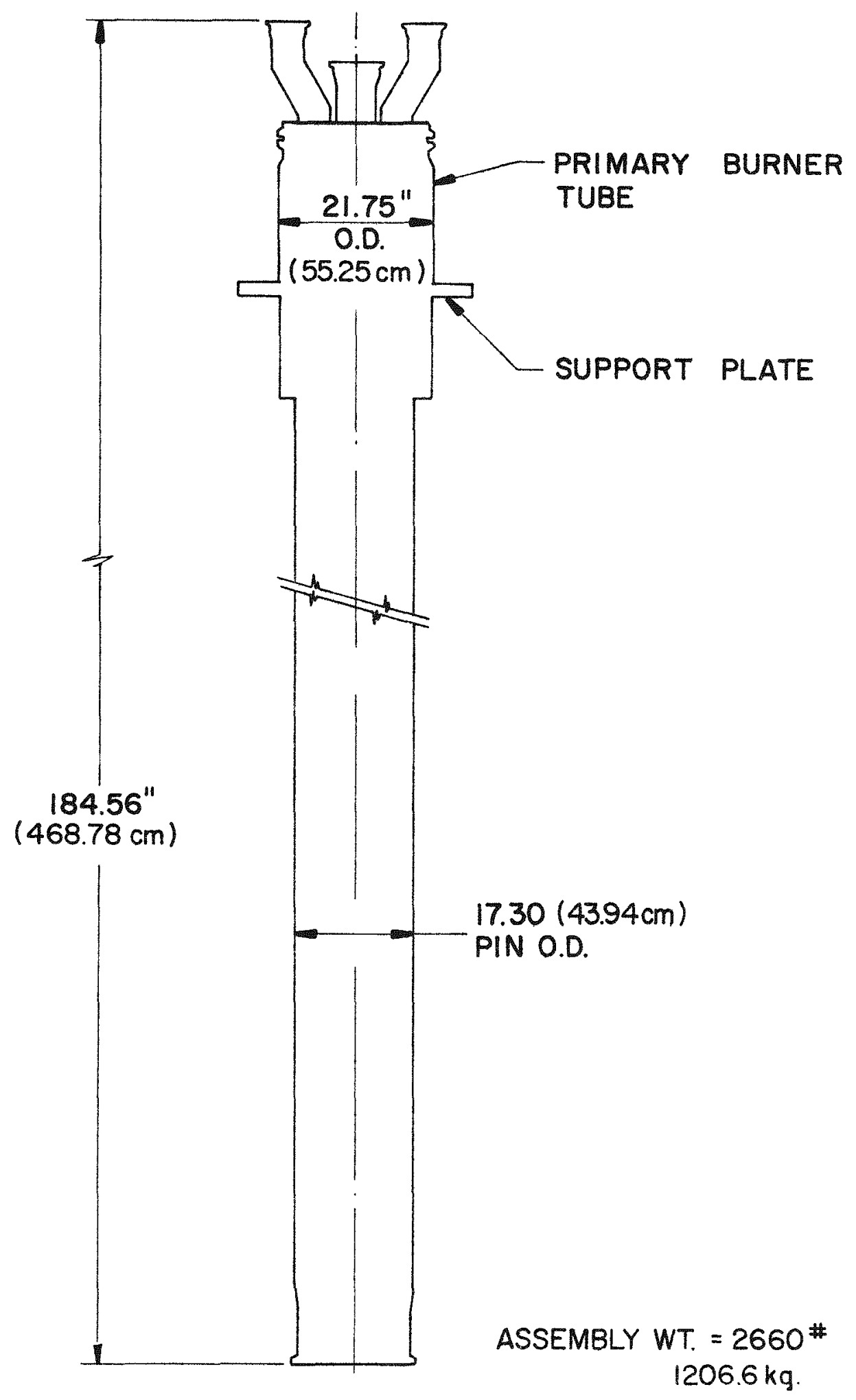

Fig. 2. Primary burner tube assembly 


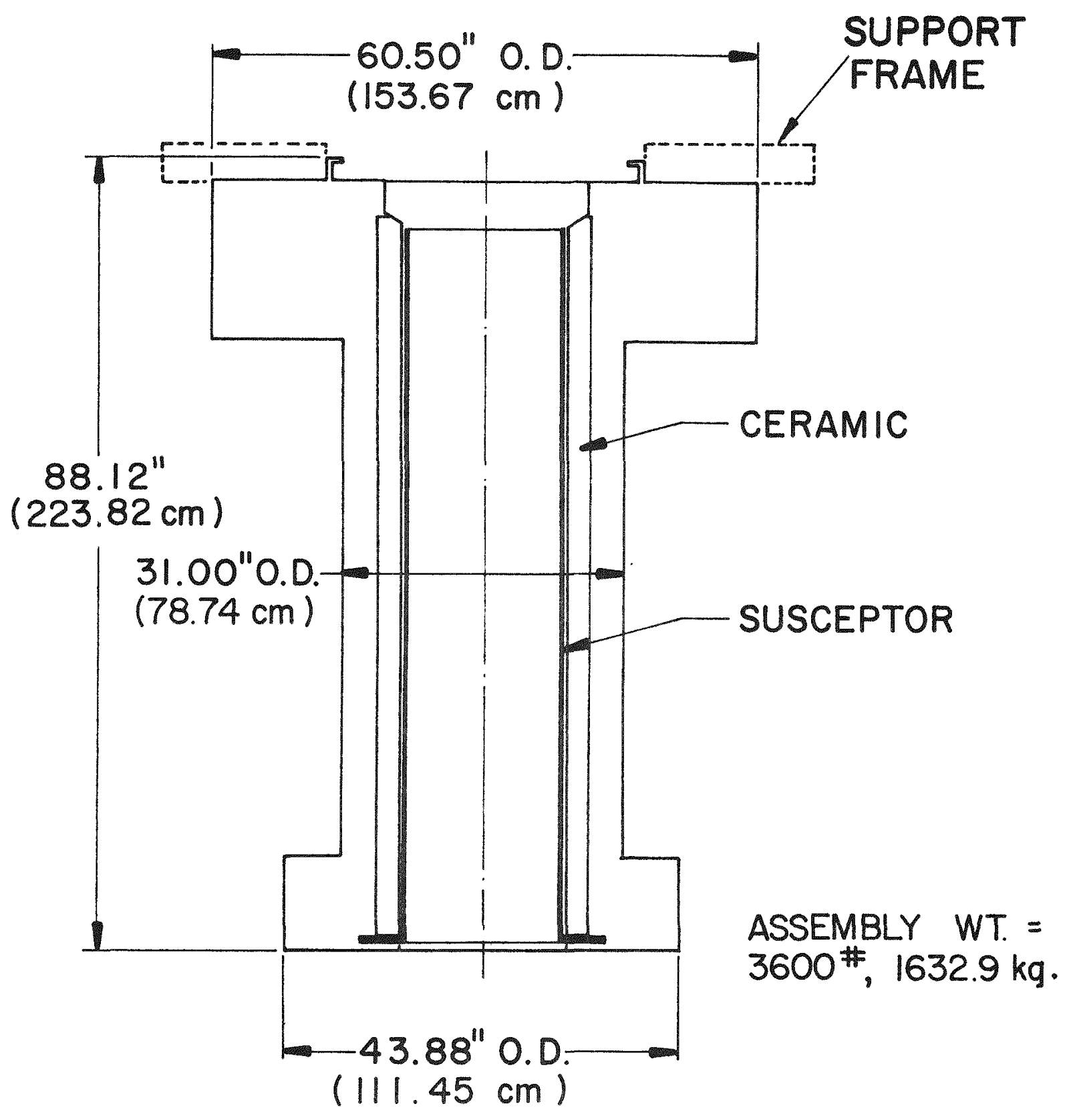

Fig. 3. Primary burner heater and lower shroud assembly 


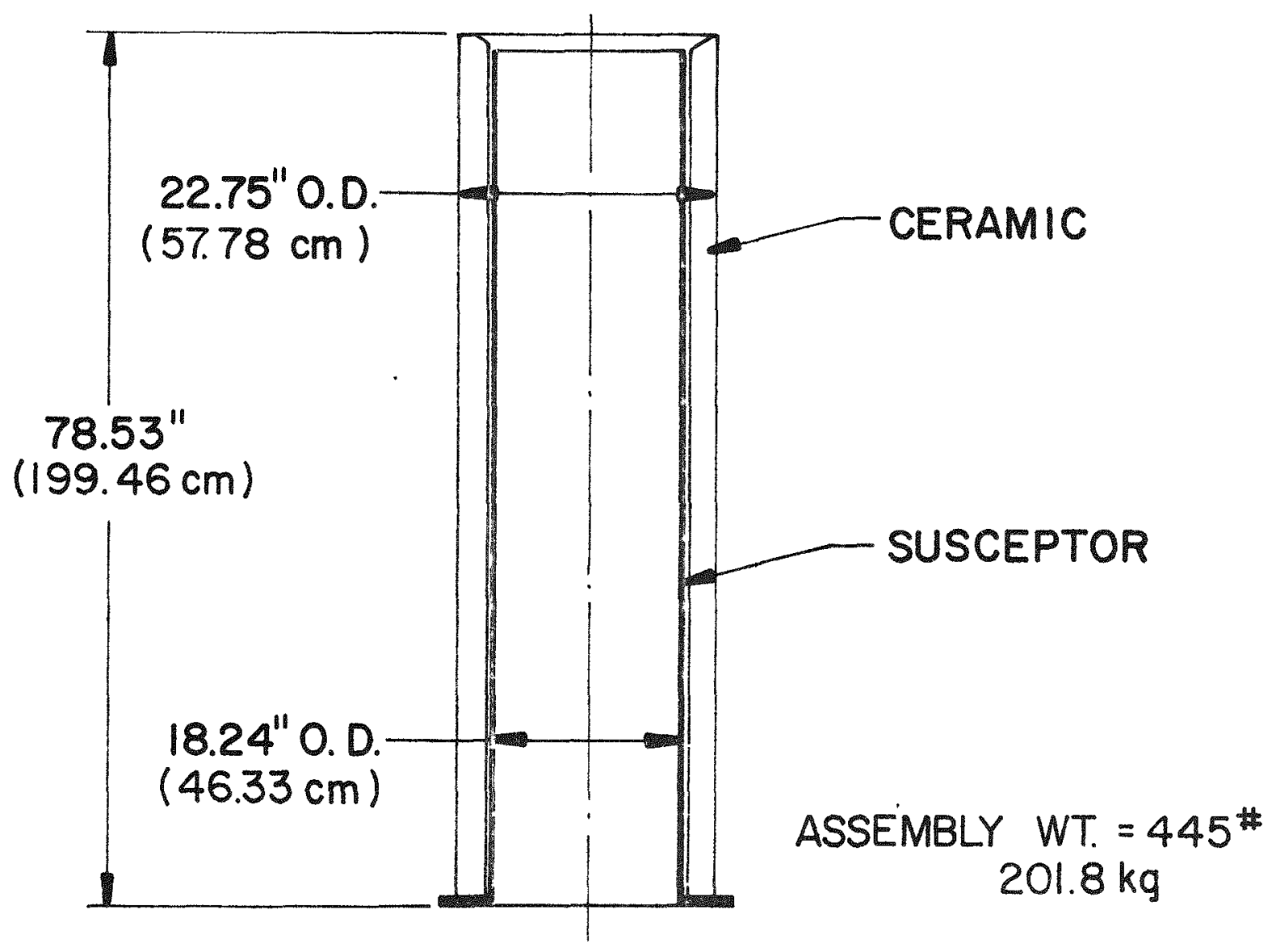

Fig. 4. Primary burner susceptor and ceramic assembly 


\subsubsection{Fixture Description}

Design layouts and analysis of various fixture arrangements indicated that an open structural steel frame could provide the strength required and still be simple to fabricate. A structural support frame was designed for the base of the fixture, and a movable cradle was provided to capture and support the burner tube. The fixture base (9-1),* designated the "support assembly," was provided with swivel casters $(9-2)$ to provide the required mobility. In addition, four retractable outriggers (10-3) were provided to stabilize the fixture during erection of the burner tubes. The support assembly is a rectangular structural steel frame, $57-1 / 4$ in. $(145.4 \mathrm{~cm})$ wide by $155-1 / 2$ in. $(394.9 \mathrm{~cm})$ long. The center of gravity (CG) of the burner tube is located near the top of the assembly, and therefore during erection the composite (CG) of the loaded fixture is placed high above the floor. With the outriggers deployed, stabilization and additional overturning protection is provided. The support assembly also houses the drive motor and worm gear (9-4) and provides the necessary load reaction support for the trunnion assembly. The movable cradle (10-5), designated the "trunnion assembly," rotates about trunnion blocks (11-6) mounted on the support assembly. The trunnion assembly is a rectangular structural steel frame, 44-1/4 in. (113 cm) wide by $132 \mathrm{in.}(335.3 \mathrm{~cm})$ long. This arrangement was chosen to permit rotation of the burner tube within the overhead clearance limits of the pilot plant building. In addition, the trunnion support saddles $(10-7,9-8)$ supporting the burner tube were provided with rollers and movable clamps to permit manual rotation of the burner tube about its longitudinal axis. The roller assemblies (12-9) that support the top of the burner tube were mounted on pivots which allow the rollers to conform to the outside diameter of both primary and secondary burner tubes. A roller assembly (9-9) is located at the rear of the trunnion assembly and supports the bottom of the primary burner only. Since the secondary burner is shorter than the primary burner, these rollers do not contact the secondary burner and hence do not interfere with its interface with the fixture.

*As previously described, part 1 shown in Fig. 9. 



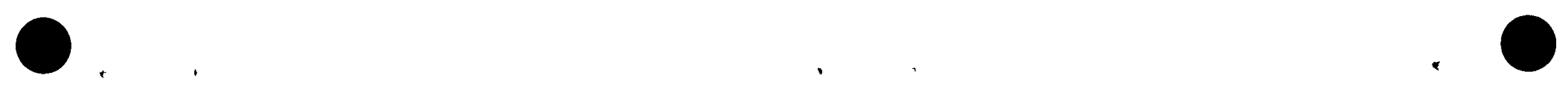




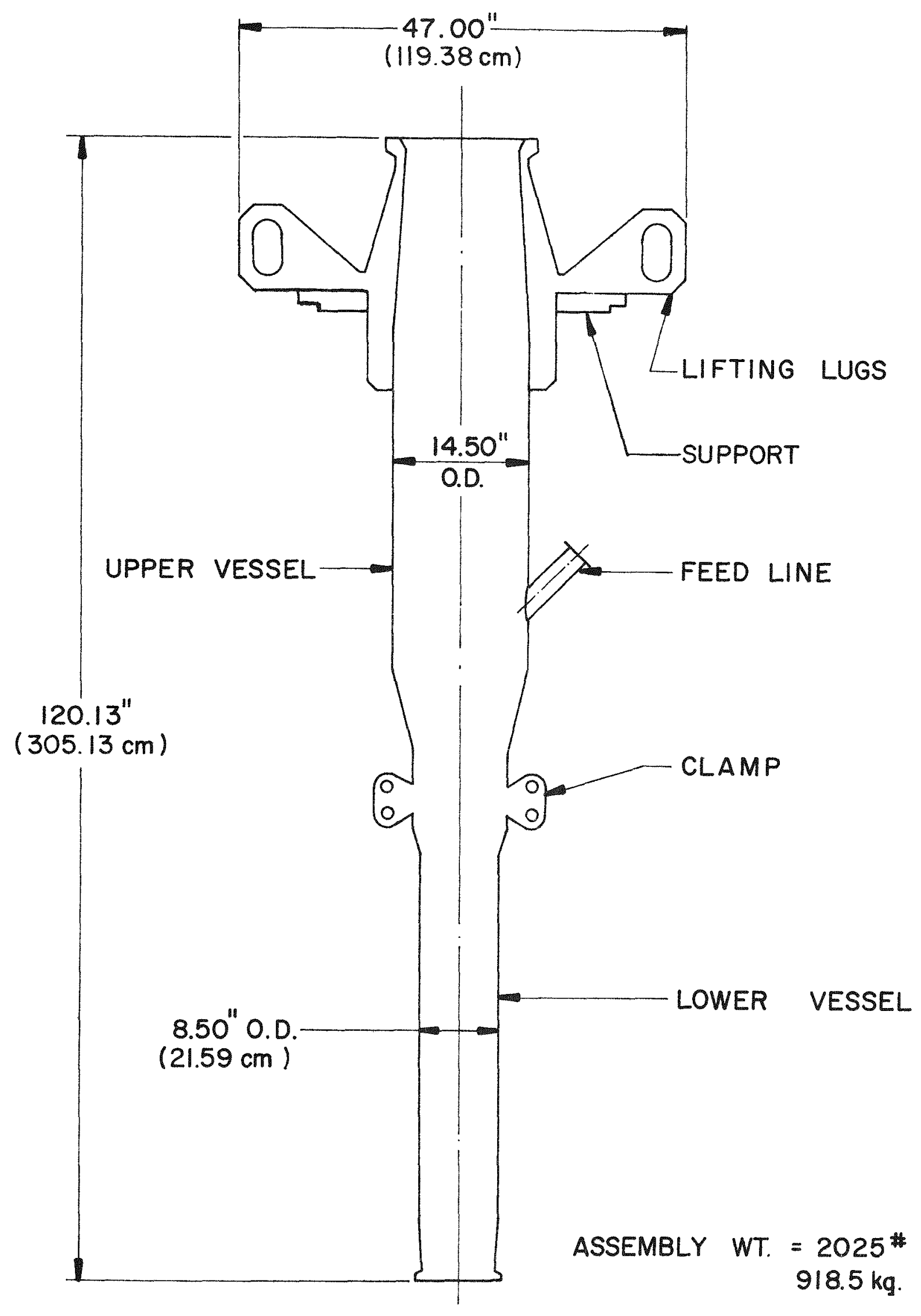

Fig. 6. Secondary burner tube assemb1y 


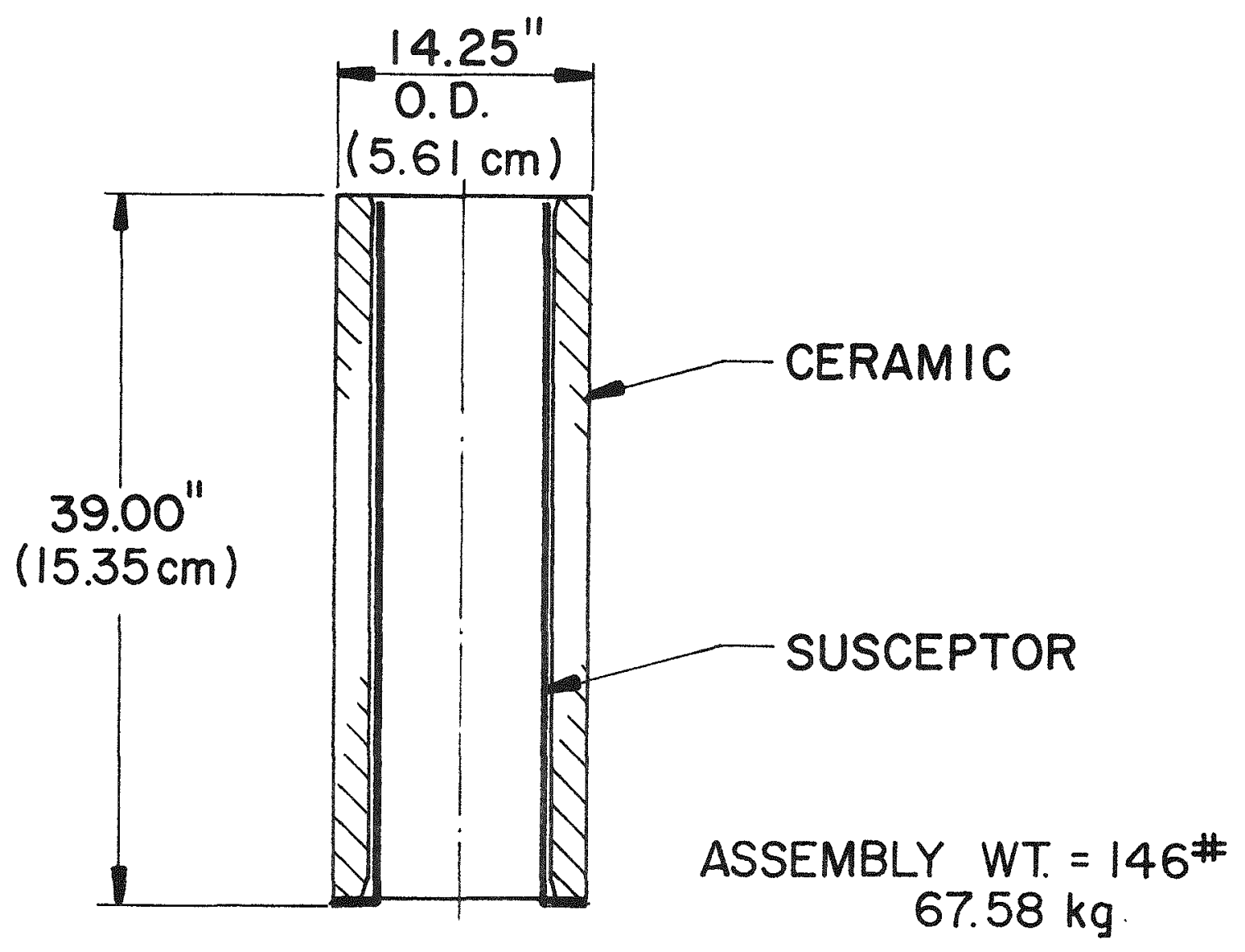

Fig. 7. Secondary burner susceptor and ceramic assembly 


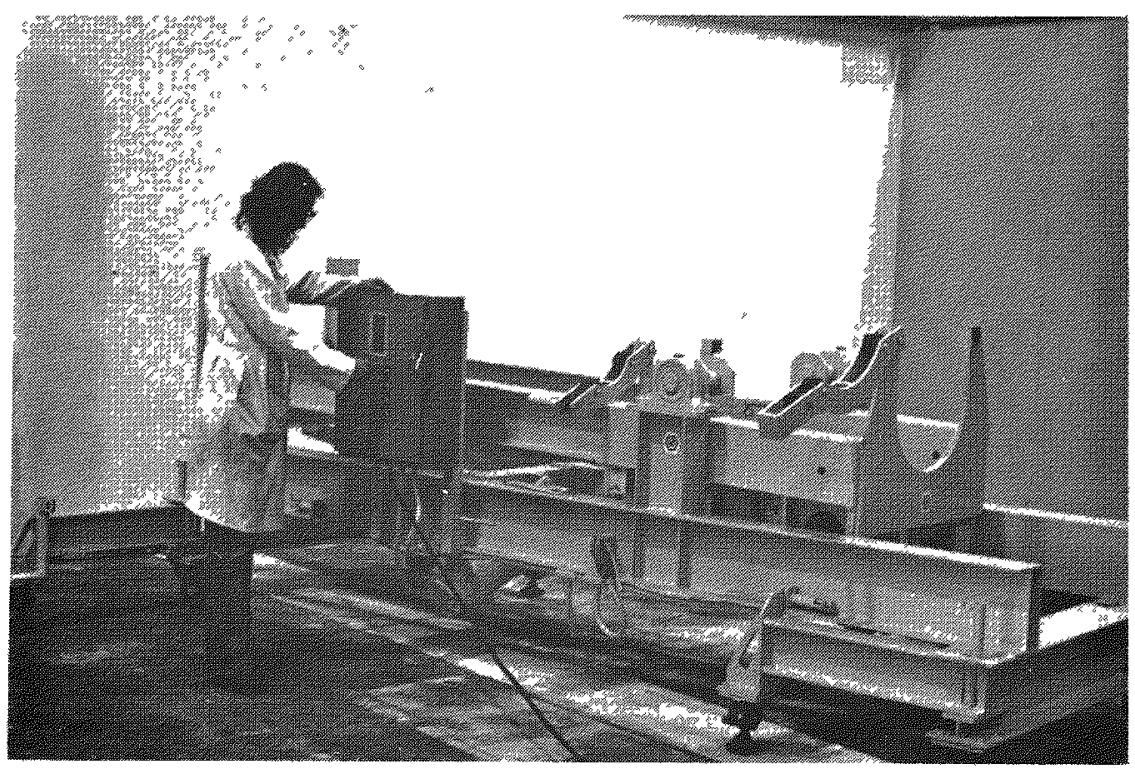

$35-135-203-18$

(a)

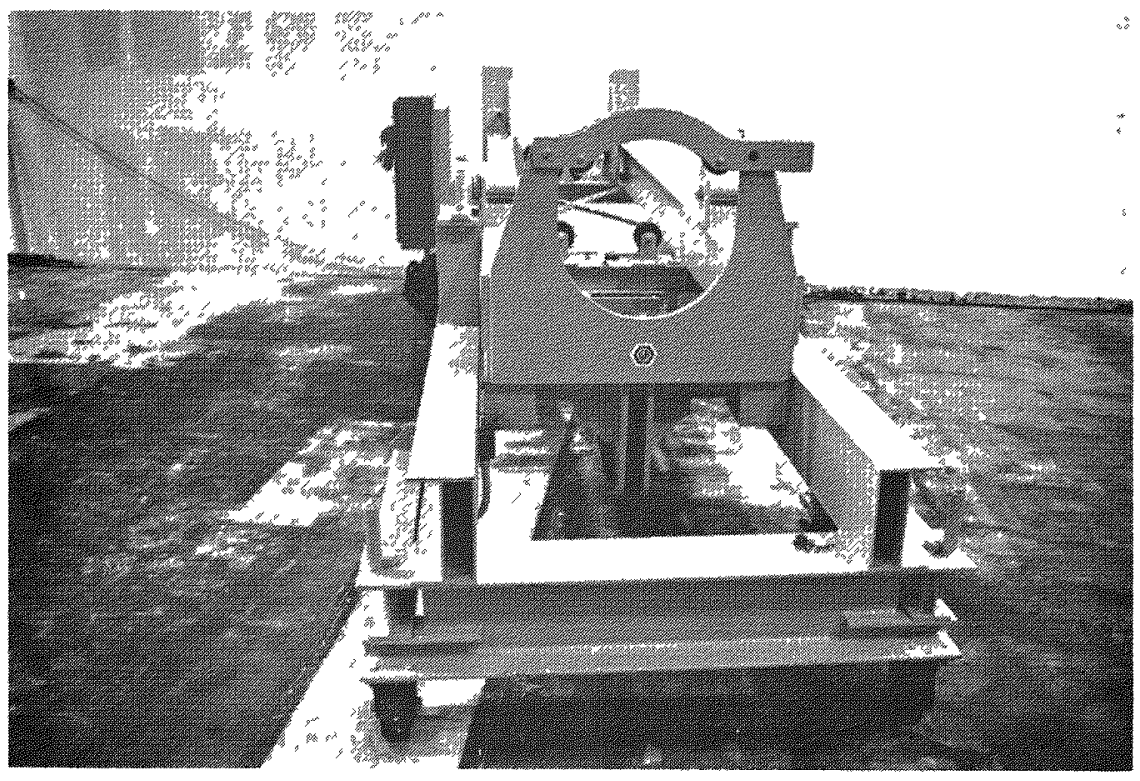

$35-135-203-7$

(b)

Fig. 8. Tilt-down fixture - primary and secondary burners 
(2) SWIVEL CASTE

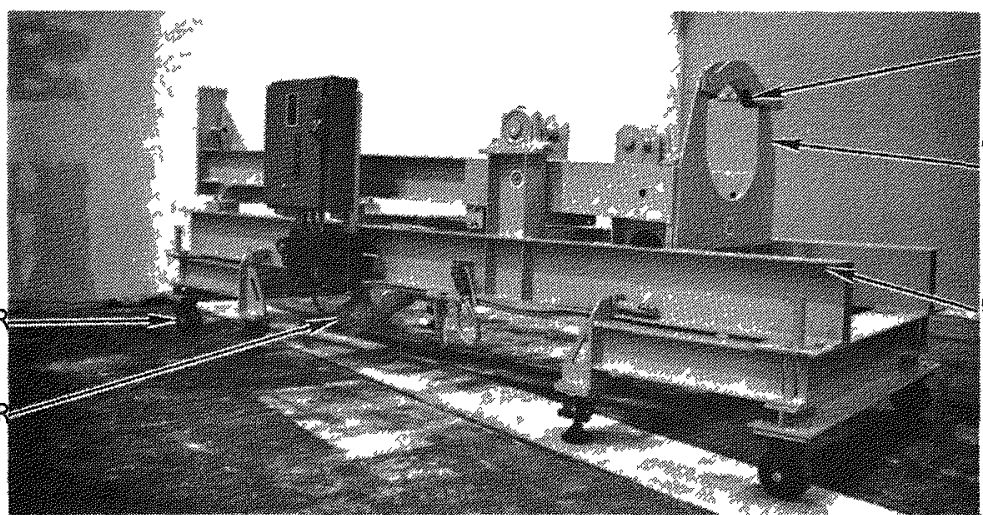

(9) LOWER BURNER SUPPORT ROLLERS

(8) PRIMARY BURNER SUPPORT SADDLE

(4) DRIVE MOTOR

$35-135-203-5$

Fig. 9. Tilt-down fixture with trunnion horizontal

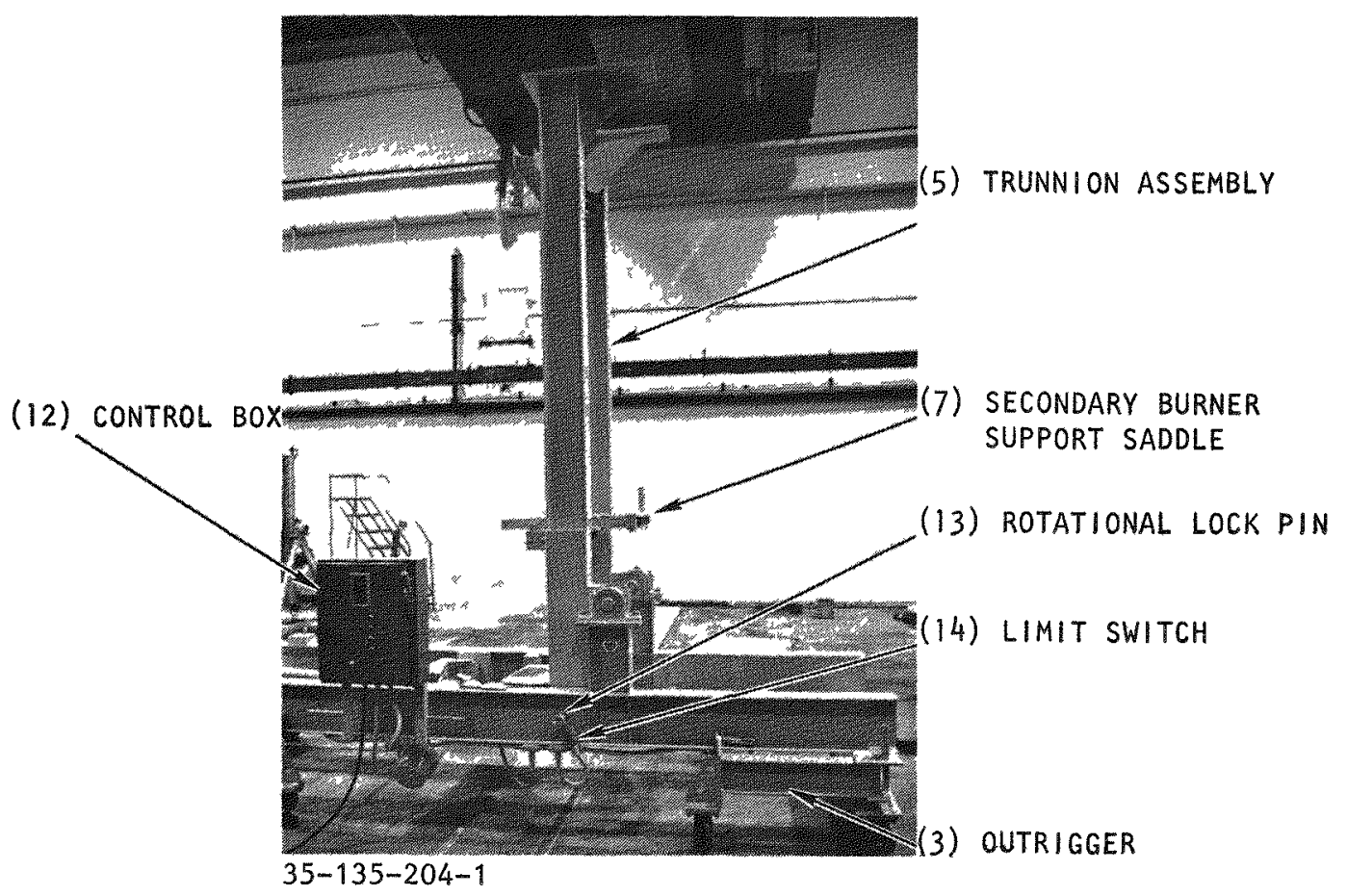

Fig. 10. Tilt-down fixture with trunnion erect 


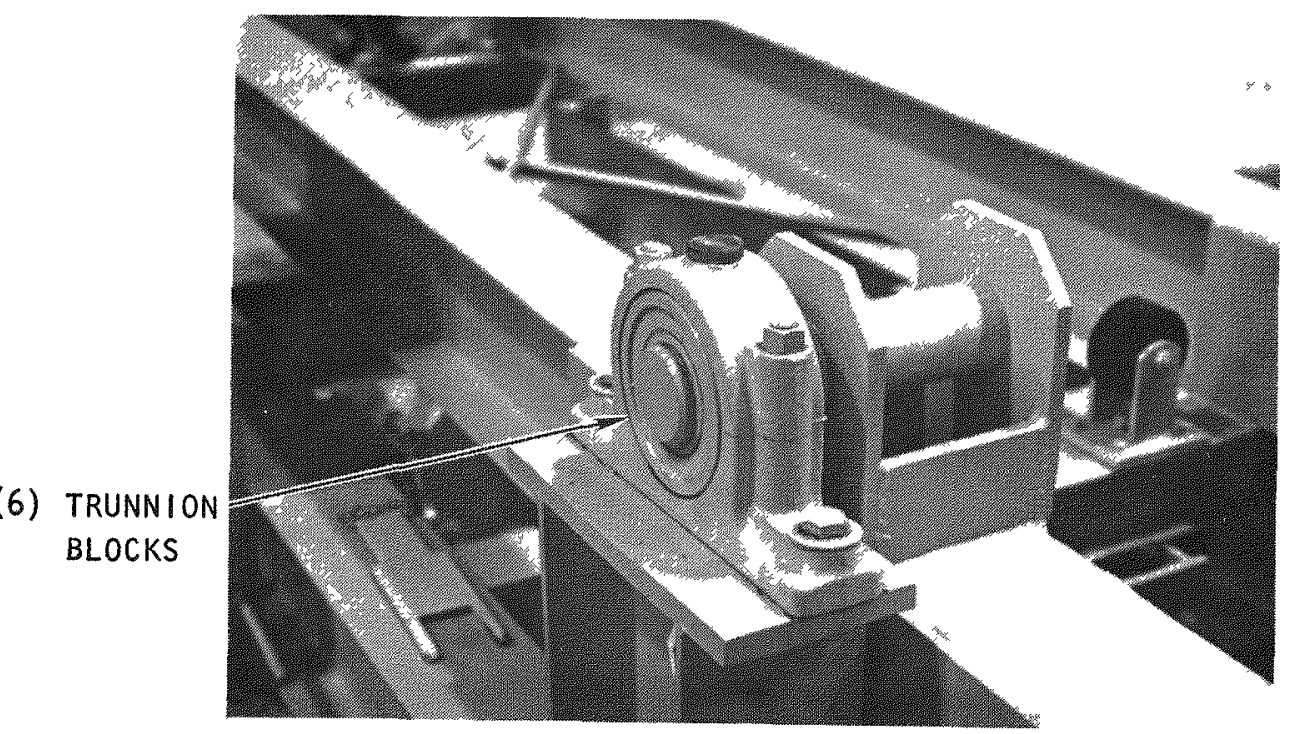

35-135-203-11

Fig. 11. Tilt-down fixture - trunnion blocks

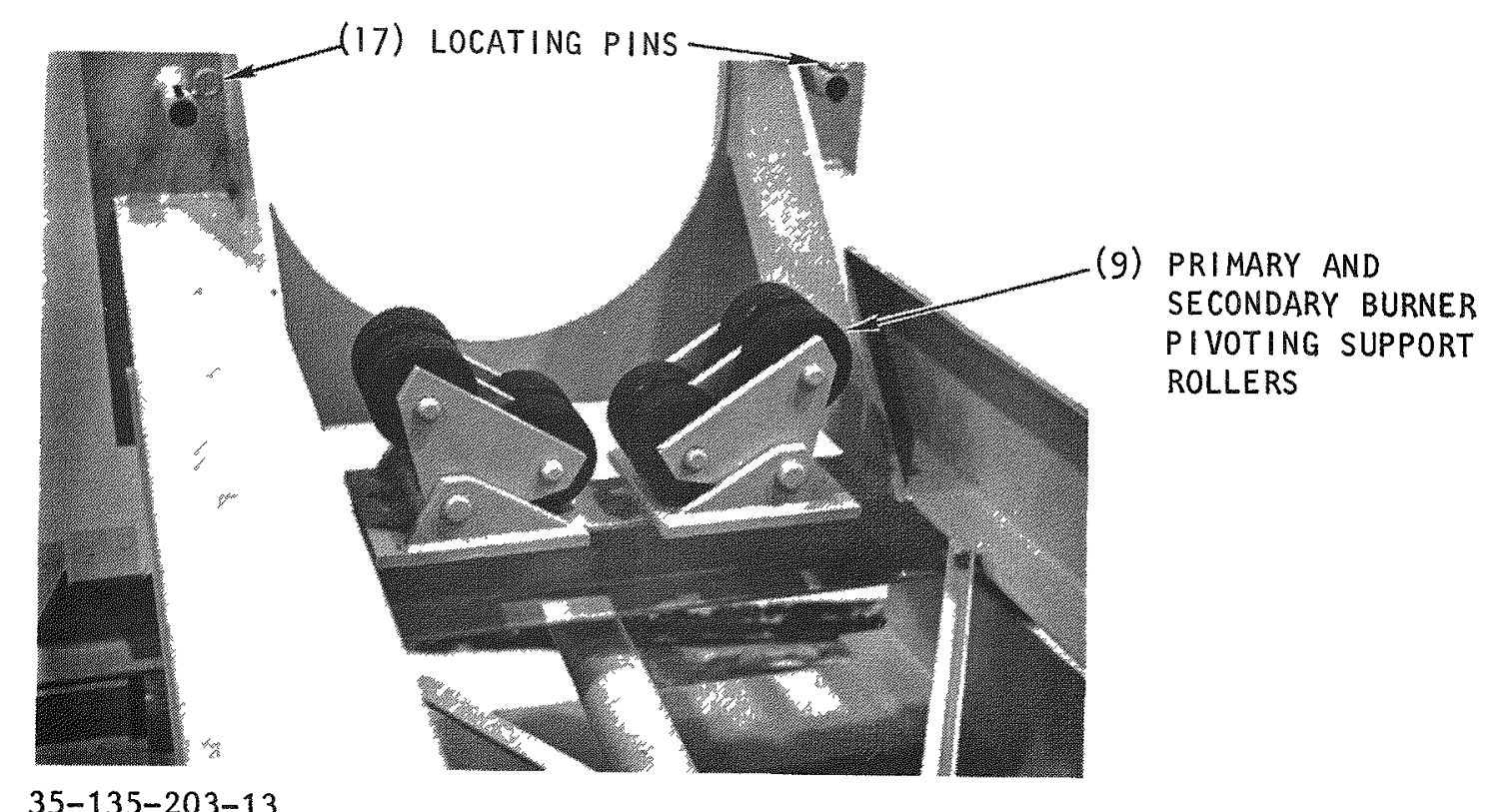

Fig. 12. Tilt-down fixture - swivel support roller for top end of burner 
A set of retractable rollers (10-7) are provided to support the bottom of the secondary burner. When in use, they are manually locked in an upright position (13-7) and will support and clamp the secondary burner. When the fixture is used with the primary burner, the intermediate supports are retracted and pivoted to a horizontal position (14-7) clear of the burner tube.

The motor drive and control system (15-10, 15-11) was provided for this fixture to demonstrate remote erection of the burner tubes. In addition, handling safety was improved and possible damage to the tubes was avoided by eliminating the need to use the overhead crane for this function. Positive control of the burner during crane operation would be difficult and would require special burner supports and lifting interfaces.

\subsubsection{Operational Description}

A summary of the operations involving the tilt-down fixture during disassembly of the primary burner assembly is given below to highlight specific operating features. Detailed operating procedures are given in Appendix A, Part 4.

After preparation of the primary burner tube for removal, the tiltdown fixture is located on a suitable floor area serviced by the pilot plant overhead crane. The four outriggers (10-3) located in the support assembly $(9-1)$ are deployed and locked. Electrical power $(460 \mathrm{~V}, 3 \phi)$ is connected to the control box (10-12). Rotational lock pins (10-13) which activate limit switches (10-14) when engaged are withdrawn and locked, permitting the motor to operate. The trunnion assembly $(10-5)$ is then erected to the vertical position by depressing the "RAISE" push button (16-15). The trunnion rises $90^{\circ}$ and stops automatically when the upper limit switch (15-16) is contacted. The rotational lock pins will be engaged, activating the limit switch and preventing inadvertent trunnion assembly movement. With the upper support plate locating pins (12-17) extended and the secondary burner rear support (13-7) retracted, the primary burner support saddle (9-8) is unlocked and opened. The primary burner tube is placed adjacent to the upright trunnion assembly opposite the open top support and lower support saddle. The burner 


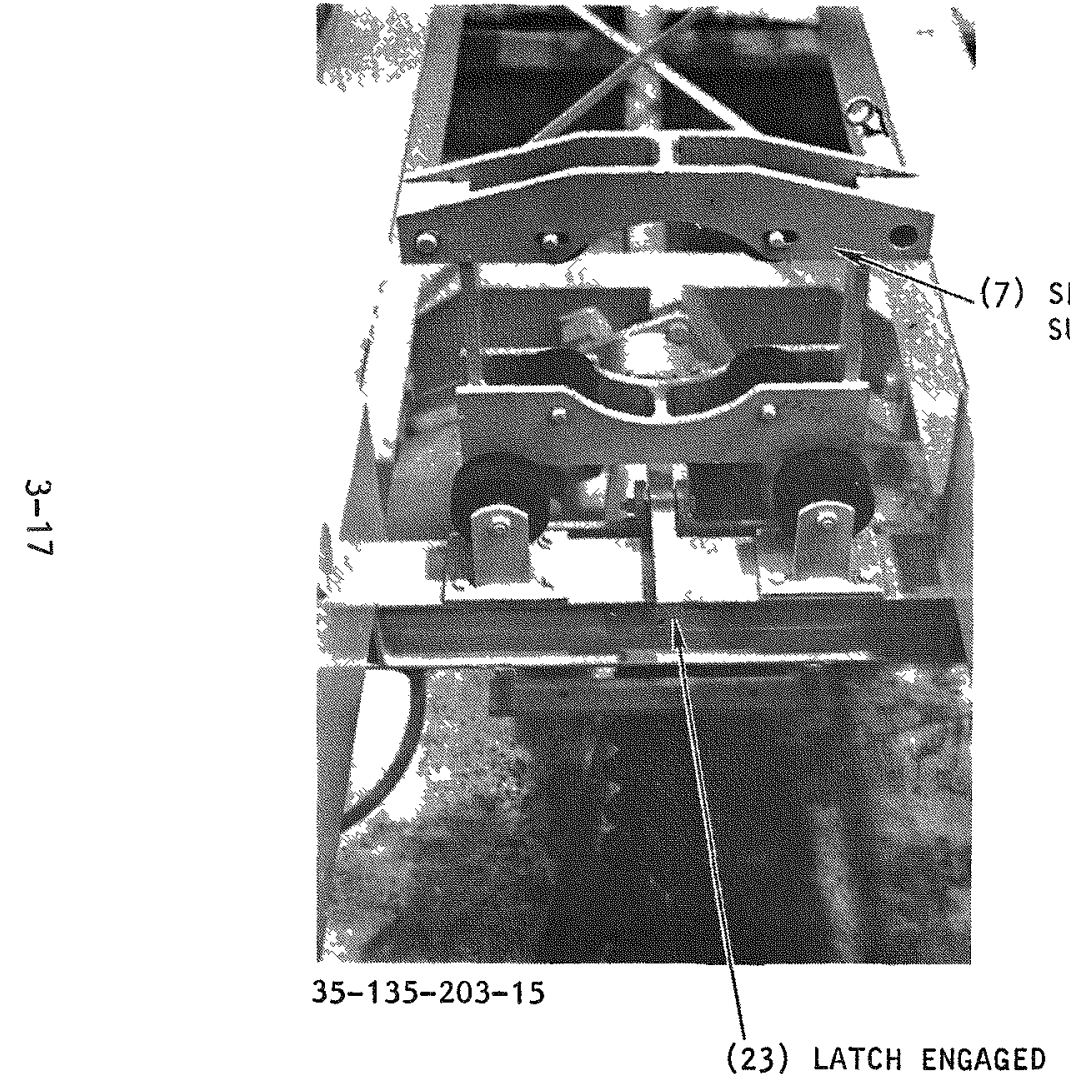

Fig. 13. Tilt-down fixture - secondary burner; roller assembly in operating position

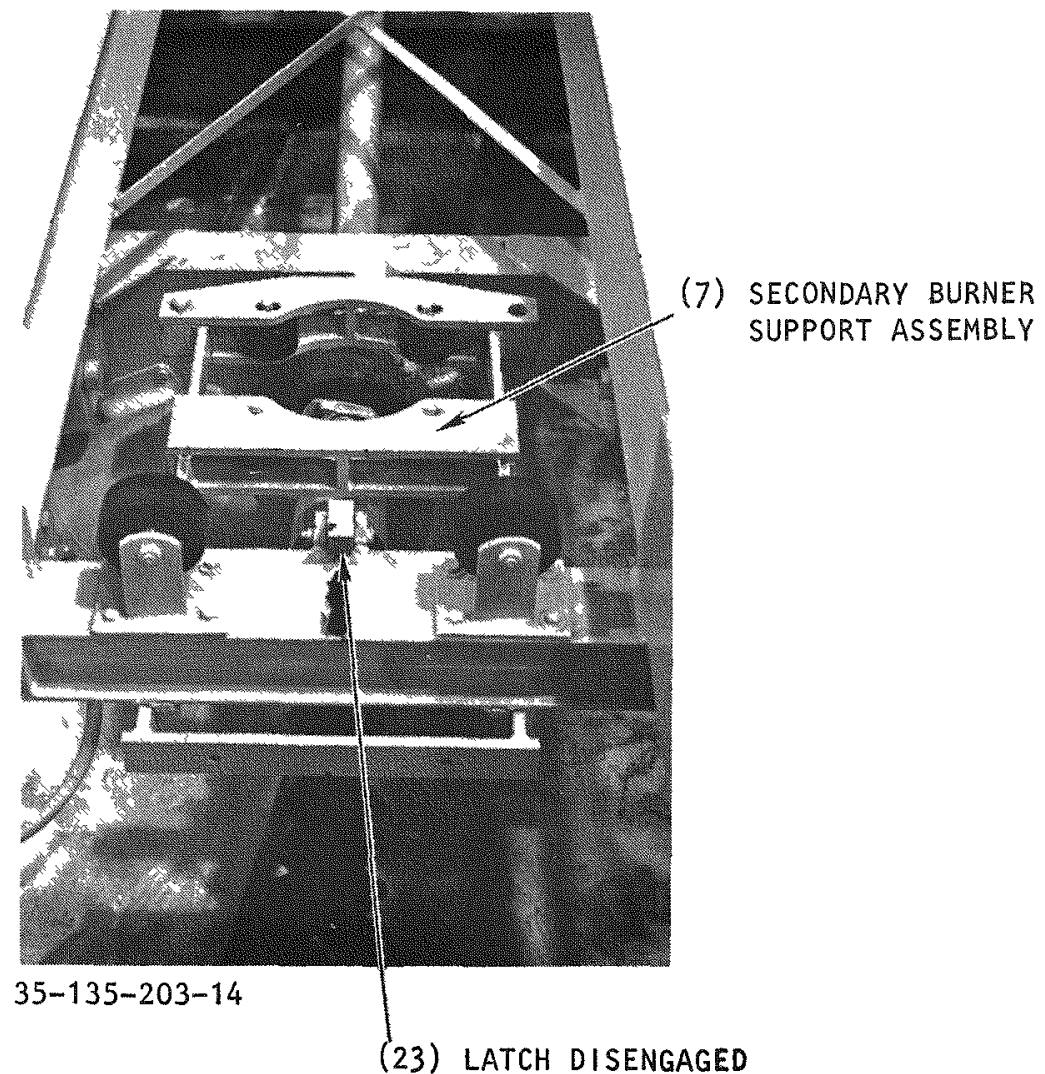

Fig. 14. Tilt-down fixture - secondary burner; roller assembly in retracted position 


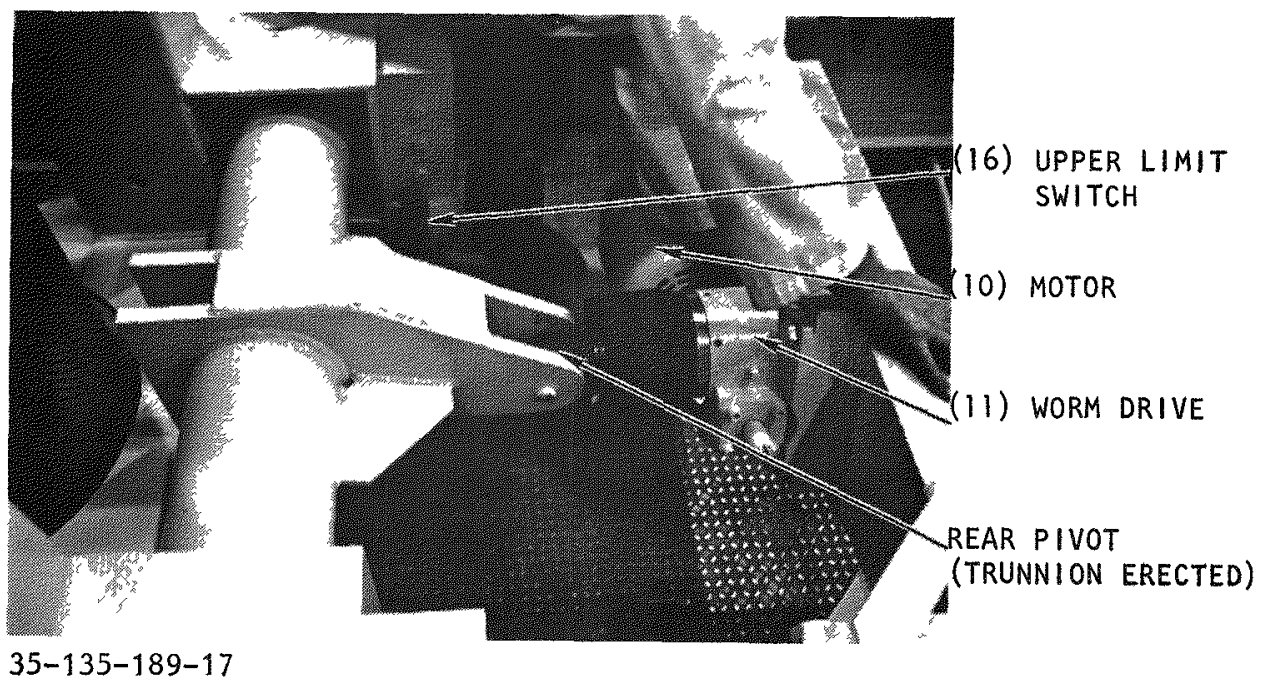

Fig. 15. Tilt-down fixture - motor and drive assembly

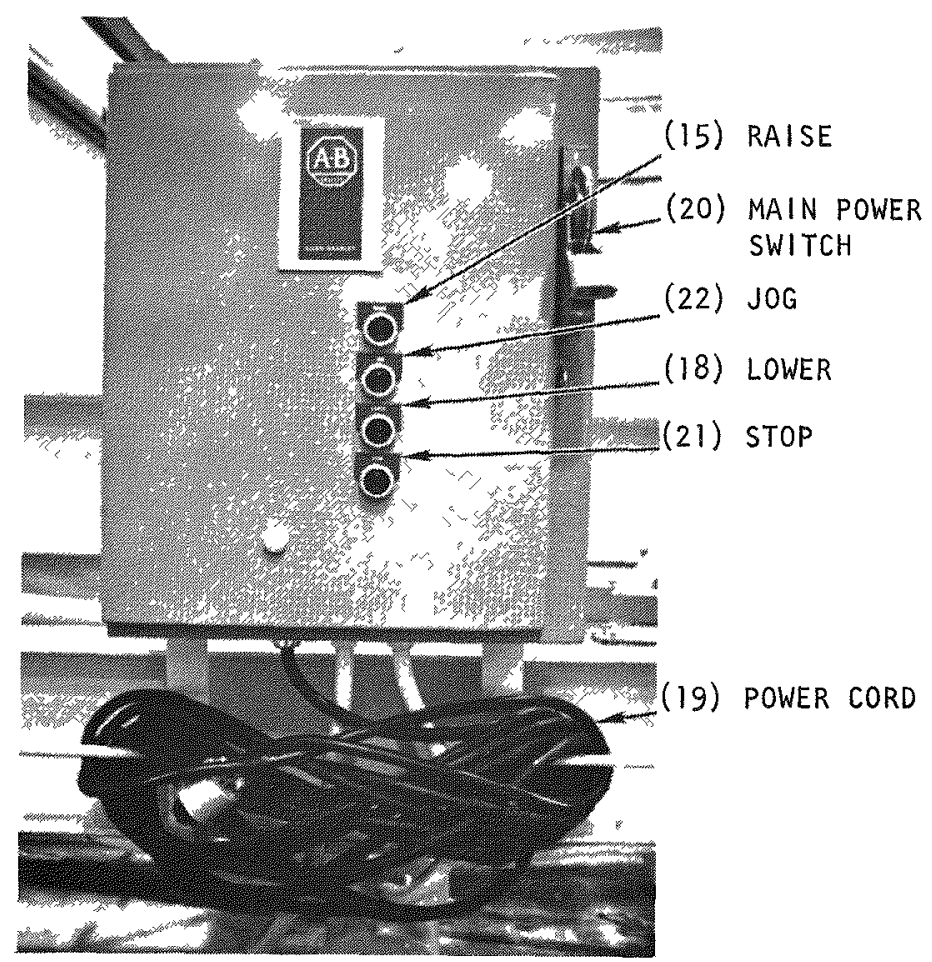

$35-135-203-6$

Fig. 16. Tilt-down fixture - control box 
tube is moved into the fixture, and the two alignment pins are engaged with mating holes in the burner support flange. The burner is lowered into the trunnion assembly top support plate. The lower clamp is closed and locked and the lifting gear is removed from the burner tube. The rotational lock pins are disengaged, reactivating the motor circuit. The "LOWER" push button $(16-18)$ is depressed, and the trunnion assembly containing the burner tube is lowered. Limit switches mounted on the support assembly cut off the motor automatically when the trunnion assembly reaches a horizontal position. The burner tube can then be manually rotated by retracting the two alignment pins (12-17) in the top support. After the outriggers are retracted and the electrical power is disconnected, the fixture and burner tube may be moved through the plant as required. An auxiliary power vehicle is required to assist movement of the fixture.

\subsubsection{Control System}

An electrical control box $(10-12)$ is located on the support assembly. The electric supply cord (16-19) is stored in an adjacent rack. The control panel has a main power "ON-OFF" switch (16-20) and four control push buttons. The "STOP" push button (16-21) will interrupt the motor cycle when depressed regardless of the trunnion position and is used to stop the raising or lowering cycle when desired. The "RAISE" push buttom (16-15) will start the motor and cause the trunnion to rise regardless of the trunnion position. Once the "RAISE" push button is pressed, the trunnion will rise to its upper limit unless interrupted by depressing of the "STOP" push button. The "LOWER" push button is similar to the "RAISE" push button with the obvious exception that it causes the trunnion assembly to lower. The "JOG" push button (16-22) is used to raise the trunnion. When it is depressed and held, the trunnion will rise until the push button is released or the upper limit switch is activated.

The worm drive (15-11) which raises and lowers the trunnion assembly is self-locking. It will hold the load at any interim position when the motor is stopped intentionally by operator action or through loss of power, thus providing positive load control throughout the operating cycle. 
3.1.5. Reliability

A detailed analysis of failure mode and effects was performed for the tilt-down fixture. Basic equipment reliability was verified, since all failure modes resulting in hazardous effects resulted from operator error. Postulated equipment failures did not cause damage to the burner tubes or adjacent pilot plant equipment. Al1 drive components are standard commercial hardware, and therefore adequate spare parts inventory can be maintained. Detailed structural analysis confirms adequate safety margins for all structura1 components.

Provided that adequate preventive maintenance programs and equipment operating procedures are followed, the tilt-down fixture is considered to have high reliability.

\subsubsection{Maintenance}

Based on anticipated usage, maintenance requirements for the tiltdown fixture will be low. Equipment degradation caused by the environment during extended periods of storage will probably exceed operational wear. Regular maintenance will involve inspection and adjustment of the electrical system and lubrication of the drive components and rollers. General cleanup and painting will be required at infrequent intervals depending on the storage environment.

Final maintenance requirements will be determined after sufficient operating experience is obtained and equipment usage requirements are established.

\subsubsection{Availability}

Since the tilt-down fixture has been designed to provide maintenance support for the burners, it is 1ikely that its use will be infrequent relative to the burner operation. Scheduled maintenance can readily be performed during extended periods of norma1 burner operation. 
Burner operating experience will determine actual fixture usage requirements. As these are determined, a review will be made of fixture availability based on wear life and environmental degradation. Maintenance and repair schedules will be adjusted to ensure availability consistent with plant operating requirements.

Future activities will include consideration of the effects of longterm exposure to high radiation fields on equipment availability.

\subsubsection{Safety}

One of the prime factors influencing this design choice was handing safety. Eliminating the need to use the overhead crane for placing the burner tubes in an upright position was desirable from a safety viewpoint. The tilt-down fixture accomplishes this objective and further contributes to personnel safety by providing positive load control in a11 operating modes.

The fixture design also incorporates other safety features such as:

1. Electrical circuit protector devices.

2. A drive overload protection clutch.

3. A self-1ocking worm gear drive.

4. Positive drive in both raising and lowering operations.

5. Travel limit switches.

6. Seismic protection via outriggers.

7. A design safety factor of 5 based on material ultimate strength.

8. A proof test at $1-1 / 2$ times the rated static load.

These features, combined with programmed maintenance and operation to specific detailed operating procedures, contribute to greater pilot plant safety. 


\subsubsection{Testing}

3.1.9.1. Structura1 Proof Testing (Figs. 17 and 18). A structural proof test was performed on the fixture in accordance with TP5820051. The test was witnessed by cognizant engineering and quality assurance personnel.

3.1.9.2. Operational Checkout (Figs. 19 and 20). Operational checkout was performed in two steps. Initially, the fixture was dry run operated in accordance with a draft operating procedure. At that time the limit switches and drive motor clutch were adjusted as necessary. The equipment was cycled approximately 10 times using various combinations of operating situations to discover any unusual operating characteristics. None were found.

The primary burner tube was placed into the fixture and was cycled between the horizontal and vertical positions approximately four times. Interfaces were also checked. No problems were noted.

Based on the results of these tests, the operating procedures were revised for use during initial installation of the primary burner tube into the primary burner assembly.

The fixture was then used during actual burner tube installation. Prior to insertion in the stack-up, thermocouples were installed on the tube, thereby demonstrating the burner longitudinal rotation feature. Subsequent operations involved erection and removal of the burner tube. Problems were encountered during burner assembly operations necessitating burner tube removal. The tilt-down fixture was used during these removal operations, thus permitting demonstration of the complete cycle.

No operations were performed with the secondary burner tube due to schedular conflicts between the primary and secondary burner installations. However, since operation was satisfactorily demonstrated with the primary burner, no problems are anticipated during operations with the secondary burnex. 


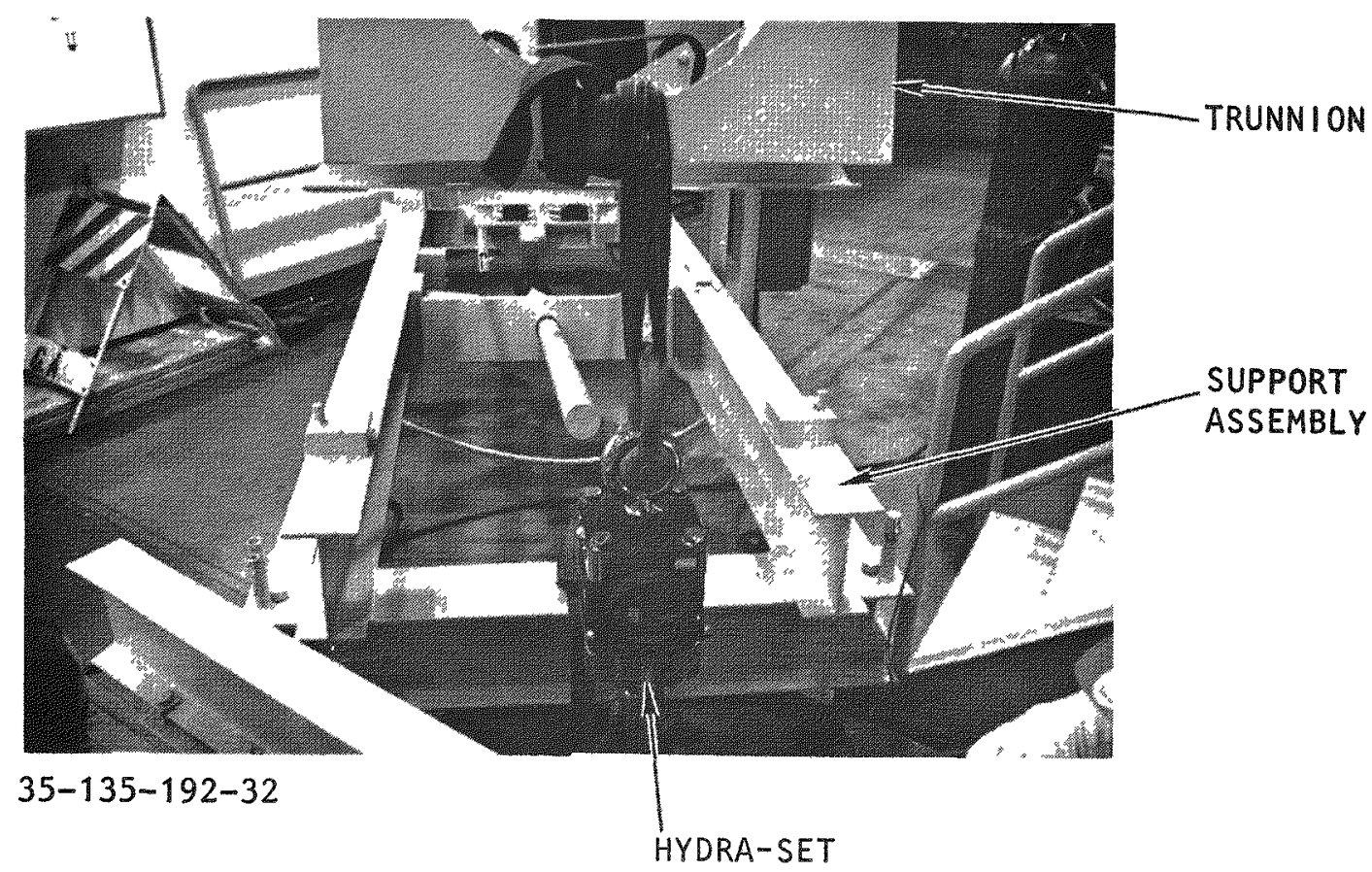

Fig. 17. Tilt-down fixture - structural proof test

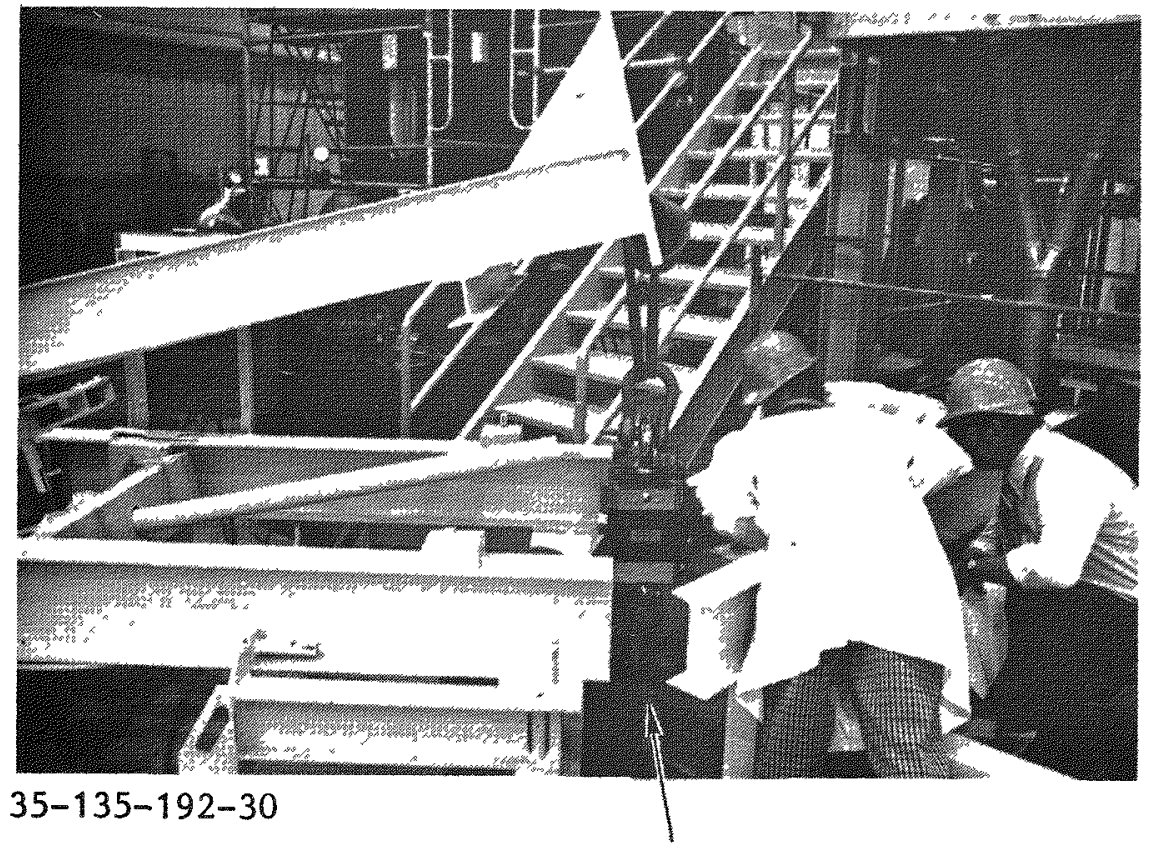

TEST ANCHOR

Fig. 18. Tilt-down fixture - structural proof test 


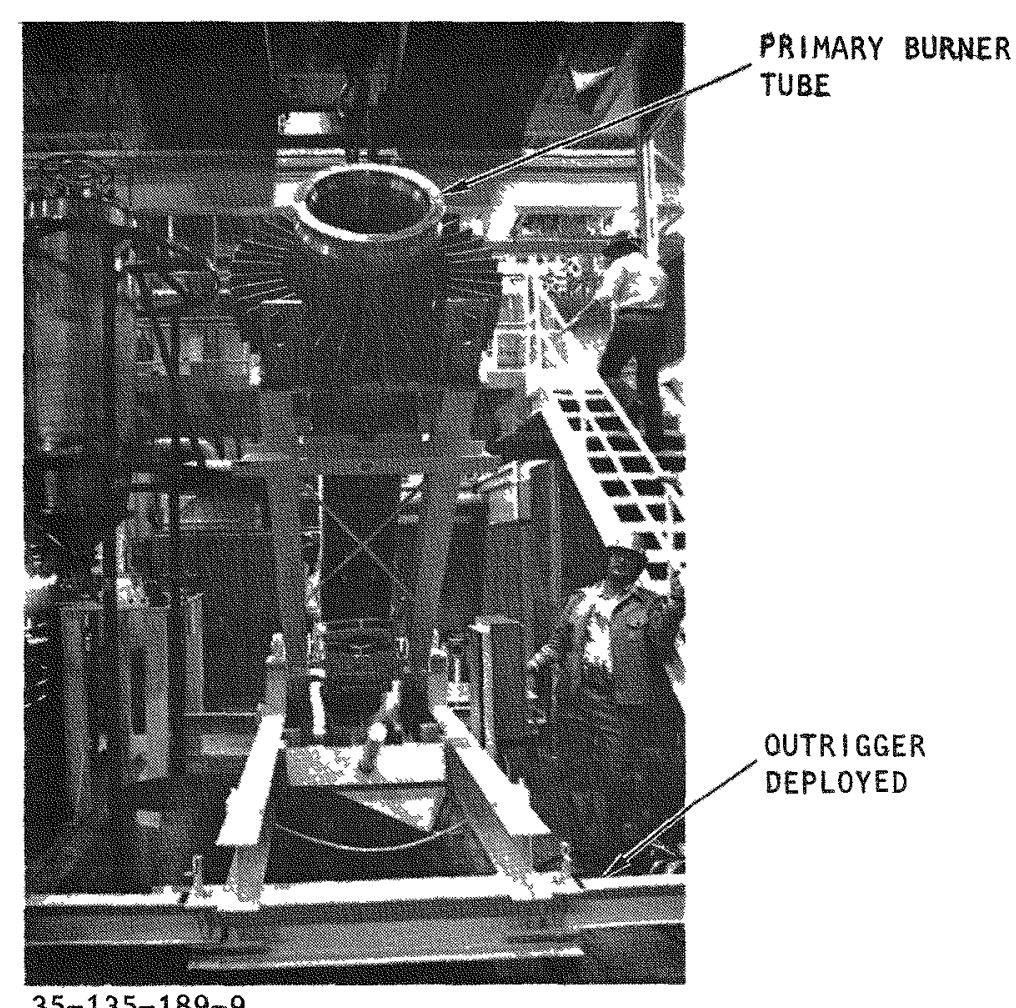

35-135-189-9

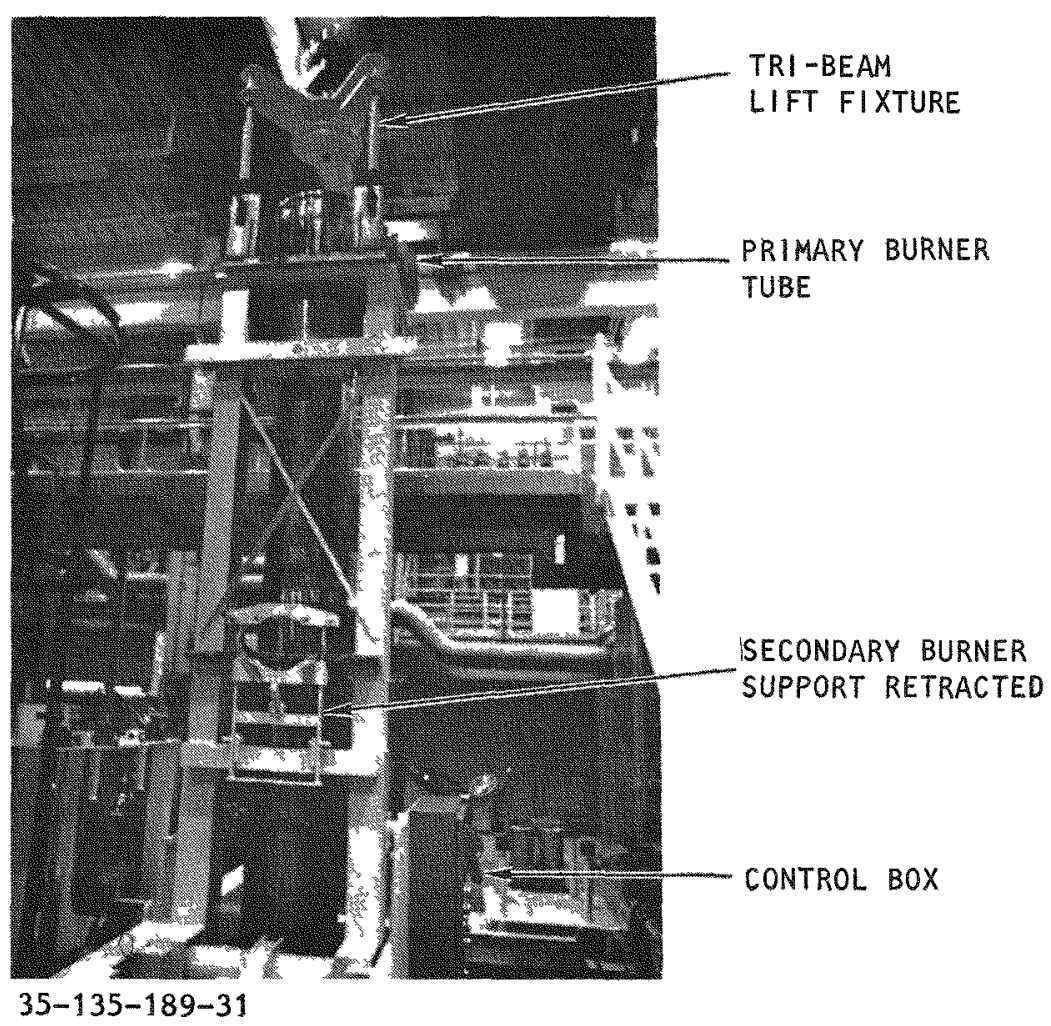
Fig. 20. Tilt-down fixture - removing primary burner

Fig. 19. Tilt-down fixture - erecting primary burner 


\subsubsection{Performance Evaluation}

The functional checkout of the tilt-down fixture performed in conjunction with initial installation of the primary burner tube demonstrated fixture suitability and compliance with the design criteria. No problems were noted subsequent to initial checkout and adjustment.

\subsubsection{Recommendations}

3.1.11.1. Existing Design. Based on the satisfactory performance demonstrated by this fixture, no design changes were noted that would improve performance within the existing design criteria. Two changes are recommended which will improve operating safety and convenience:

1. Electrical interlocks should be provided on the four outrigger assemblies. They should be designed to prevent motor operation unless the outriggers are properly deployed and locked. As presently designed, the outriggers do not include this feature and motor operation is controlled by administrative control. The failure mode analysis has shown that under seismic situations, overturning of the fixture is possible if the outriggers are not deployed. It is conceivable that under some circumstances improper crane handling of the burner tube while interfacing with the erected fixture could cause loads similar to those postulated for a seismic event and lead to fixture overturning. The operating procedures require deployment of the outriggers prior to fixture operation; however, through operator error this could be omitted and an unsafe condition would result. The recommended interlock system would eliminate the problem.

2. The secondary burner roller and clamp assembly design should be modified to improve retention and deployment. The clamp assembly (13-7) is retracted to a horizontal position during handling of the primary burner tube and re-erected during handing of a secondary burner tube. This operation is cumbersome and may lead to operator 
injury if the clamp is not held by the operator while the latch (13-23) is released. If dropped, the clamp will fall quickly and could cause injury. It is recommended that lock pins be added for both horizontal and vertical positions and that the clamp latch be redesigned.

3.1.11.2. Future Design Recommendations. The present design requires significant manual operation and manipulation of the tilt-down fixture. Future design activities should address improvement of remote features to reduce operations requiring manipulator assistance.

In addition, existing materials and equipment used on the fixture should be reviewed for suitability within a cell radiation environment.

\subsection{TRI-BEAM LIFT HOOK ASSEMBLY - PRIMARY BURNER (FIG. 21)}

\subsubsection{Design Requirements}

A review of the burner tube handling disclosed the need for specialized handling requirements. Inherent in the basic handling operations was the requirement to ensure that the primary burner tube could be inserted into and withdrawn from its operating position in the heater and shroud assemblies. It was established that the tube assembly must be plumb within $\pm 1 / 8 \mathrm{in.}(3.17 \mathrm{~mm})$ when suspended from its lifting fixture. In addition, manual guidance during operations associated with the tilt-down fixture is required.

The semiremote interface handling during installation and removal of the burner tube from the shroud assemblies and tilt-down fixture and the requirement for maintaining the burner tube plumb establish the fixture design requirements.

\subsubsection{Fixture Description}

The fixture design chosen is responsive to all established criteria. The tri-beam approach is basic to lifting gear and provides a stable three- 


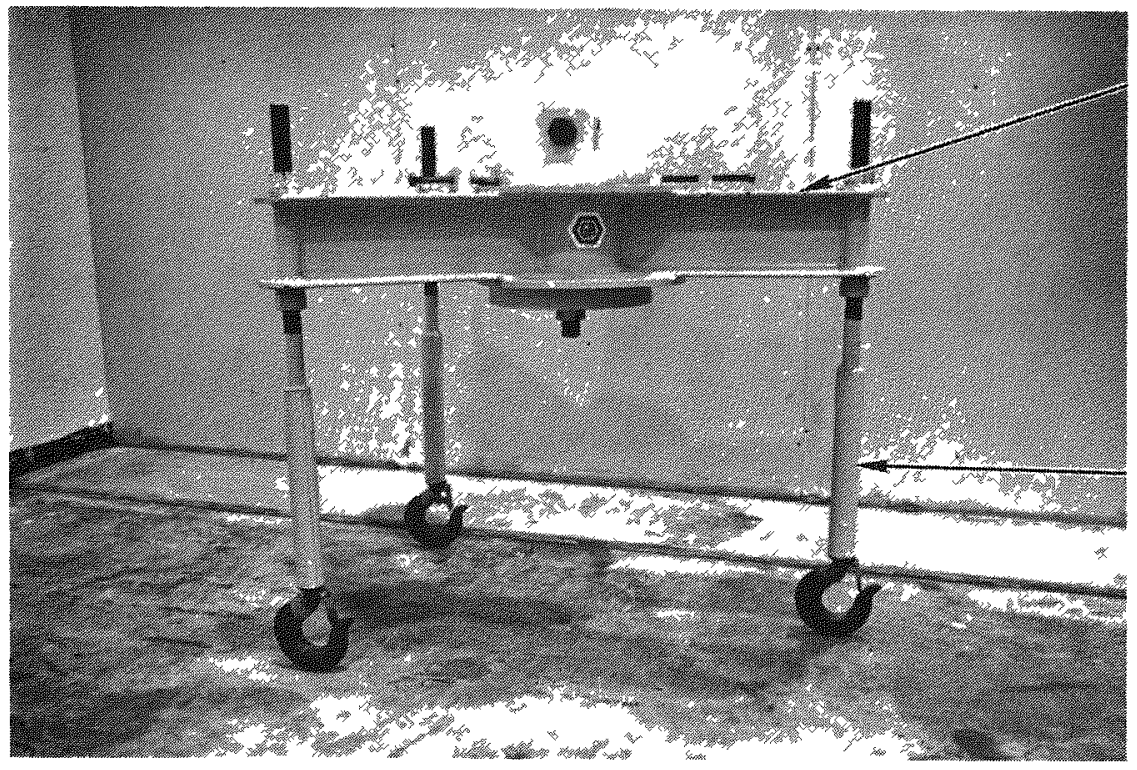

(1) BEAM ARM

35-135-204-15

(3) VERTICAL LIFT HOOK

Fig. 21. Tri-beam 1ift fixture 
point platform. The fixed positioning of the three hook legs provides positive orientation of each hook relative to the others and readily permits simultaneous engagement when properly aligned with the burner lug brackets. The adjustable hub located at the center of the fixture provides the capability to adjust the center of lift effort and therefore permits adjustment of the fixture to suit the as-built tube CG. When the fixture is adjusted, a restoring moment is induced by the unbalanced lift, causing the burner tube assembly to hang plumb. Adjustments provide the required $\pm 1 / 8$ in. $(3.17 \mathrm{~mm})$ sensitivity.

The tri-beam lift hook assembly consists of three beam arms (21-1) located around a center lift hub (22-2). Each arm is welded to the center hub at one end and has a vertical lift hook (21-3) at the other. The angular spacing of the arms matches the location of burner tube lugs. Each lift hook was adjusted during manufacture so that the hooks are aligned in the same direction and the lifting palms are at the same elevation.

The center hub assemb1y (22-2) consists of a center pipe assembled to the three beam arms. Plates (23-4) are mounted on the top and bottom of the center pipe and are connected by a stud (23-5) passing through the pipe. Two lift lugs (22-6) are welded to the top plate and form the lifting interface. The central stud passes through the bottom plate and is captured by a heavy nut (23-7). Each beam arm is provided with a 1 ug (22-8) and adjusting screw (22-9) which extends toward the center of the hub assembly. When the center stud nut is loosened, the adjusting screws can be turned to displace the center lifting lugs, thus shifting the fixture center of lift.

\subsubsection{Operational Description}

When in operation, the tri-beam fixture is connected to the shop crane with the Hydra-set (24-10) located between the crane hook and the lift fixture. This assembly is then located over the primary burner tube assemb1y. The fixture is manually rotated to provide the necessary orientation and lowered into position adjacent to the burner tube lift lugs (24-11). 


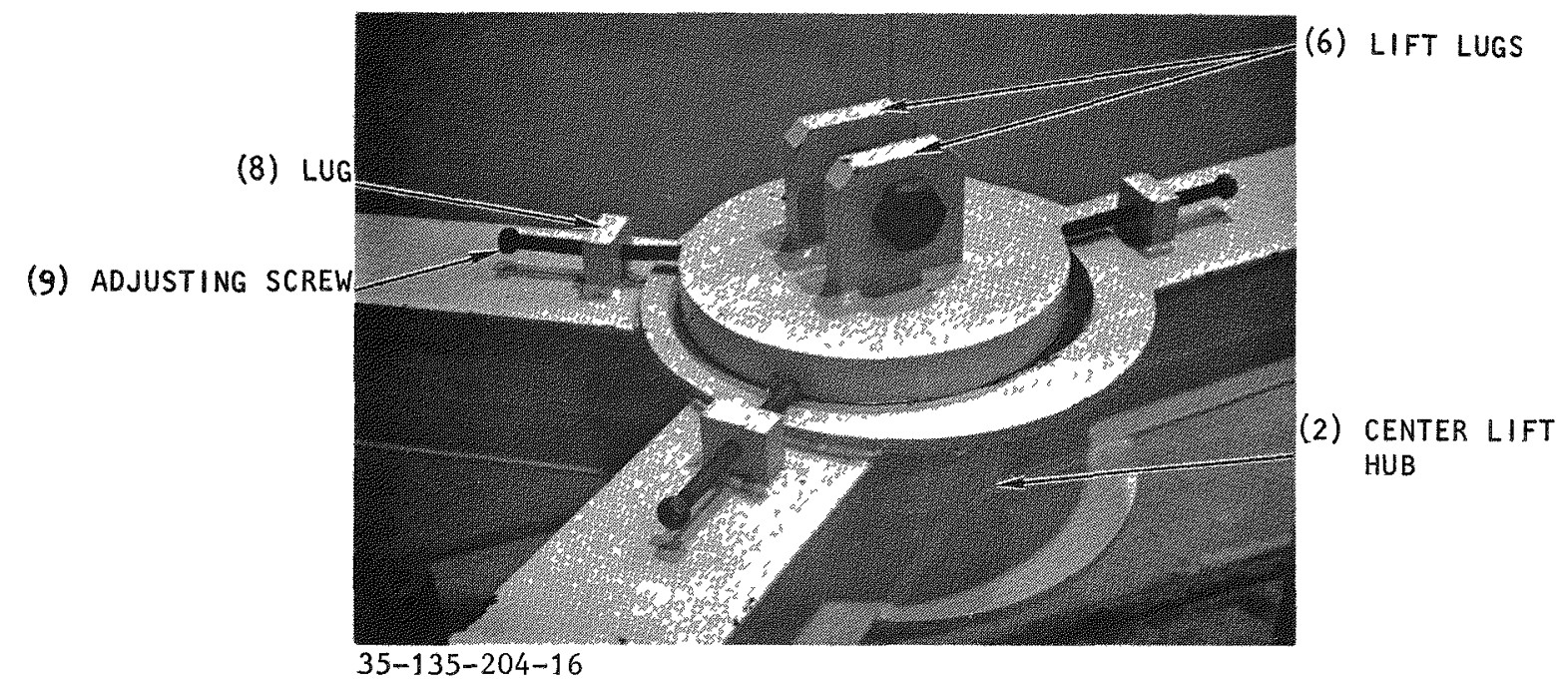

Fig. 22. Tri-beam lift fixture - center hub adjustment and lift lugs

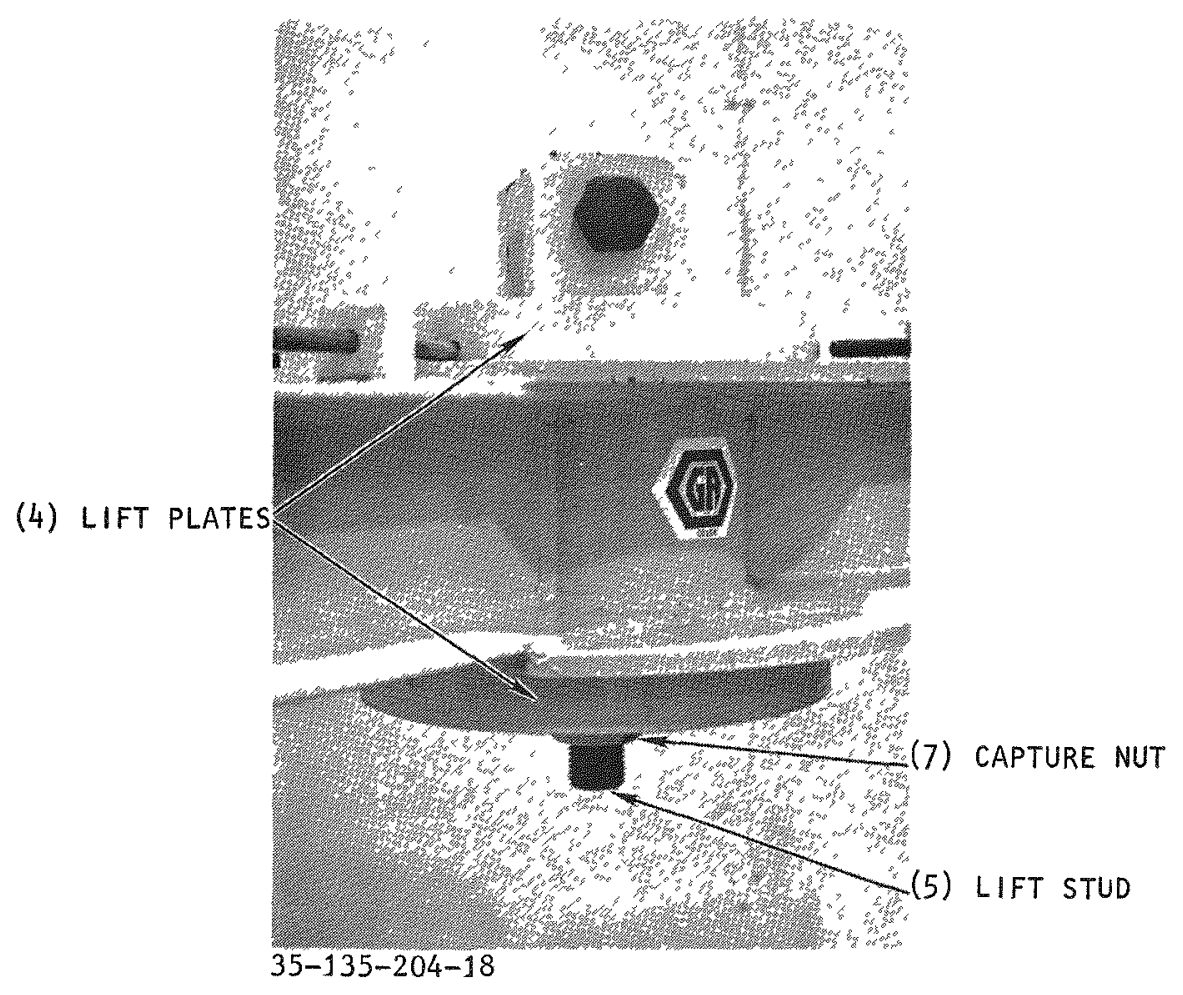

Fig. 23. Tri-beam lift fixture - center hub assembly 


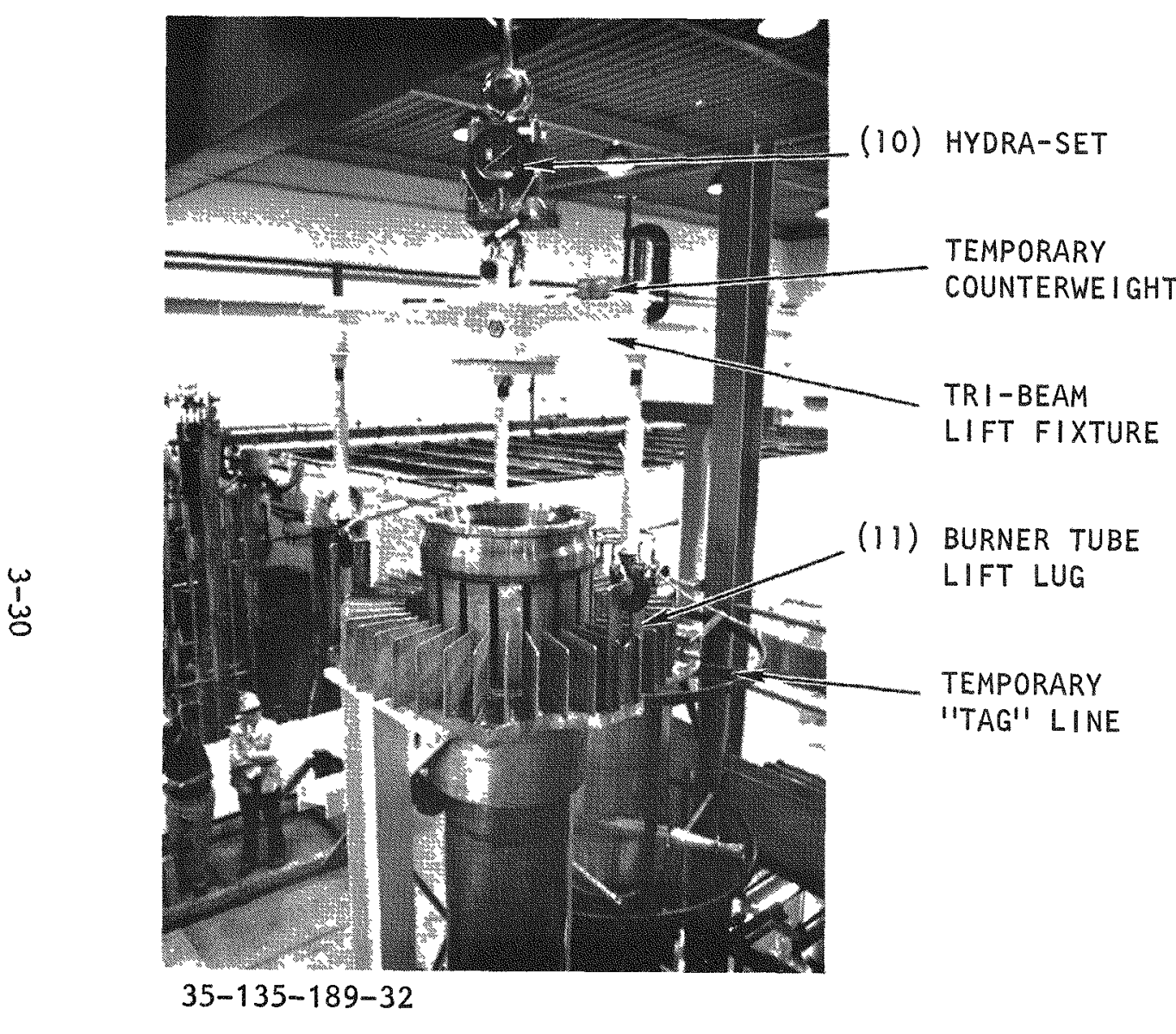

(a)

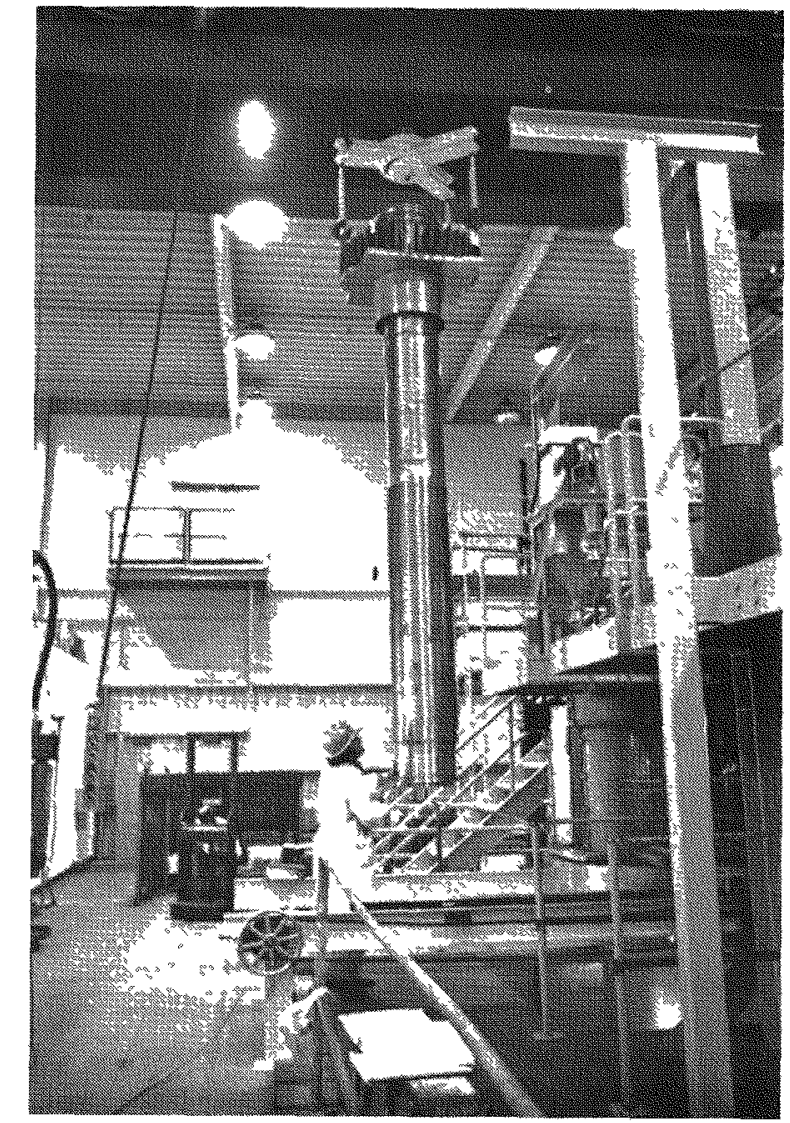

$35-135-189-28$

(b)

Fig. 24. Tri-beam lift fixture - lifting primary burner 
The crane is used to move the fixture lift hooks into engagement with the burner lugs. The burner tube is lifted clear of the shrouding or tiltdown fixture.

Center adjustments are made for the burner tube prior to initial insta1lation. This is accomplished by lifting the burner tube so that it is suspended clear of any supports. A level, plumb line, or other suitable means are employed to measure the perpendicularity of the burner tube center line. After the direction and degree of correction required have been determined, the center lifting hub is moved with the three adjustment screws. Once adjustments are made for a particular burner tube, no further adjustments are required until a new burner tube is used in the stack-up.

Complete operating procedures are given in Appendix A, Part 1.

\subsubsection{Contro1 System}

Control of the tri-beam lift fixture is provided indirectly through the plant crane and Hydra-set. Direct control is provided during initial orientation by manual means simulating manipulator actions. Gross vertical and lateral movements are controlled with the shop cranes. By using special crane drive modifications, these movements are controlled to within $\pm 1 / 8$ in. ( $3.17 \mathrm{~mm})$. The Hydra-set provides further vertical control to within \pm 0.005 in. $(0.127 \mathrm{~mm})$. In addition, the Hydra-set provides a continuous readout of the load. During initial withdrawal and final seating, this fine sensitivity is used to sense possible burner tube hang-up or binding due to interference with the shrouds or susceptor assemblies.

\subsubsection{Re1iability}

A detailed structural analysis performed for the tri-beam lift fixture confirms adequate safety margins for all structural components. Load testing (see Section 3.2.9) demonstrated structural adequacy for the intended purpose. 
A detailed failure mode and effects study must be performed to demonstrate overall operational reliability. This activity is included in the future work scope for this fixture.

Since this is essentially a "zero" maintenance fixture, reliability is not directly influenced by a maintenance program.

\subsubsection{Maintenance}

Maintenance requirements for the tri-beam lift fixture are minima1. It is likely that equipment degradation caused by the environment will exceed operational wear. Maintenance will consist of general clean-up and painting and load testing at infrequent intervals, depending on storage environment and equipment usage.

\subsubsection{Availability}

Since the tri-beam lift fixture was designed for maintenance support during burner removal, its use will be infrequent relative to the burner operation. Maintenance requirements are low and will therefore have a negligible effect on fixture availability.

Based on confirmation of fixture reliability as noted and minimal maintenance requirements, availability is considered high.

\subsubsection{Safety}

Overall plant safety is improved by using the tri-beam lift fixture by virtue of its special nature. All modes of burner tube handling were studied in detail and were the basis for the speciflc design criteria adopted. This approach avoided makeshift lifting arrangements and eliminated the potential risks associated with them. In addition, the fixture design also incorporates other safety features such as: 
1. An adjustable center hub for load stabilizing.

2. Safety latches on each hook (plant use only).

3. A design margin of 5 based on material ultimate strength.

4. A proof test at $1-1 / 2$ times the maximum static load.

These features, combined with programmed maintenance and operation to specific detailed operating procedures, contribute to greater pilot plant safety.

\subsubsection{Testing}

3.2.9.1. Structural proof Testing. A structural proof test of the tribeam lift fixture was performed by the manufacturer at $1-1 / 2$ times the rated load. The test was witnessed by cognizant engineering and quality assurance personnel.

Certification of proof testing was provided as part of the vendor's data package and is retained in GA files.

3.2.9.2. Operational Checkout. Operational checkout was performed in two steps. Initially, the center lifting hub assembly was adjusted with the burner tube to provide the necessary lift attitude with respect to center line plumb. The fixture was then used during initial burner tube installation.

One minor problem was encountered during checkout. It was found that a. counterweight was required on one of the beam arms to balance the fixture in a level attitude when unloaded. For purposes of the demonstration, a temporary weight was added and no further difficulties were encountered.

Technical problems were encountered during burner assembly operations necessitating burner tube removal. This provided the opportunity to use the tri-beam fixture to demonstrate the complete handling cycle. 


\subsubsection{Performance Evaluation}

The functional checkout of the tri-beam lift fixture performed in conjunction with initial installation of the primary burner tube demonstrated fixture suitability and compliance with the design criteria.

Three problems were encountered during demonstration testing:

1. Adjustment of the center lifting hub assembly (see Fig. 25) is difficult. The beam arms are not located $120^{\circ}$ apart; therefore, adjustment screws located on the beam center line do not provide sufficient side adjustment. Also, it is difficult to operate the adjustments under load, both from the standpoint of accessibility and mechanical efficiency. Attempting to overcome the friction load caused damage to the adjusting screws. The adjustments were made with the fixture unloaded on a trial and error basis. Since this is a one-time operation for any given burner tube, a certain amount of inefficiency can be tolerated; however, the operation of the adjustment screws must be evaluated and appropriate changes made. This problem does not affect fixture safety during lifting.

2. A permanent counterweight (see Fig. 24) must be incorporated into the fixture design. This is required to permit the unloaded fixture to hang level, which is vital to disengagement of the three burner lugs. If more than $2^{\circ}$ or $3^{\circ}$ of tilt exist, engagement is difficult to accomplish. Also, if one lift hook engages the burner, it is difficult to achieve engagement with the other two because of the twist induced by the unbalanced 1oad. Damage to the fixture or the burner lugs could easily result. Although manual guidance can overcome this situation, it is not considered acceptable to employ this or expect to provide adequate guidance with manipulators. 


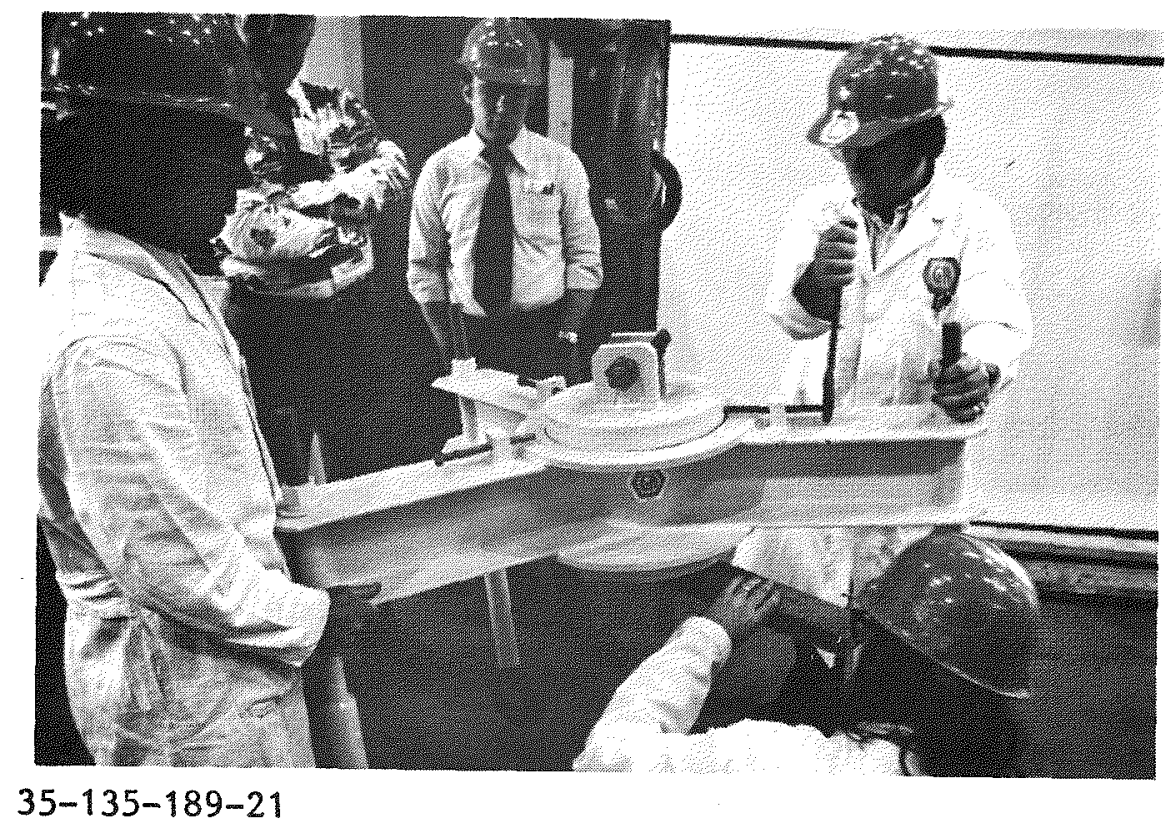

Fig. 25. Tri-beam lift fixture - adjusting center hub 
3. The burner lug/lift hook interface (see Fig. 24a) presented a problem when engagement was attempted. With the fixture level as required and the lugs positioned properly for engagement, it was necessary to provide a manual "pull" in the direction of desired engagement. This was accomplished by a "tag line" attached to the forward hook arm. With this method, engagement was readily accomplished. When attempting engagement without "manual" assistance, it is necessary to "jog" the crane trolly. The forward burner lug is sometimes contacted without engagement, preventing forward motion and causing the two rear hooks to raise above the lug engagement slots. This places the fixture in an attitude of being balanced on the forward lug and lift hook. The fixture immediately rotates to one side making engagement impossible. As pointed out previously, this situation could result in damage to either the fixture or burner tube lugs. No problems were encountered during disengagement and "manual" assistance was not necessary.

Once adjusted and leveled, the fixture performed satisfactorily. The "manual" assistance provided could readily be accomplished by a manipulator, provided overhead crane operation and manipulator actions could be coordinated. However, from a safety and operating standpoint, future interface work is recommended.

\subsubsection{Recommendations}

3.2.11.1. Existing Design. Based on the tri-beam lift fixture performance evaluation, three recomnendations are made:

1. Incorporate a permanent counterweight on the forward beam arm. The weight should be sized and located so that the beam arms are level when the fixture is suspended "unloaded." The counterweight location should be adjustable to compensate for the center of lift adjustments made to accommodate the burner tube. 
2. Modify the center hub lift assembly adjustment feature to improve performance and ease of operation.

3. Perform a failure mode and effects analysis.

3.2.11.2. Future Design. Future design activities should address improvement of remote operating capabilities. Although most operations involving requirements for manipulator assistance are judged to be within this capability, these operations should be reviewed for possible improvements.

Specifically, the burner lug/lift hook crane attachment interfaces should be redesigned to improve remote operability. In addition, materials used on the fixture should be reviewed for suitability within a cell radiation environment. Duty cycle and equipment life should be determined to establish fixture availability based on relative equipment usage predictions.

\subsection{LIFT FIXTURE - SECONDARY BURNER (FIG. 26)}

\subsubsection{Design Requirements}

Two basic criteria were established for the secondary burner lift fixture:

1. Required interfaces shall be provided between the pilot plant crane and the secondary burner tube lift lugs.

2. Overall lifting and handling capabilities shall be provided as necessary to demonstrate the semiremote installation and removal of the burner tube assembly. These operations involve the burner shroud assemblies and the tilt-down fixture.

These criteria, combined with basic improvement of equipment handling safety, established the fixture design requirements. 


\subsubsection{Fixture Description}

The fixture design chosen is responsive to all established criteria and reflects an alternate choice to a tri-beam arrangement. The selection of this more basic approach was made to establish suitability of the yoketype lift fixture for these specific semiremote applications.

The fixture models a basic yoke configuration. It consists of two vertical lift arms (26-1) attached to a main cross beam (26-2). The center of the cross beam is provided with a pair of lift lugs (26-3) which interface with the pilot plant crane. The vertical lift arms are spaced to interface with the burner tube lift lugs. The lower end of each lift arm has a special 1ift hook (27-4) for engaging the burner lugs.

\subsubsection{Operational Description}

In operation the lift fixture is connected to the pilot plant overhead crane by means of the Hydra-set and appropriate shackles.

Lifting (see Figs. 28 and 29) is accomplished by locating the fixture adjacent to the burner lugs (29-5) with the open side of the lift hook facing the lug. Engagement is accomplished by simultaneously moving the fixture toward the lug until contacted and raising it slightly as the hook enters the lug slot. Manual guidance is required to provide the necessary orientation and alignment during this operation.

Complete operating procedures are given in Appendix A, Part 1.

\subsubsection{Control Systems}

Control of the lift fixture is provided indirectly through the plant crane and Hydra-set. Direct control is provided during initial orientation by manual means simulating manipulator actions. Gross vertical and lateral movements are controlled with the pilot plant crane to within $\pm 1 / 8$ in. (3.17 $\mathrm{mm})$. The Hydra-set provides further vertical control to within \pm 0.005 in. 


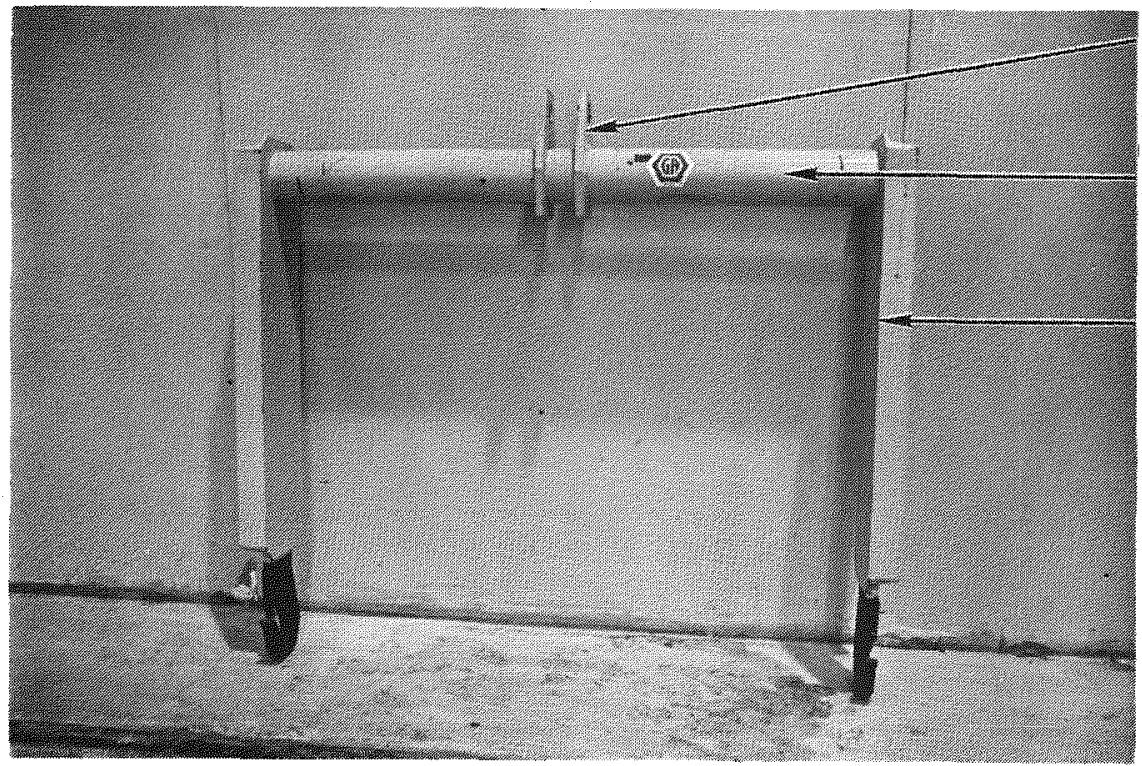

(3) LIFT LUGS

(2) MAIN CROSS BEAM

(1) VERTICAL LIFT ARM

$35-135-204-12$

Fig. 26. Secondary burner lift fixture

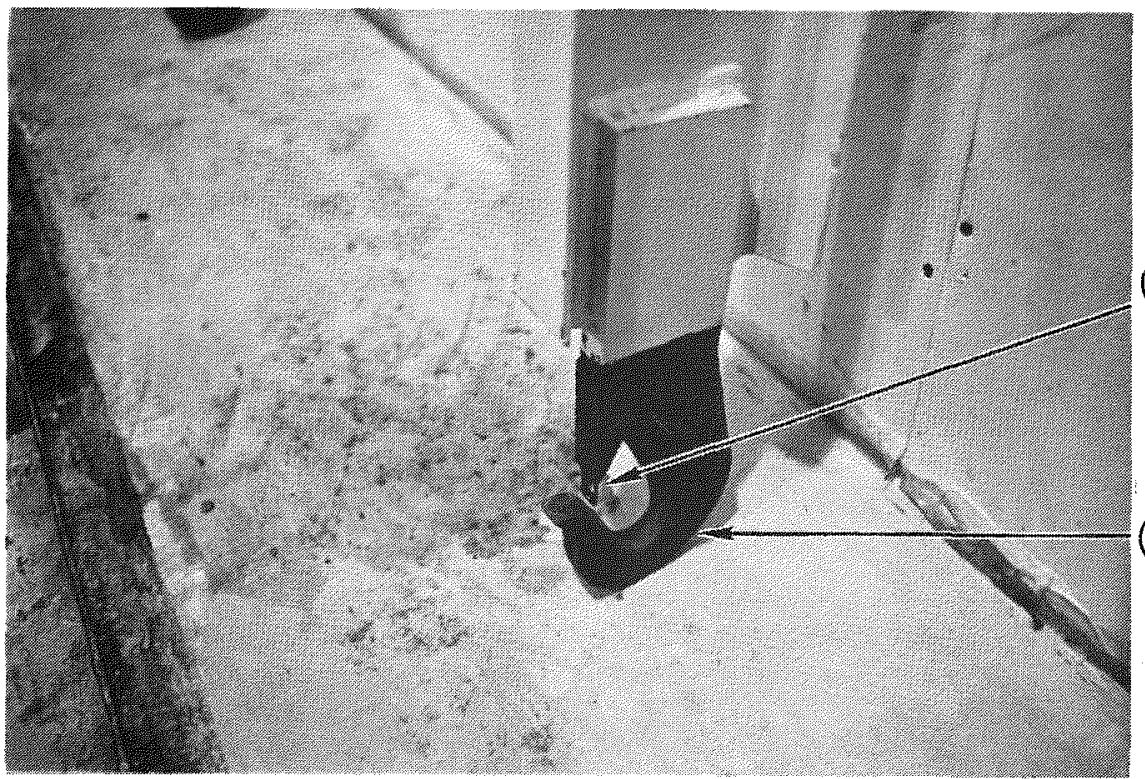

(6) MOVABLE SAFETY LATCH

(4) LIFT HOOK

$35-135-204-13$

Fig. 27. Secondary burner 1ift fixture - 1ift hook 


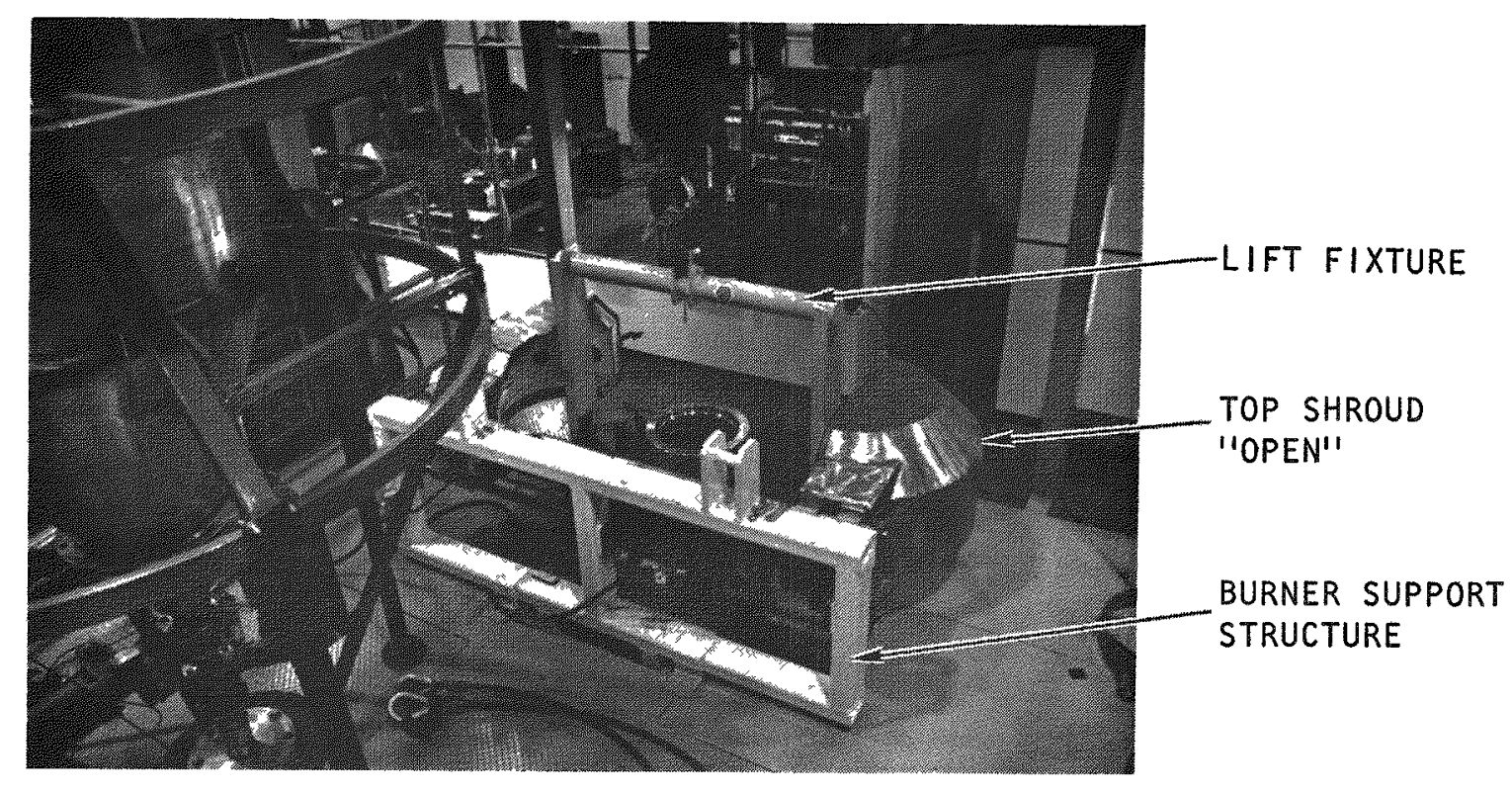

$35-135-191-4$

Fig. 28. Secondary burner lift fixture - lifting burner tube

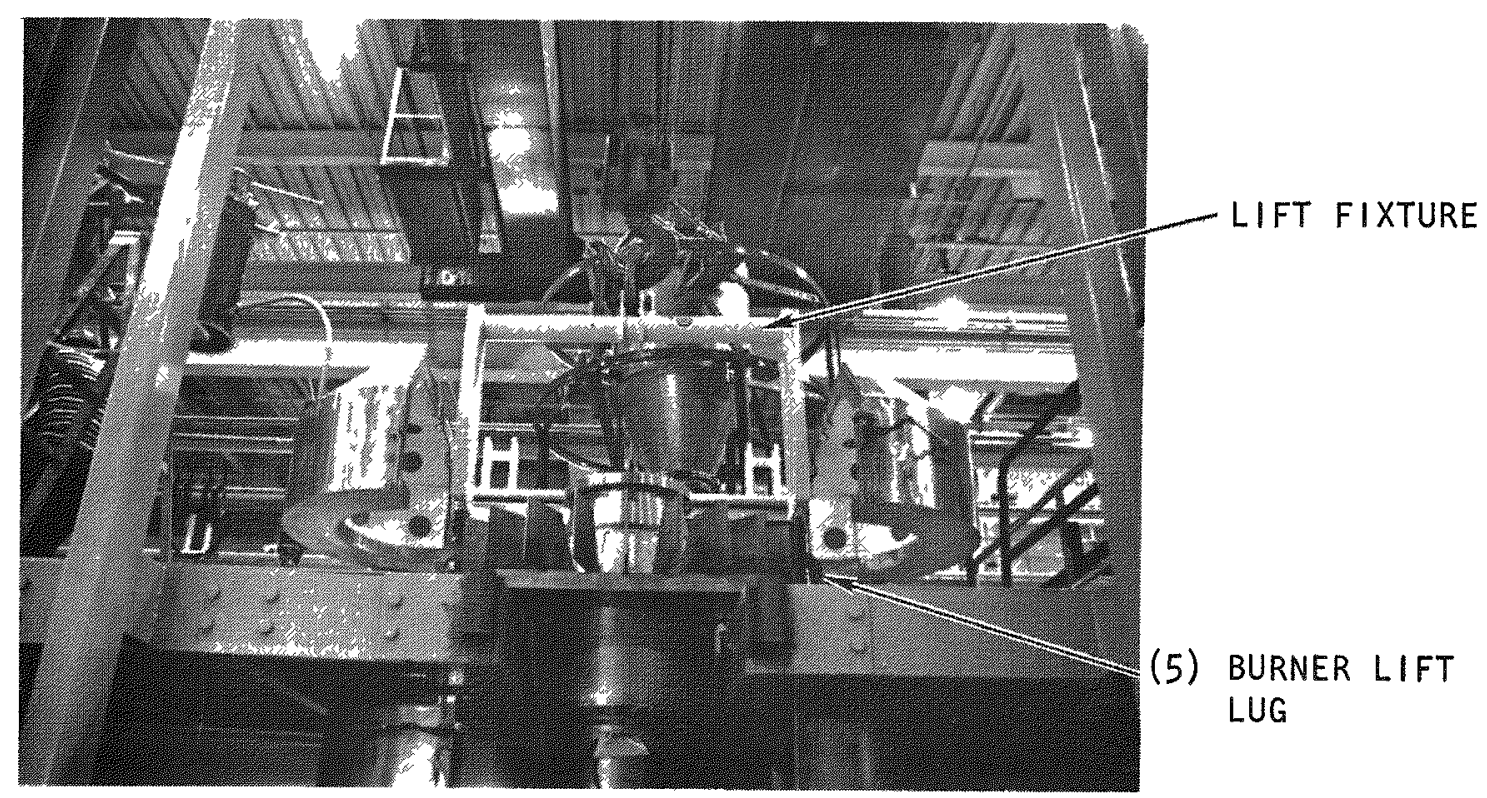

$35-135-191-3$

Fig. 29. Secondary burner lift fixture - lifting burner tube 
$(0.127 \mathrm{~mm})$. In addition, the Hydra-set provides continuous load readout. During initial withdrawal and final seating, the fine control and load readout are used to sense possible burner tube hang-up or binding due to interference with the shrouds or susceptor assemblies.

\subsubsection{Reliability}

A detailed structural analysis performed for the lift fixture confirms adequate safety margins for all structural components. Load testing demonstrated structural adequacy for the intended purpose.

A detailed failure mode and effects study must be performed to determine overall operational reliability. This activity is included in the future work scope for this fixture.

Since this is essentially a "zero" maintenance fixture, reliability is not directly influenced by a maintenance program.

\subsubsection{Maintenance}

Maintenance requirements for the lift fixture are minimal. It is likely that equipment degradation caused by the environment will exceed operational wear. Maintenance will consist of general clean-up, painting, and load testing. Frequency will depend on the storage environment and equipment usage.

\subsubsection{Availability}

The lift fixture was designed for maintenance support during burner removal, and therefore its use will be infrequent relative to the burner operation. Maintenance requirements are low and will thus have a negligible affect on fixture availability. 


\subsubsection{Safety}

Overall handling safety is improved by using this fixture since it was designed to suit a specific handing situation. This approach avoided makeshift lifting arrangements and eliminated potential risks associated with them. Additionally, the following safety features were considered:

1. A design safety factor of 5 based on material ultimate strength.

2. A proof test at $1-1 / 2$ times the rated static 1oad.

3. Hook safety latches.

These features, combined with handling operations performed in accordance with specific operating procedures approved by cognizant interface organizations and supervised by trained and qualified technicians, contribute to greater pilot plant safety.

\subsubsection{Testing}

3.3.9.1. Structural Proof Testing. A structural proof test was performed by the manufacturer at twice the rated load. The test was witnessed by cognizant engineering and quality assurance personnel.

\subsubsection{Operational Checkout. Due to schedulax conflicts between the} installation of the primary and secondary burner tubes, a complete operational cycle test could not be performed which would include the tilt-down fixture to verify interface compatibility. Tests were run with the secondary burner to demonstrate the essential design interface of the fixture. Difficulty was experienced when attempting to engage the fixture lift hooks with the burner lugs. This was due to interference caused by the safety latch (27-6) attached to the lift hook. These latches were provided to satisfy OSHA Plant Safety Requirements and would not be included for hot cell applications. Additional testing will be scheduled in accordance with the activity plan to demonstrate complete functional capability and resolve the interference problem. 


\subsubsection{Performance Evaluation}

The partial functional checkout of the lift fixture performed in conjunction with installation of the secondary burner tube demonstrated basic fixture suitability and compliance with the design criteria. Additional testing is required as previously stated. Evaluation of fixture overall performance will be made after completion of these tests.

\subsubsection{Recommendations}

3.3.11.1. Existing Design. Based on the partial functional testing, the following recommendations are made:

1. Revise the lift hook design to permit engagement with the burner lugs by semiremote methods. The present configuration includes a safety latch which interferes with engagement.

2. Perform a complete functional checkout.

3. Perform a failure mode and effects analysis.

3.3.11.2. Future Design Recommendations. Future design activities should address improvement of remote operating capabilities.

3.4. SUSCEPTOR AND CERAMIC HOLDING AND TRUNNION FIXTURE - PRIMARY BURNER (Figs. 30a, 30b)

\subsubsection{Design Requirements}

A review of the susceptor and ceramic assembly handling requirements indicated that a special purpose fixture was needed to restrain and support the assembly and provide the capability to withdraw the susceptor for inspection, repair, or replacement. The fragile nature of the ceramic insulating material required full support and protection during this operation. Four basic criteria were established: 


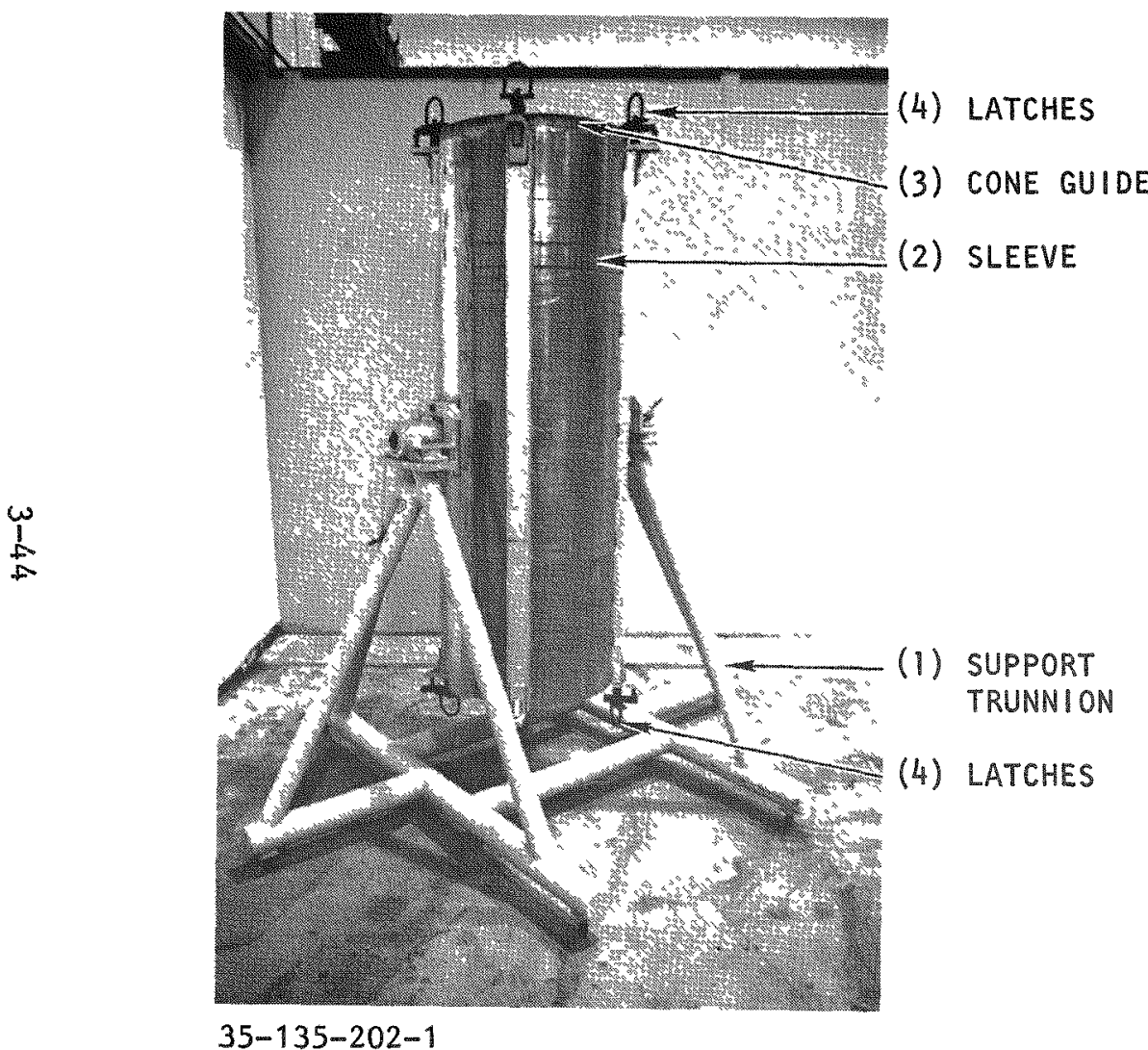

(a)

Fig. 30a. Susceptor and ceramic holding and trunnion fixture (upright)

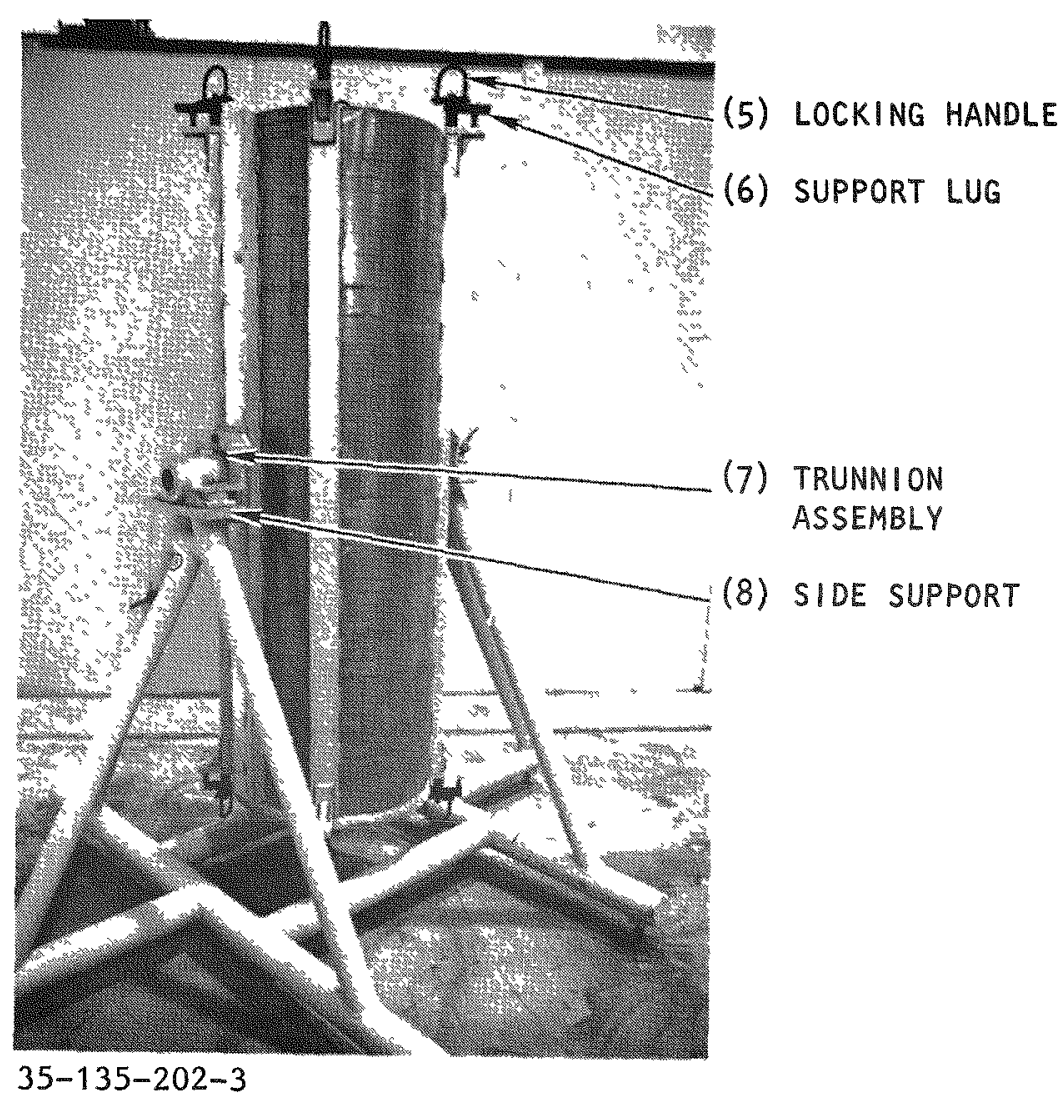

(b)

Fig. 30b. Susceptor and ceramic holding and trunnion fixture (extended) 
1. The fixture envelope and operation shall be compatible with the susceptor and ceramic removal fixture (see Section 3.5).

2. The fixture shall support and retain the ceramic during handing operations.

3. The fixture shall provide the capability to invert the susceptor and ceramic assembly and shall permit removal of the susceptor from the fixture when inverted.

4. The fixture shall be capable of being locked in either the upright or inverted position.

In addition, the support frame and base (trunnion) of this fixture shall be compatible with the susceptor and ceramic holding and trunnion fixture adapters for the secondary burner (see Section 3.6). The primary burner sleeve components shall be removable for this purpose.

\subsubsection{Fixture Description}

The fixture design adopted consists of two basic assemblies: the support trunnion $(30 a-1)$ and the sleeve $(30 a-2)$. This approach permits removal of the sleeve designed for handing the primary burner and substitution of a sleeve for handling the secondary burner. The support trunnion was designed to provide a stable platform and a mounting for the rotating pillow blocks. The support and trunnion assembly therefore can be readily adapted for either ceramic sleeve assembly. The sleeve assembly was designed with trunnions located on the outside of the cylinder at the CG. This location provides ease of rotation for inverting the susceptor and ceramic. The sleeve is provided with four lugs on each end to support the susceptor and ceramic. The solid sleeve cylinder protects and supports the delicate ceramic material and prevents inadvertent damage during handing. 
The rotation and activation of the sleeve support lugs will require manual assistance. However, these operations can be accomplished readily by manipulators.

Aluminum was chosen for the sleeve assembly to maintain the lowest practical weight for the rotating component. Also, if carbon steel were chosen, means to prevent contaminating the ceramic with rust or paint would be necessary.

The sleeve $(30 a-2)$ is an aluminum cylinder approximately $23-3 / 8$ in. $(60.3 \mathrm{~cm})$ in diameter by $75-3 / 4 \mathrm{in.}(192.4 \mathrm{~cm})$ long. The top of the sleeve is cone shaped $(30 a-3)$ to aid in inserting the ceramic. Four latches (30a-4) are provided on each end of the sleeve.* Each latch consists of a locking handling $(30 \mathrm{~b}-5)$ and support lug $(30 \mathrm{~b}-6)$. The lug moves radially in and out and supports either the susceptor tube or the ceramic. The center of the sleeve is furnished with two trunnion assemblies (30b-7) attached to the outside boss. The trunnions are located on the sleeve CG, and the sleeve is rotated about them during inversion of the ceramic.

The trunnion assemb1y $(30 a-1)$ is a pipe structure with a rectangular base and two side supports. This assembly is approximately $72 \mathrm{in.}(182.8$ $\mathrm{cm})$ wide by $88 \mathrm{in.}(233.5 \mathrm{~cm})$ long by $56-1 / 4 \mathrm{in.}(142.8 \mathrm{~cm}) \mathrm{high}$. The side support assemblies $(30 \mathrm{~b}-8)$, one on each side of the structure, house the rotating bearing pillow blocks $(33 a-8)$. This is the interface with the sleeve assembly via the sleeve trunnions. Each pillow block assembly is provided with a removable lock pin (33a-9). The pin engages a hole in the pillow block assembly and one of two holes in the sleeve trunnion base $(33 a-10)$. This permits locking the sleeve in either the upright or inverted position.

*Figures 31 and 32 show the arrangement of the locking handle and support lugs. 
(4) LOCKING HANDLE

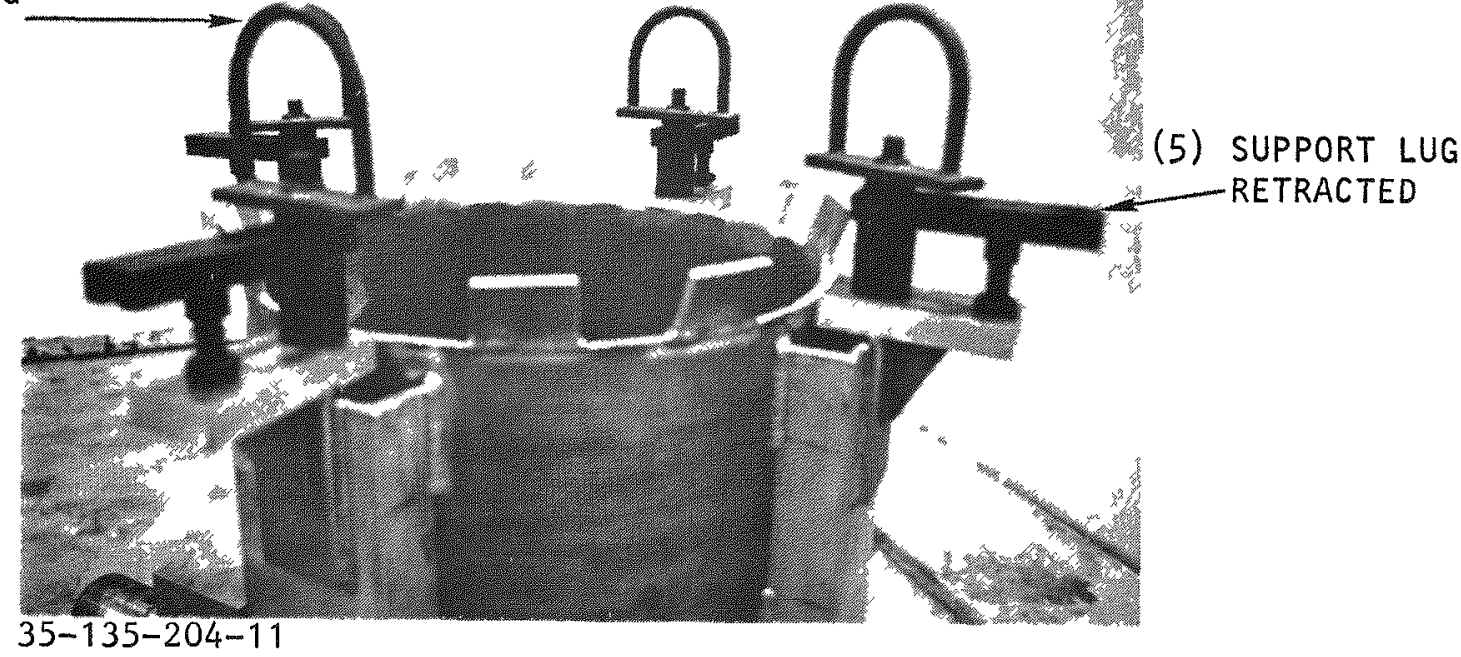

Fig. 31. Susceptor and ceramic holding fixture - secondary burner; support
lugs retracted

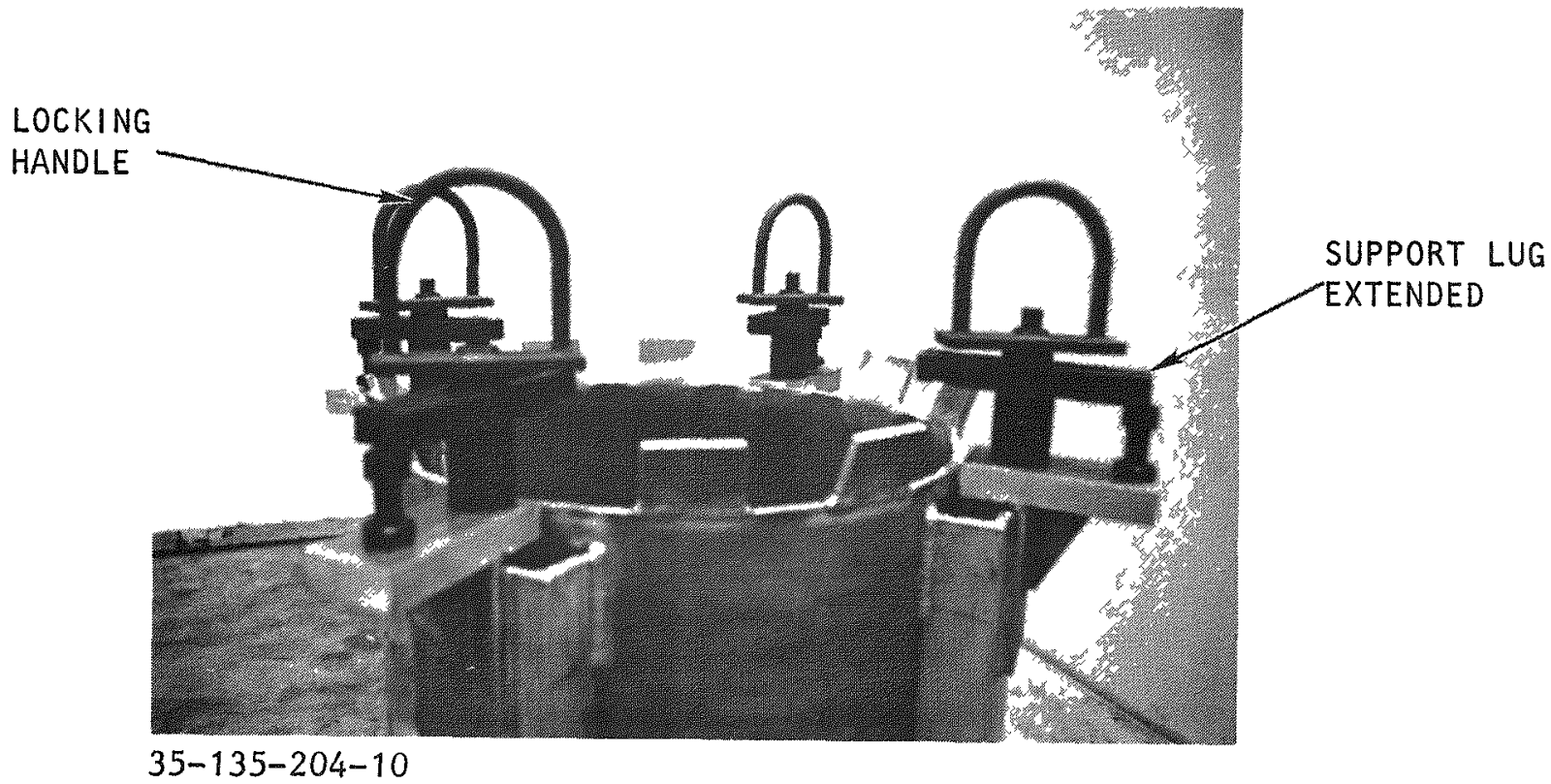

Fig. 32. Susceptor and ceramic holding fixture - secondary fixture; support
lugs extended 


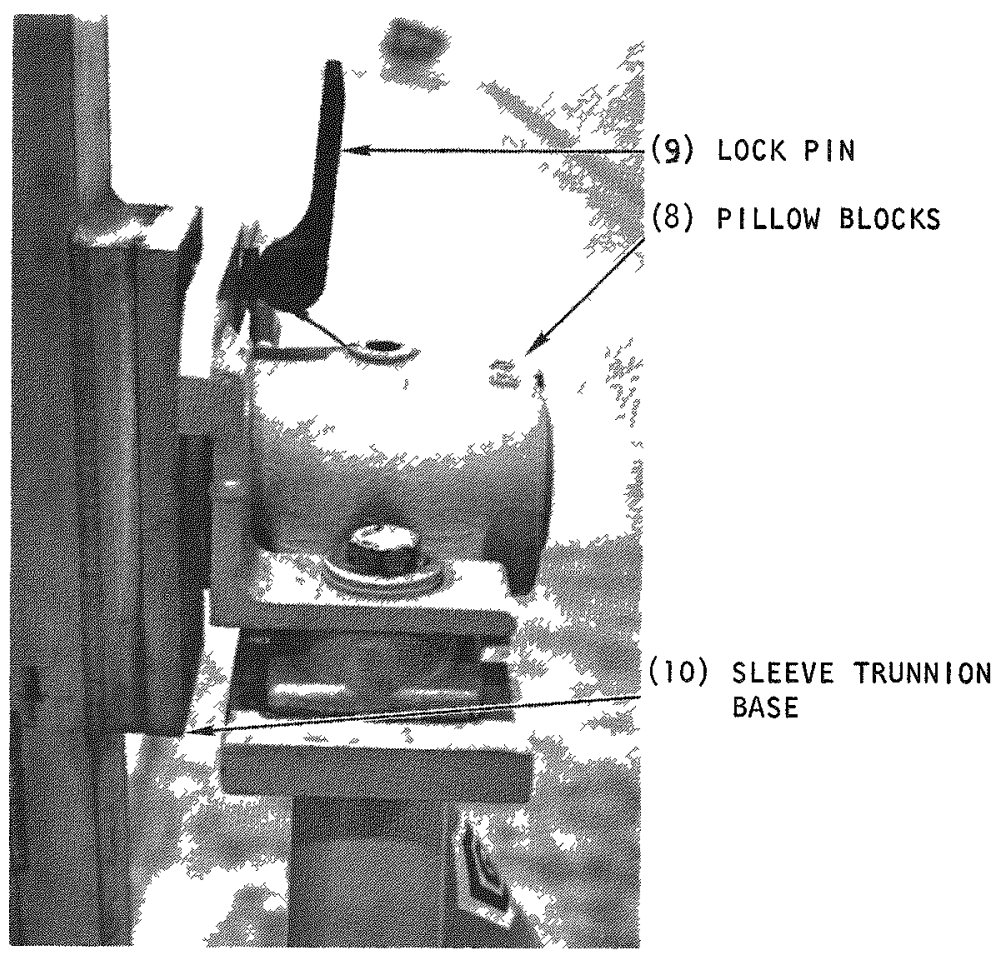

$35-135-204-19$

(a)

Fig. 33a. Susceptor and ceramic holding fixture - bearing pillow blocks and lock arrangement

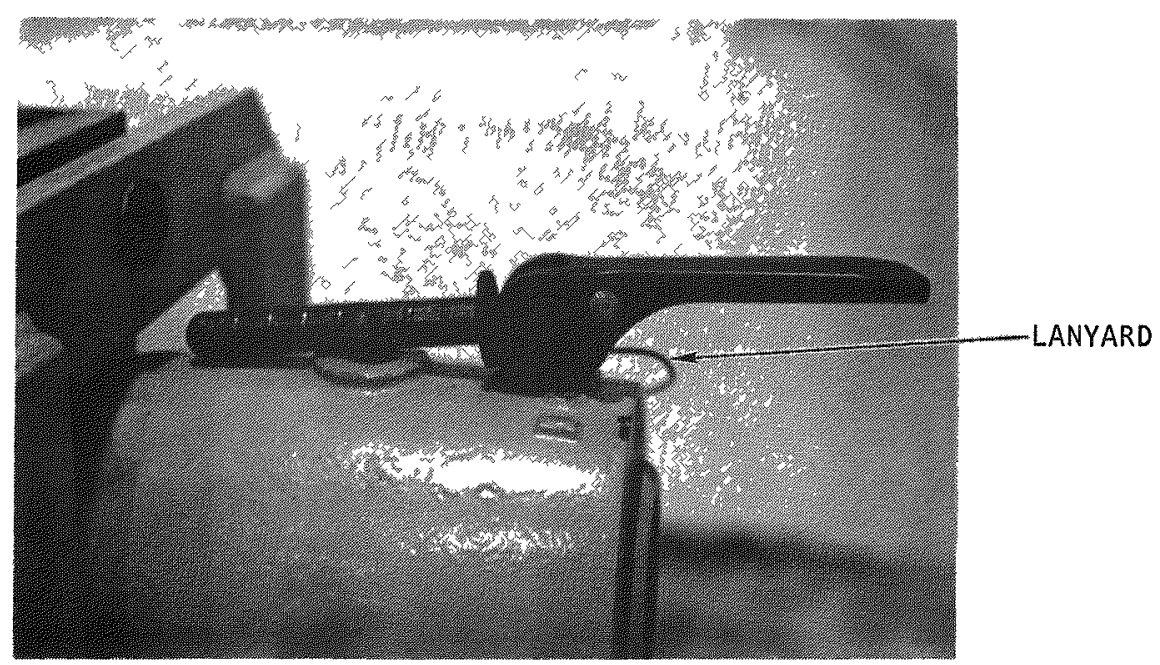

$35-135-204-20$

(b)

Fig. 33b. Susceptor and ceramic holding fixture - lock pin withdrawn 


\subsubsection{Operationa1 Description}

A summary of the operations involving the susceptor and ceramic holding and trunnion fixture is provided herein to highlight specific operating features. Detailed operating procedures are given in Appendix A, Part 3.

The fixture is presented for use by locking the sleeve in the upright position, that is, with the "cone end" up. The previously loaded ceramic and susceptor removal tool is suspended over the upright sleeve.

After ensuring that the sleeve top support lugs are retracted and the bottom lugs are extended, the removal tool is used to lower the ceramic and susceptor into the sleeve (Fig. 34). Once these are seated, the top support lugs are extended to engage the top of the ceramic. The removal fixture is disengaged from the susceptor and withdrawn. The sleeve lock pins are disengaged and the sleeve is inverted by manually rotating it $180^{\circ}$. The top support lugs (bottom rotated $180^{\circ}$ ) are retracted and the removal tool is reinserted into the susceptor. The susceptor support lug on the tool is engaged and the susceptor is withdrawn from the assembly.

\subsubsection{Control Systems}

There are no electrical or auxiliary mechanical drives or controls associated with this fixture. Position control during rotation is provided manually.

\subsubsection{Reliability}

Structural analysis performed for this fixture has confirmed adequate safety margins for all structural components for the specified loading conditions.

A detailed failure mode and effects study must be performed to determine overall operational reliability. This activity is included in the future work scope. 


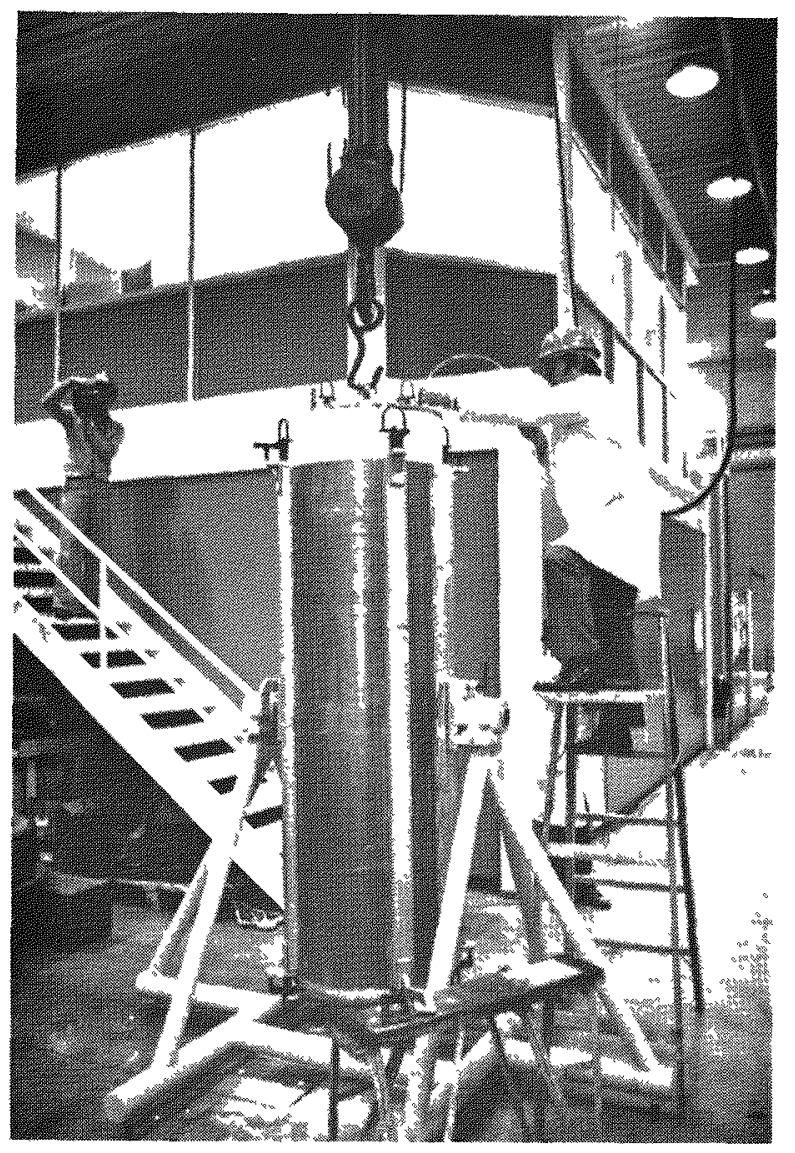

Fig. 34. Installation of ceramic/susceptor into holding and trunnion fixture 


\subsubsection{Maintenance}

Maintenance requirements for this fixture are low. It is likely that equipment degradation caused by the environment will exceed operational wear. Maintenance will consist of lubrication of the pillow block bearing and corrosion protection of the support lugs. The support stud (trunnion) will require general clean-up and painting at intervals depending on storage environment and equipment usage.

\subsubsection{Availability}

The fixture was designed for maintenance support during removal of the susceptor and ceramic; therefore, its use will be infrequent relative to the burner operation. Maintenance requirements are low and will have a negligible effect on fixture availability.

\subsubsection{Safety}

Overall handling safety is improved by using this fixture since it was designed to suit a specific handling situation. This approach avoided makeshift lifting and handling arrangements and eliminated the potential risks associated with them. All handling operations are performed in accordance with operating procedures approved by cognizant interface organizations and supervised by trained and qualified technicians.

\subsubsection{Testing}

3.4.9.1. Structural Proof Testing. A structural proof test was performed by the manufacturer at twice the rated load. The test was witnessed by cognizant engineering personnel.

3.4.9.2. Operational Checkout (Figs. 35a-35b). The fixture was used during initial assembly of the primary burner to demonstrate susceptor and ceramic handling. The operations involved initial placement of the ceramic into the sleeve assembly and subsequent installation and handling of the 


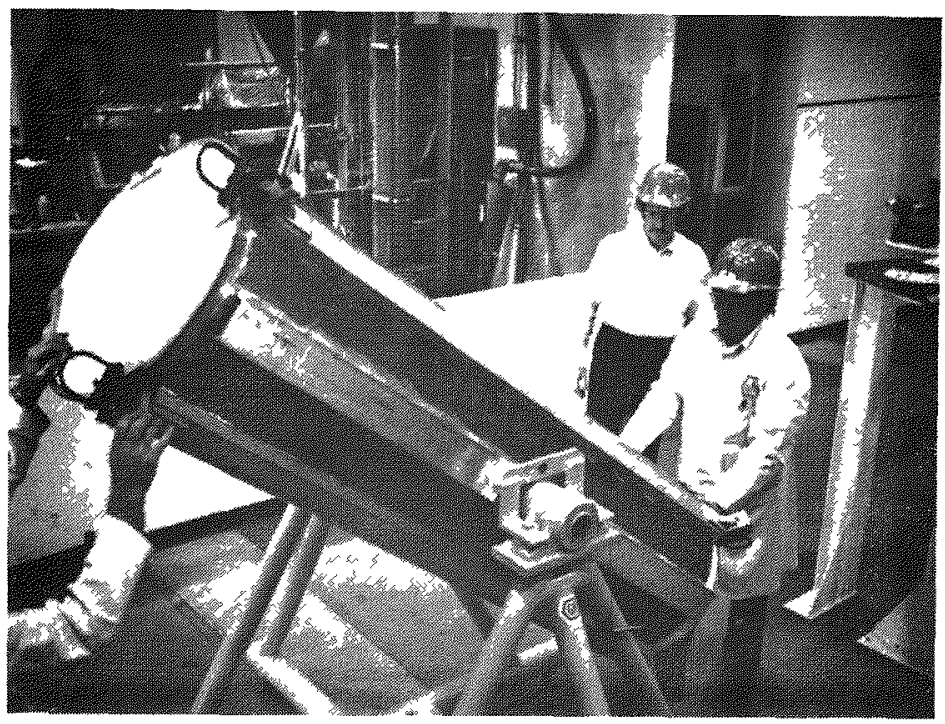

(a) Fixture is rotated so that ceramic insulation is bottom-side up.

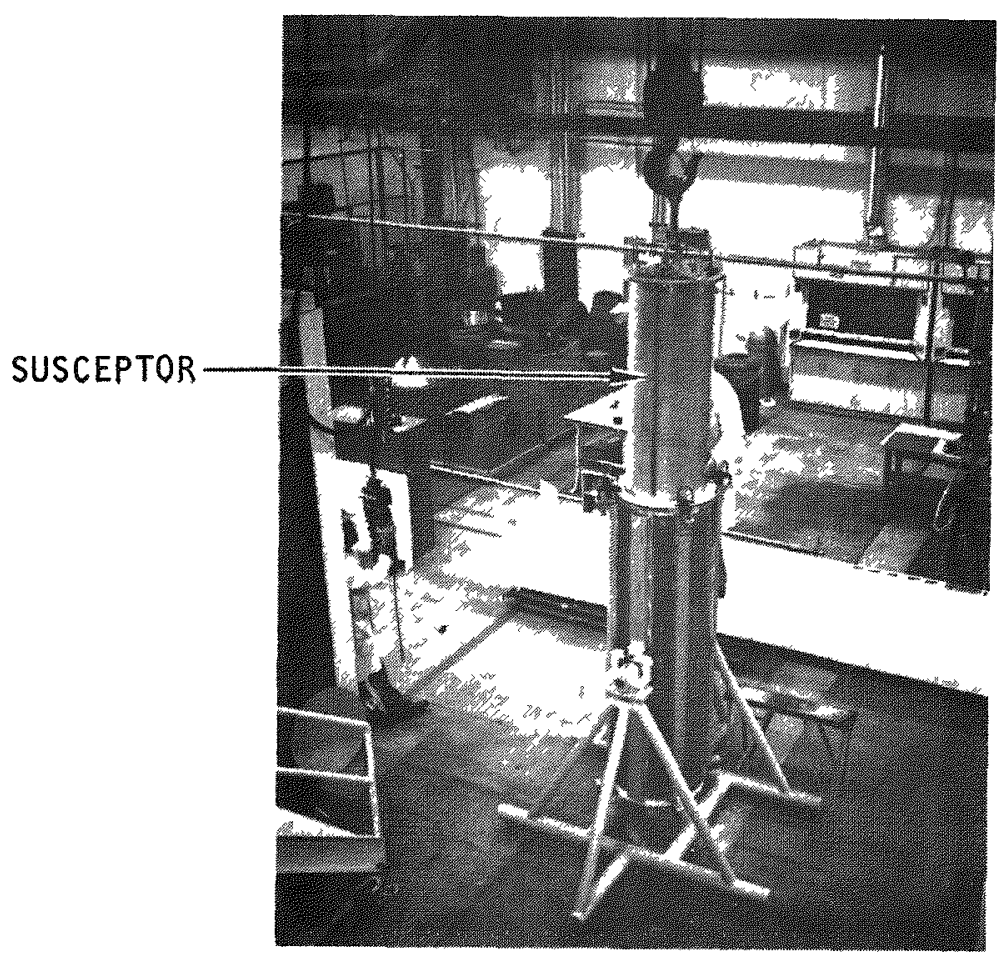

(b) Susceptor is inserted into the ceramic insulation with the susceptor lifting fixture.

Fig. 35. Sequence for assembly of 16-in. (40 cm) primary burner heater section (sheet 1 of 2 ) 


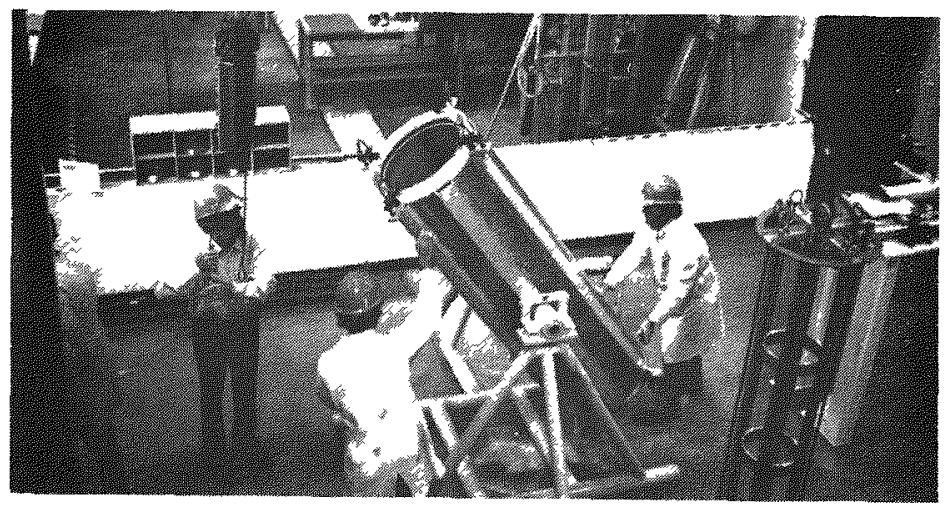

(c) Susceptor-ceramic assembly is rotated so that it is right-side up.

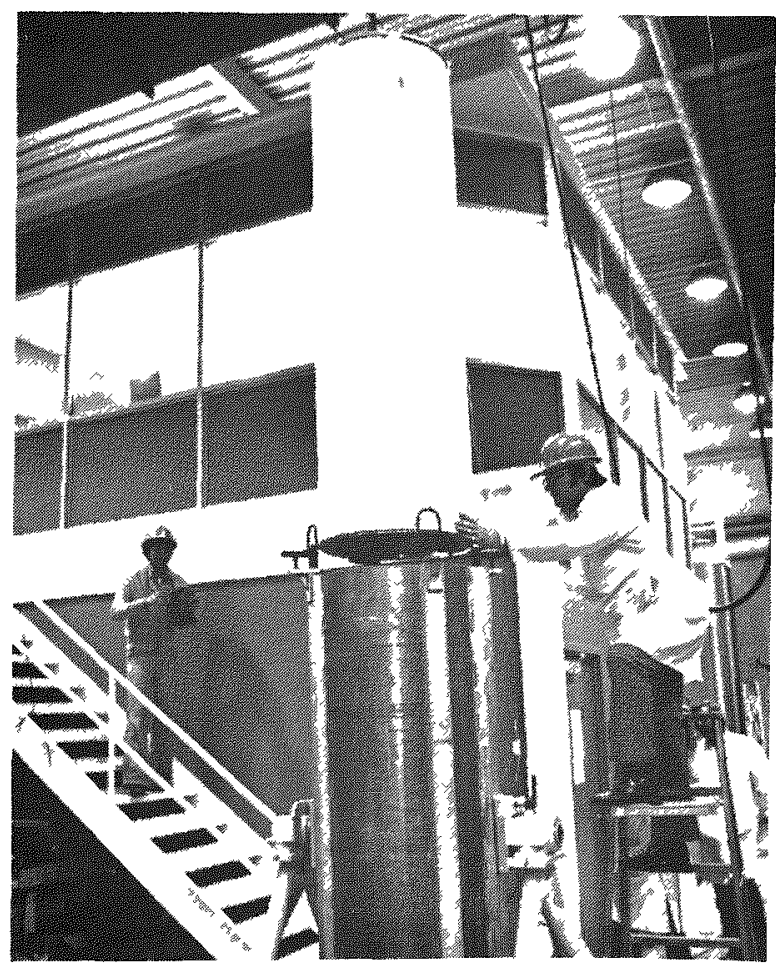

(d) Susceptor-ceramic assembly is picked up by the susceptor flange with the lifting fixture.

Fig. 35. Sequence for assembly of 16-in. $(40 \mathrm{~cm})$ primary burner heater section (sheet 2 of 2) 
susceptor and ceramic removal tool. One problem was encountered during the checkout; however, the fixture performed satisfactorily. The problem involved the fit between the outside diameter of the ceramic and the inside diameter of the sleeve. Owing to slight ovality in the sleeve and distortions in the ceramic, interference was noted during insertion of the ceramic. The ceramic liner is formed with bricks stacked in appropriate positions and mortered in place. The entire assembly is then fire cured. Dimension control is difficult relative to the tolerances established. Corrective action is described in Section 3.4.11.

Checkout of the fixture during burner disassembly has not been completed but is included in the program activity plan.

\subsubsection{Performance Evaluation}

The functional checkout of the fixture performed in conjunction with initial installation of the primary burner demonstrated fixture suitability and compliance with the design criteria.

Operationa1ly, no problems were encountered. However, three problems were noted which require further resolution:

1. The fit between the ceramic and the sleeve was unsatisfactory.

2. The locking action of the top latches was difficult owing to:

a. The length of the ceramic.

b. Perpendicularity of the ceramic top face to the center line.

c. The fit of the ceramic shield ring on top of the ceramic.

These items reflect dimensional interferences which could not be accommodated with the shield ring in place. Handing was accomplished by replacing the ring with wood spacers during handing. Redefinition of the ceramic envelope and subsequent modification of the fixture will be required 
if the manufacturing tolerances of the ceramic cannot be maintained within the presently specified limits.

\subsubsection{Recommendations}

3.4.11.1. Existing Design. Based on the performance evaluation, two recommendations are made:

1. Increase the inside diameter of the sleeve to provide additional clearance with the ceramic.

2. Evaluate the manufacturing tolerances on the shield ring and ceramic (length). Revise the fixture or components as appropriate.

3.4.11.2. Future Design Recommendations. Future design activities should address improvement of remote operating capabilities. Although most operations involving manipulator assistance are judged to be within this capability, these operations should be reviewed for possible improvement.

Specifically, the disassembly of the pillow blocks, removal of the primary sleeve, and reassembly with the secondary sleeve and adapters are cumbersome and require improvement for remote applications.

The feasibility of redesigning the sleeve to be compatible with both primary and secondary burner ceramics should be evaluated. This could eliminate the need for the secondary sleeve and adapters and avoid complicated assembly and disassembly.

3.5. SUSCEPTOR AND CERAMIC REMOVAL FIXTURE - PRIMARY BURNER (FIGS. 36a, 36b)

\subsubsection{Design Requirements}

The unique handling and interface requirements for removing the primary burner susceptor and ceramic established the need for a special fixture. Three basic criteria were established for this fixture: 


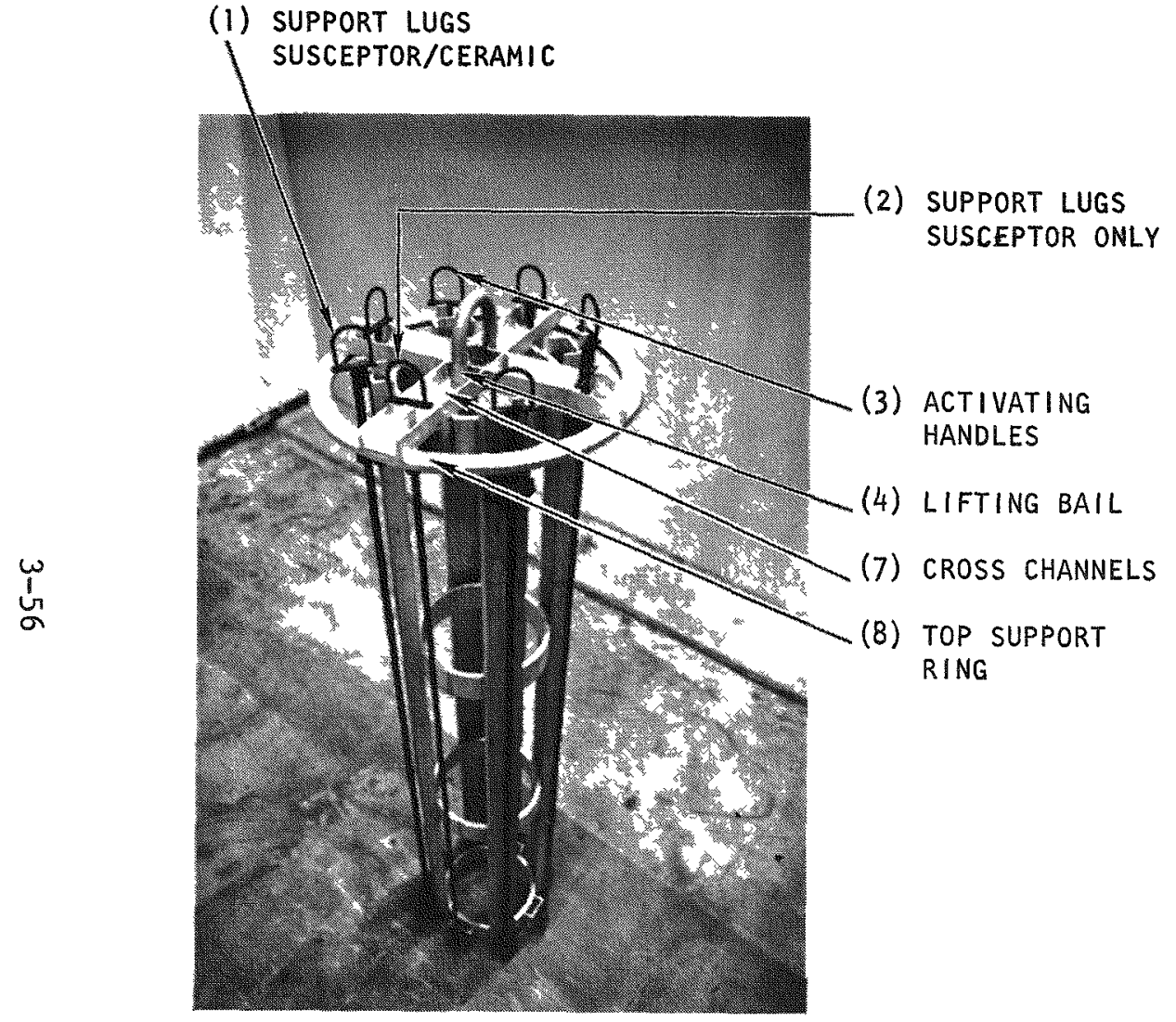

$35-135-204-6$

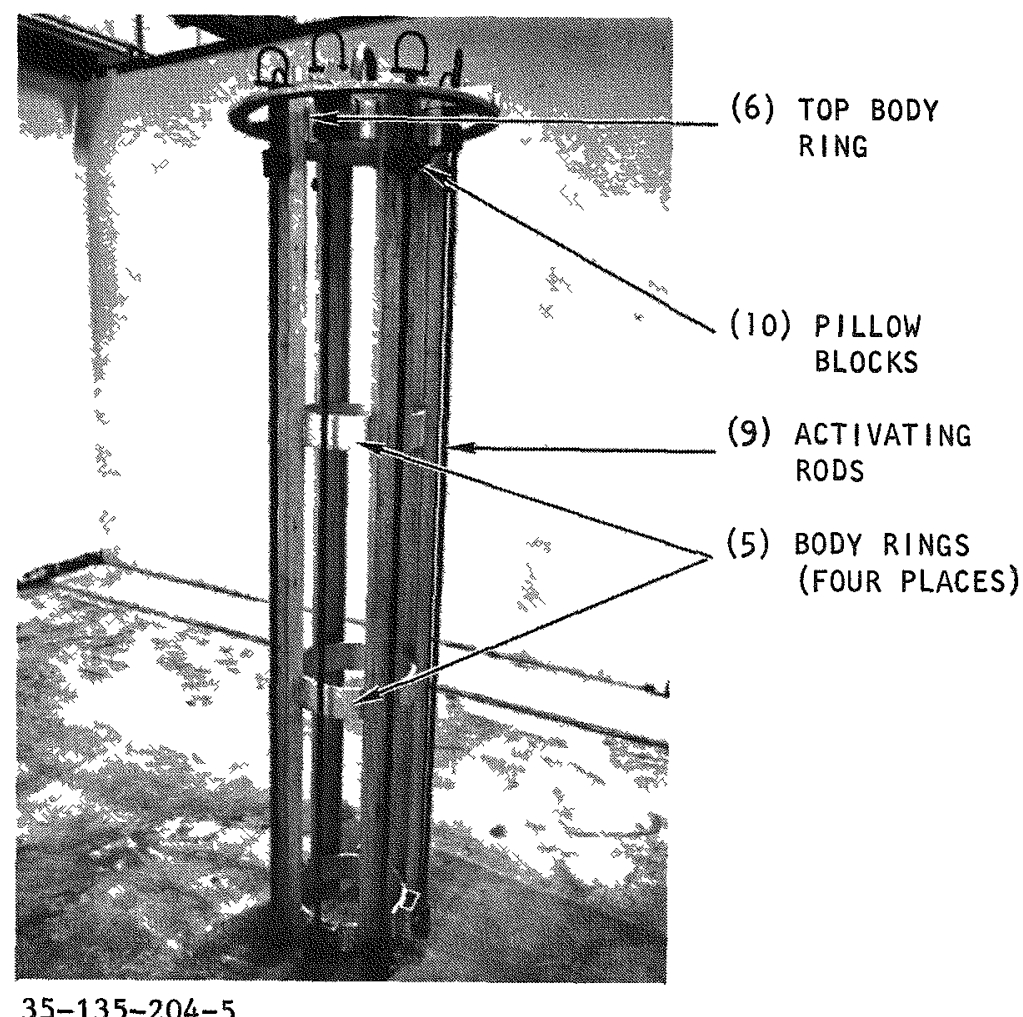

(b)

Fig. 36. Susceptor and ceramic removal tool 
1. With the fixture connected to the pilot plant overhead crane, the semiremote removal and replacement of the susceptor and ceramic assembly from the lower shroud assembly shall be demonstrated.

2. The susceptor and ceramic assembly shall be placed into the trunnion and holding fixture sleeve.

3. The removal and replacement of the susceptor tube from the inverted ceramic shall be demonstrated.

In addition, certain interface requirements were established for the primary burner equipment to accommodate the fixture and provide the accessibility required. These included:

1. Clearance in the burner heater base for the fixture lower support lugs.

2. Orientation guide marks to provide means to align the fixture in the proper position.

3. Capability to withdraw the burner tube sufficiently to clear the susceptor tube.

4. Capability to displace the lower shroud assembly (containing the susceptor and ceramic) sufficiently to provide overhead access for the removal fixture.

\subsubsection{Fixture Description}

The handling fixture design adopted consists of a cylindrical, lightweight aluminum frame provided with two sets of support lugs. This concept was chosen because it provides the required lifting capability with simple construction requirements. The fixture has an overall diameter of $22-7 / 8$ in. $(58.1 \mathrm{~cm})$ and an overa11 length of $87-1 / 16 \mathrm{in.}(22.1 \mathrm{~cm})$. The fixture body consists of a series of four rings (36b-5) connected by four channels 
running the length of the fixture. The top body ring ( $36 b-6)$ is connected to a set of cross channels terminating in a top support ring (36a-8). The center of the top cross channels is provided with a lifting bail (36a-4) for connection to the pilot plant crane. Each of the 1ongitudinal channels connected to the inner rings acts as a mounting station for the support lug activating rods $(36 \mathrm{~b}-9)$ and pillow blocks $(36 \mathrm{~b}-10)$. Both sets of lugs are manually activated by means of rods topped with handles $(36 a-3)$. The handles are designed to permit activation by manipulators; therefore, the required manual operation simulates manipulator actions.

The two sets of four support lugs provided on the fixture take advantage of the susceptor and ceramic relationship. One set $(37 b-11)$ is used to install the susceptor/ceramic assembly into and remove it from the burner shroud. This set of lugs lifts and supports the assembly when it is in the upright position. It does this by supporting the flange around the outside of the susceptor tube bottom. The flange supports the ceramic, permitting it and the susceptor tube to be lifted as a unit. The flange also provides a convenient support for lifting the ceramic without causing damage to this fragile material. Each of the activating rods for this set of lugs is equipped with a set of centering devices $(37 \mathrm{~b}-12)$. They center the fixture within the susceptor tube and assure proper clearance positioning with the heater base slots.

The second set of four lugs $(37 \mathrm{~b}-13)$ is used only during installation or removal of the susceptor tube. It lifts and supports the tube when it is in the inverted position. When the tube is inverted, removal is accomplished by supporting the tube on its top edge. The activating rods for these lugs are each furnished with one centering spring device (37a-14) which centers the lower end of the susceptor when a lug is activated. This ensures engagement between the narrow end of the tube and the lug.

\subsubsection{Operational Description (Figs. 34, 35b, 35d, 38)}

A summary of the operations involving the removal fixture during handling of the primary burner susceptor and ceramic is provided herein to 


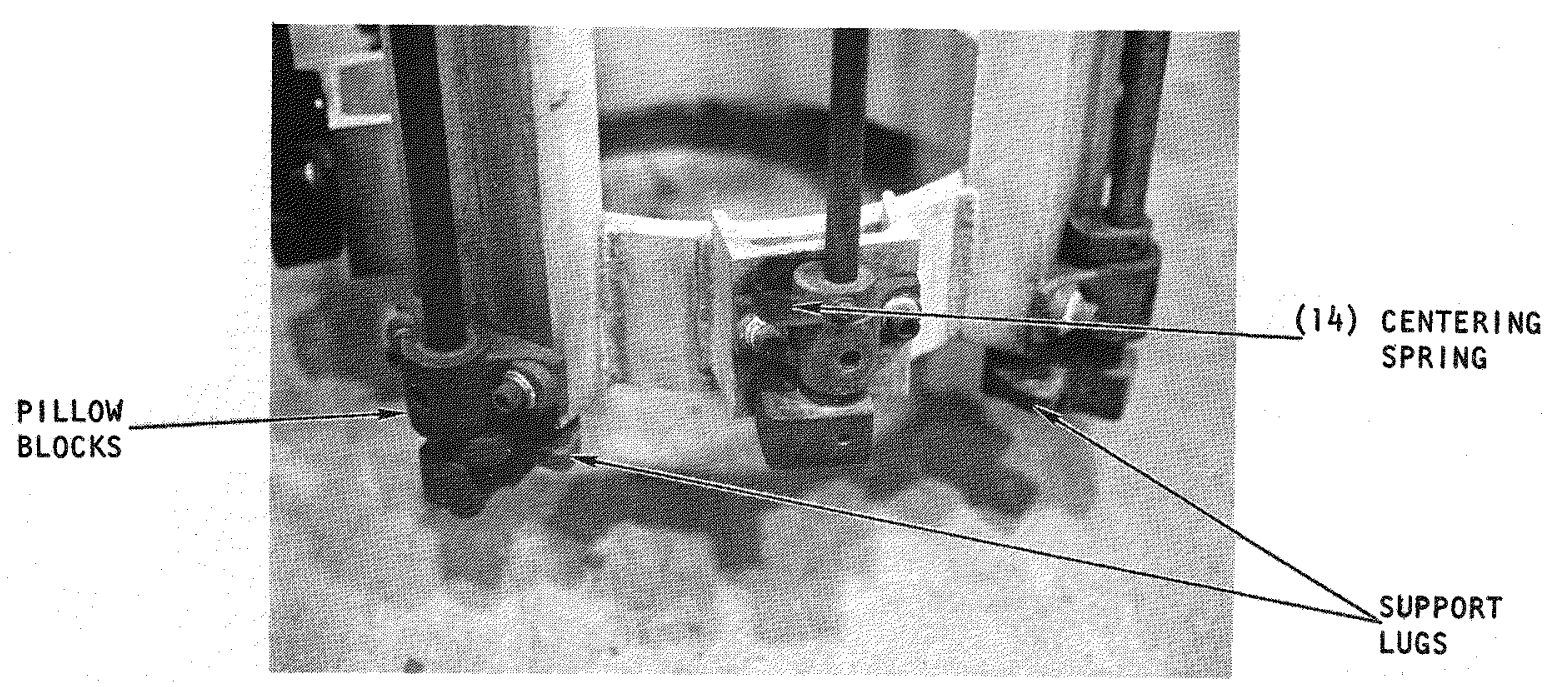

$35-135-204-8$

Fig. 37a. Susceptor and ceramic removal tool - support lugs "retracted"

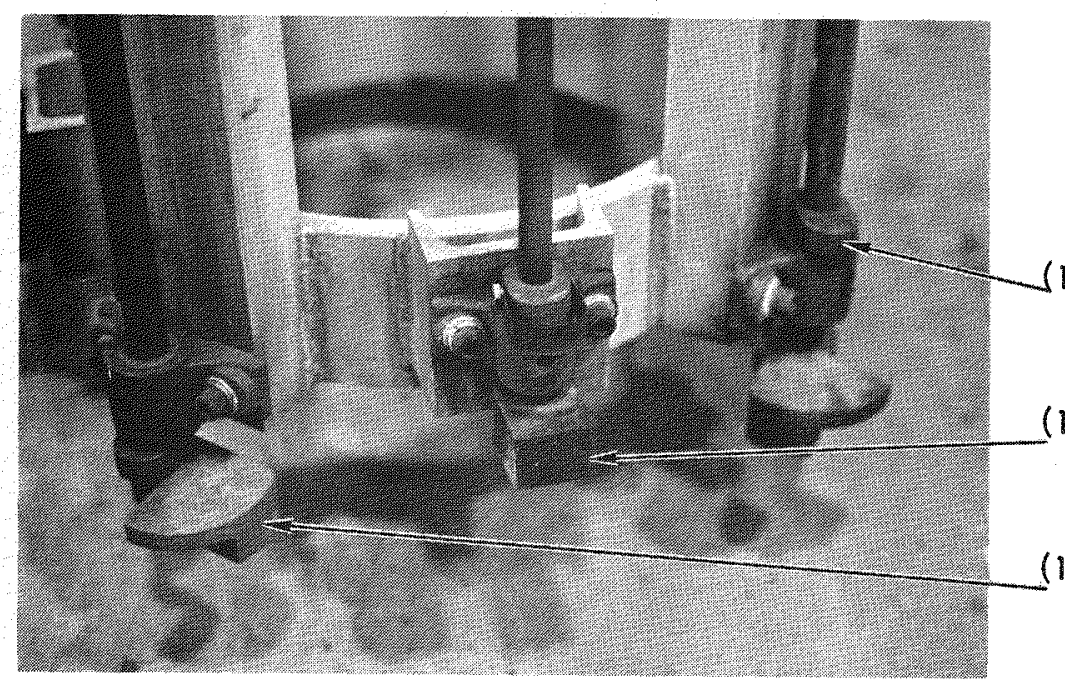

(12) CENTERING DEVICE

(13) SUSCEPTOR SUPPORT LUG

(11) SUSCEPTOR AND CERAMIC SUPPORT LUG

$35-135-204-7$

Fig. 37b. Susceptor and ceramic removal tool - support lugs "extended" 


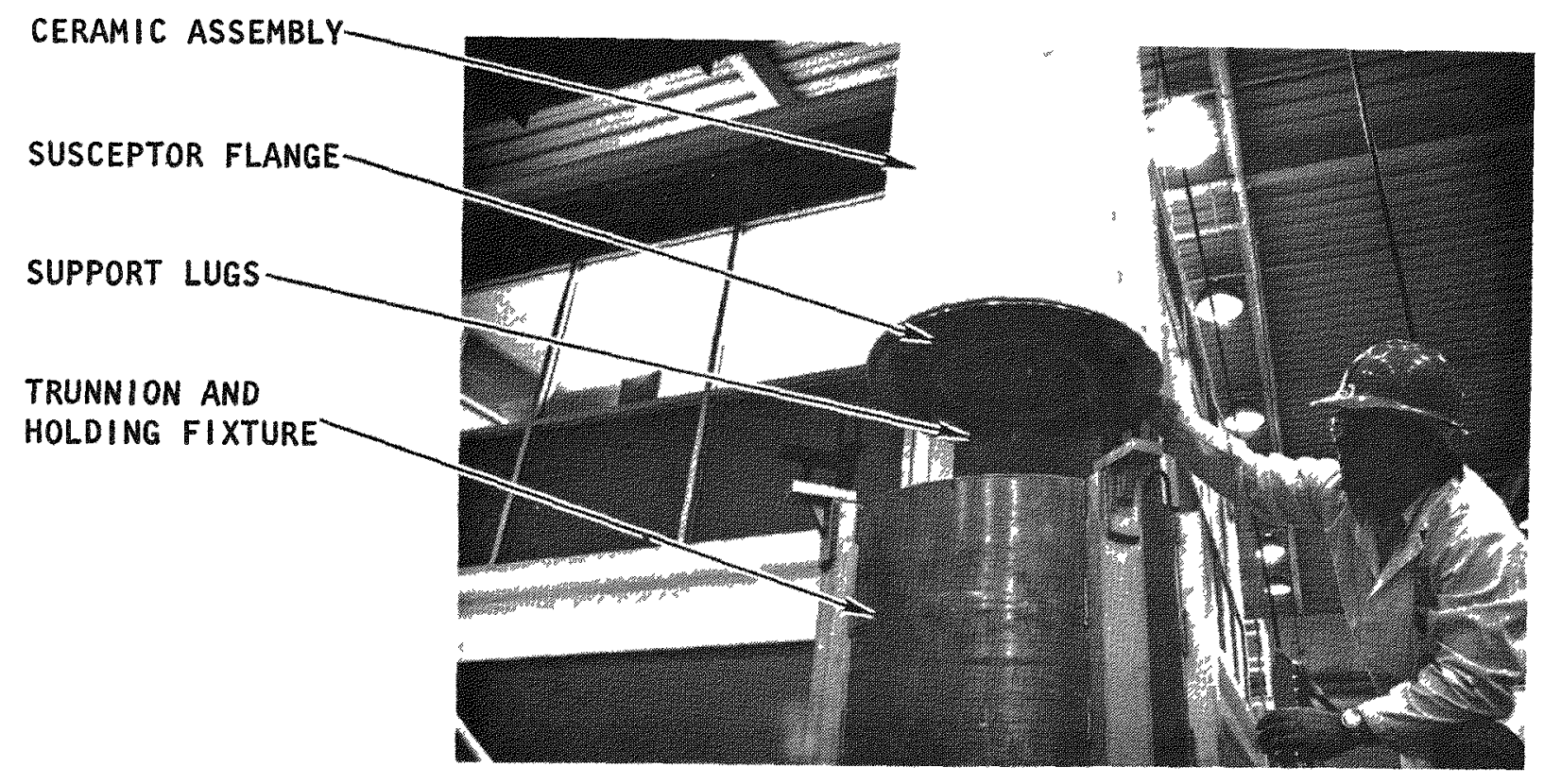

Fig. 38. Installation of susceptor/ceramic into trunnion holding fixture sleeve 
highlight specific operating features. Detailed operating procedures are given in Appendix A, Part 2.

After preparation of the susceptor and ceramic for removal, the removal fixture is connected to the overhead crane and positioned over the lower shroud assembly. The fixture is lowered into the susceptor tube using manual guidance. When the fixture is nearly seated on the top of the ceramic shield plate, final orientation is obtained by visually observing the alignment of match marks located on the shield plate and fixture support ring. When the fixture is seated, the four support lugs located at Stations $1,3,5$, and 7 are rotated into position. When activated, the lugs rotate within clearance slots in the heater support so that contact with the lower susceptor flange is obtained. The centering devices located on each activating rod are also brought to bear against the inside diameter of the susceptor tube, causing the fixture to be centered as required. The fixture is then raised vertically clear of the shroud assembly, bringing with it the susceptor tube and the captive ceramic insulator. The fixture is next moved and positioned over the previously described (Section 3.4) trunnion fixture. The susceptor and ceramic are then lowered into the fixture, and the removal tool is unlatched and withdrawn.

After the susceptor and ceramic are inverted, the removal tool is reinserted into the susceptor tube. The second set of four lugs located at Stations 2, 4, 6, and 8 are rotated into position. When activated, these lugs rotate to a position under the susceptor tube upper edge (rotated $180^{\circ}$ to place it at the bottom of the trunnion fixture). The centering devices located on each activating rod are also brought to bear against the inside diameter of the susceptor tube, causing the fixture to be centered as required. The fixture is then raised vertically clear of the ceramic, bringing with it the susceptor tube only. Subsequent maintenance and inspection operations are performed, and the susceptor is replaced in a manner similar to its removal. 


\subsubsection{Reliability}

A detailed failure mode and effects analysis must be performed for the removal fixture to determine its overall reliability.

Detailed structural analysis and load tests have confirmed adequate safety margins for all structural components.

Overall fixture maintenance is low and therefore should not have a significant effect on fixture reliability.

\subsubsection{Maintenance}

Maintenance requirements for the removal fixture will be low based on anticipated usage. Equipment degradation due to the environment during extended periods of storage will likely exceed operational wear. Regular maintenance will involve inspection and lubrication of the activator rod bearings and general fixture clean-up. Frequency will be based on equipment usage and storage environment.

Final maintenance requirements will be determined after sufficient operating experience is obtained and equipment usage requirements are established.

\subsubsection{Availability}

Since the removal fixture has been designed to provide maintenance support for the burners, it is probable that its use will be infrequent relative to the burner operation. Scheduled maintenance can readily be performed during extended periods of normal burner operation.

Burner operating experience will dictate actual fixture usage. Tests using the fixture after burner operation will also confirm its suitability for removing the susceptor should it become distorted through hightemperature operation. Final assessments of fixture availability will be made after completion of reliability studies and final functional tests. 


\subsubsection{Safety}

The basic design approach taken whereby a special fixture was provided for a unique handing situation improved overall plant safety by eliminating the need for makeshift lift arrangements.

Since problems related to lift lug engagement were encountered during preliminary equipment checkout, final assessments of fixture safety will be made after a complete evaluation has been made and appropriate corrective action has been implemented.

\subsubsection{Testing}

3.5.8.1. Structural Proof Testing. A structural proof test was performed by the equipment manufacturer at twice the rated load. The test was witnessed by cognizant engineering and quality assurance personnel.

3.5.8.2. Operational Checkout (Figs. 34, 35b, 35d, 38). Operational checkout was performed during initial installation and assembly of the primary burner lower shroud assembly. In addition to demonstrating the basic functions, the fixture was used to install the bare ceramic over the susceptor tube. Although this was not part of the design criteria, the operation was successfully performed and aided greatly in the assembly operations. While the checkout provided demonstration of the assembly functions for the fixture, the disassembly or removal operation was not performed due to schedular considerations related to the pilot line assemb1y.

A number of problems were encountered during the checkout which raise concern over fixture suitability. These problems are identified and discussed in detail in Section 3.5.9.

Complete evaluation of these portions of the test run should be completed and appropriate corrective action implemented prior to performance of additional checkout operations. 


\subsubsection{Performance Evaluation}

The functional checkout of the susceptor and ceramic removal fixture performed in conjunction with initial assembly of the lower shroud assembly demonstrated basic fixture performance. Although a number of operational problems were encountered, the fixture performed sufficiently to allow completion of the assembly operations.

The operations performed with the fixture simulated actual assembly operations with the exception of accessibility. The shroud was initially assembled from the inside out, which provided the opportunity to observe fixture operations normally obscured by the shroud and other associated equipment. The specific problems encountered are of two types: (1) interface equipment and fixture manufacturing problems and (2) operational problems. The problems are identified and their effect on fixture performance is discussed briefly below. Specific recommendations and corrective actions are given in Section 3.5.10.

\subsubsection{Interface Equipment and Fixture Manufacturing Problems.}

1. Out-of-roundness of the susceptor tube. Manufacturing tolerances exceeded those anticipated, which caused interference with the centering cams and springs located in the support lug activating rods and prevented full rotation and engagement.

2. Distortion of the ceramic and ceramic shield ring. This resulted in improper seating of the shield ring on the ceramic, which caused the fixture top support ring to contact the high spots in the shield ring and placed the support lugs above the heater base clearance slots. This permitted the lugs to contact the bottom of the susceptor tube, preventing rotation and engagement of the lugs under the susceptor flange.

3. Mislocation of two of the fixture lugs which interface with the susceptor flange. This resulted in misalignment of the support 
lugs with the heater base clearance slots and caused the two lugs to contact the inner edge of the heater base, thus preventing rotation.

\subsubsection{Operationa1 Problems.}

1. Unsatisfactory alignment of match marks on the fixture and shroud. Positive relationship between the heater base and shroud is not assured owing to assembly configuration; this results in misalignment of the lugs and slots, preventing rotation of the lugs.

2. Ineffective fixture lug activating rod rotational stop. This permits over-rotation of the lug, resulting in hang-up with the heater base during withdrawal.

3. Insufficient clearance between the 1 ug and heater base slot. This requires very close alignment and positioning of the fixture to effect rotation of all four lugs. Interference with one lug causes the fixture to shift slightly, resulting in interference with one or more of the remaining lugs.

4. Failure of the fixture to hang plumb when suspended from the overhead crane (compounded by susceptor out-of-roundness).

Two major goals were established for the initial performance demonstration:

1. Heater and shroud assembly.

2. Fixture remote operation.

The first goal was satisfactorily accomplished even though the fixture performed marginally and alternate handing and assembly techniques had to be used. Achievement of the second goal was not satisfactory. A detailed review and evaluation of the fixture design and operation must be performed and additional performance demonstrations scheduled after implementation of appropriate corrective action. 


\subsubsection{Recommendations}

3.5.10.1. Existing Design. Based on the results of the performance demonstration, the following specific actions are recommended:

1. Review all interface equipment to determine maximum/minimum interface dimensions and tolerances. This should include detailed determination of "as-built" conditions and reconciliation of any discrepancies with the requirements of the manufacturing drawings. It is likely that dimensions and tolerances may require redefinition to suit material characteristics and manufacturing process or capability considerations. Results of failure mode and effects analysis should also be factored into definition of "worst case" interface envelopes.

2. Perform a detailed study of existing operational requirements. This should include consideration of problems encountered during initial performance testing.

Basic fixture design should be evaluated for suitability based on:

1. Results of interface review and redefinition.

2. Improved understanding of specific remote operations required.

This review should result in the following:

1. Recommended interface envelopes for burner and shroud equipment.

2. Recommended corrective action necessary to upgrade the existing fixture or recommended redesign of the fixture as necessary to meet equipment envelope and/or remote operational needs.

3.5.10.2. Future Design. Based on the assumption that the essential features of the existing design are retained, future activities should address improvement of remote features. This should include minimizing operations 
requiring manual or manipulator assistance, addition of power assistance for Iug activation, and remote crane/grapple interface.

Future design studies should include handing requirements for the secondary burner susceptor and ceramic and the feasibility of providing a fixture responsive to both primary and secondary burner handling needs.

\subsection{SUSCEPTOR AND CERAMIC HOLDING FIXTURE - SECONDARY BURNER (FIG. 39)}

\subsubsection{Design Requirements}

The design requirements for this fixture are the same as those given in Section 3.4.1 for the primary burner susceptor and ceramic holding fixture. There is no requirement for interface with the removal fixture since this operation is done manually for the secondary burner. Manual handling of the secondary burner susceptor and ceramic was chosen because of their small size and weight and the fact that a special fixture is used for the primary burner to demonstrate the required remote capability applicable to both burners.

It was decided to utilize the existing primary burner trunnion fixture base and only provide an additional sleeve assembly and interface adapters to demonstrate the required handling capability for the secondary burner.

\subsubsection{Fixture Description}

The holding fixture consists of two assemblies: the sleeve assembly and the trunnion support assembly. The sleeve (40-1) is an aluminum cylinder approximately $14-3 / 4 \mathrm{in.}(37.5 \mathrm{~cm})$ in diameter by $36-3 / 8 \mathrm{in}$. $(92.4 \mathrm{~cm})$ long. The top of the sleeve is a castlated cone $(40-2)$ to aid in inserting the ceramic. Four latches (40-3) are provided on each end of the sleeve. Each latch consists of a locking handle (31-4) and support lug (31-5). The lug moves radially in and out and supports either the susceptor tube or the ceramic. The center of the sleeve is furnished with two trunnion assemblies (40-6) attached to the outside boss. The trunnions are located on the sleeve $\mathrm{CG}$, and the sleeve is rotated about them during inversion of the ceramic. 


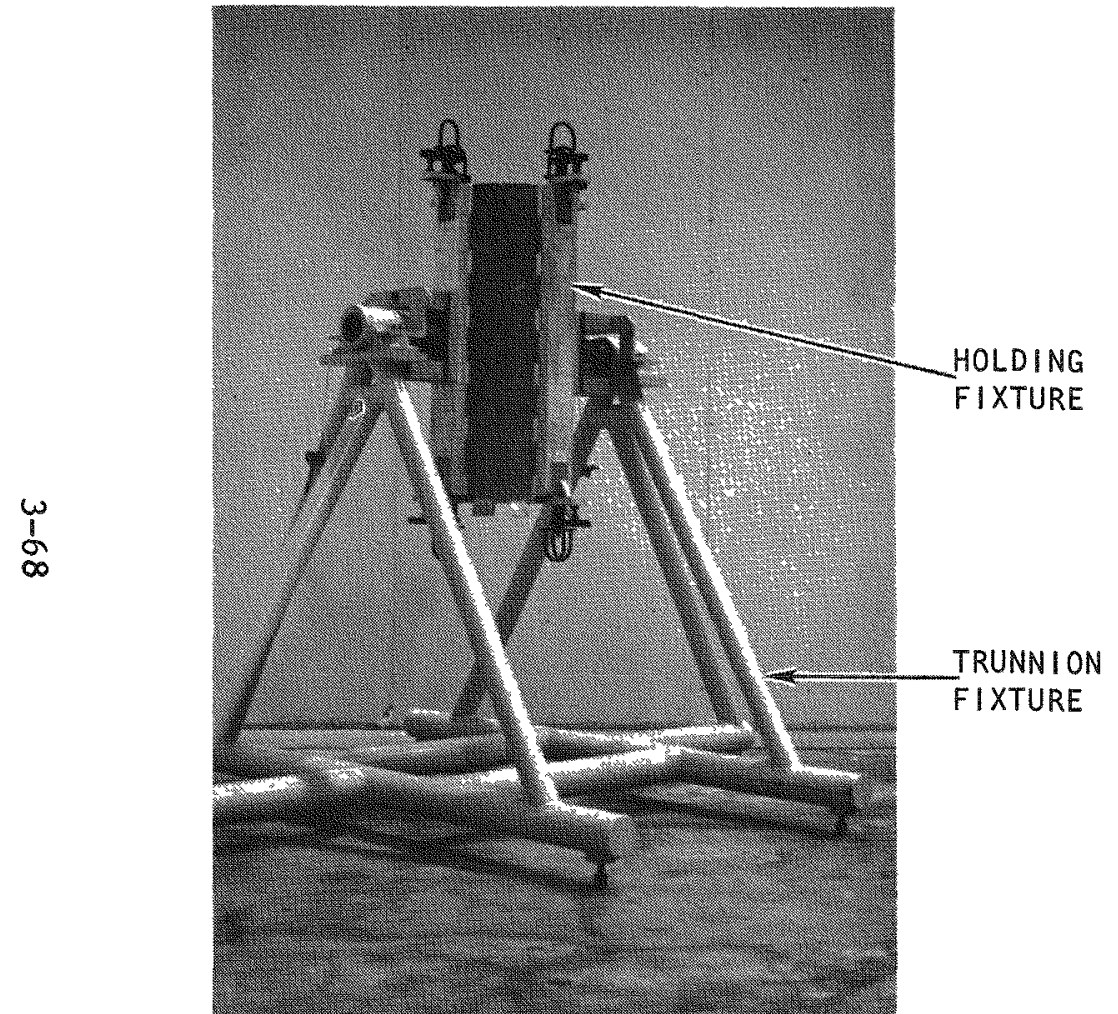

$35-135-202-15$

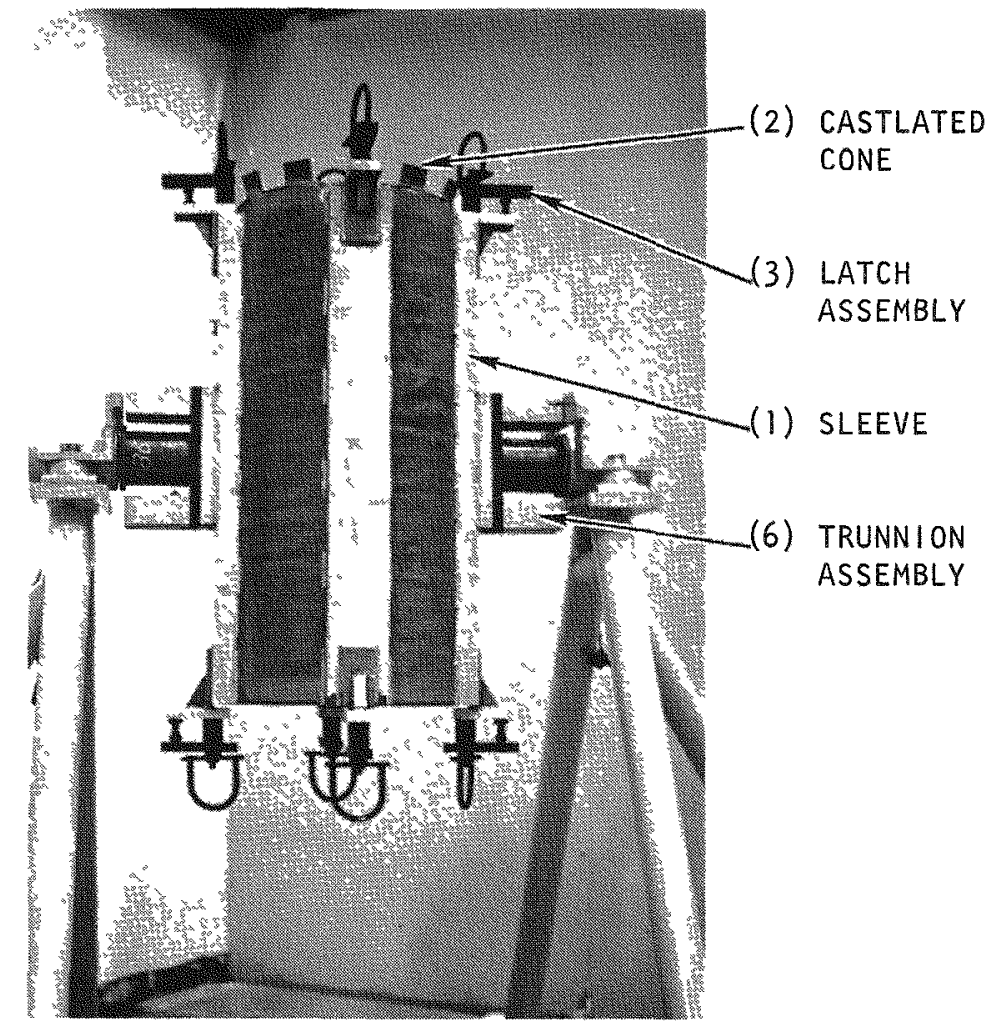

$35-135-202-10$
Fig. 39. Susceptor and ceramic holding fixture - secondary burner "upright"
Fig. 40. Susceptor and ceramic holding fixture - secondary burner "inverted" 
The primary burner susceptor and ceramic trunnion and holding fixture base is used in conjunction with the secondary burner sleeve assembly. The sleeve trunnions are compatible with the pillow blocks mounted on the base side supports.

A complete description of the base is given in Section 3.4.2.

\subsubsection{Operational Description}

A summary of the basic operations involving the susceptor and ceramic holding and trunnion fixture for the secondary burner is given in section 3.4.3. These operations are identical to those for the primary burner except the ceramic and susceptor are inserted manually. Detailed operating procedures for this specific fixture are given in Appendix A, Part 3.

\subsubsection{Control Systems}

There are no electrical or auxiliary mechanical drives or controls associated with this fixture. Position control during rotation is provided manually.

\subsubsection{Reliability}

Structural analysis performed for this fixture has confirmed adequate safety margins for all structural components for the specified loading conditions.

A detailed failure mode and effects study must be performed to determine overall operational reliability. This activity is included in the future work scope.

\subsubsection{Maintenance}

Maintenance requirements for this fixture are low. It is likely that equipment degradation caused by the environment will exceed operational 
wear. Maintenance will consist of cleaning and protection of carbon steel components.

\subsubsection{Availability}

The fixture was designed for maintenance support during removal of the susceptor and ceramic; therefore, its use will be infrequent relative to the burner operation. Maintenance requirements are low and will have a negligible effect on fixture availability.

\subsubsection{Safety}

Overall handling safety is improved by using this fixture since it was designed to suit a specific handing situation. This approach avoided makeshift lifting and handling arrangements and eliminated the potential risks associated with them. All handling operations are performed in accordance with operating procedures approved by cognizant interface organizations and supervised by trained and qualified technicians.

\subsubsection{Testing}

3.6.9.1. Structura1 Proof Testing. A structural proof test was performed by the manufacturer at twice the rated load. The test was witnessed by cognizant engineering personnel.

3.6.9.2. Operational Checkout. Due to schedular considerations during assembly of the secondary burner, no operational checkout was performed for this fixture. The sleeve assembly was assembled with the primary burner fixture base to check interfaces. No difficulties were experienced.

\subsubsection{Performance Evaluation}

A performance evaluation will be prepared after completion of operational checkout. Current activity plans require equipment demonstration as part of burner disassembly and maintenance operations. 


\subsubsection{Recommendations}

3.6.11.1. Existing Design. No recommendations are offered at this time.

3.6.11.2. Future Design Recommendations. Future design activities should address improvement of remote operating capabilities. Although most operations involving requirements for manipulator assistance are judged within this capability, these operations should be reviewed for possible improvement.

Specifically, the disassembly of the pillow blocks, removal of the primary sleeve, and reassembly with the secondary sleeve and adapters are cumbersome and require improvement for remote applications.

The feasibility of redesigning the sleeve to be compatible with both primary and secondary burner ceramics should be evaluated. This could eliminate the need for the secondary sleeve and adapters and avoid complicated assembly and disassembly.

3.7. HEATER AND SHROUD HANDLING FIXTURE - PRIMARY BURNER (FIGS. 41, 42)

\subsubsection{Design Requirements}

A review of the lower shroud handling requirements and the equipment arrangement within the pilot plant established the need for a special handling fixture. Five basic criteria were established:

1. The fixture shall interface with existing pilot plant facilities. These include the burner pit area and the burner support structure.

2. The fixture shall provide the capability to support and translate the lower shroud from its operating position to a position adjacent to the pit wall. This provides overhead access for susceptor and ceramic removal. 


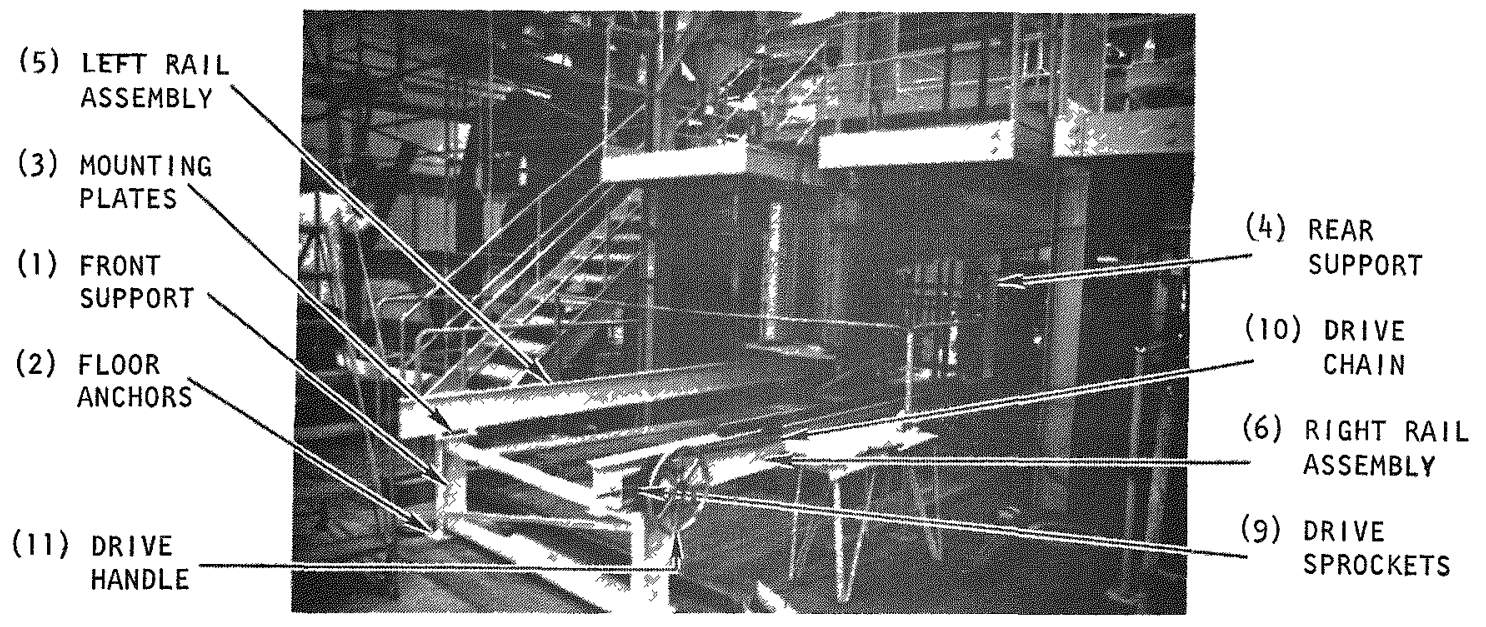

Fig. 41. Heater and shroud handling fixture - primary burner

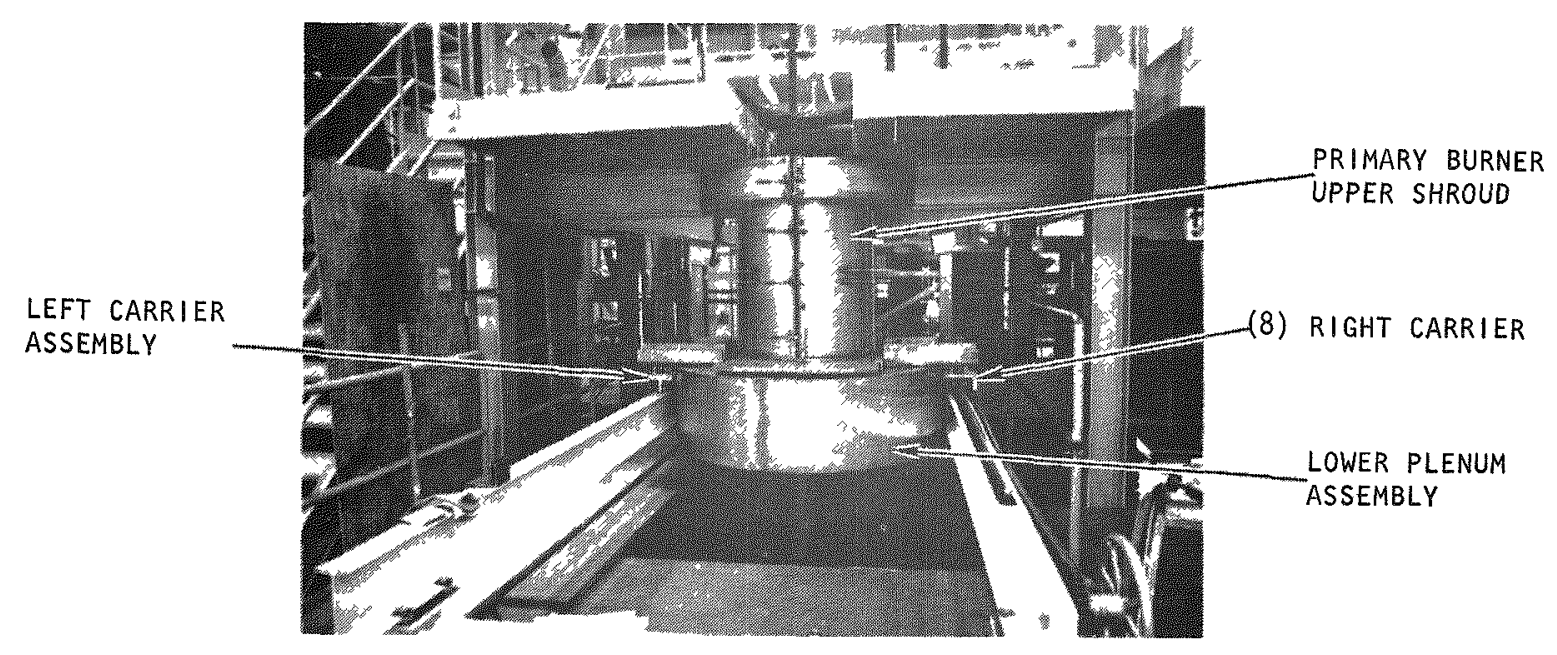

Fig. 42. Heater and shroud handling fixture - upper shroud and lower plenum in position 
3. The fixture shall not interfere with the operation of other burner equipment or remote operating features.

4. Portions of the fixture shall be removable if desired to provide access to the burner during operation.

5. The fixture shall provide the capability to raise and lower the shroud vertically sufficient to align the support flanges for insertion and removal of the lower shroud.

\subsubsection{Fixture Description}

The front support (41-1) is a structural pedestal which is mounted on the pilot plant main floor adjacent to the pit and centered on the primary burner center line. The support is attached to the floor with expandingtype anchors and nuts $(41-2)$. The top of the support is furnished with two mounting plates (41-3) which mate with the forward end of the rail assemblies. The support plates are provided with holes to permit bolting to the rail assemblies.

The rear support (41-4) is permanently attached to the main burner support platform. This structure was assembled and aligned during initial installation and does not require further manipulation. The lower ends of the rear support columns are each provided with an angle bracket. The brackets are provided with holes to permit bolting to the rail assemblies.

The rail assemblies (41-5, 41-6) span the burner pit and are supported by the front and rear support assemblies. The left rail assembly (41-5) is simply a beam with the flanges horizontal. The left carrier assembly $(43 c-7)$ is provided with cam rollers $(43 c-20)$ which roll in the top flange of the rail assembly. The top of the left rail assembly is provided with two travel stops. They stop carrier movement during insertion and withdrawal of the lower shroud and prevent contact with the pit wall during withdrawal and provide alignment guides during insertion. The right rail assembly (41-6) is supplied with a special bearing shaft track (43a-14) and 


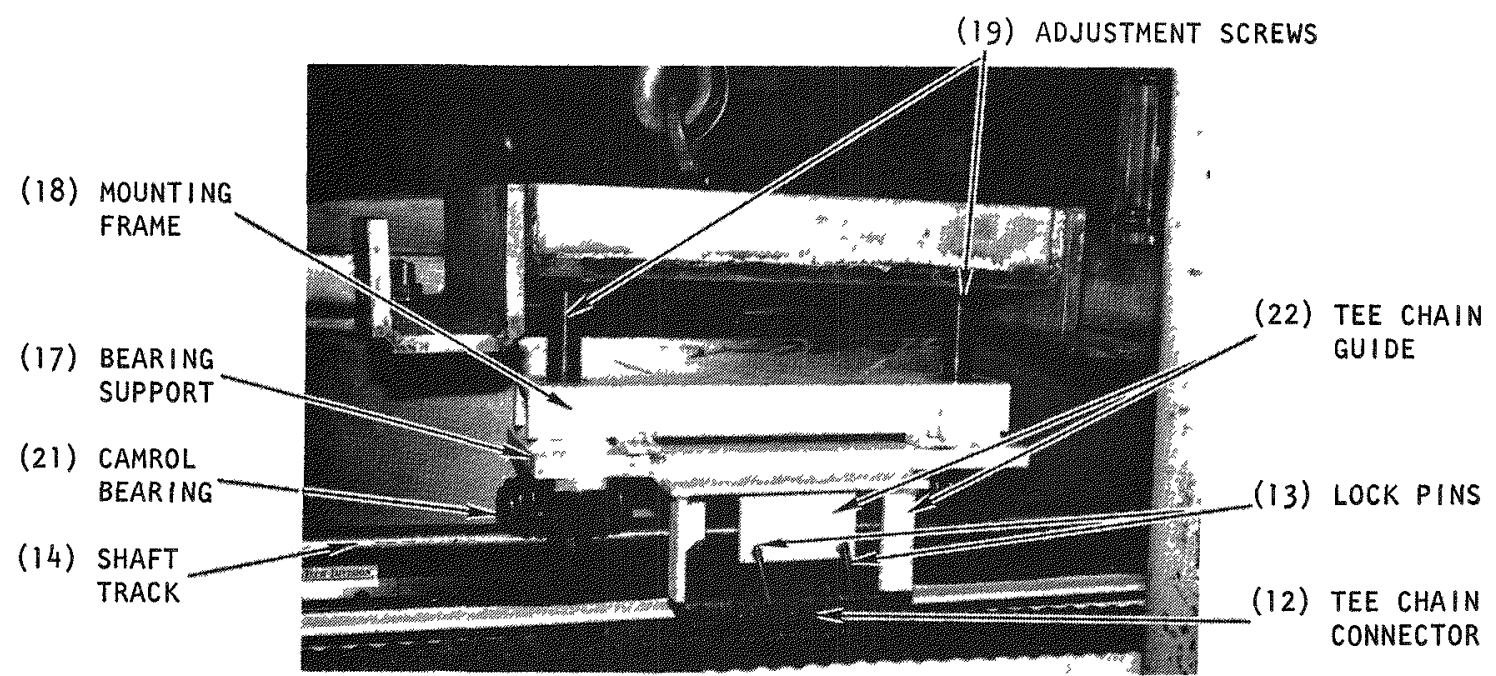

Fig. 43a. Right carrier assembly

(16) SUPPORT FRAME

(23) UPPER SHROUD BASE PLATE

(24) LOWER SHROUD SUPPORT ANGLE

(15) TROLLEY/CARRIER ASSEMBLY
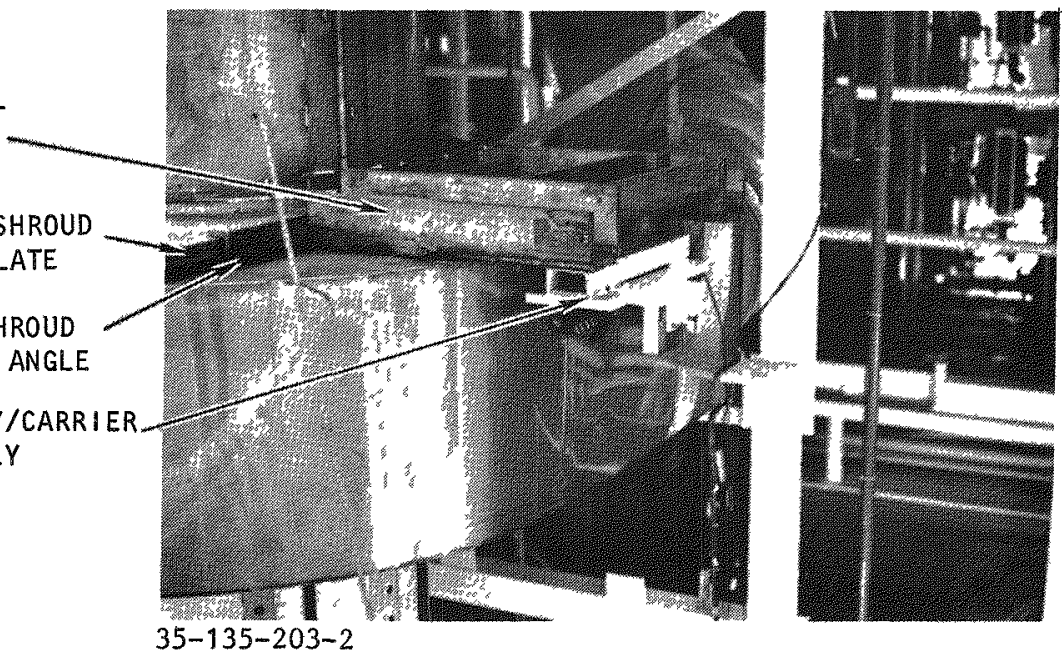

Fig. 43b. Right carrier assembly 


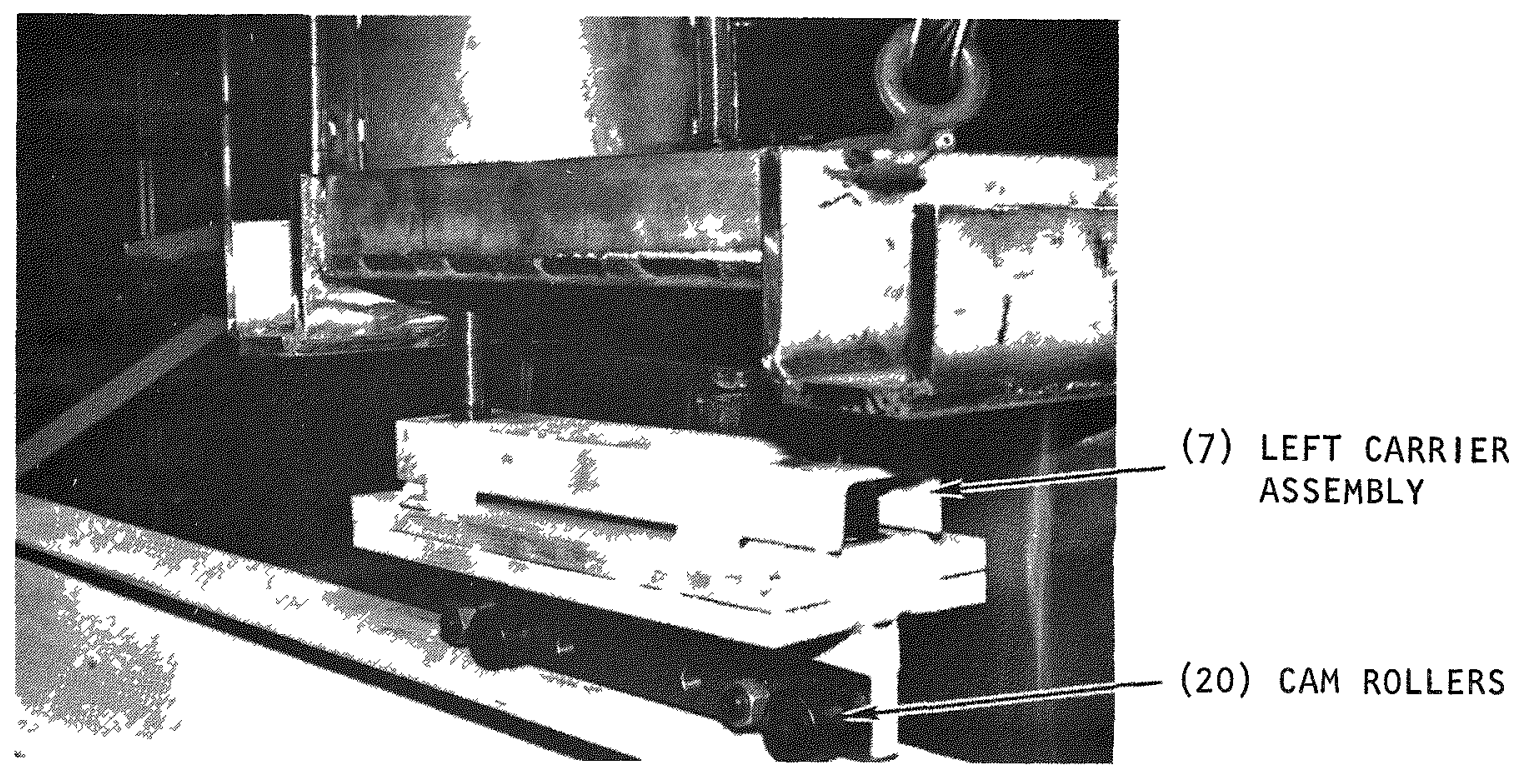

Fig. 43c. Left carrier assembly 
the drive mechanism assembly. The shaft track $(43 c-14)$ interfaces with the special Camrol bearing on the right carrier assembly. The drive mechanism consists of two sprockets (41-9), a drive chain (41-10) and handle (41-11), and a tee chain connector $(43 a-12)$. The tee chain connector interfaces with the right carrier assembly by means of two lock pins (43-13).

Two trolley/carrier assemblies $(43 b-15)$ are provided on the lower shroud exhaust plenum mounting plate. Support frames $(43 \mathrm{~b}-16)$ are bolted to the mounting plate, which in turn supports the right and left carrier assemblies. Each carrier assembly consists of a bearing support (43a-17), a mounting frame (43a-18), and two adjustment screws (43a-19). The adjustment screws permit vertical adjustment of the shroud assembly. The left bearing support is provided with four cam rollexs $(43 c-20)$. The right bearing support is provided with the special Camrol bearing (43a-21), tee chain guides (43a-22), and two lock pins (43a-13). The tee chain guides capture the tee chain connector by means of the two lock pins. This connects the right carrier to the drive mechanism.

\subsubsection{Operationa1 Description (Figs. $42,44,45$ )}

A summary of the operations involving this fixture during removal of the lower shroud assembly is provided herein to highlight specific operating features. Detailed operating procedures are given in Appendix A, Part 5 .

After installation of the shroud handing fixture and preparation of the heater and shroud for removal, the fixture drive mechanism is manually operated to position the tee chain connector adjacent to the right carrier assembly. The two lock pins are installed, connecting the drive to the carrier. The adjusting screws located on top of both carrier assemblies are then adjusted to raise the lower shroud assembly approximately $1 / 8$ in. $(3 \mathrm{~mm})$. This raises the support angles $(43 \mathrm{~b}-24)$ located on the exhaust plenum slightly above the base plate $(43 b-23)$ on the upper intake plenum. This in turn allows the lower shroud to be withdrawn by manually turning the handwheel drive counterclockwise. The lower shroud then rolls out of 


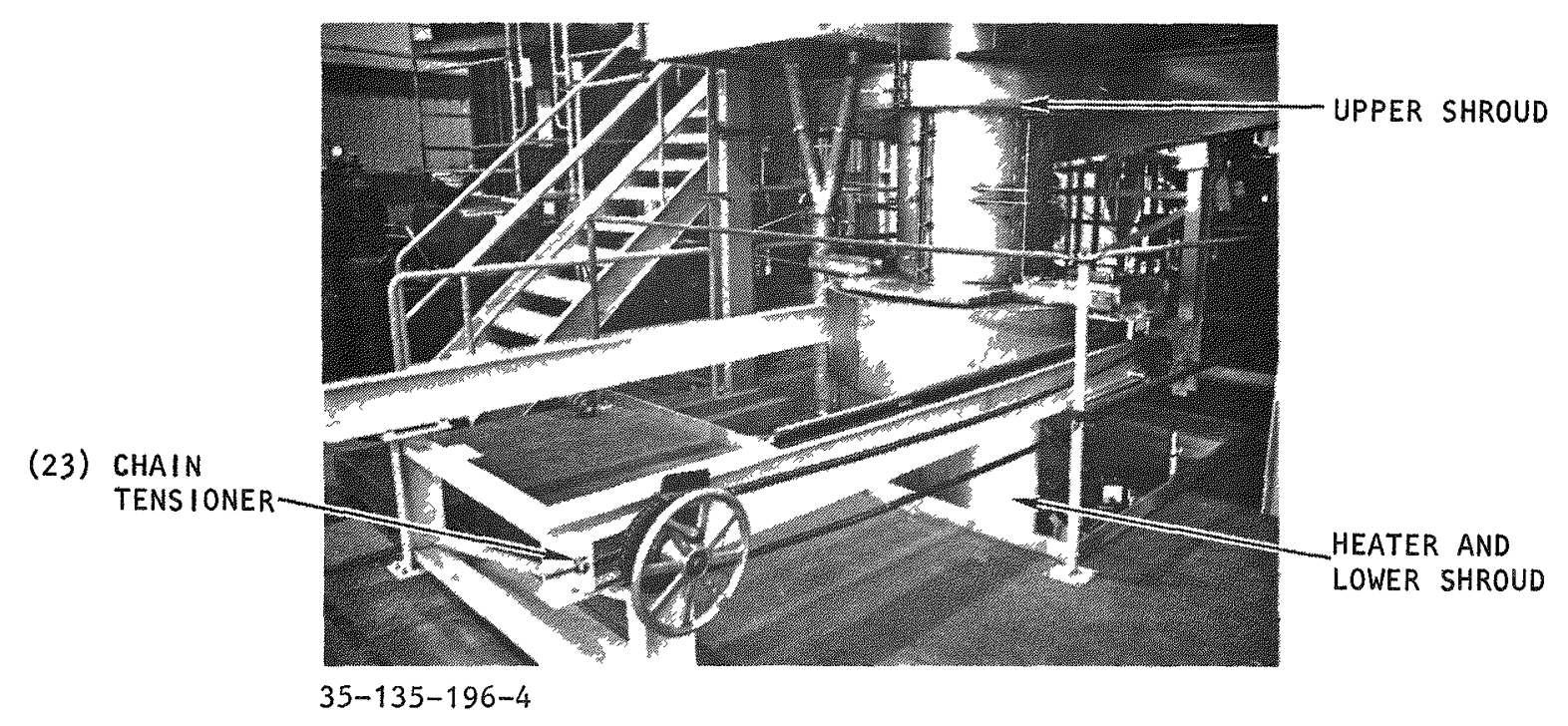

Fig. 44. Primary burner heater and shroud removal fixture - upper and lower shroud assemblies in position

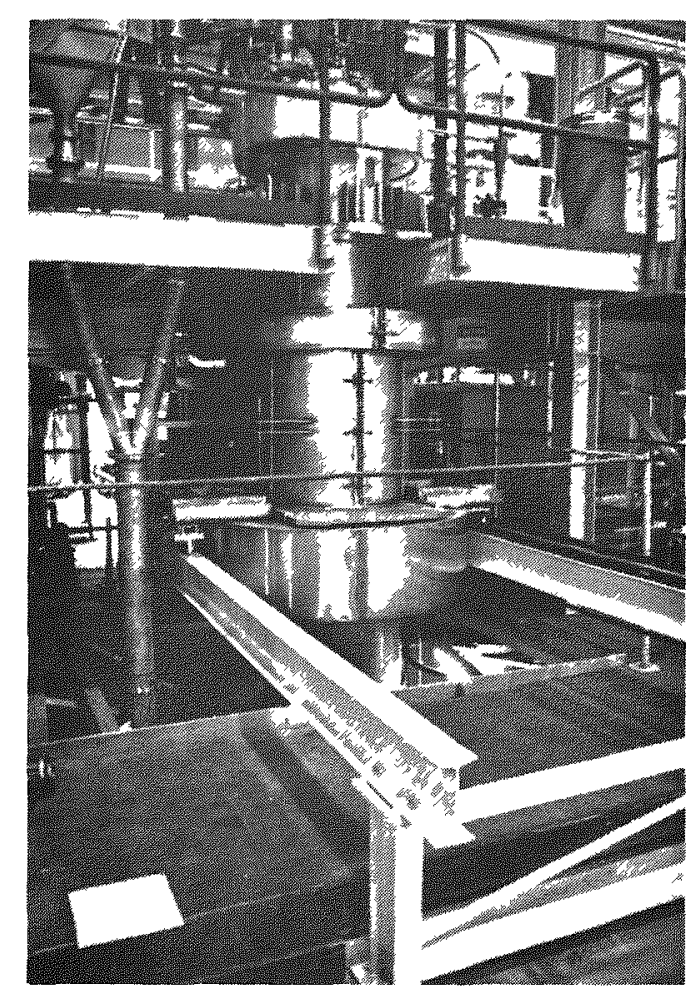

$35-135-196-5$

Fig. 45. Primary burner heater and shroud removal fixture - upper and lower shroud assemblies in position 
the stack-up to a position adjacent to the burner pit wall. This places the shroud clear of the burner support platform and provides clear overhead access to the susceptor and ceramic.

Reinstallation is accomplished in the reverse order. Once these operations are complete, the fixture can be dismantled and stored for future use.

\subsubsection{Contro1 Systems}

There are no electrical drives or controls associated with this fixture. Manually operated mechanical drives are used throughout. Two separate control or operating schemes are used.

The basic fixture drive utilizes a chain and sprocket arrangement. The drive system includes a chain tensioner (44-23) and appropriate bearing pillow blocks. The drive is connected to the shroud by means of the tee chain connected to the chain. Owing to the efficiency of the Camrol bearings, approximately $10 \mathrm{lb}$ of effort on the handwheel is required to translate the shroud during insertion and withdrawal.

The adjustment system utilizes two screws (43a-19) 1ocated in each carrier assembly. Turning the screws causes the shroud assembly to rise or lower sufficiently to disengage its support plate.

Both of these operating systems could readily be powered with conventional equipment to make this operation completely power driven.

\subsubsection{Reliability}

Structural analysis performed for this fixture has confirmed adequate safety margins for all structural components for the specified loading conditions. 
A partial failure mode and effects study was performed to determine operational reliability. Specific recommendations were implemented to prevent inadvertent "de-railing" of the shroud during operation.

A complete failure mode and effects study must be performed to determine overall operational reliability.

\subsubsection{Maintenance}

Maintenance requirements for this fixture are moderate. Maintenance will consist of lubrication of the drive chain, sprockets, pillow block bearings, and chain tensioner and Camrol bearings. Periodic inspection and tightening of the chain will also be required. The support stands and rail assembly beams will require periodic clean-up and painting. Maintenance frequency will depend on storage environment. Final maintenance requirements will be established after sufficient operating experience is gained.

\subsubsection{Availability}

The fixture was designed for maintenance support during removal and reinstallation of the primary burner lower shroud assembly; therefore, its use will be infrequent relative to the burner operation. Maintenance requirements are moderate and will have a negligible effect on fixture availability based on the large maintenance "window" available.

\subsubsection{Safety}

Overall handling safety is improved by using this fixture since it was designed to suit a specific handing situation. This approach avoided makeshift lifting and handling arrangements and eliminated the potential risks associated with them. All handling operations are performed in accordance with operating procedures approved by cognizant interface organizations and supervised by trained and qualified technicians. 


\subsubsection{Testing}

3.7.9.1. Structural Proof Testing. Because of the configuration and placement of the fixture components, it was decided that a structural proof test would not be conclusive. The structural analysis indicated adequate safety margins on all structural load-bearing components. Initial installation of the fixture was monitored closely by cognizant engineering personnel to ensure compliance with manufacturing and installation requirements. No structural problems were noted during performance testing.

3.7.9.2. Operational Checkout. The fixture was used during initial assembly of the primary burner. Operations involved initial placement of the blower shroud assembly. The demonstration included repeated placement of the entire shroud assembly on the rails and translation into operating position. Technical problems involving the shroud and associated equipment necessitated assembly and disassembly a number of times. This afforded the opportunity to perform a complete checkout of the handling fixture.

The fixture demonstrated compliance with all design criteria and performed to full expectation.

\subsubsection{Performance Evaluation}

Although the fixture performed satisfactorily, two minor problems were noted. Both problems were overcome during the checkout; however, corrective action is suggested.

1. The vertical adjustment screws located in the bearing support carriers were difficult to operate. Unless carefully turned together, jamming occurred. This would lead to damage of the bearing sleeves and adjusting screws if not controlled and could also affect maintenance and equipment wear.

2. The drive system bearings and alignment were ineffective. This causes excessive slack in the drive chain. 
Specific corrective action is described in Section 3.7.11.

\subsubsection{Recommendations}

3.7.11.1. Existing Design. Based on the performance evaluation, the following recommendations are made:

1. Redesign the carrier adjustment screws to improve performance. Consider use of self-aligning guide bushings. Improve the assembly and disassembly of the carriers and screw.

2. Review the drive system for improvements. Increase the size of the chain tensioner to improve its operation with the heavy drive chain. Provide intermediate idler sprockets to support the chain at mid-span.

3.7.11.2. Future Design Recommendations. Future design activities should address improvement of remote operating capabilities. Although most operations involving requirements for manipulator assistance are judged within this capability, these operations should be reviewed for possible improvement. Specifically, the following recommendations are made:

1. Improve the drive system to incorporate dual drive (both carriers) and provide power drives to eliminate the manual handwheel.

2. Review the vertical adjustment feature to provide power assistance and eliminate manual operation. Provide electrical limit switches for travel control.

\subsection{REMOTE CARTS - PRIMARY AND SECONDARY BURNERS (FIGS. 46, 47)}

Detailed discussions of the design and operation of the remote carts will be provided in a later report. 


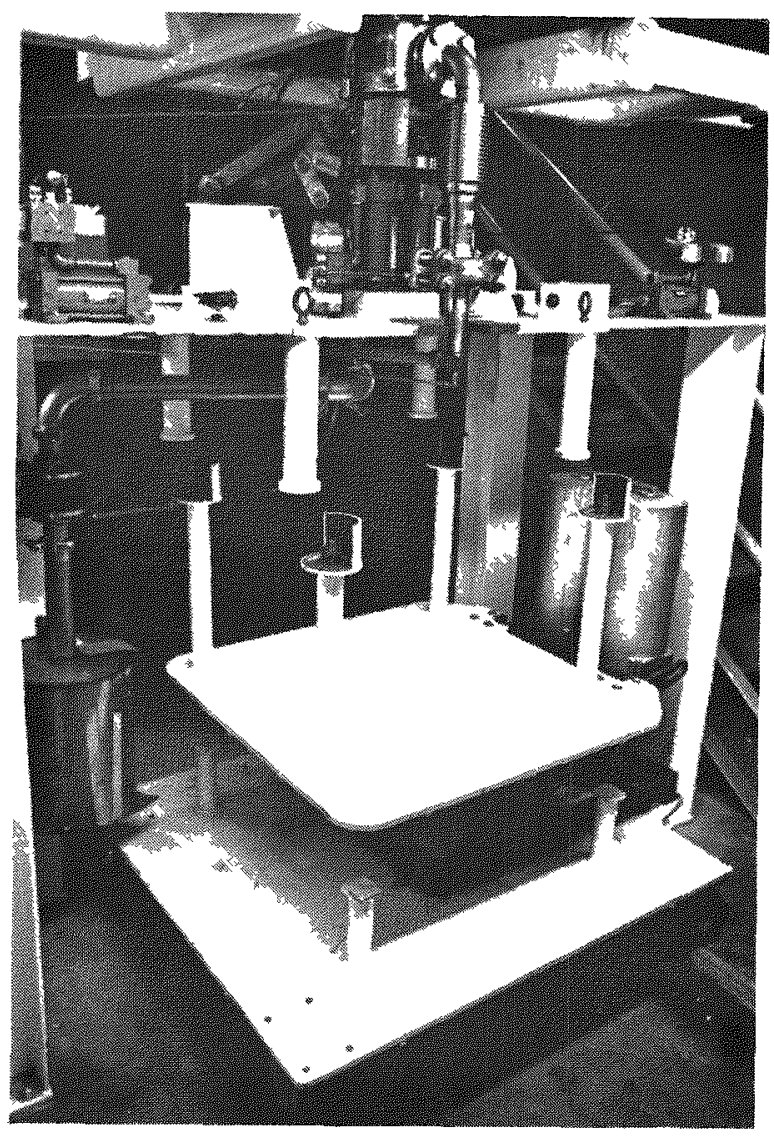

$35-135-195-21$

Fig. 46. Secondary burner plenum remote cart 


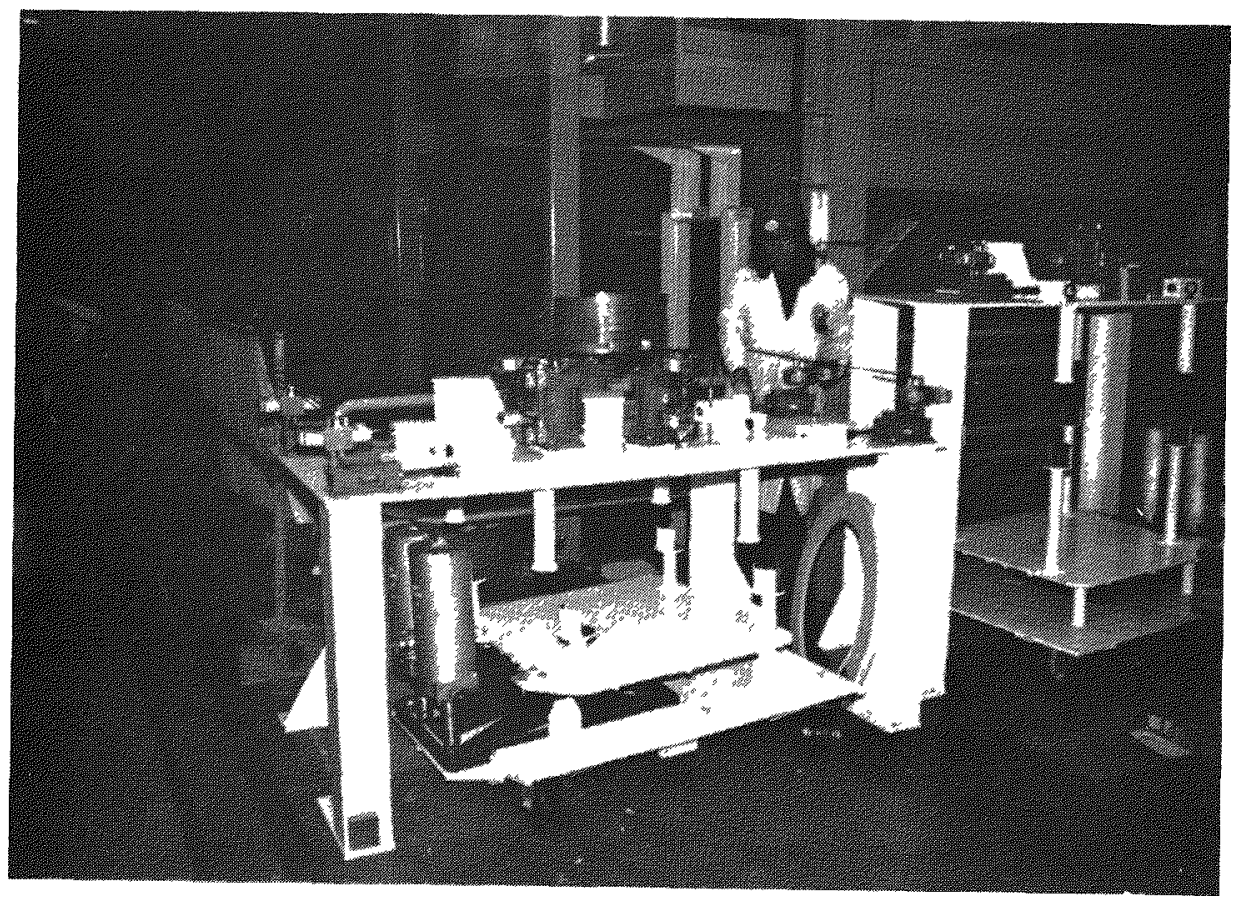

Fig. 47. Primary burner plenum remote cart 
Initial fixture installation is still in progress in conjunction with initial installation of the primary and secondary burners. Final adjustment and connection of hydraulic drives have not been completed. Documentation of installation has been maintained, and appropriate revisions are being made to reflect modifications required to suit burner as-built conditions and to accommodate auxiliary equipment. Some of this equipment was not completely defined and identified during the early phase of cart design and manufacture, which resulted in some degree of retrofitting. This is under way, and no problems affecting cart operation are anticipated. 


\section{ACKNOWLEDGMENTS}

The author wishes to thank all of the technicians, especially T. D. Wright and M. D. True, who contributed expert aid during the initial installation and operation of the remote burner fixtures.

The author would also like to recognize the fine design efforts provided by R. W. Kee, A. J. Hilber, J. Jack, and J. Teren. 


\begin{abstract}
APPENDIX A, PART 1
OPERATING PROCEDURE: PRIMARY AND SECONDARY BURNER LIFT FIXTURES (DOCUMENT No. OP 5820011)
\end{abstract}

A. 1-1 
GA 777 (Rev 5/74)

\section{GENERAL ATOMIC COMPANY}

OPERATING PROCEDURE: PRIMARY AND SECONDARY BURNER LIFT FIXTURES

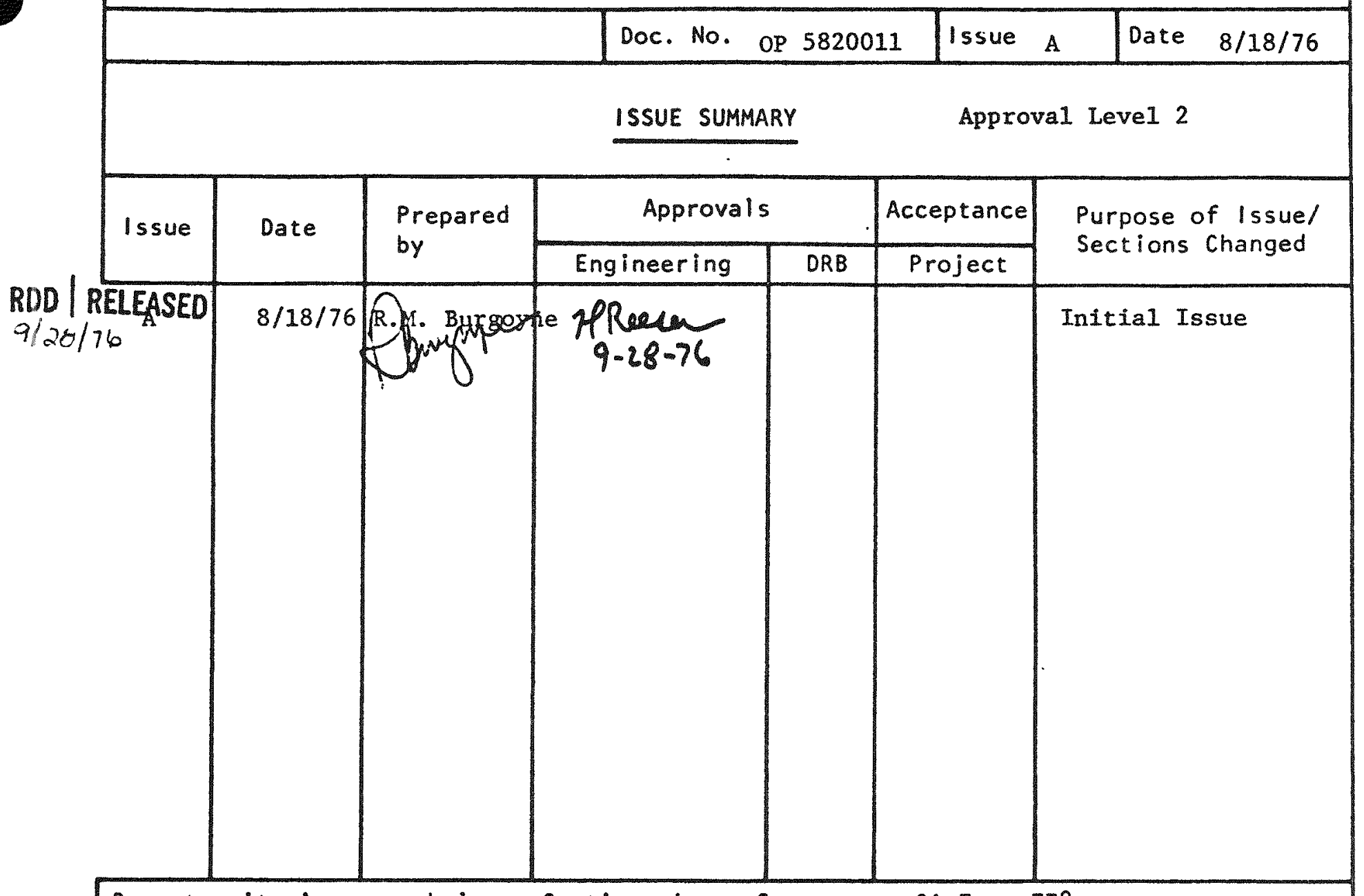

Do not write in space below. Continue Issue Summary on GA Form 778 . 
GA $541(\operatorname{Rev} 5 / 74)$

\section{GENERAL ATOMIC COMPANY}

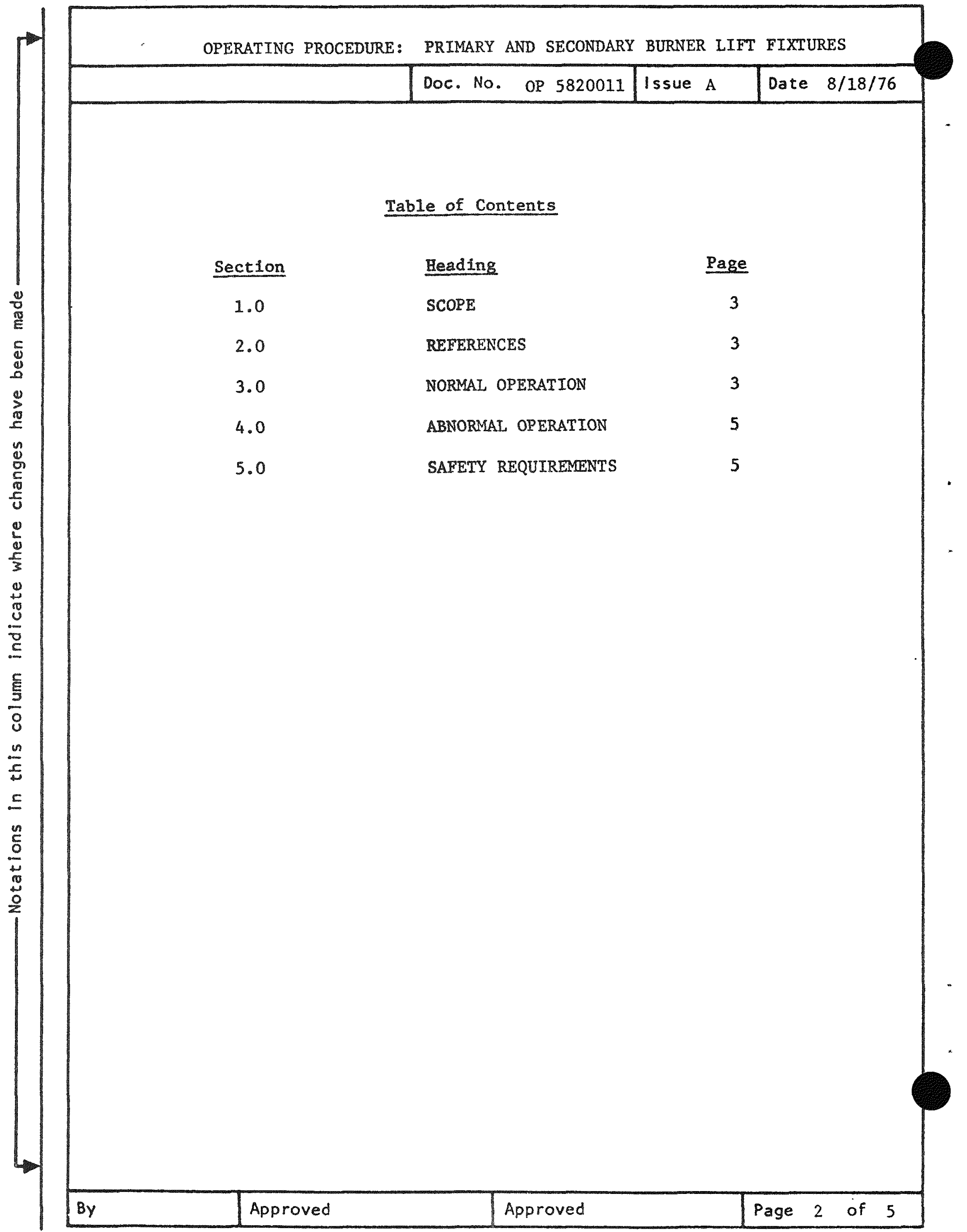




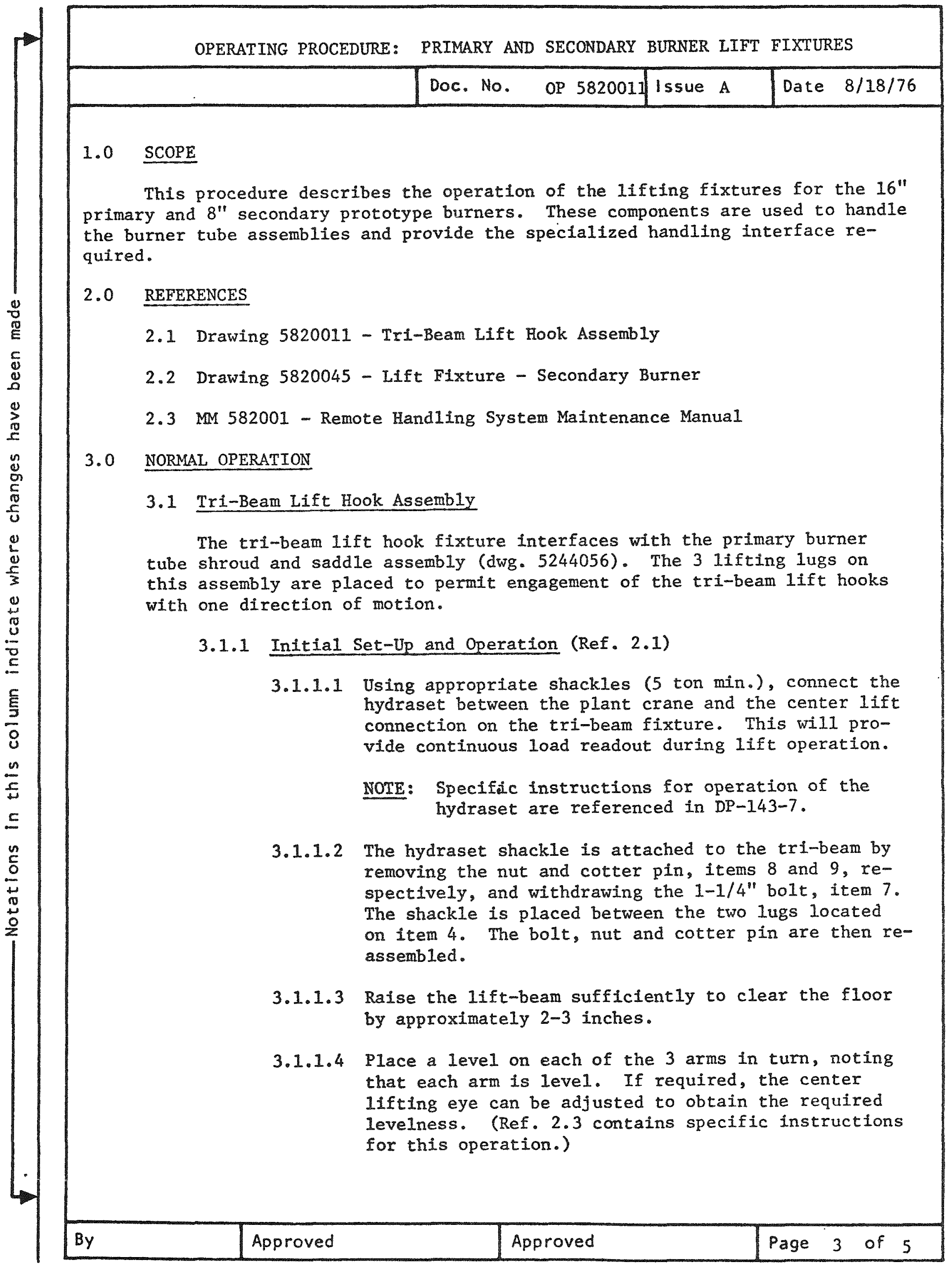




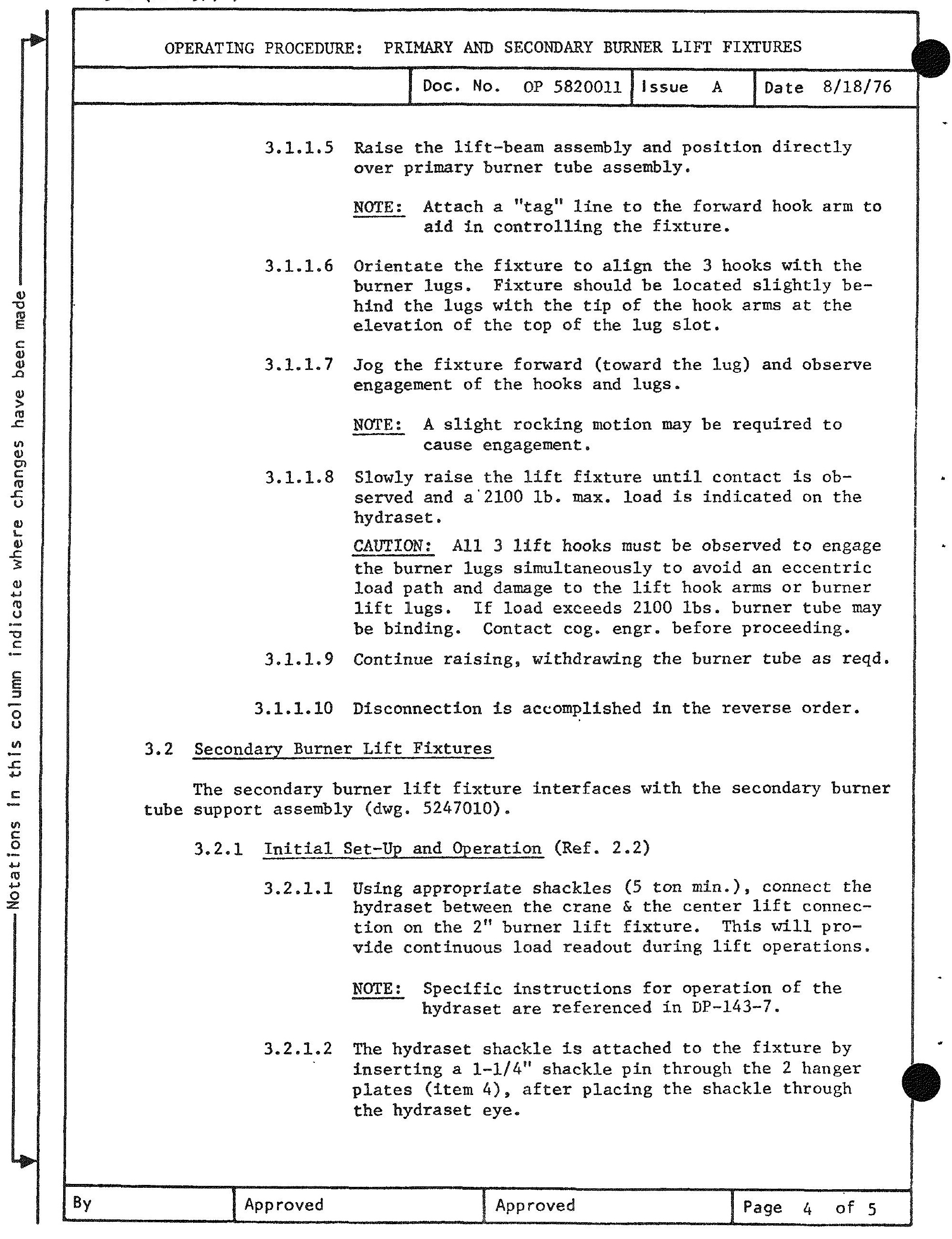


GA $541(\operatorname{ReV} 5 / 74)$

\section{GENERAL ATOMIC COMPANY}

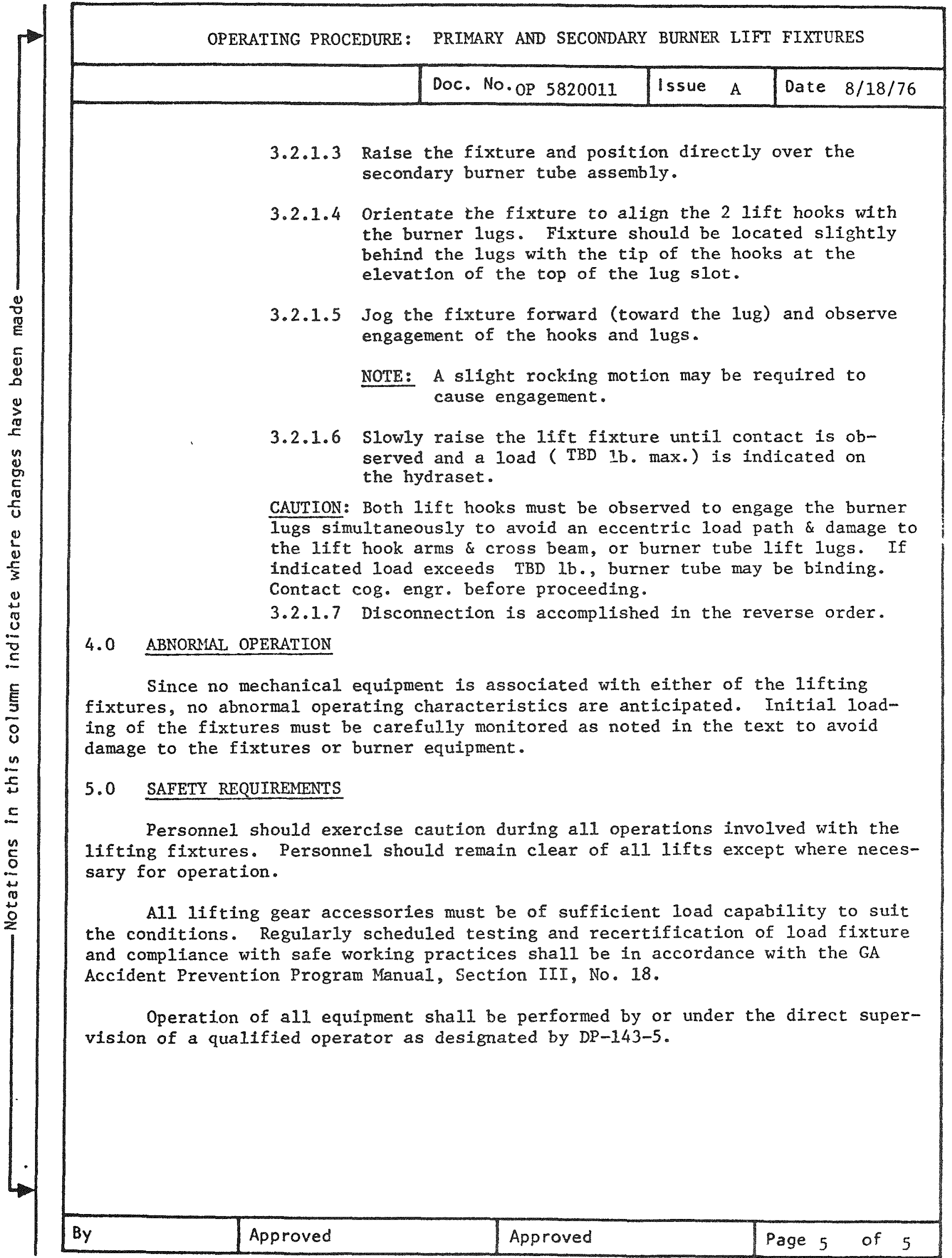


APPENDIX A, PART 2

OPERATING PROCEDURE: PRIMARY BURNER SUSCEPTOR AND CERAMIC REMOVAL TOOL (DOCUMENT No. OP 5820034) 
GENERAL ATOMIC COMPANY

GA $777(\operatorname{Rev} 5 / 74)$

OPERATING PROCEDURE: PRIMARY BURNER SUSCEPTOR AND CERAMIC REMOVAL TOOL

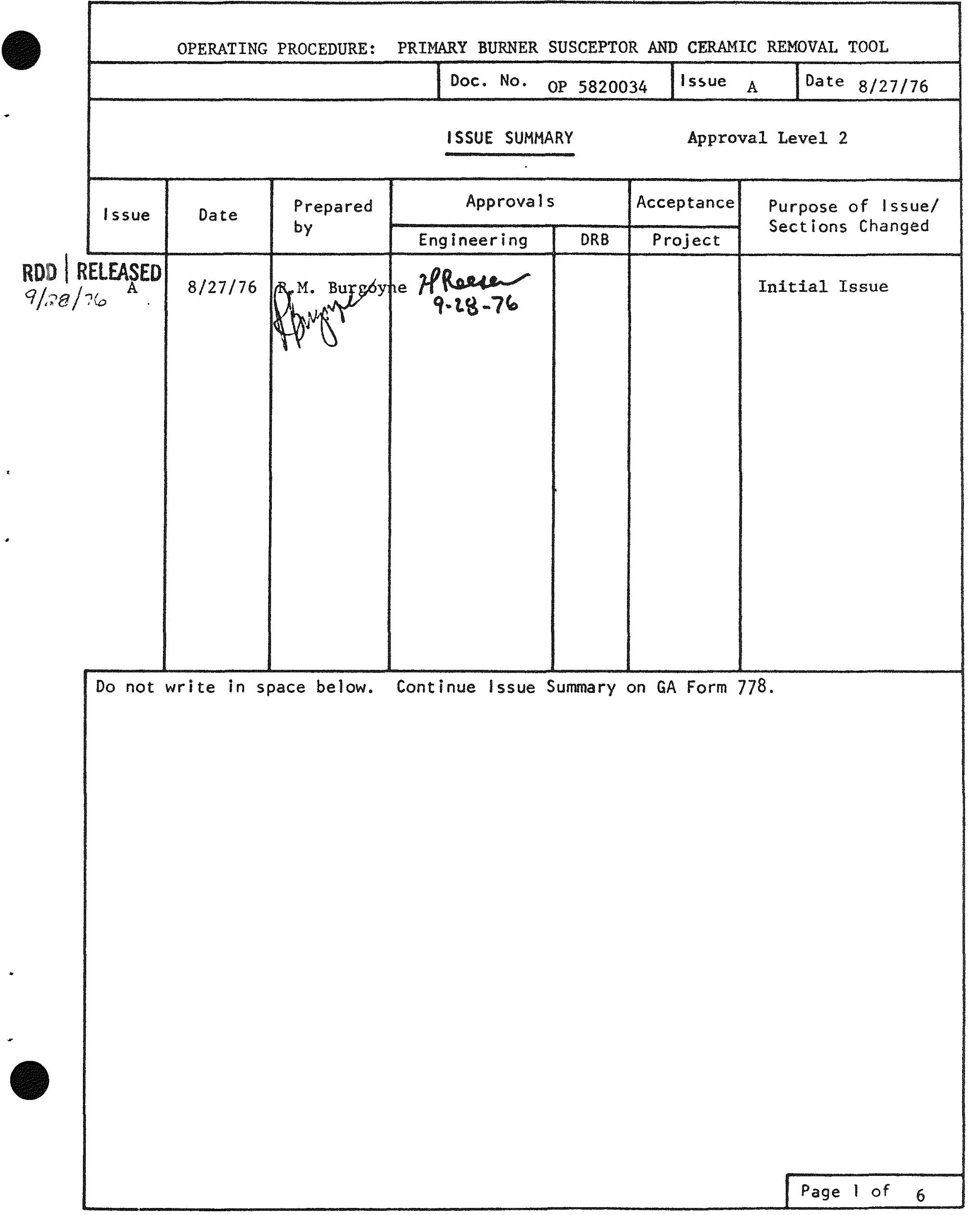


GA $541(\operatorname{Rev} 5 / 74)$

\section{GENERAL ATOMIC COMPANY}

OPERATING PROCEDURE: PRIMARY BURNER SUSCEPTOR AND CERAMIC REMOVAL TOOL

DoC. No. OP 5820034

Issue A

Date $8 / 27 / 76$

Table of Contents

Section

1.0

2.0

3.0

4.0

5.0
Heading

SCOPE

REFERENCES

NORMAI OPERATION

ABNORMAL OPERATION

SAFETY
Page

3

3

3

5

6 
OPERATING PROCEDURE: PRIMARY BURNER SUSCEPTOR AND CERAMIC REMOVAL TOOL

\begin{tabular}{|l|l|l|l|}
\hline Doc. No. OP 5820034 & Issue A & Date $8 / 27 / 76$ \\
\hline
\end{tabular}

\section{$1.0 \quad$ SCOPE}

This procedure defines the operation of the primary burner susceptor and ceramic removal tool. This fixture, when used in conjunction with the trunnion fixture (OP 5820042), provides the capability to remove the susceptor and ceramic assembly from the lower burner shroud for Inspection and/or replacement of the susceptor liner.

\subsection{REFERENCES}

2.1 Dwg. 5820034 - Susceptor and Ceramic Removal Too1

2.2 Dwg. 5820042 - Trunnion Fixture Assy.

2.3 OP 5820042 - Operation Procedure: Trunnion Fixture

2.4 M 524403 - Shroud and Heater Removal and Installation Procedure

2.5 Dwg. 5244025 - Susceptor Tube Assembly

2.6 Dwg. 5244026 - Heater Base

2.7 OP 5820060 - Operating Procedure: Heater and Shroud Handling Fixture

2.8 MM 5820011 - Maintenance Manual, Remote Handiing System

3.0 NORMAL OPERATION (Ref. 2.1)

\subsection{Removal of Susceptor and Ceramic}

3.1.1 Complete prerequisite operations in Ref. 2.4 and 2.7.

3.1.2 Using appropriate slings and shackles (2 ton min.), connect the tool to the plant crane.

3.1.3 Verify that the (8) movable lift lugs (items 7,10 \& 30 , Ref.2.1) are in their retracted position. This is accomplished by rotating the upper handles clockwise for item 7 and counterclockwise for items 10 and 30 .

3.1.4 Raise and position the fixture directly over the heater and shroud assembly positioned on the heater and shroud handling fixture. (Ref. 2.7)

3.1.5 Manually guide the fixture while lowering into the top of the susceptor tube (dwg. 5244025, item 4). Stop lowering when the fixture ring support (item 3 ) is approximately $I^{\prime \prime}$ above the shield ring (dwg. 5244025, item 40).

3.1.6 Manually rotate the fixture to align the match mark on the fixture with the match mark on the top of the heater shroud (dwg. 5244025, item 7). 
OPERATING PROCEDURE: PRIMARY BURNER SUSCEPTOR AND CERAMIC REMOVAL TOOL,

\begin{tabular}{|l|l|l|l|} 
Doc. No. OP 5820034 & Issue A & Date $8 / 27 / 76$
\end{tabular}

3.1.7 While retaining orlentation, lower the fixture until seated on the ceramic shield ring.

NOTE: If seating is not accomplished, raise the fixture approximately $1 / 8$ " and rotate slightly to achieve the required alignment. The movable lifting lugs should be "felt" to engage the slots in the heater base (dwg. 5244026).

3.1.8 Manually rotate the movable lugs as follows:

Stations 1 and 5 counter-clockwise.

Stations 3 and 7 clockwise.

Rotate the handle approximately $90^{\circ}$ until the stops are contacted.

NOTE: Refer to Ref.. 2.1 for station locations.

3.1.9 Slowly ralse the fixture approximately $1^{\prime \prime}$. Note the hydraset load (approx. 445 Ibs). Confirm that the ceramic has begun to rise by observing that the edge of the shield ring is above the top of the shroud (item 7).

3.1.10 Continue to raise the fixture clear of the heater and shroud assembly. A lift of approx. $7^{\prime}-0^{\prime \prime}$ is required for clearance.

3.1.11 Transfer the fixture to the trunnion fixture.

3.1.12 Perform operations per para. 3.1 and 3.3.1 through 3.3 .7 of Ref. 2.3.

3.1.13 Manually rotate the movable lugs as follows:

Stations 1 and 5 clockwise.

Stations 3 and 7 counter-clockwise.

Rotate the handles approx. $90^{\circ}$ until stops are contacted.

3.1.14 Slowly lift the removal tool clear of the trunnion assembly.

3.1.15 Perform operations per para. 3.3.9 through 3.3.12 of Ref. 2.3.

3.1.16 Reinsert the removal tool into the trunnion sleeve assembly until the support plate contacts the susceptor support ring (Ref. 2.5).

3.1.17 Engage the susceptor tube supports by rotating the (4) handles at stations $2,4,6$ and 8 clockwise. Verify engagement of lugs by visually observing lug position. 
OPERATING PROCEDURE: PRIMARY BURNER SUSCEPTOR AND CERAMIC REMOVAL TOOL

Doc. No. OP 5820034 Issue A

Date $8 / 27 / 76$

3.1.18 S1owly withdraw the susceptor tube from the ceramic.

3.1.19 Move the removal tool and susceptor tube to an appropriate maintenance area. Disconnect crane fittings.

3.1.20 The susceptor tube can be removed from the tool by conventional means.

3.2 Reinstallation of the Susceptor Tube and Susceptor and Ceramic into the Burner Shroud

3.2.1 Verify that the lugs at stations 2, 4, 6 and 8 are deployed and locked in position, and that the lugs at stations 1, 3, 5 and 7 are retracted and 1 ocked.

3.2.2 Insert the susceptor tube into the removal tool with the support ring at the top of the tool. The susceptor tube is handled by conventional means.

3.2.3 Connect appropriate crane lifting slings to center lifting bail.

3.2.4 Reinstallation of the susceptor tube and subsequent reinsta1lation of the susceptor and ceramic into the shroud is accomplished in the reverse order of removal.

\subsection{ABNORMAL OPERATION}

4.1 Tool will not enter susceptor tube * Verify that ceramic support lugs (items 7 and 30) are retracted. Verify that the susceptor support lugs (item 10) are retracted. Check for interference of centering spring assemblies (item 29). These may be removed if interference is caused by out-of-round tube. Check for interference from centering cams (items 8 and 32). They may also be removed, if required.

4.2 Failure of ceramic support lugs to engage - Verify that tool support ring is seated on ceramic shield ring. Check orientation arrow alignment. Check interference from centering springs (item 29) and cams (items 8 and 32). These components may be removed, if required.

4.3 Failure of susceptor support lugs to engage - See para. 4.2 for possible corrective action.

NOTE: Tool support ring will be resting on the susceptor tube support ring in lieu of the ceramic shield ring.

4.4 Tool cannot be withdrawn from susceptor tube - See para. 4.1 for possible corrective action. 
OPERATING PROCEDURE: PRIMARY BURNER SUSCEPTOR AND CERAMIC REMOVAL TOOL

\begin{tabular}{|l|l|l|l|l|}
\hline & Doc. No. OP 5820034 & Issue A & Date $8 / 27 / 76$ \\
\hline
\end{tabular}

\subsection{SAFETY}

5.1 Equipment shall be operated by or under the direct supervision of a qualified operator as designated by DP-143-5.

5.2 Work platforms and ladders required to provide access to this equipment shall comply with the requirements of the GA Accident Prevention Program Manual, Sect. III, No. 17.

5.3 All lifting gear accessories must be of sufficient load capability to suit conditions. Regularly scheduled testing and recertification of load fixture compliance with safe working practices shall be in accordance with the GA Accident Prevention Program Manual, Sect. III, No. 18. 
APPENDIX A, PART 3

OPERATING PROCEDURE: PRIMARY AND SECONDARY BURNER TRUNNION FIXTURE (DOCUMENT No. OP 5820042)

A. 3-1 
GA $777(\operatorname{Rev} 5 / 74)$

\section{GENERAL ATOMIC COMPANY}

OPERATING PROCEDURE: PRIMARY AND SECONDARY BURNER TRUNNION FIXTURE

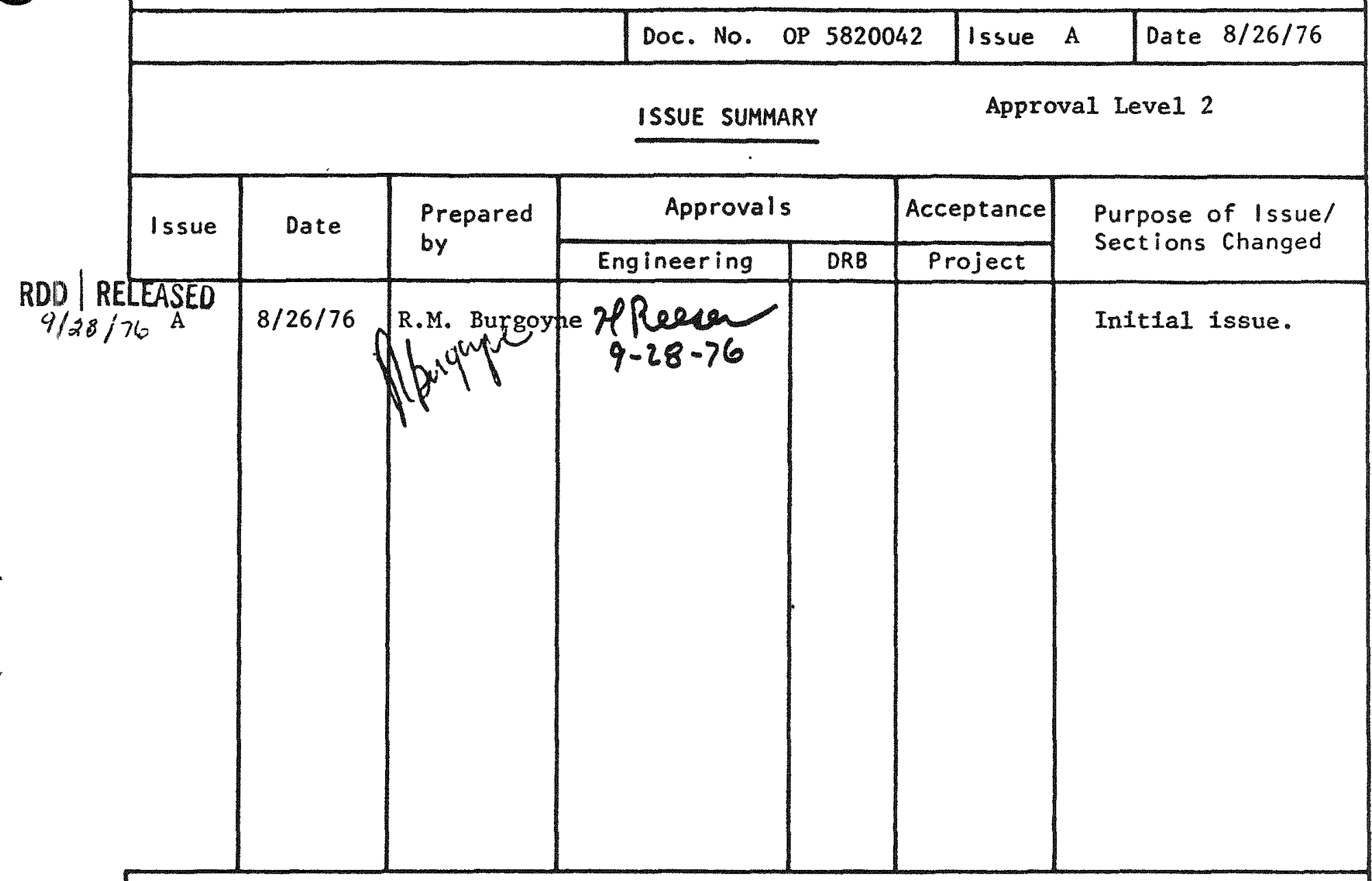

Do not write in space below, Continue Issue Summary on GA Form 778 . 
GA $541(\operatorname{Rev} 5 / 74)$

\section{GENERAL ATOMIC COMPANY}

OPERATING PROCEDURE: PRIMARY AND SECONDARY BURNER TRUNNION FIXTURE

Doc. No. OP 5820042 Issue A

Date $8 / 26 / 76$

Table of Contents

Section

1.0

2.0

3.0

4.0

5.0
Heading

SCOPE

REFERENCES

NORMAL OPERATION

ABNORMAL OPERATION

SAFETY
Page

3

3

3

6

6 
OPERATING PROCEDURE: PRIMARY AND SECONDARY BURNER TRUNNION FIXTURE

Doc. No. OP 5820042 Issue A

Date $8 / 26 / 76$

\subsection{SCOPE}

This procedure defines the operation of the primary and secondary burner trunnion fixture. The trunnion base; when used in conjunction with appropriate adapters, provides support and rotational capability for the burner ceramic and susceptor assemblies. This fixture is used with the susceptor and ceramic removal tool (Ref. 2.3) for replacement of the susceptor liner.

\subsection{REFERENCES}

2.1 Dwg. 5820042 - Trunnion Fixture - Primary Burner

2.2 Dwg. 5820043 - Holding Fixture - Secondary Burner

2.3 OP 5820034 - Operating Procedure: Susceptor and Ceramic Removal Too1

\subsection{NORMAL OPERATION}

\subsection{Initial Set-up (Primary Burner)}

3.1.1 Assemble components in the configuration shown in Ref. 2.1.

3.1.2 Verify that the sleeve assembly (item 3) is locked in the vertical position with the "cone end" up.

3.1.3 Engage the (4) lower support lugs by rotating the handles (item 7) counter-clockwise sufficiently to permit sliding the support lugs (item 24) inward. Manually tighten the (4) handles by rotating clockwise.

Assure that the guide groove in the lug (item 24) is engaged with the support screw located in item 37.

3.1.4 Verify that the (4) top support lugs are withdrawn by rotating the handles (item 17) counter-clockwise sufficiently to permit sliding the support lugs (item 24) outward. Manua11y tighten the (4) handles by rotating clockwise.

\subsection{Initial Set-up (Secondary Bumer)}

3.2.1 Assemble components in configuration shown in Ref. 2.2.

3.2.2 Verify that the sleeve assembly (item 3) is locked in the vertical position with the "cone end" up.

3.2.3 Engage the (4) lower support lugs by rotating the handles (item 7) counter-clockwise sufficiently to permit sliding the support lugs (iten 8) inward.) Manually tighten the (4) handles by rotating clockwise. Assure that the guide groove in the lug (item 8 ) is engaged with the support screw located in item 11. 
OPERATING PROCEDURE: PRIMARY AND SECONDARY BURNER TRUNNION FIXTURE

DOC. No. OP 5820042

Issue A

Date $8 / 26 / 76$

3.2.4 Verify that the (4) top support lugs are withdrawn by rotating the handles (item 7) counter-clockwise sufficiently to permit sliding the support lugs (item 8) outward. Manually tighten the (4) handles by rotating clockwise.

3.3 Operation (Primary Burner) (Ref. 2.1)

3.3.1 Complete set-up operations defined in para. 3.1.

3.3.2 Suspend the loaded susceptor and ceramic handling tool (ref. 2.3) directly over the vertical sleeve assembly (item 3).

3.3.3 Slowly lower the loaded fixture into the sleeve while manually guiding, as required.

NOTE: Care must be exercised when handing the ceramic material due to its fragile nature.

3.3.4 Continue lowering the ceramic fixture into the sleeve until the bottom of the ceramic is observed below the sleeve.

3.3.5 Rotate the ceramic fixture as required to align the index arrow located on the ceramic fixture support ring with the mark on top of the sleeve assembly.

3.3.6 Continue lowering fixture until seated on sleeve lower support lugs.

3.3.7 Loosen the (4) top support iug handles by turning counterclockwise sufficiently to permit sliding the (4) lugs inward. Retighten the lug handles.

3.3.8 Perform operations per paras. 3.1 .13 and 3.1 .14 of Ref. 2.3.

3.3.9 Remove the (2) expando grip pins (item 29), 1 each located in the trunnion index assembly (item 44). This is accomplished by depressing the thumb safety button and rotating the handle outward $90^{\circ}$ while pulling on the pin.

NOTE: The pin is attached to the trunnion by a lanyard.

3.3.10 Manual1y rotate the sleeve assembly $180^{\circ}$ (either direction).

3.3.11 Align the holes in each trunnion index assembly and reinstall the (2) expando grip pins. The pins are activated by inserting the pin into the hole and rotating the handle inward until the safety button is heard to "click" into position.

3.3.12 Disengage the (4) top support lugs (bottom lugs rotated $180^{\circ}$ ) by turning the handles counter-clockwise sufficiently to permit 
GA $541(\operatorname{ReV} 5 / 74)$

OPERATING PROCEDURE: PRIMARY AND SECONDARY BURNER TRUNNION FIXTURE

Doc. No. OP 5820042

Issue A

Date $8 / 26 / 76$

sliding the (4) lugs outward. Retighten the lug handles.

3.3.13 Perform operations per para. 3.1.16 through 3.1.20 of

Ref. 2.3.

3.4 Operation (Secondary Burner) (Ref. 2.2)

3.4.1 Complete set-up operations defined in para. 3.2.

3.4.2 Remove the ceramic and susceptor assembly manually.

3.4.3 Suspend the ceramic/susceptor directly over the vertical sleeve assembly (item 3 ).

3.4.4 Slowly lower the assembly into the sleeve, providing guidance as required.

NOTE: Care must be exercised when handing the ceramic material due to its fragile nature.

3.4.5 Continue lowering until seated on the lower support lugs.

3.4.6 Loosen the (4) top support lug handles by turning counterclockwise sufficiently to permit sliding the (4) lugs inward. Retighten the lug handles.

3.4.7 Remove the (2) expando grip pins (dwg. 5820042, item 29), 1 each located in the trunnion index assembly (item 22). This is accomplished by depressing the thumb safety button and rotating the handle outward $90^{\circ}$ while pulling on the pin.

NOTE: The $\mathrm{p}$ in is atteched to the trunnion by a lanyard.

3.4.8 Manually rotate the sleeve assembly $180^{\circ}$ (either direction).

3.4.9 Align the holes in each trunnion index assembly and reinstall the (2) expando grip pins. The pins are activated by inserting the pin into the hole and rotating the handle inward until the safety button is heard to "click" into position.

3.4.10 Disengage the (4) top support lugs (bottom lugs rotated $180^{\circ}$ ) by turning the handles counter-clockwise sufficiently to permit sliding the (4) lugs outward. Retighten the lug handles.

3.4.11 Manually withdraw the susceptor tube.

3.4.12 Reinstallation of the susceptor tube is accomplished in the reverse manner. 
OPERATING PROCEDURE: PRIMARY AND SECONDARY BURNER TRUNNION FIXTURE

DOC. No. OP 5820042

Issue A

Date $8 / 26 / 76$

\subsection{ABNORMAL OPERATIONS}

Since no major mechanical or electrical components are associated with

this fixture, no abnormal operation is anticipated.

\subsection{SAFETY}

5.1 Equipment shall be operated by or under the direct supervision of a qualified operator as designated by DP-143-5.

5.2 Work platforms and ladders required to provide access to this equipment shall comply with the requirements of GA's Accident Prevention Manual, Sec. III, No. 17.

5.3 A11 lifting gear accessories must be of sufficient load capability to suit conditions. Regularly scheduled testing and recertification of load fixture compliance with safe working practices shall be in accordance with GA's Accident Prevention Program Manual, Sec. III, No. 18. 
APPENDIX A, PART 4

OPERATING PROCEDURE: TILT-DOWN FIXTURE FOR PRIMARY AND SECONDARY BURNERS (DOCUMENT No. OP 5820051) 
GENERAL ATOMIC COMPANY

GA $777(\operatorname{Rev} 5 / 74)$

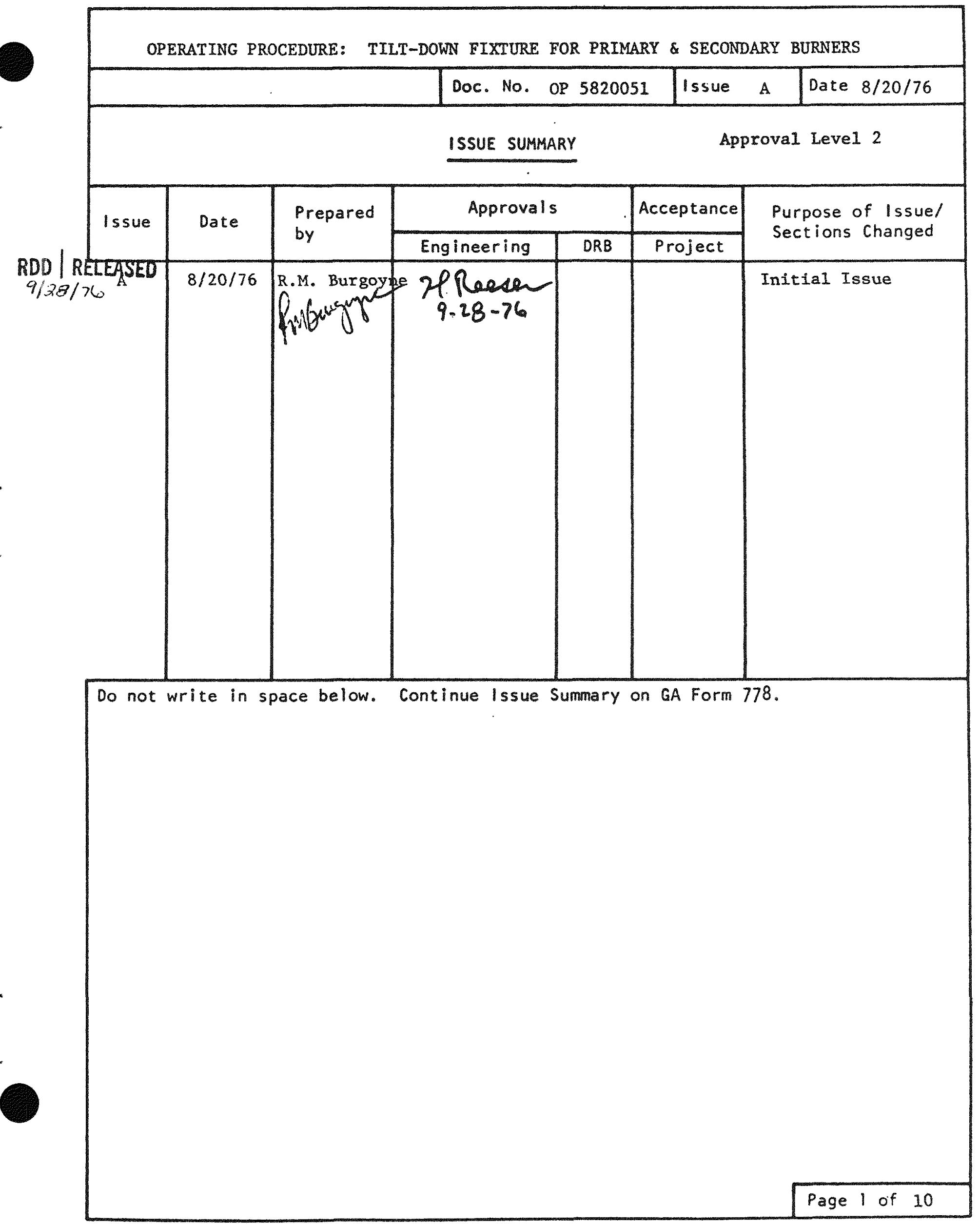


GA $541(\operatorname{Rev} 5 / 74)$

\section{GENERAL ATOMIC COMPANY}

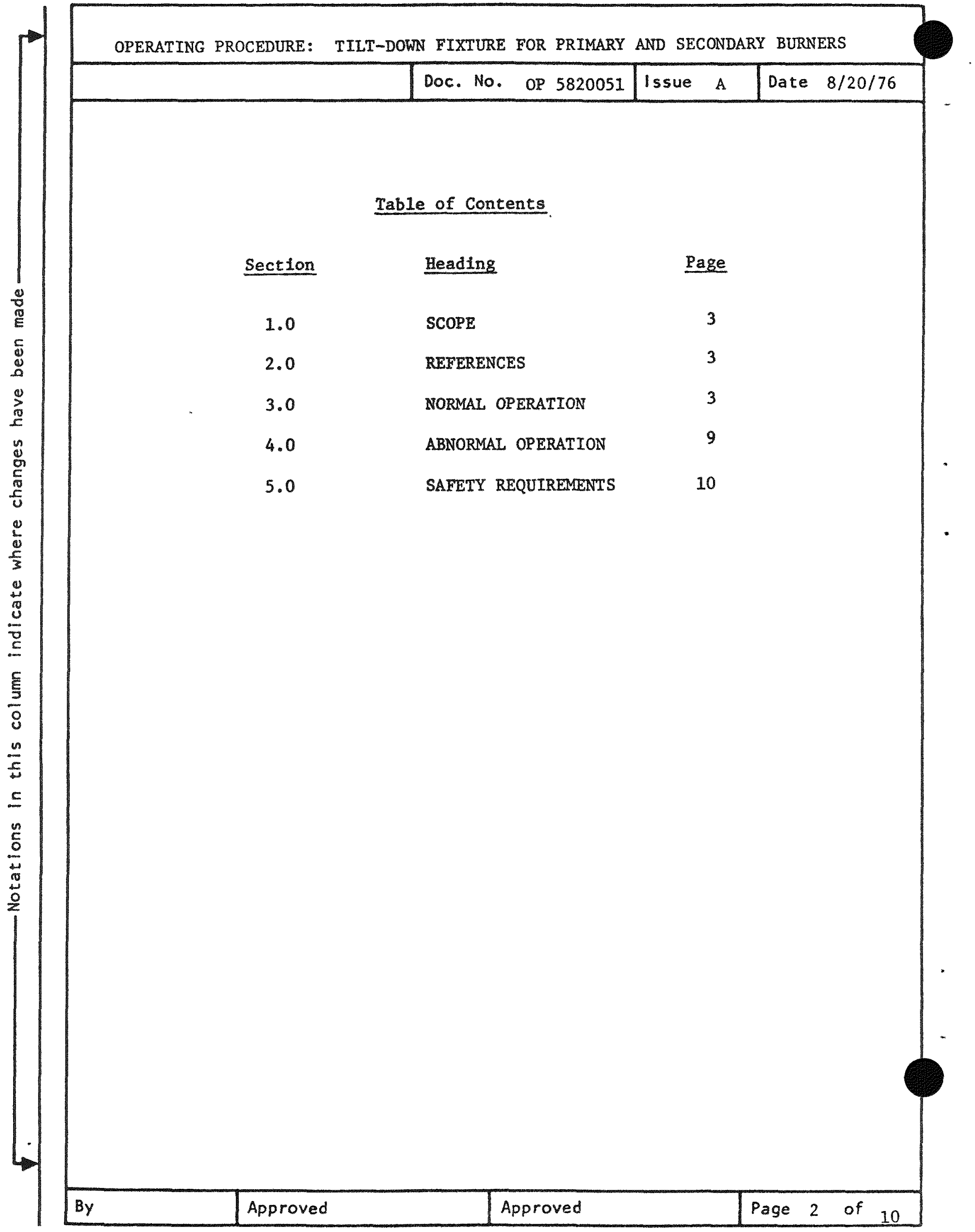


OPERATING PROCEDURE: TILT-DOWN FIXTURE FOR PRIMARY AND SECONDARY BURNERS

\begin{tabular}{|l|l|l|l|l|} 
Doc. No. OP 5820051 & Issue A & Date $8 / 20 / 76$
\end{tabular}

\subsection{SCOPE}

This procedure describes the operation of the tilt-down fixture for the primary and secondary burners. The fixture described herein will provide the following functions:

1.1 Permits movement of the burner tube assemblies to both the horizontal and vertical positions.

1.2 Permits rotation of the burner tubes while in the horizontal position for purposes of inspection, installation or maintenance of thermocouples, etc.

1.3 Permits transport of the bumer assembly throughout the pilot plant area.

\subsection{REFERENCES}

2.1 Dwg. 5820051 - Assemb1y Tilt-Down Fixture

2.2 TP 5820051 - Test Procedure: Tilt-Down Fixture

2.3 Dwg. 5244006 - Primary Burner Tube

2.4 Dwg. 5247006 - Secondary Burner Tube

2.5 M 582001 - Maintenance Manual: Remote Handling System

\subsection{NORMAL OPERATION}

The tilt-down fixture consists of two basis sub-assemblies: the support assembly and the trunnion assembly.

The support assembly is a rectangular structural steel frame, 57-1/4" wide $x$ 155-1/2" 1ong. It is the fixed portion of the tilt-down fixture and is provided with the casters, outrigger supports, motor drive system and controls. The support assembly rests on the floor and forms the base for the trunnion assembly via two pillow blocks mounted on the gusset assemblies.

The trunnion assembly is a rectangular structural steel frame, $44-1 / 2^{\prime \prime}$ wide $x 132^{\prime \prime}$ long. It is the rotating portion of the tilt-down fixture and is provided with the burner tube support plates, guides, rollers, locating pins and drive connection. The trunnion assembly rests on the support assembly when horizontal and pivots in the pillow blocks located on the gusset assemblies when rotated.

The tilt-down fixture is operated by an electric motor driven screw jack mounted on the support assembly and connected to the tie plates on the trunnion assembly. The trunnion assembly rotates approximately $90^{\circ}$ from the horizontal to the vertical position. 
OPERATING PROCEDURE: TILT-DOWN FIXTURE FOR PRIMARY AND SECONDARY BURNERS

\begin{tabular}{|l|l|l|l|} 
Doc. No. OP 5820051 & Issue A & Date $8 / 20 / 76$ \\
\hline
\end{tabular}

\subsection{Pre-Operational Checkout}

3.1.1 Locate the fixture on a level floor area of suitable size (approximately $10-1 / 2^{\prime} \times 15-1 / 2^{\prime}$ ).

3.1.2 Remove protective covers from all components.

3.1.3 Visually inspect for obvious damage or missing parts, including inside of electrical control box.

3.1.4 Verify that main power switch is off. Connect power cord to a sultable $460 \mathrm{~V}, 3 \phi, 60 \mathrm{~Hz}$ power source.

3.1.5 Verify that the 2-rotational lock pins are retracted and locked. Pins are located on each side of the support assembly near the gusset assemblies and just beneath the limit switches.

NOTE: The motor will not operate unless the pins are fully retracted.

3.1.6 Verify that the bottom primary burner tie-down assembly is in its closed and locked position. (Tie-down assembly is located at the far right end of the trunnion assembly when viewed from the control box.)

3.1.7 Verify that the bottom secondary burner tie-down assembly is in its closed and locked position. (Tie-down assembly is located to the left of the gusset assembly when viewed from the control box.)

NOTE: This assembly may be located in its horizontal or vertical position during checkout operation.

3.1.8 Turn main power switch to "ON" position.

3.1.9 Depress "Raise" pushbotton. Confirm smooth raising operation.

3.1.10 Depress "Stop" pushbutton when trunnion assembly is in midstroke, approximately $45^{\circ}$.

3.1.11 Depress and release "Jog" pushbutton 3 or 4 times to confirm proper jogging operation.

3.1.12 Depress "Raise" pushbutton. Confirm "up" limit switch operation when trunnion assembly reaches top of stroke or $90^{\circ}$ erect position.

NOTE: Motor will stop automatically when upper limit is reached

3.1.13 Slide 2-rotational lock pins into locked position. 
OPERATING PROCEDURE: TILT-DOWN FIXTURE FOR PRIMARY AND SECONDARY BURNERS \begin{tabular}{|l|l|l|l|}
\hline Doc. No. op 5820051 & Issue A & Date $8 / 20 / 76$ \\
\hline
\end{tabular}

3.1.14 Depress "Lower" pushbutton. Confirm that motor will not run.

3.1.15 Retract 2-rotational lock pins.

3.1.16 Depress "Lower" pushbutton. Confirm smooth lowering operation. NOTE: Motor will stop automatically when lower limit is reached. Tilt-down fixture is ready for operation with burnex tube assemblies.

\subsection{Operation - Primary Burner Installation/Removal}

3.2.1 Complete pre-operational checkout, para. 3.1.

3.2.2 Extend 4-outrigger assemblies by removing lock pins retaining the outrigger assemblies against the support assembly. Lift slightly and swing out approximately $90^{\circ}$. Lock pins will engage automatically. Activate floor locks located at the end of each outrigger by depressing with the foot until the unit is felt to "lock" in the extended position.

3.2.3 Lower the secondary burner support to its stored position.

3.2.4 Extend and lock the 2-burner alignment pins in the burner support plate located at the left end of the trunnion assembly when viewed from the control box.

3.2.5 Depress the "Raise" pushbutton. The trunnion assembly will rotate approximately $90^{\circ}$ and automatically stop.

3.2.6 Engage the rotational lock pins.

3.2.7 Unlock and open the lower burner tie-down assembly.

3.2.8 Suspend the burner tube assembly adjacent to the erect trunnion assembly so the burner is opposite the open side of the support plates and the bottom of the saddle support plate is approximately $I^{\prime \prime}$ above the top of the trunnion assembly alignment pins.

3.2.9 Translate and rotate the burner tube as required to align the holes in the saddle plate with the alignment pins.

3.2.10 Lower the burner tube onto the trunnion assembly upper support plate.

3.2.11 Close and lock the lower burner tie-down assembly.

3.2.12 Disconnect a11 crane rigging and lifting gear from the burner tube assembly. 


\section{GENERAL ATOMIC COMPANY}

OPERATING PROCEDURE: TILT-DOWN FIXTURE FOR PRIMARY AND SECONDARY BURNERS

\begin{tabular}{|l|l|l|} 
Doc. No. op 5820051 & Issue A & Date $8 / 20 / 76$ \\
\hline
\end{tabular}

3.2.13 Verify that the alignment pins are fully engaged and locked in position.

3.2.14 Remove the 2-rotational lock pins.

3.2.15 Depress the "Lower" pushbutton. The trunnion assembly with burner tube will automatically lower and stop in the horizontal position.

3.2.16 Insert the rotational lock pins.

3.2.17 Retract the trunnion assembly alignment pins. The burner can now be rotated as required for inspection or maintenance.

3.2.18 Rotate the burner tube assembly as required to align the holes in the saddle plate with the trunnion assembly alignment pins.

3.2.19 Engage and lock the alignment pins.

3.2.20 Verify that the lower burner tube tie-down assembly is closed and locked and that the outriggers are positioned and locked.

3.2.21 Retract the rotational lock pins.

3.2.22 Depress the "Raise" pushbutton.

3.2.23 Depress the "Stop" pushbutton when the trunnion is approximately $15^{\circ}$ from vertical.

3.2.24 Continue the erection using the up "Jog" button until the upper limit switch is tripped.

3.2.25 Insert the rotational lock pins.

3.2.26 Connect suitable rigging and lifting gear to the burner tube.

3.2.27 Unlock and open the lower burner tie-down assembly.

3.2.28 Retract the trunnion assembly alignment pins.

3.2.29 Raise the burner assembly approximately 1". Translate away from the trunnion assembly.

3.2.30 Close and lock the lower burner tie-down assembly.

3.2.31 Retract the rotational lock pins.

3.2.32 Depress the "Lower" pushbutton.

3.2.33 Engage the rotational lock pins.

\begin{tabular}{|l|l|l|l|l|}
\hline By & Approved & Approved & Page 6 of 10 \\
\hline
\end{tabular}




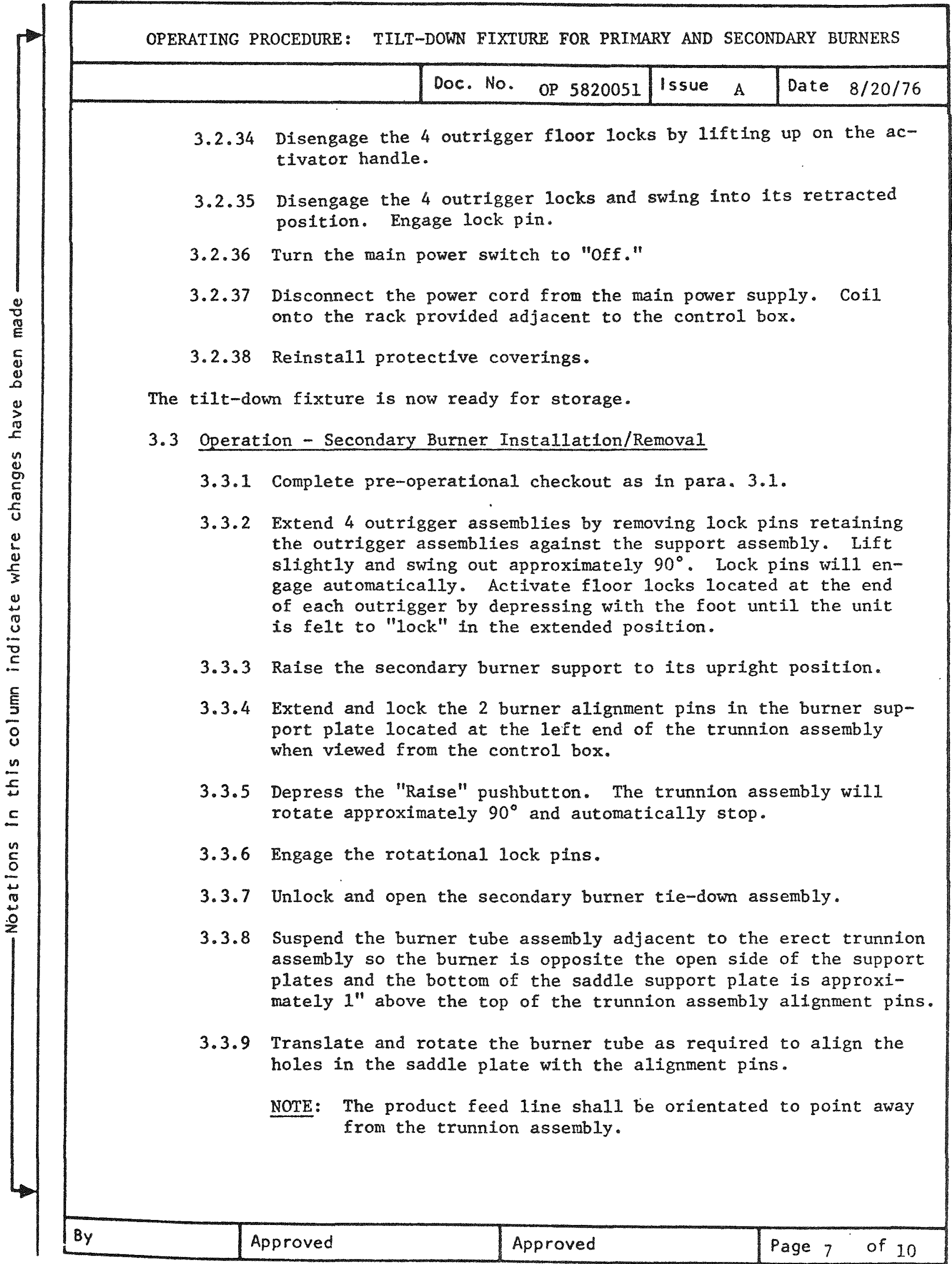


OPERATING PROCEDURE: TILT-DOWN FIXTURE FOR PRIMARY AND SECONDARY BURNERS

\begin{tabular}{|l|l|l|l|} 
Doc. No. OP 5820051 & Issue A & Date $8 / 20 / 76$ \\
\hline
\end{tabular}

3.3.10 Lower the burner tube onto the trunnion assembly upper support plate.

3.3.11 Close and lock the secondary burner tie-down assembly.

3.3.12 Disconnect all crane rigging and lifting gear from the burner tube assembly.

3.3.13 Verify that the alignment pins are fully engaged and locked in position.

3.3.14 Remove the 2 rotational lock pins.

3.3.15 Depress the "Lower" pushbutton. The trunnion assembly with burner tube will automatically lower and stop in the horizontal position.

3.3.16 Insert the rotational lock pins.

3.3.17 Retract the trunnion assembly alignment pins. The burner can now be rotated as required for inspection or maintenance, etc.

NOTE: Exercise care when rotating secondary burner to prevent damage to the feed line.

3.3.18 Rotate the burner tube assembly as required to align the holes in the saddle plate with the trunnion assembly alignment pins.

3.3.19 Engage and lock the alignment pins.

3.3.20 Verify that the secondary burner tube tie-down assembly is closed and locked and that the outriggers are positioned and locked.

3.3.21 Retract the rotationa1 1cok pins.

3.3.22 Depress the "Raise" pushbutton.

3.3.23 Depress the "Stop" pushbutton when the trunnion is approximately $15^{\circ}$ from vertical.

3.3.24 Continue the erection using theup "Jog" button until the upper limit switch is tripped.

3.3.25 Insert the rotational lock pins.

3.3.26 Connect suitable riggins \& lifting gear to the burner tube. Ref. OP 5820011.

3.3.27 Unlock and open the secondary burner tie-down assembly.

3.3.28 Retract the trunnion assemb1y alignment pins. 
OPERATING PROCEDURE: TILT-DOWN FIXTURE FOR PRIMARY AND SECONDARY BURNERS

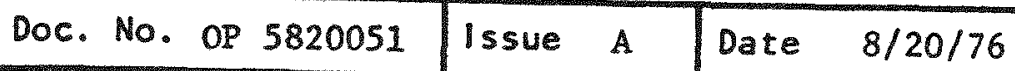

3.3.29 Raise the burner assembly approximately 1". Translate away from the trunnion assembly.

3.3.30 Close and lock the secondary burner tle-down assembly.

3.3.31 Retract the rotational lock pins.

3.3.32 Depress the "Lower", pushbutton.

3.3.33 Engage the rotational lock pins.

3.3.34 Disengage the 4 outrigger floor locks by lifting up on the activator handle.

3.3.35 Disengage the 4 outrigger locks and swing into its retracted position. Engage lock pin.

3.3.36 Turn the main power switch to "Off."

3.3.37 Disconnect the power cord from the main power supply. Coil onto the rack provided adjacent to the control box.

3.3.38 Reinstall protective coverings.

The tilt-down fixture is now ready for storage.

4.0 ABNORMAL OPERATION

4.1 Stoppages and Malfunctions

4.1.1 Shutdown during operation - Fail-safe operation has been assured by the use of machine jack screws which will not allow overrunning. Component failure requires judgmental action by qualified operator; shut down equipment, assure personnel safety and inform cognizant engineer.

4.1.1.1 Problem: trunnion assembly will not raise when loaded; motor is operating. Cause: clutch is slipping. Solution: see M 5820051 for adjustment instructions.

4.1.1.2 Problem: trunnion assembly will not raise or lower; motor will not operate. Check position of rotation lock pins; verify complete withdrawal. Check circuit breaker reset. Check main power circuit.

4.1.1.3 Problem: motor continues to run after trunnion is elther fully up or down. Solution: press stop button Immediately. See M 5820051 for limit switch adjustment instructions. 
GA $541(\operatorname{ReV} 5 / 74)$

\section{GENERAL ATOMIC COMPANY}

OPERATING PROCEDURE: TILT-DOWN FIXIURE FOR PRIMARY AND SECONDARY BURNERS

Doc. No. OP 5820051

Issue

A

Date $8 / 20 / 76$

\subsection{SAFETY}

\subsection{Deployment of Outriggers}

When operating the fixture with a burner in position, the outriggers must be deployed in accordance with the operating procedures to prevent tipping of the fixture when the burner/trunnion assembly is raised to the vertical position.

"Jogging" should be used with care as sudden stopping and starting under load causes vibration of the fixture.

As with any lifting equipment, personnel should exercise caution during operation and should remain clear of the trunnion assembly during operation.

Operation of all equipment shall be performed by or under the direct supervision of a qualified operator as designated in DP-143-5. Operation of handling equipment and establishment of safe working conditions shall be in accordance with GA Accident Prevention Manual, Section III, No. 18. 
APPENDIX A, PART 5

OPERATING PROCEDURE: PRIMARY BURNER HEATER AND SHROUD HANDLING FIXTURE (DOCUMENT No. OP 5820060) 
GA $777(\operatorname{Rev} 5 / 74)$

\section{GENERAL ATOMIC COMPANY}

OPERATING PROCEDURE: PRIMARY BURNER HEATER \& SHROUD HANDLING FIXTURE

\begin{tabular}{|l|l|l|l|}
\hline Doc. No. OP 5820060 & Issue A & Date $8 / 16 / 76$
\end{tabular}

ISSUE SUMMARY Approval Leve1 2

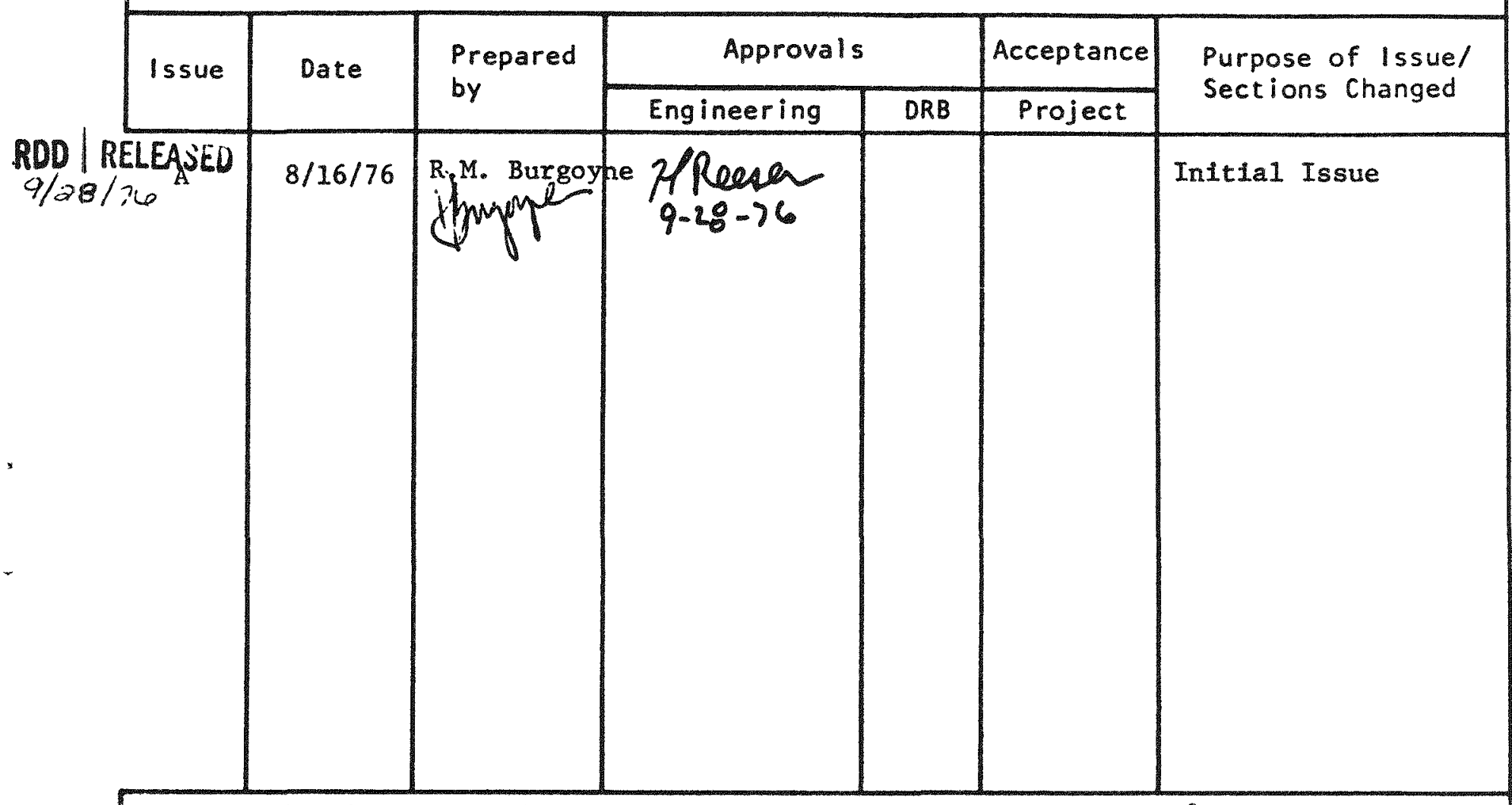

Do not write in space below. Continue Issue Summary on GA Form 778. 


\section{GENERAL ATOMIC COMPANY}

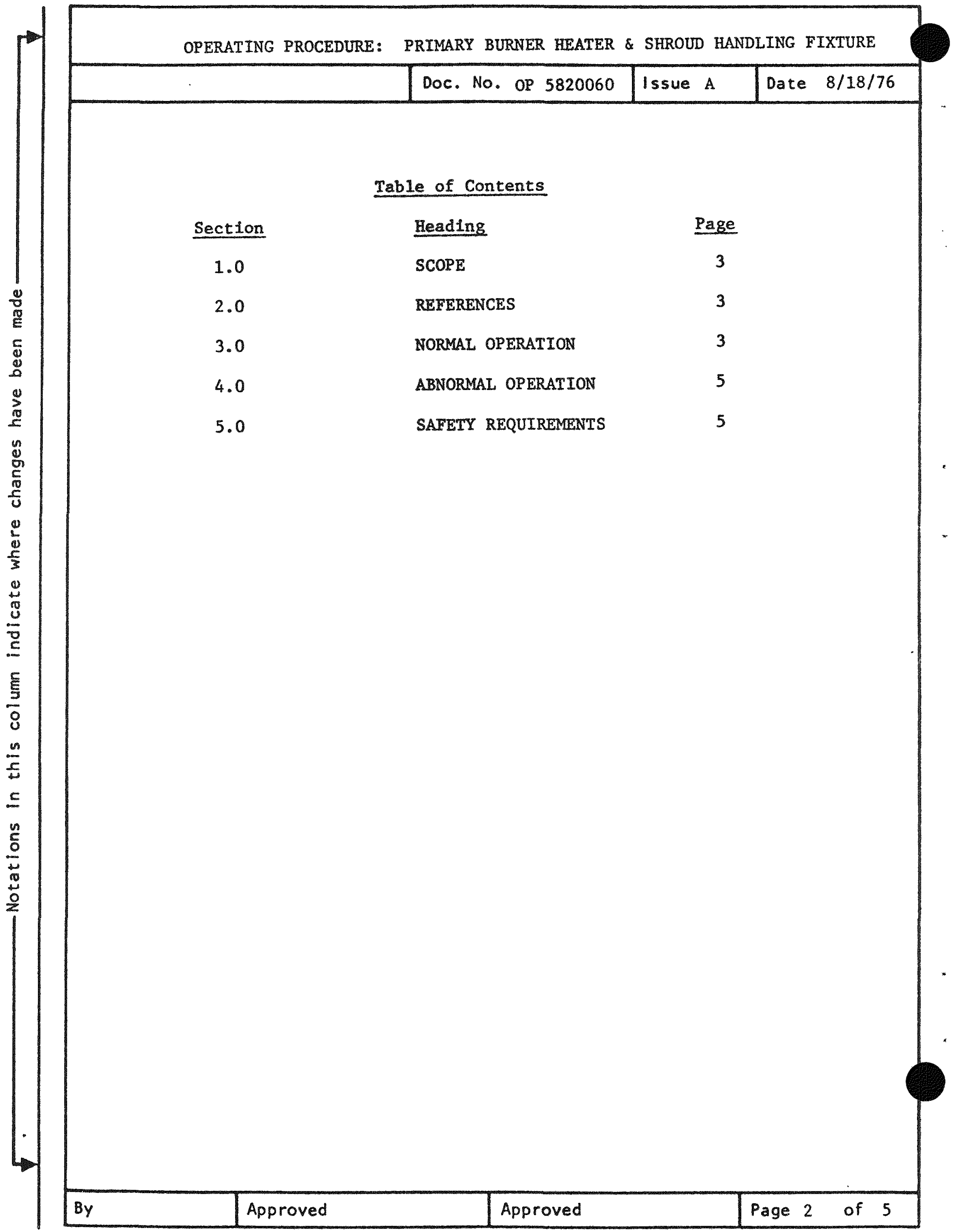


OPERATING PROCEDURE: PRIMARY BURNER HEATER \& SHROUD HANDLING FIXTURE

\begin{tabular}{|l|l|l|}
\hline Doc. No. OP 5820060 & Issue A & Date $8 / 18 / 76$ \\
\hline
\end{tabular}

\section{$1.0 \quad$ SCOPE}

This procedure describes the operation of the primary burner heater and shroud handling fixture. This fixture is used to translate the heater and shroud assembly from its operating position in the burner stack-up to a position adjacent to the pit wall to provide overhead access for susceptor and ceramic removal and maintenance.

\subsection{REFERENCES}

2.1 Dwg. 5820060 - Heater and Shroud Handling Fixture

2.2 Dwg. 5244025 - Heater and Shroud Assembly

2.3 Dwg. 5244032 - Exhaust Plenum Assembly

2.4 MM 524403 - Removal and Reinstallation Procedure: Primary Burner and Heater and Shroud

2.5 MM 582001 - Remote Handling System Maintenance Manual

\subsection{NORMAL OPERATION}

3.1 Initial Installation (Ref. 2.1)

3.1.1 Secure the forward support frame, item 3, to the shop floor in accordance with detail $\mathrm{E}$.

3.1.2 Install the right and left-hand rail beams (items 4 and 5). Secure the track beams to the rear support (item 2) which is permanently attached to the burner support structure.

3.1.3 Level the rail assemblies and shim between the forward support and the beams as required.

3.1.4 Secure the rail beams to the forward support.

3.1.5 Inspect the drive assembly mounted on the right-hand rail beam. Lubricate with dry graphite lubricant as required.

3.1.6 Verify alignment of the shaft assembly (item 21) with the right-hand round way bearing assembly (item 22).

3.1.7 Turn the hand wheel (item 15) and move the tee chain attachment (item 10) and align with the trolley carrier (item 9). Engage with the carriage by depressing the chain and inserting the tee bracket between the guide angles as shown in detail $\mathrm{C}$. Install lock pins.

\subsection{Operation (Shroud Removal) (Ref. 2.1)}

3.2.1 After removal of the primary burner tube and completion of 


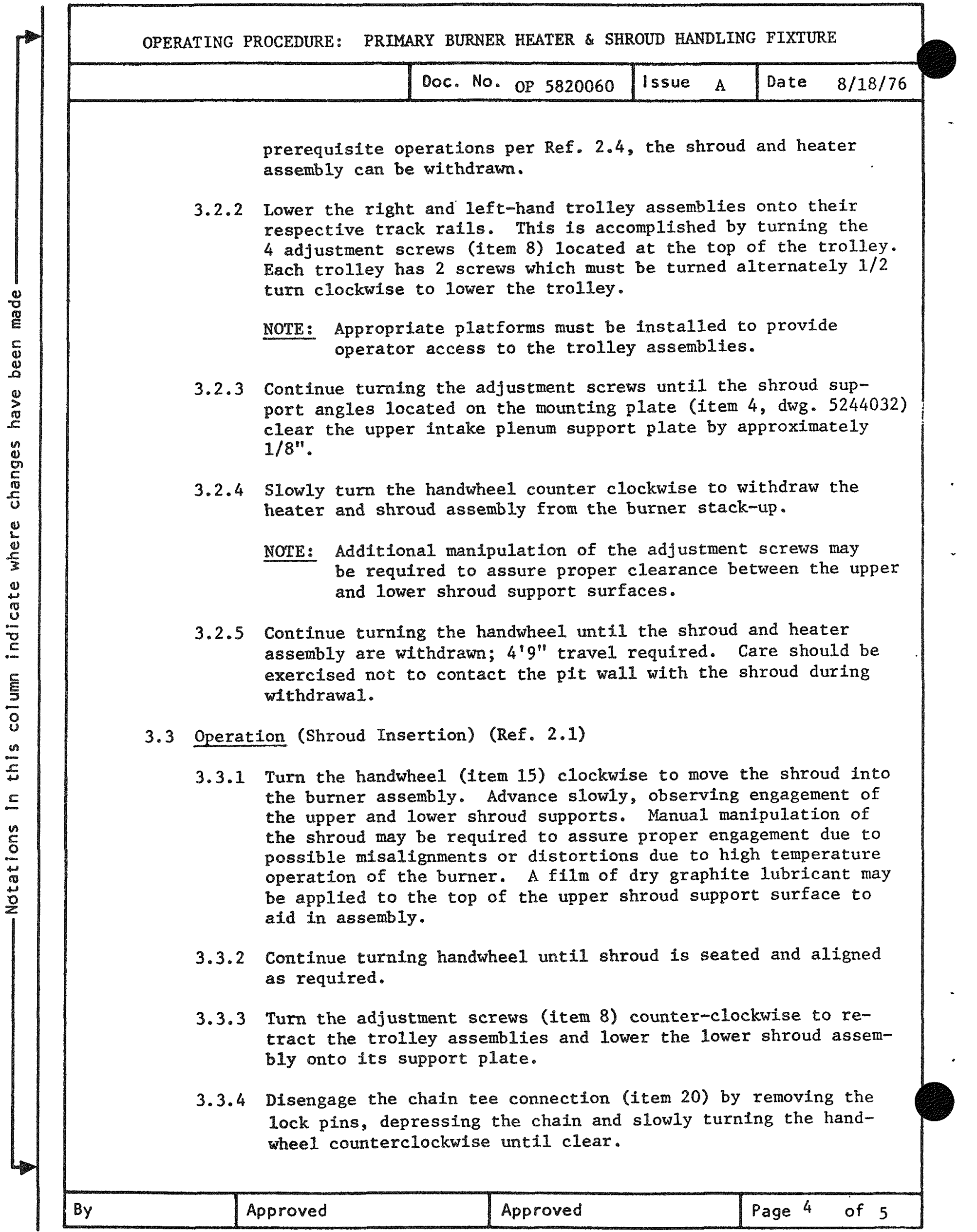


GA $541(\operatorname{Rev} 5 / 74)$

\section{GENERAL ATOMIC COMPANY}

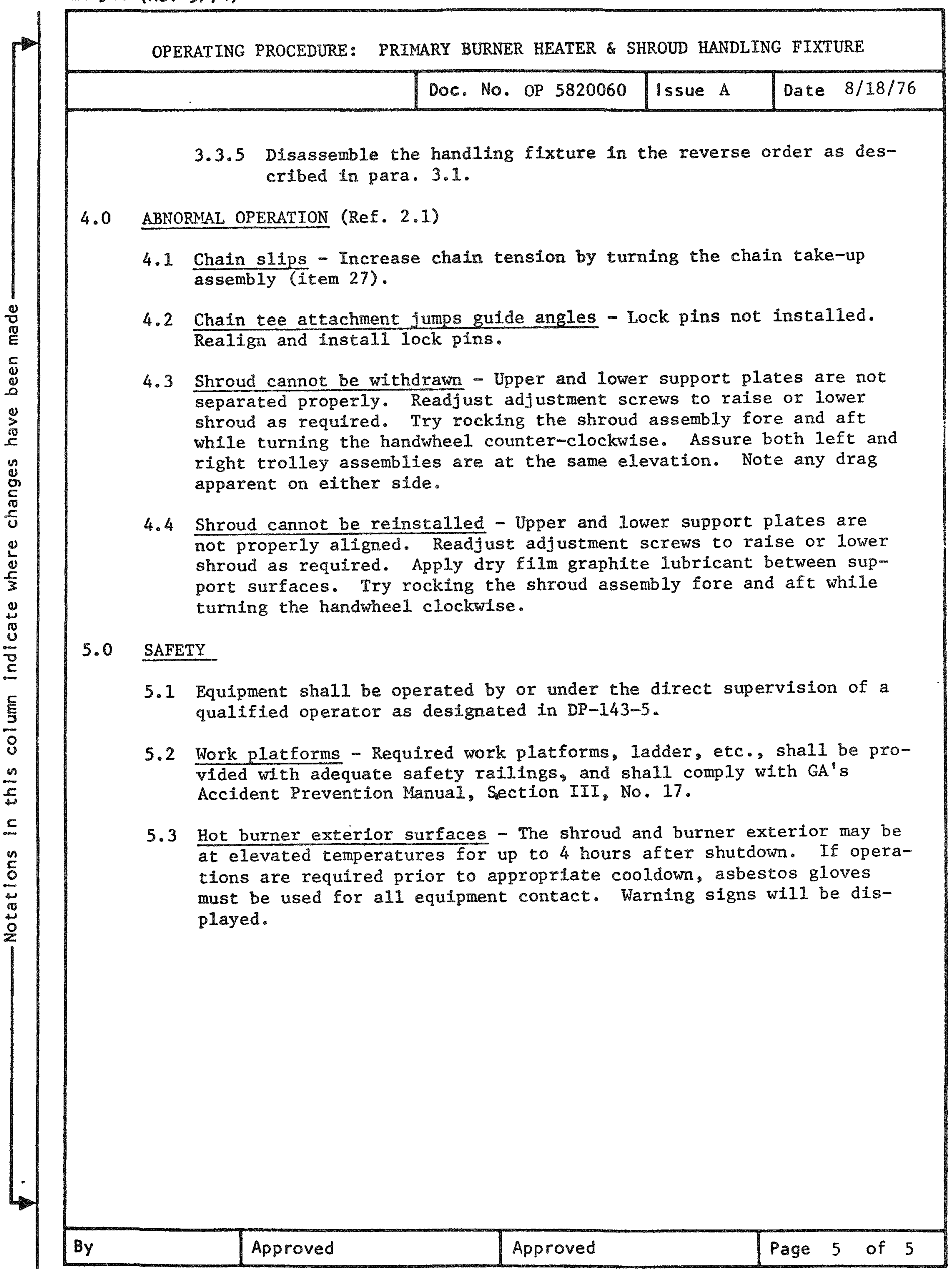


APPENDIX B

MANUFACTURING DRAWINGS

$\mathrm{B}-1$ 


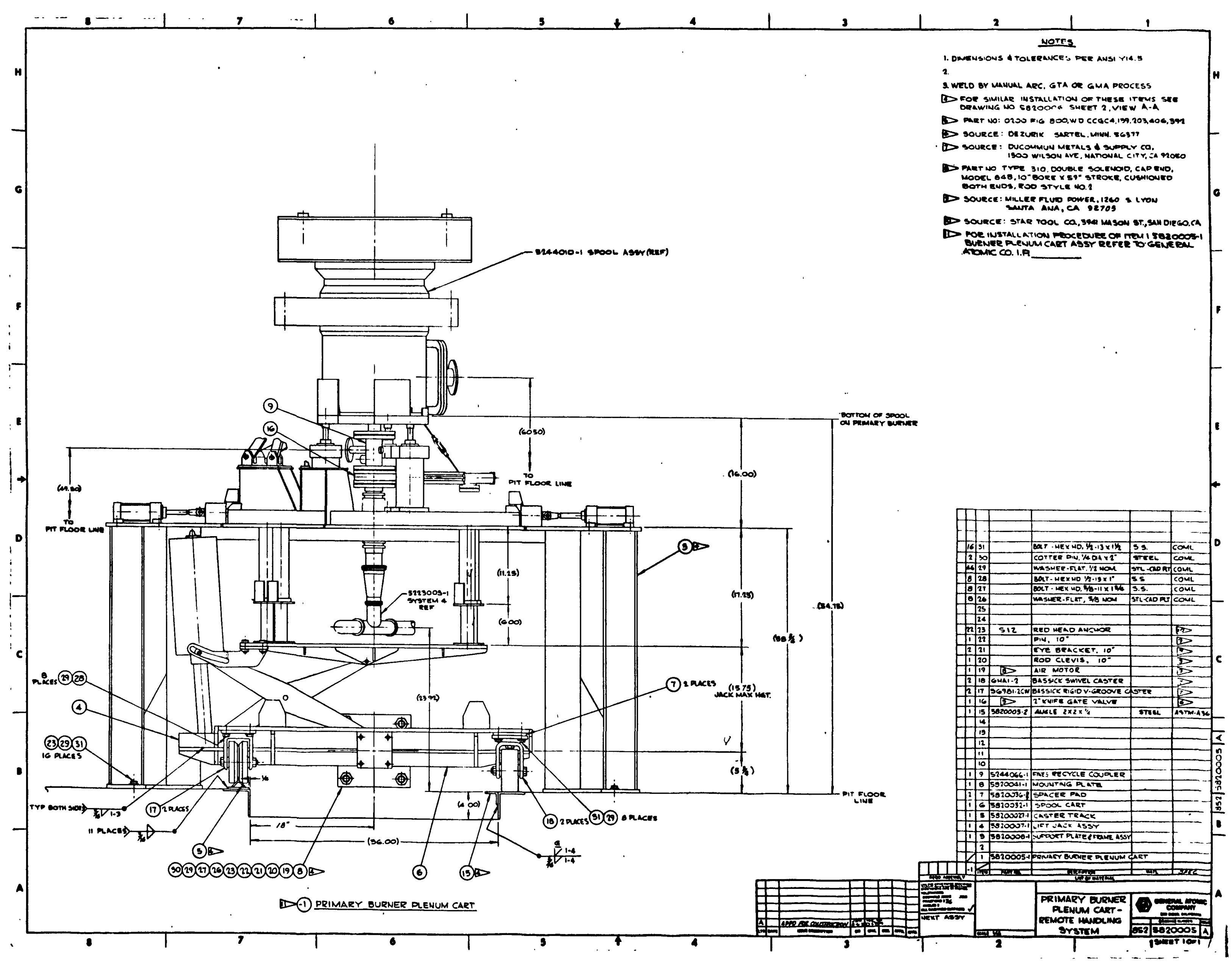





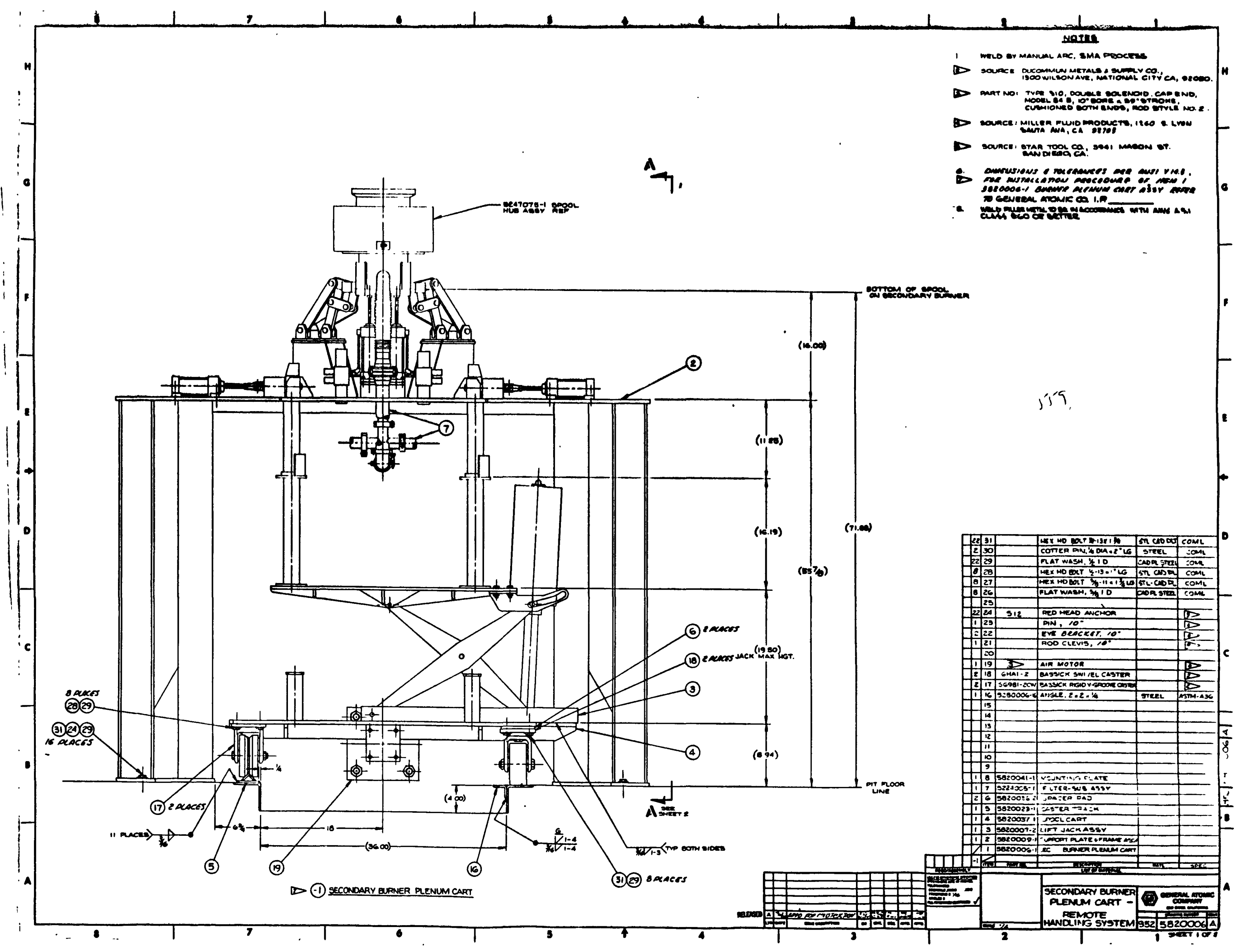





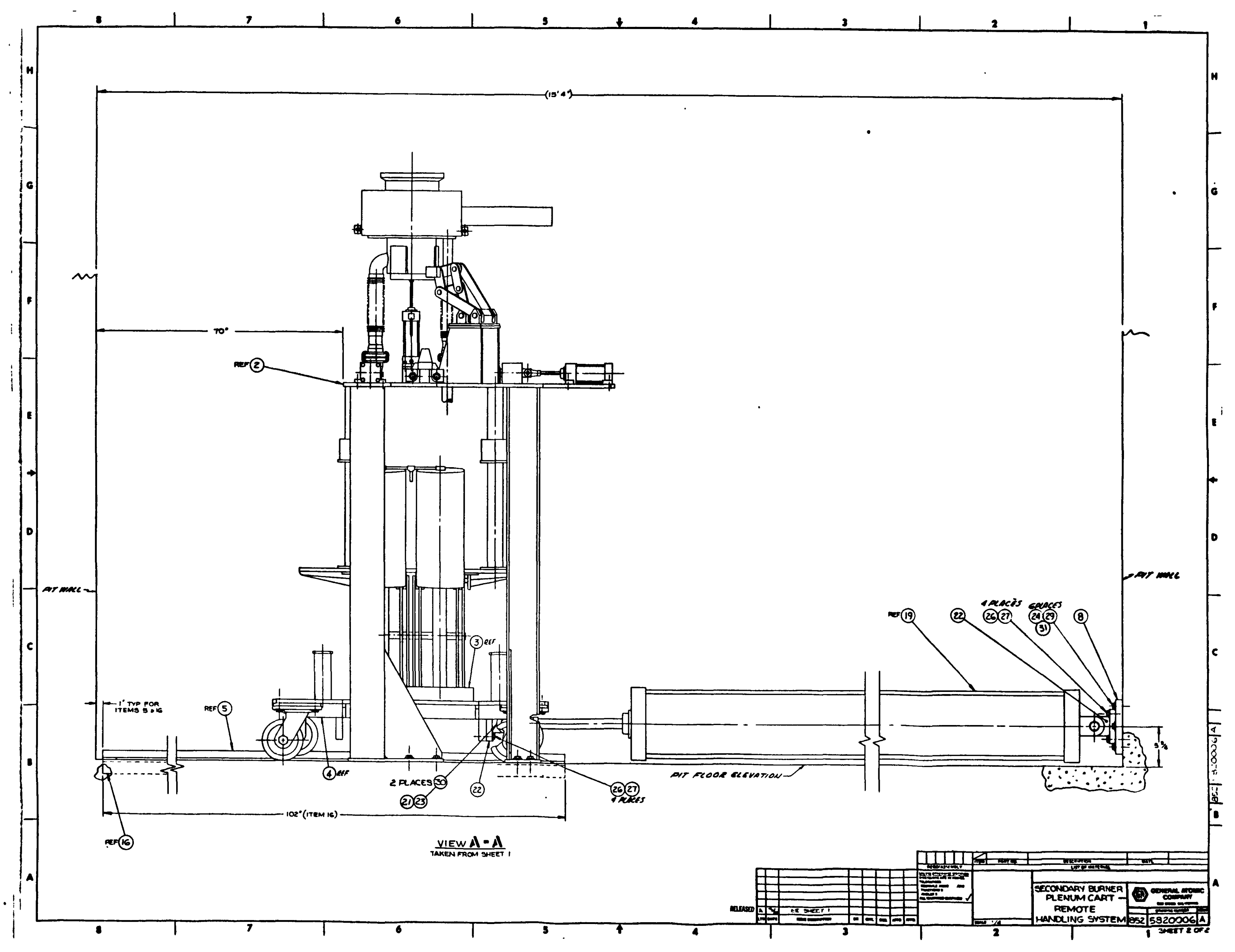




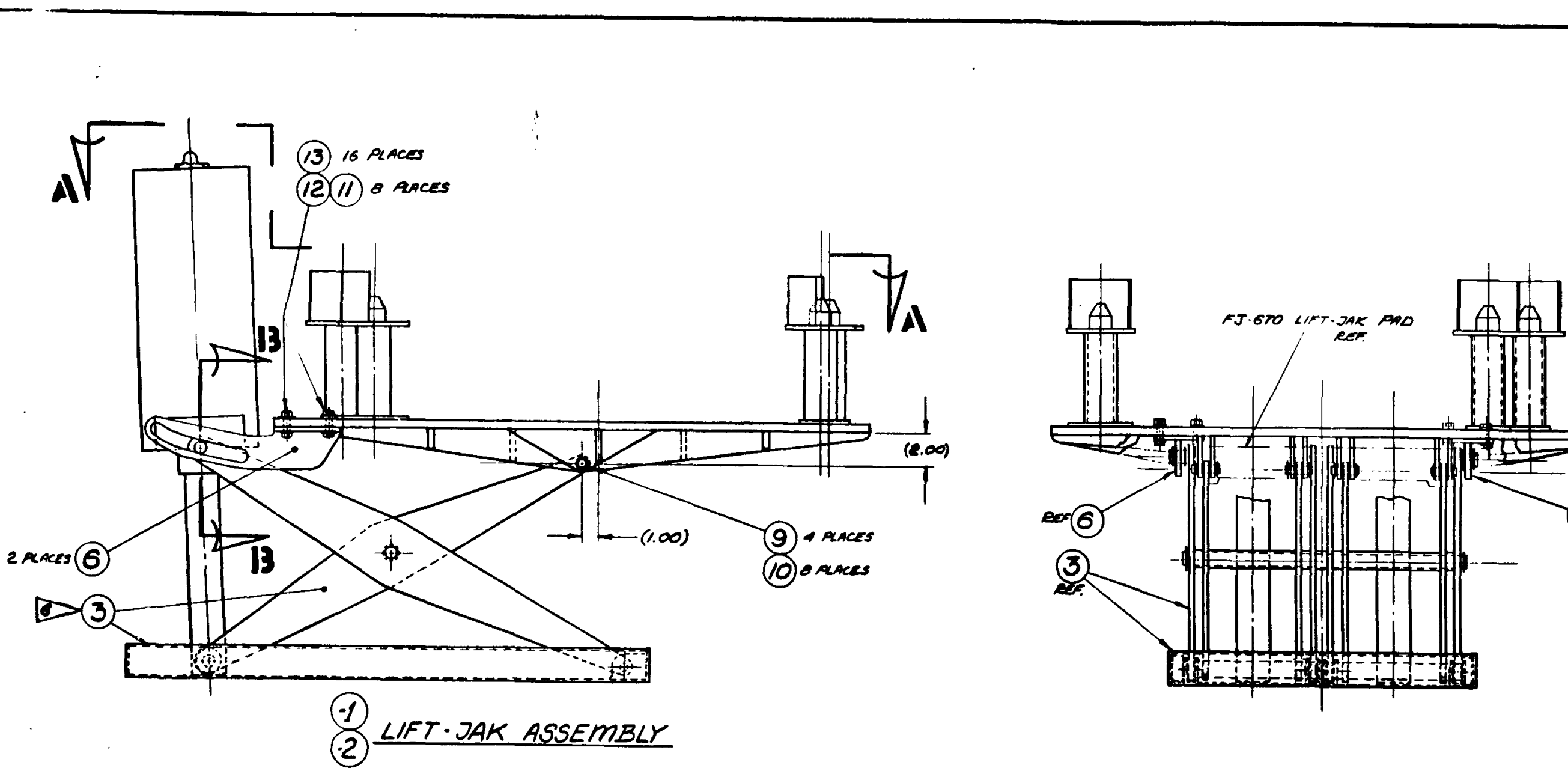

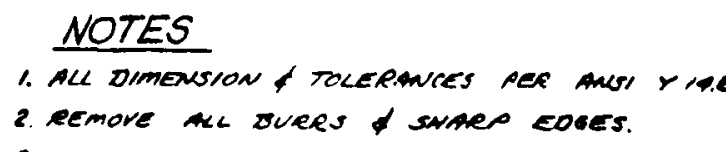

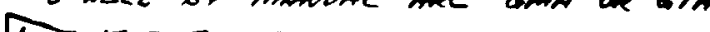

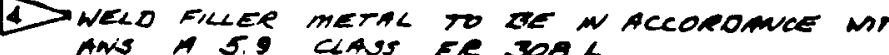

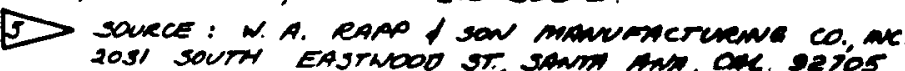

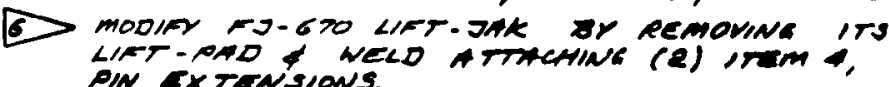

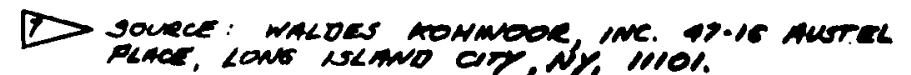
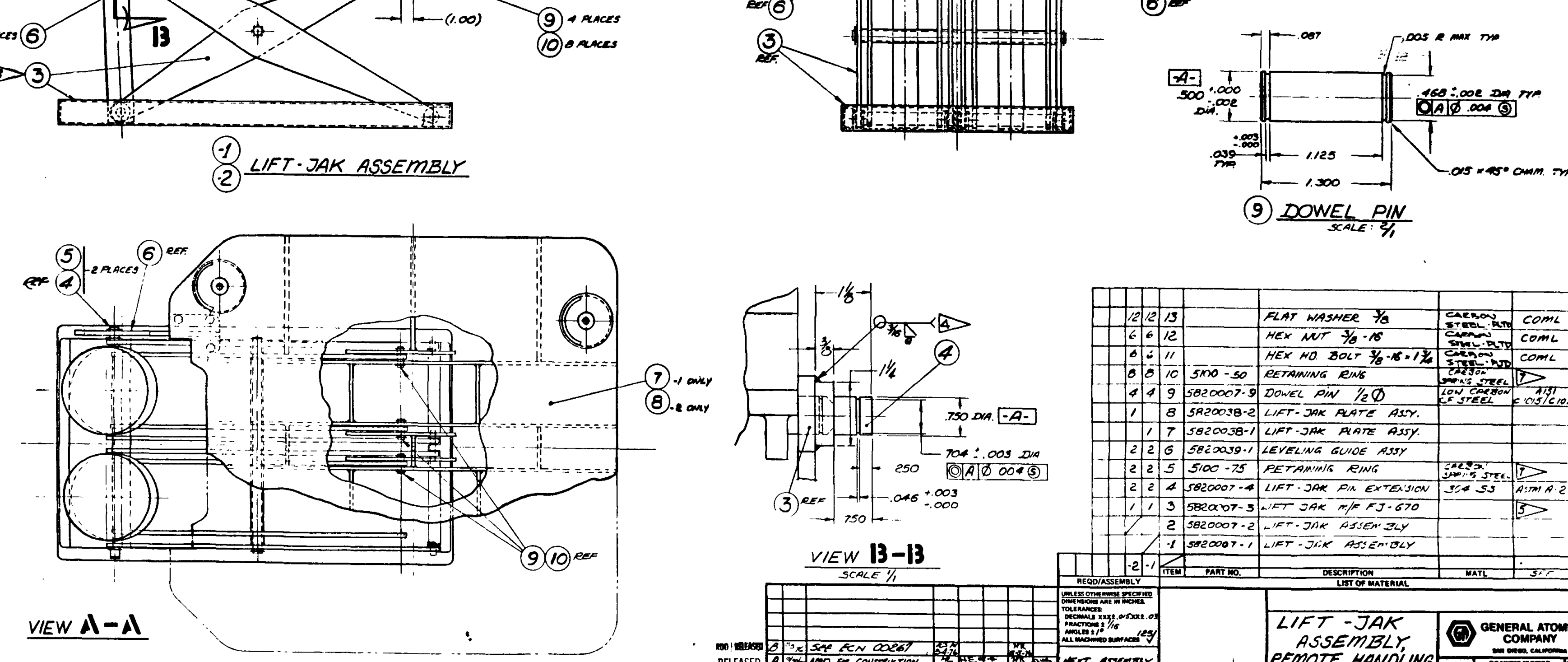

(9) $\frac{\text { DOWEL PIN }}{S \times L E F \% \%, ~}$
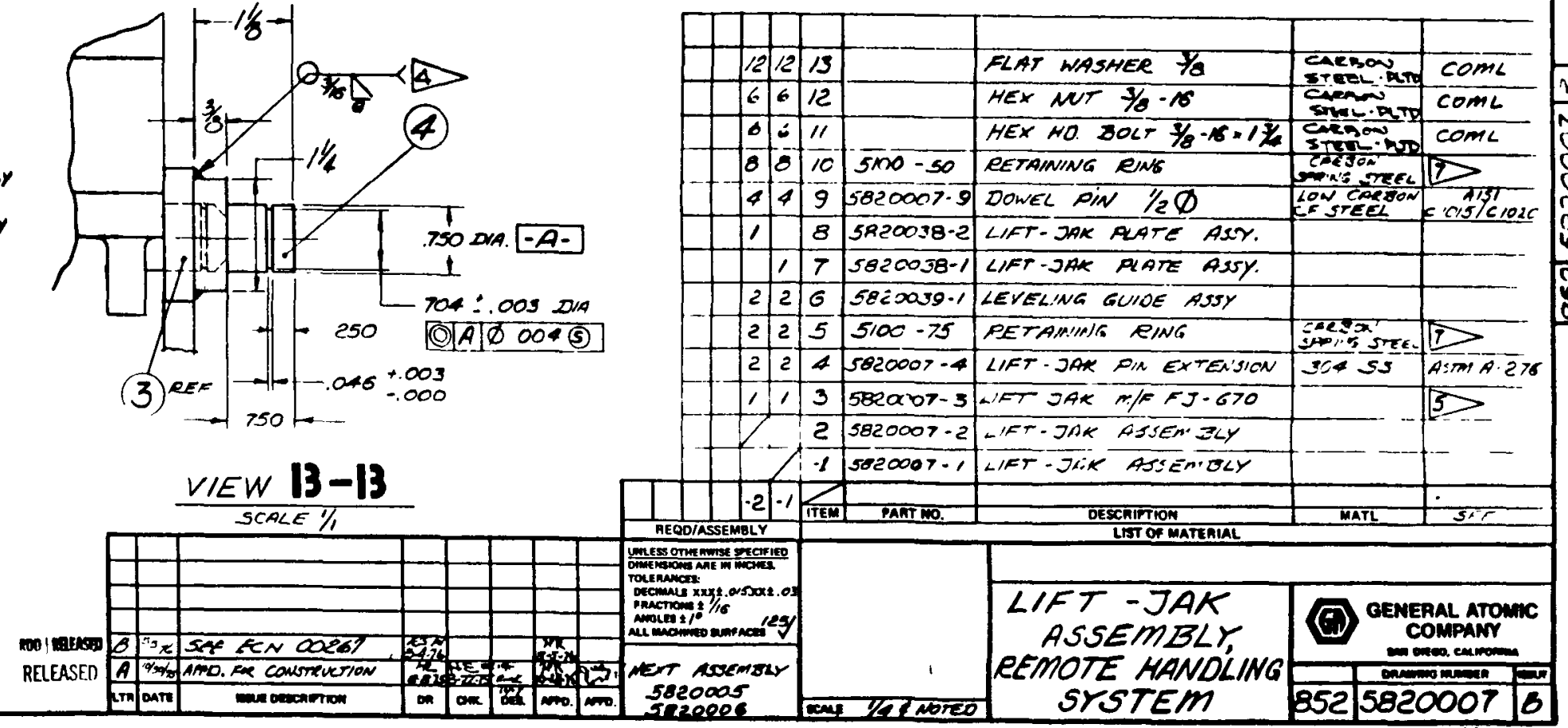



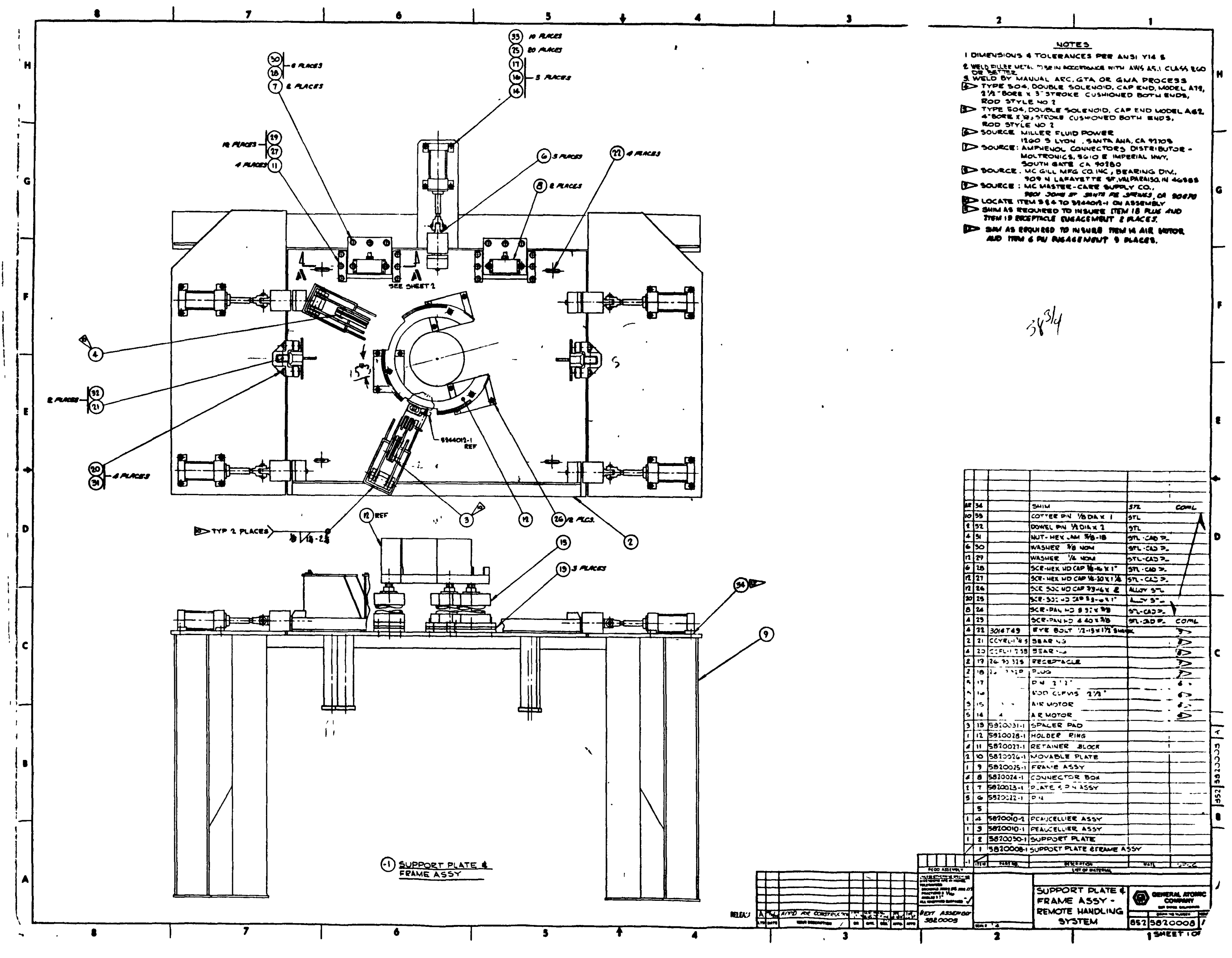


○. . . 


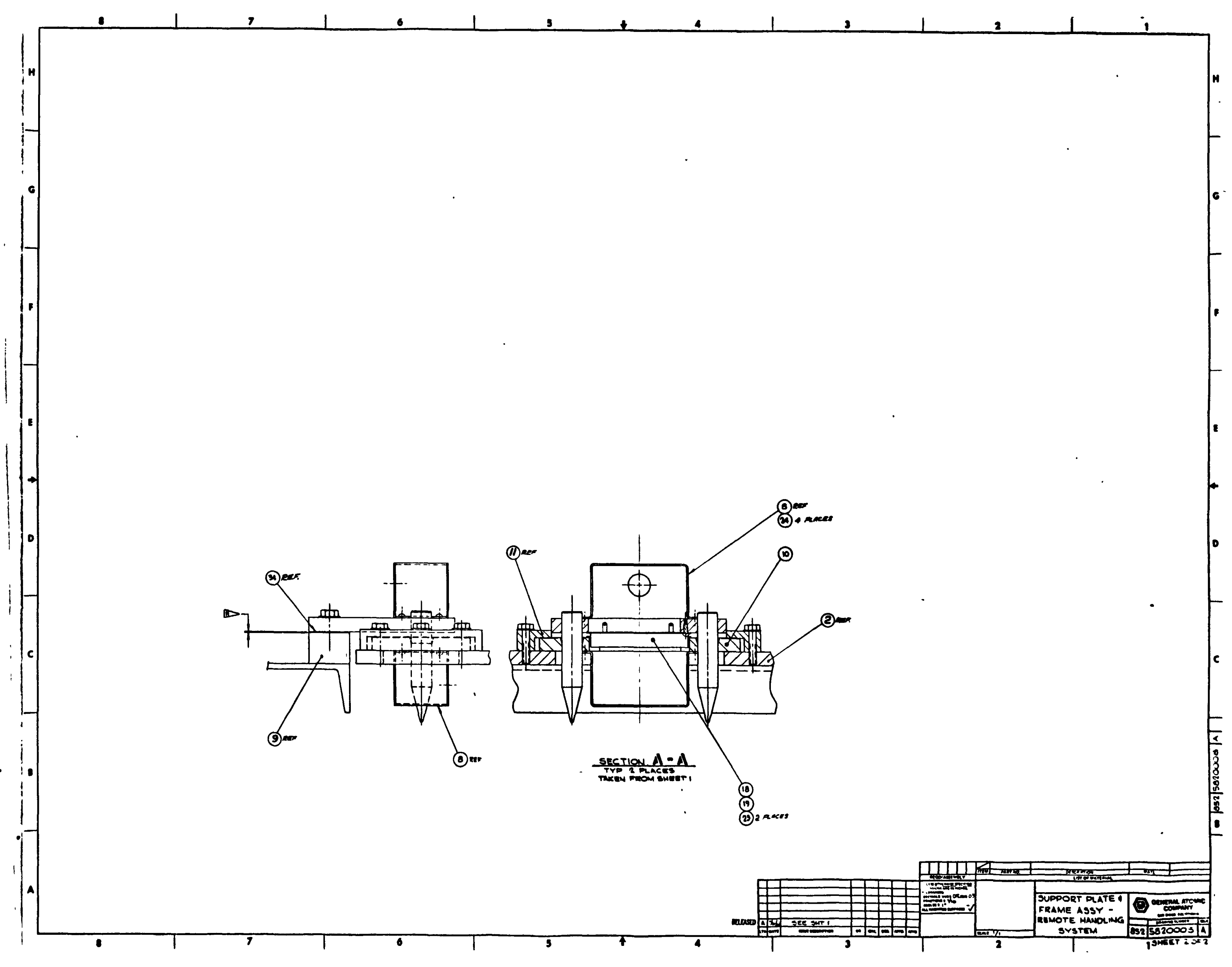





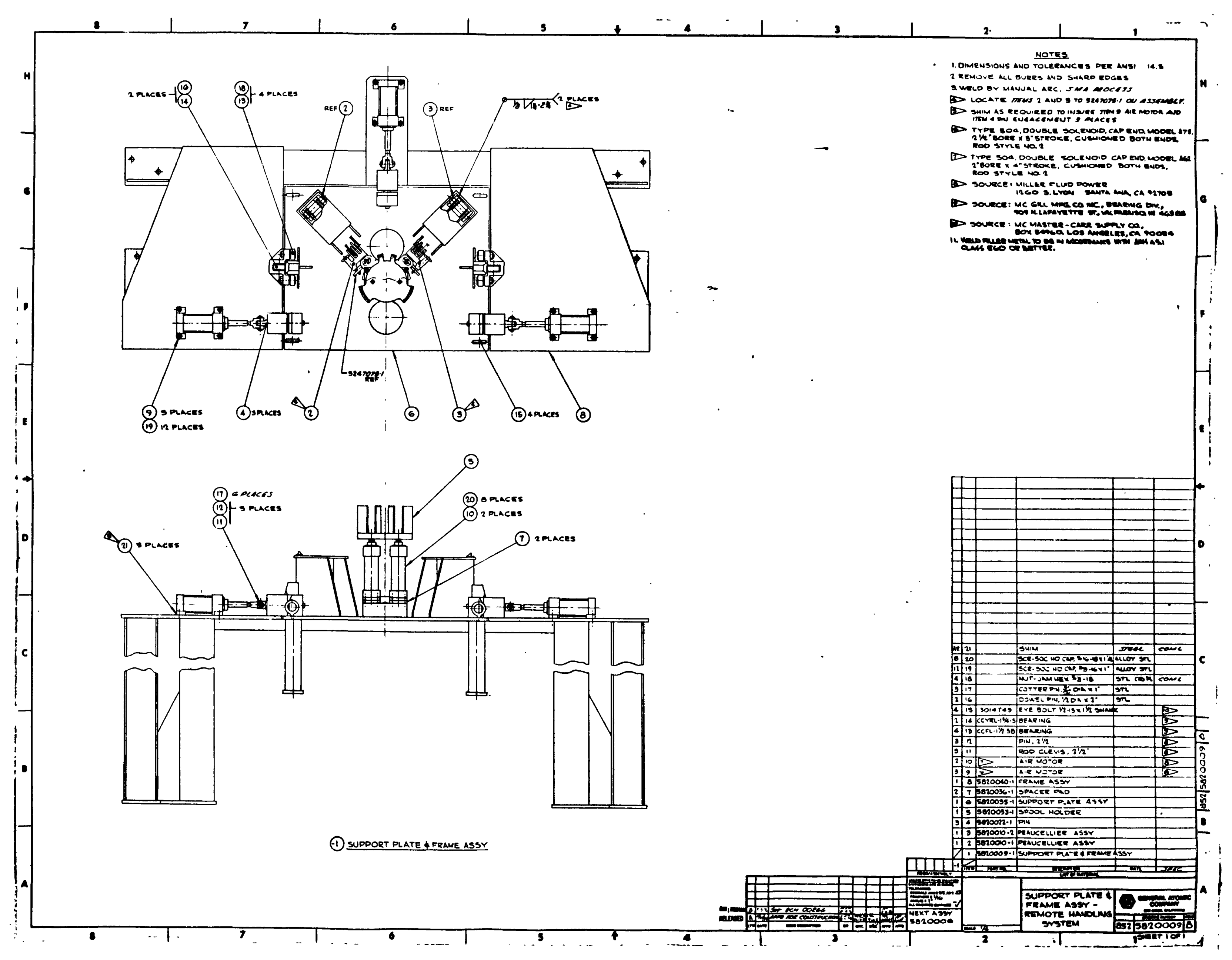





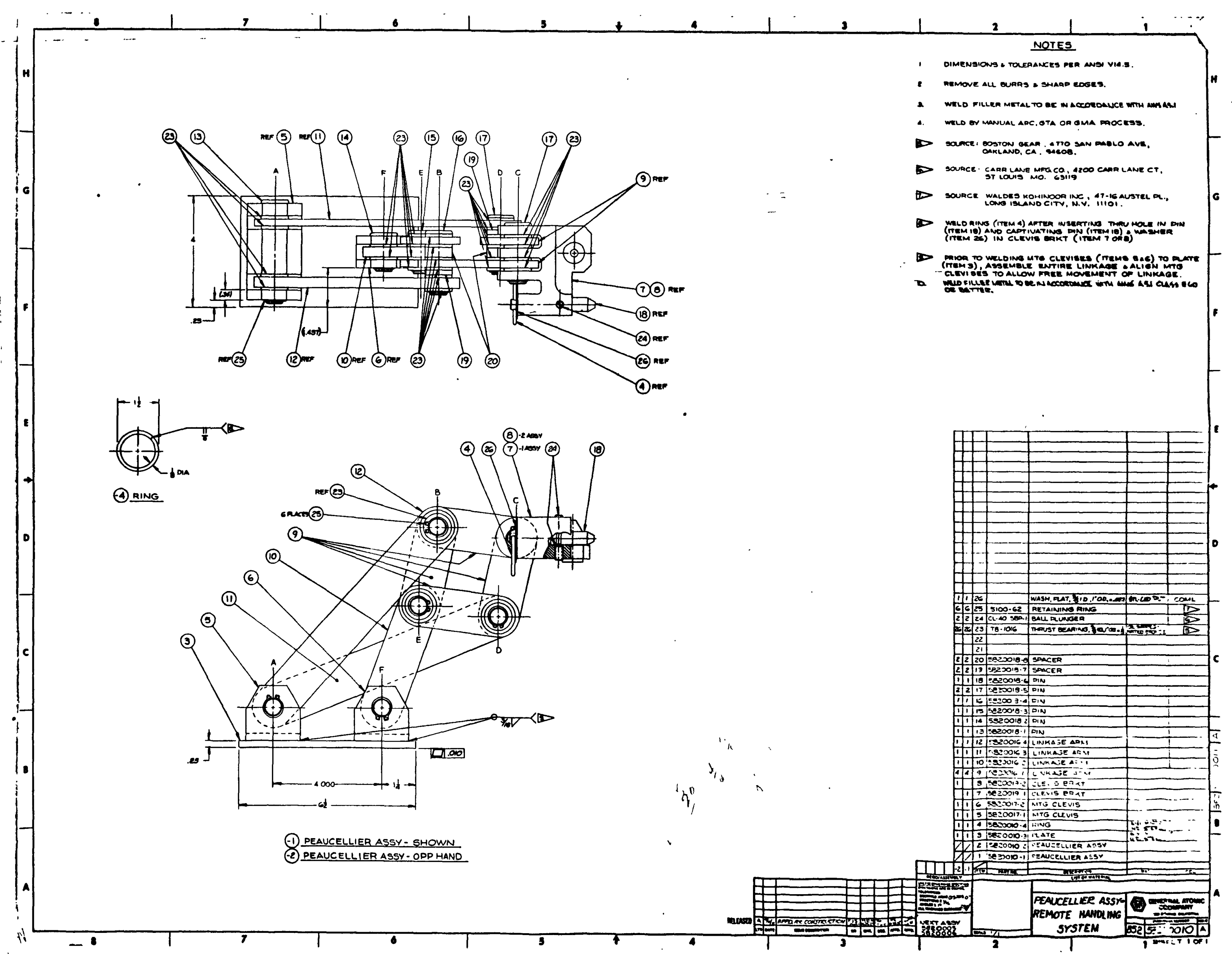


O. . . . . . . 0 


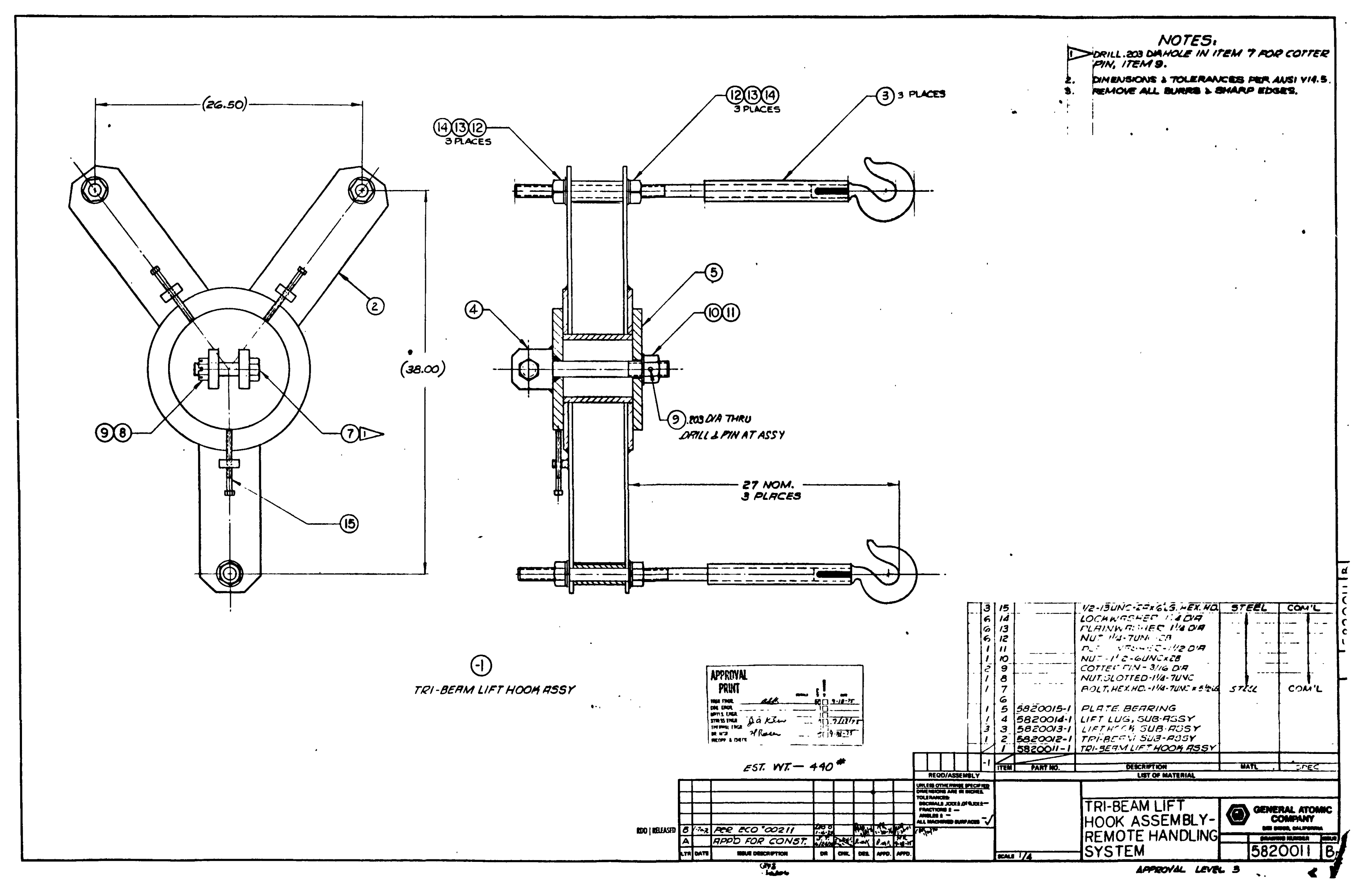






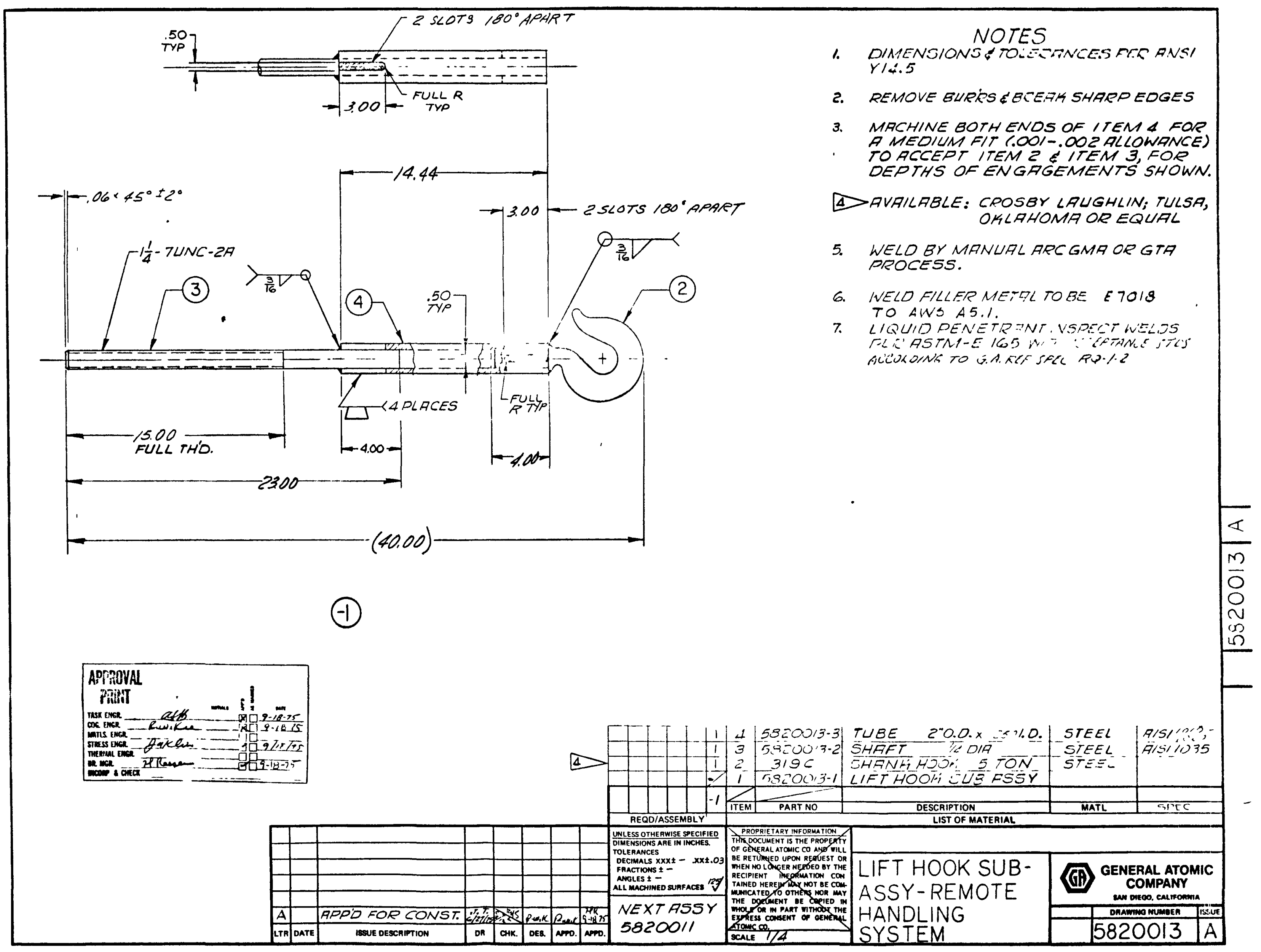





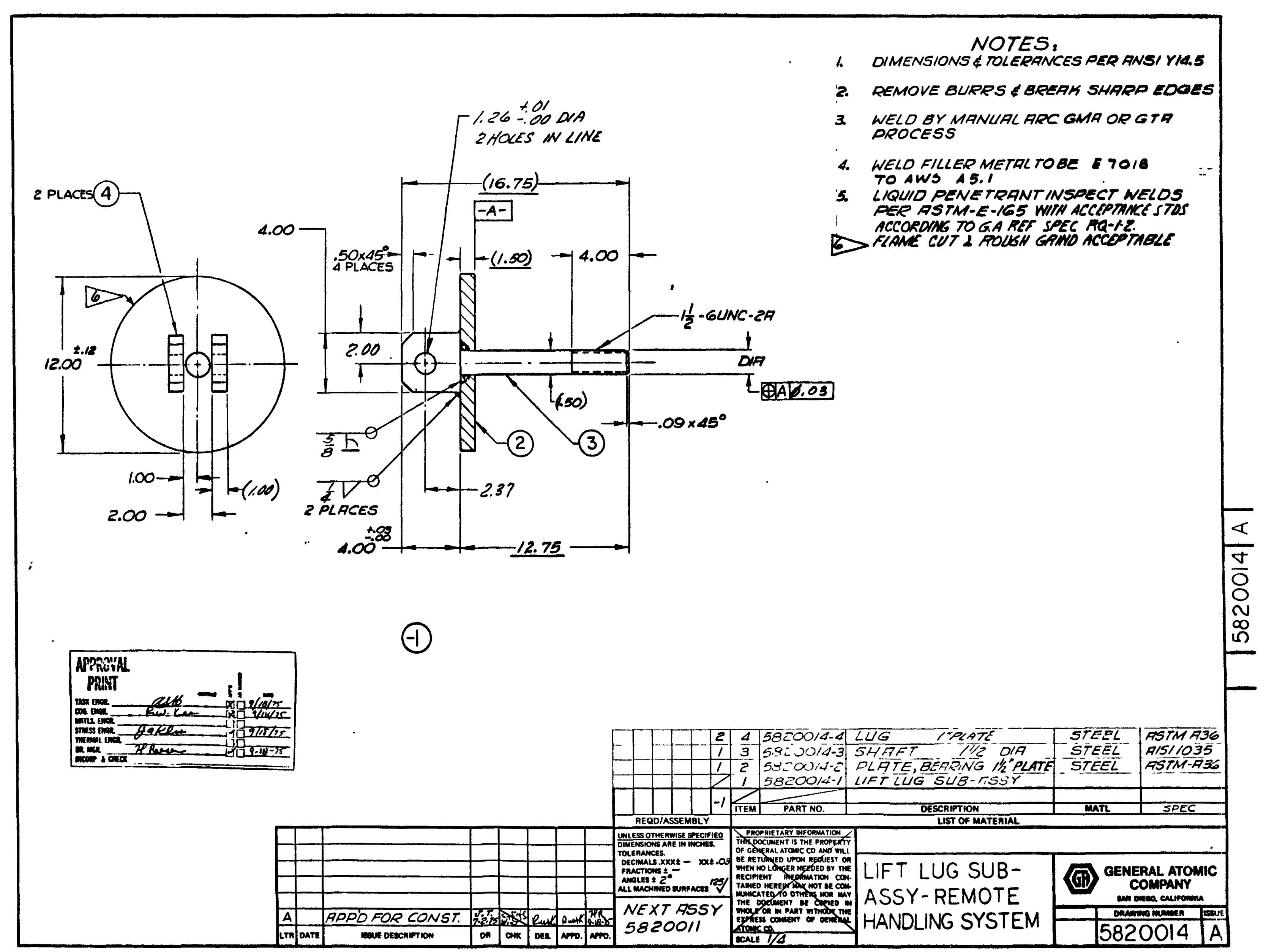


-

- 


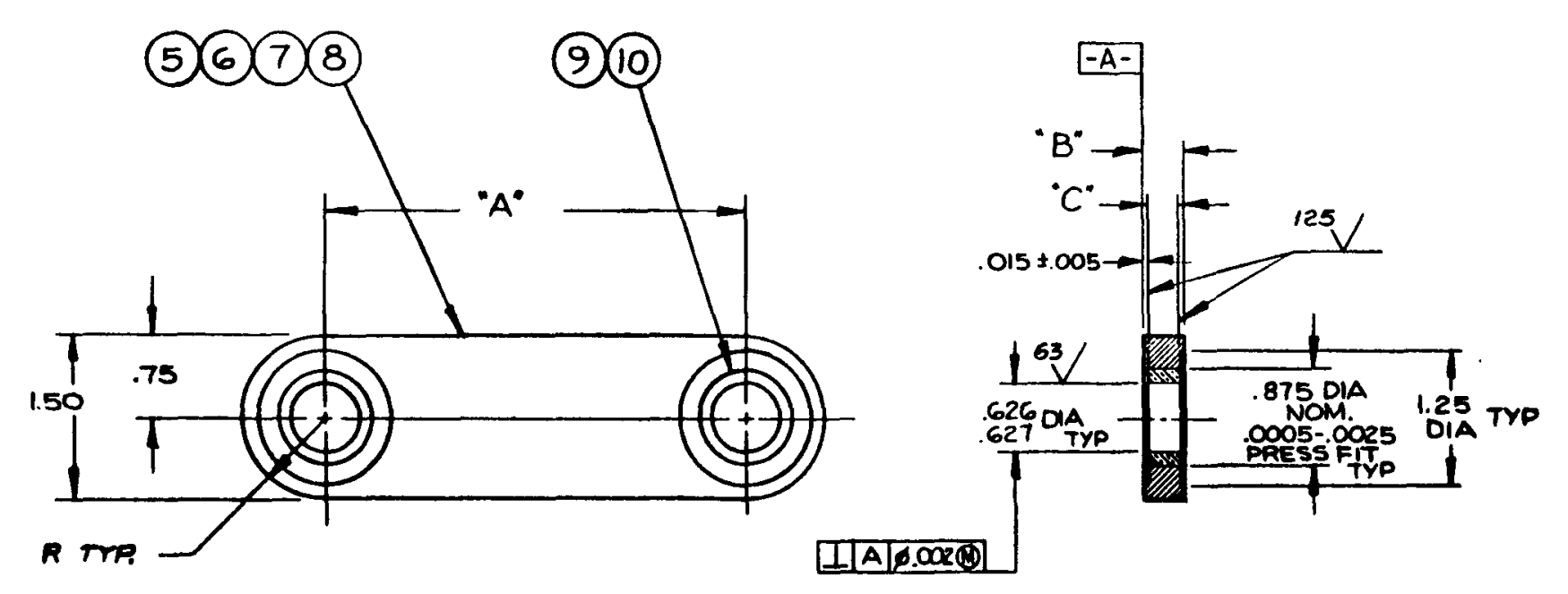

(1)-2(-3)-4) LINKAGE ARM ASST.

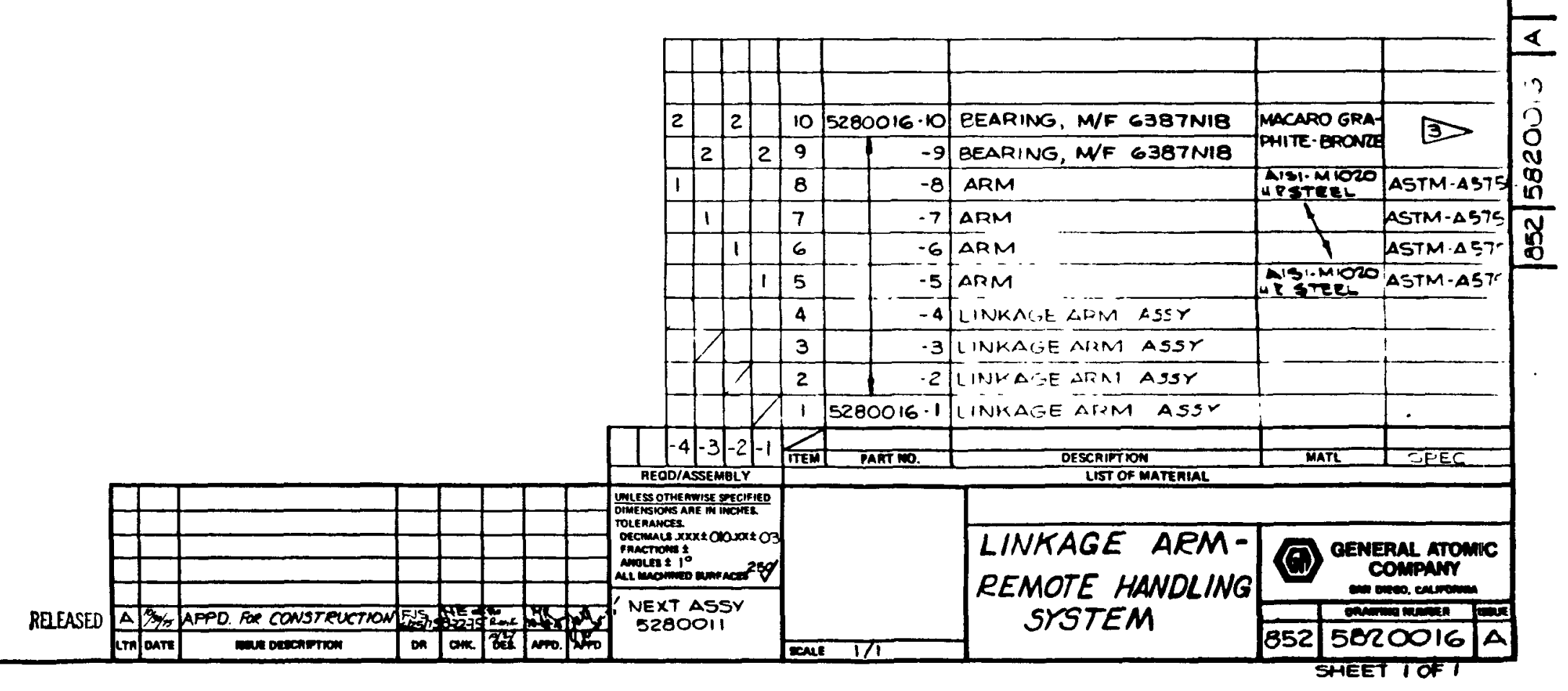



2. DMmensions \& TOLERANCES PER ANSI Y14.3.
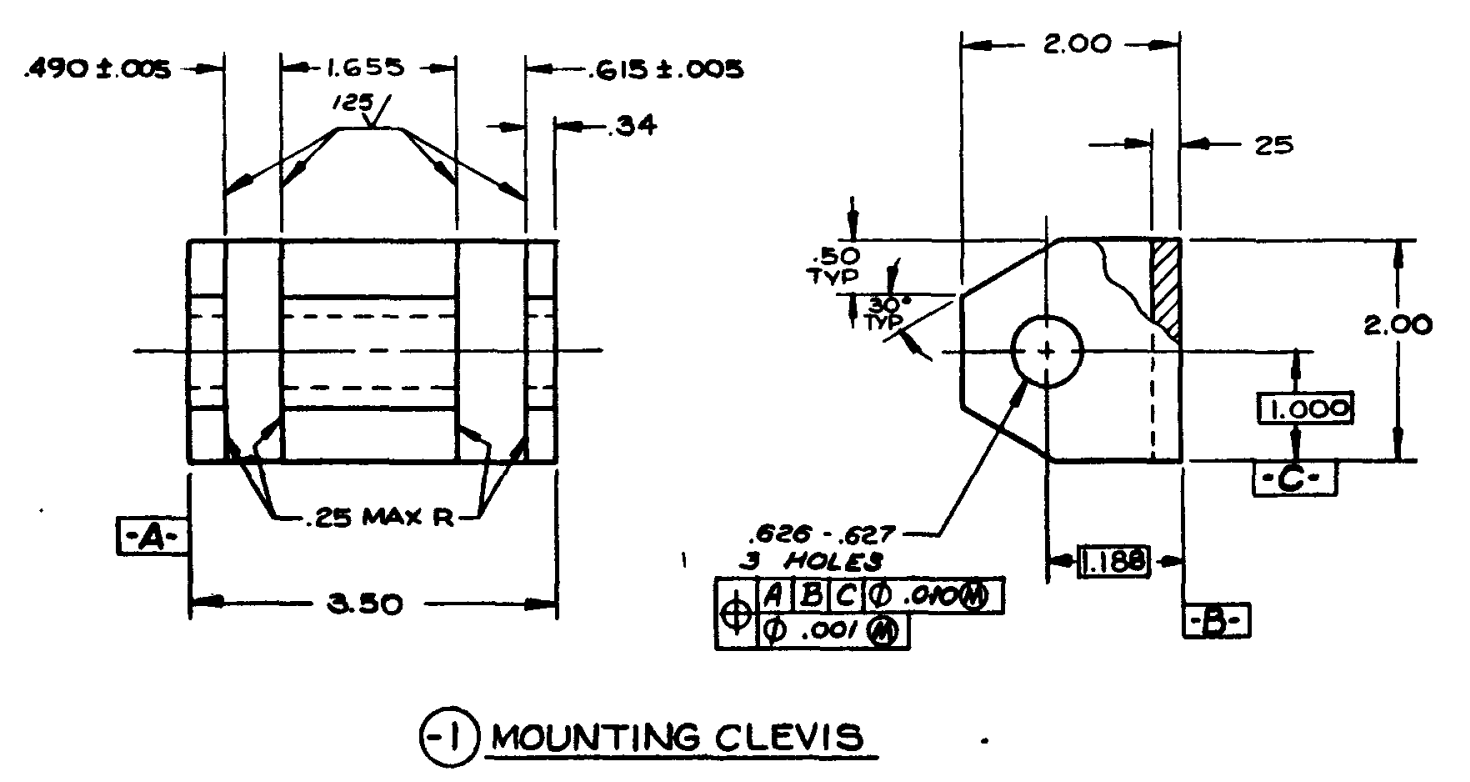

(1) MOUNTING CLEVIS
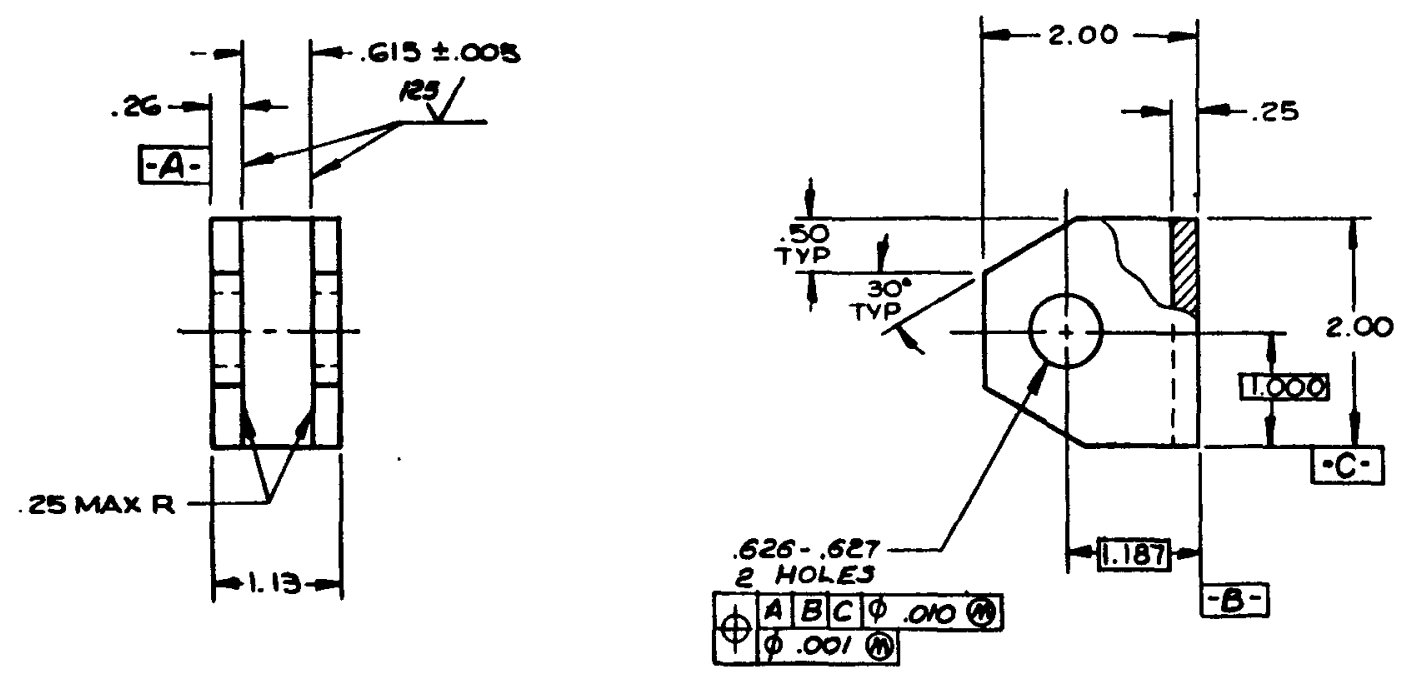

(-2) MOUNTING CLEVIS

5 $5820017-2$ MOUNTING CLEVIS

int Paner wo. 



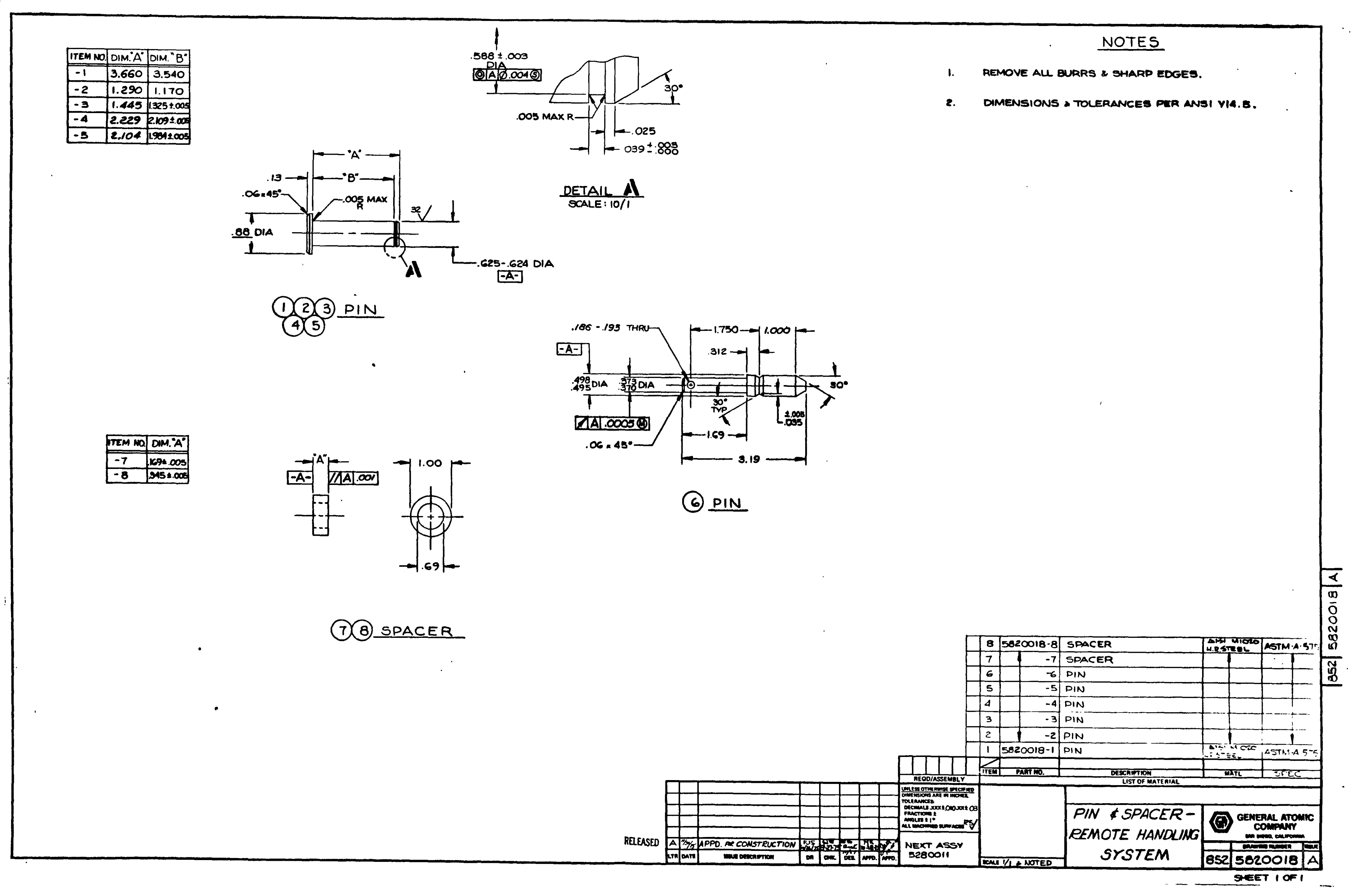


0 


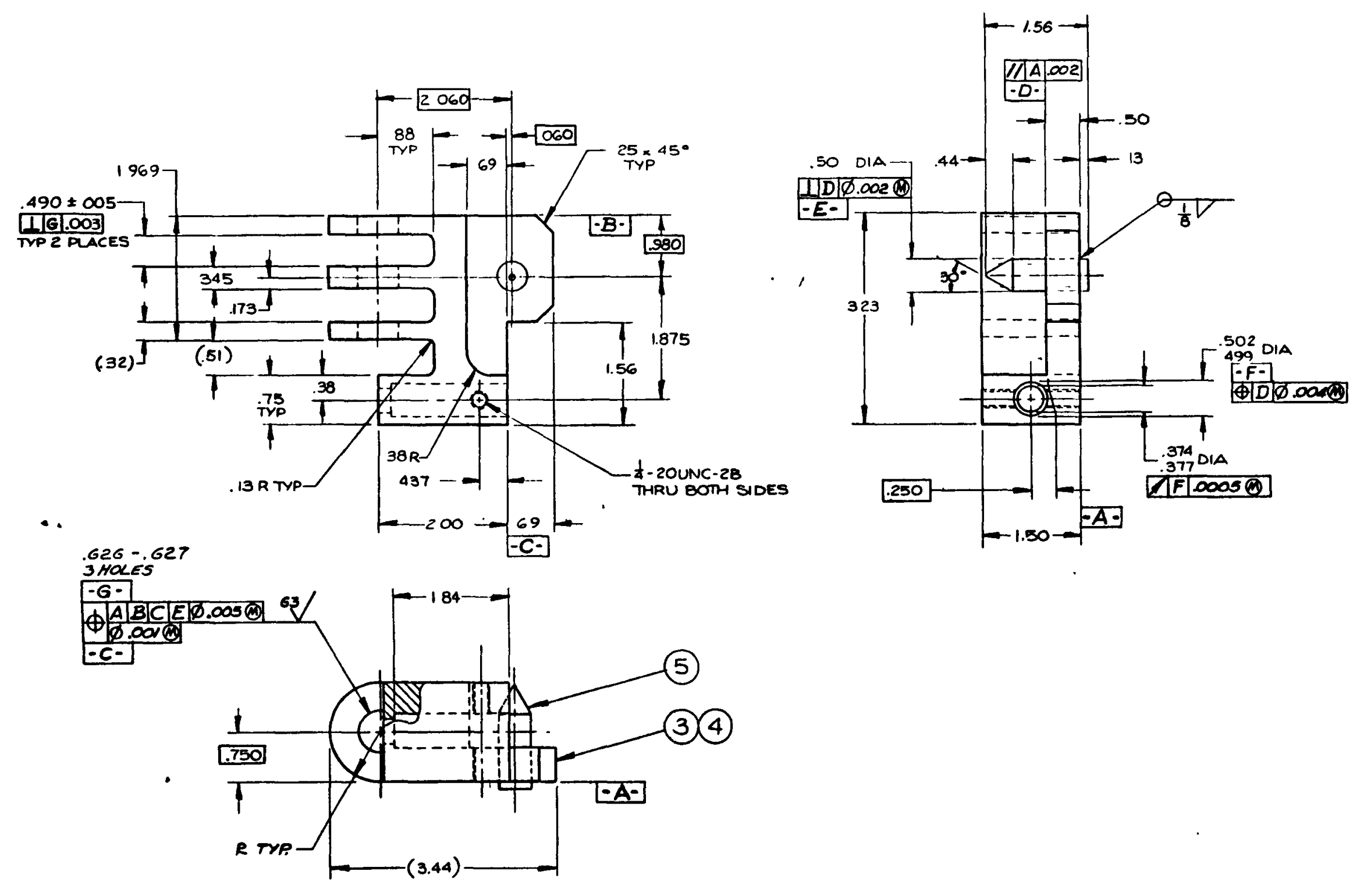

1. DIMENSIONS \& TOLERANCES PER ANSI Y14.5.

R. REMOVE ALL BURRS \& SHARP EDGES.

3. WELD FILLER METAL TO JE IN ACCORDANCE

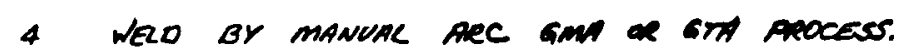

(1) CLEVIS BRACKET-SHOWN

(2) CLEVIS BRACKET-OPP HAND

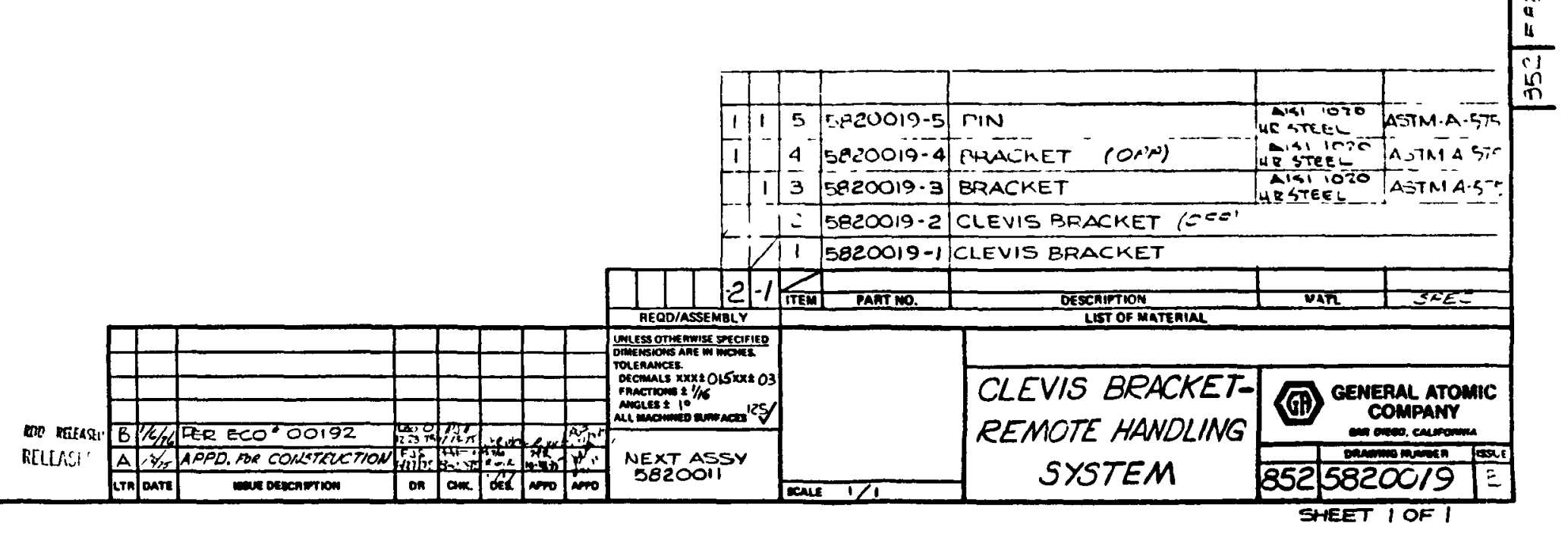


. . . . . . 

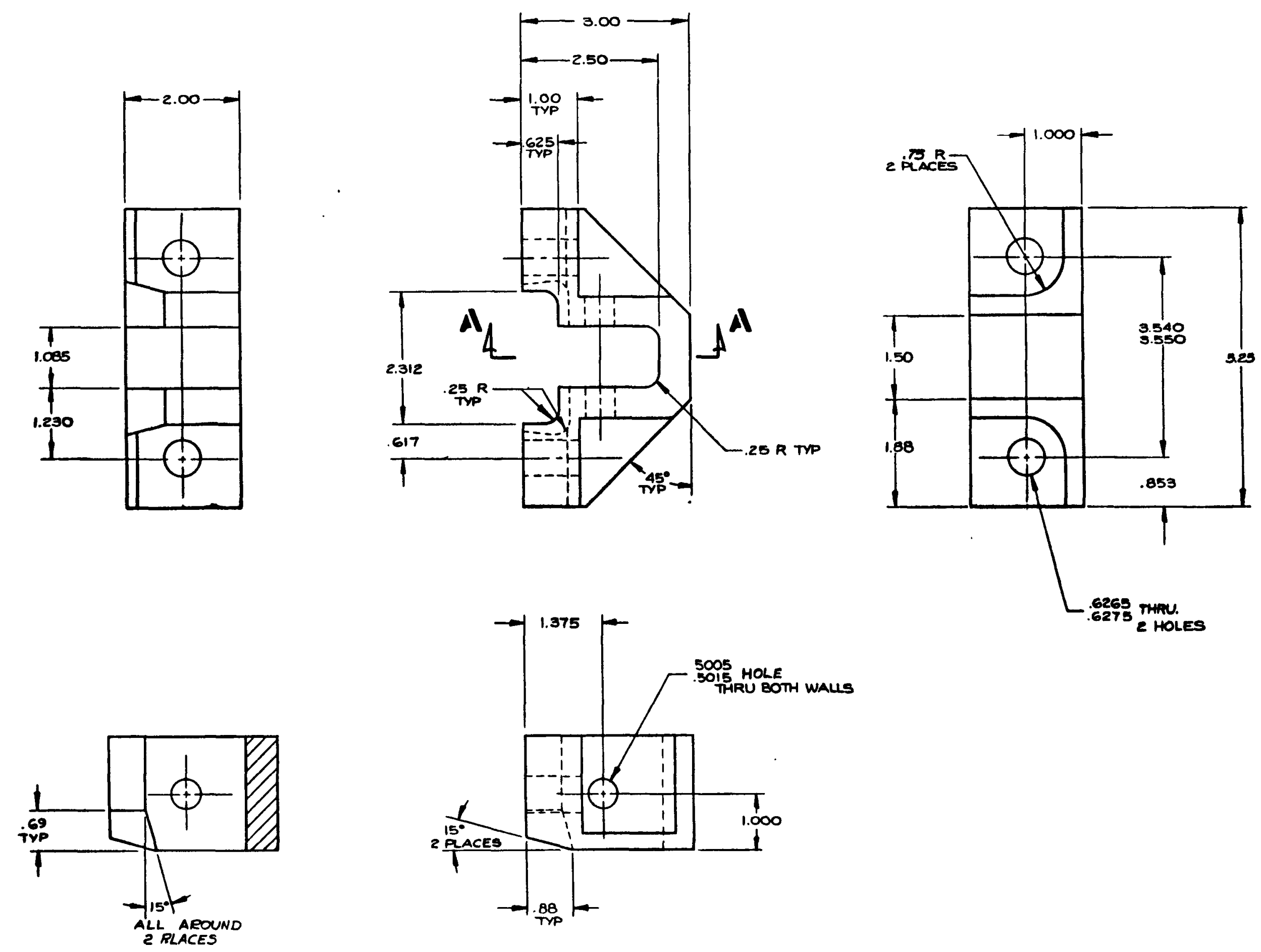

1. Remove ALl BurRS a SHARP EDGES.

DIMENSIONS \& TOLERANCES DER ANSI YIA.5 SECTION A-A

(1) MOUNTING YOKE

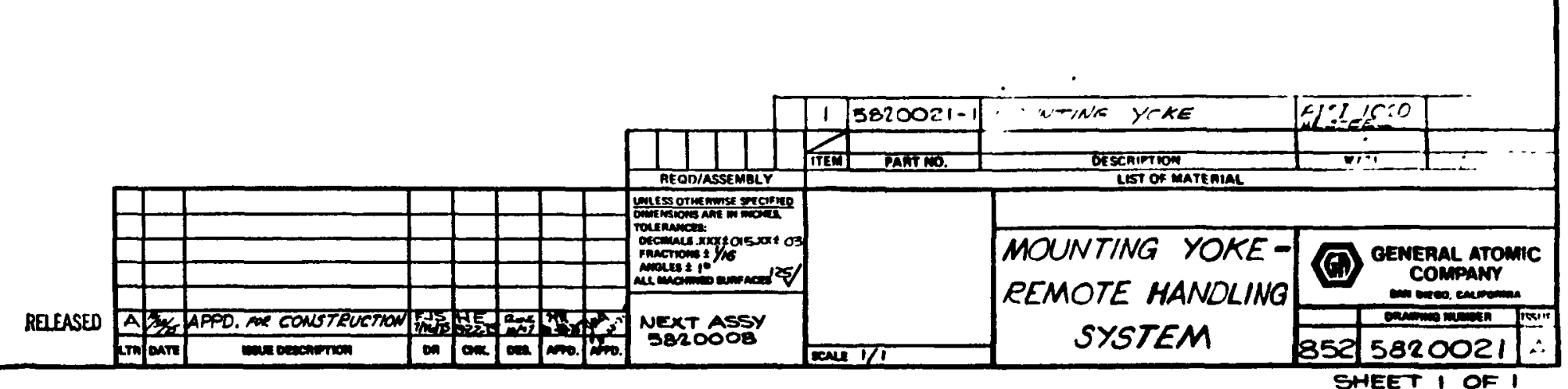


○. . 0 
1 DIMENSIONS $\%$ TOLERANCES DER ANSI YIA.E.

2. REMOVE ALL BURRS \& SMARP EDGES.

3. AFTER MACHINING, HEAT TREAT TO 190,000 P.S.I.
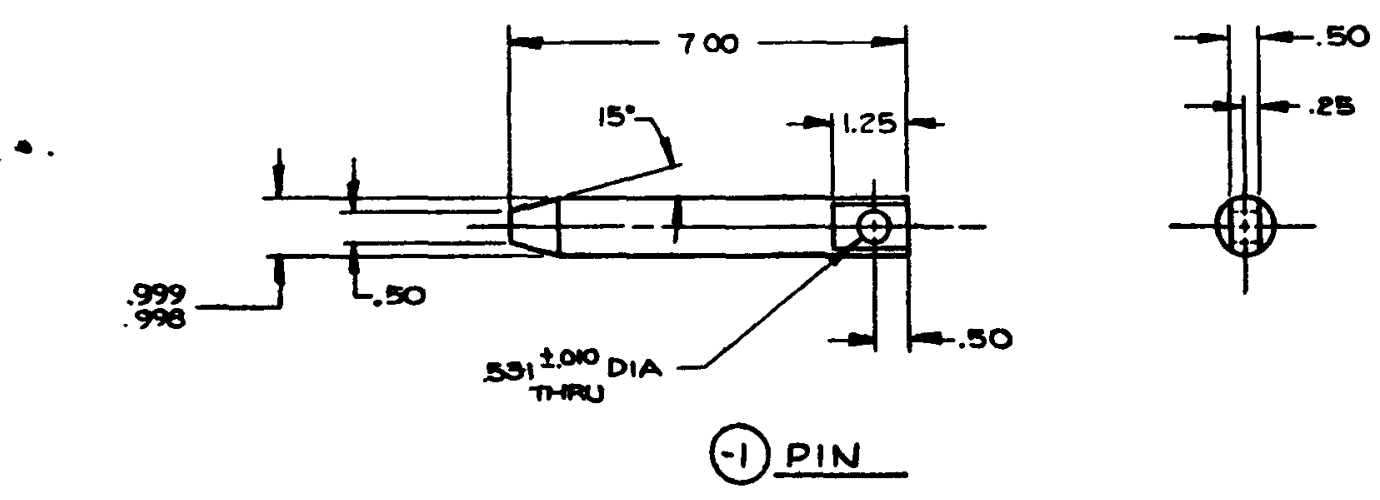

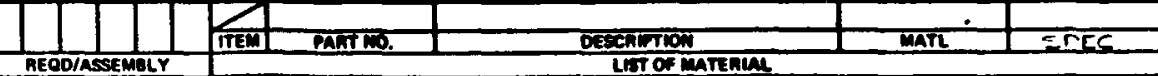


-

- 


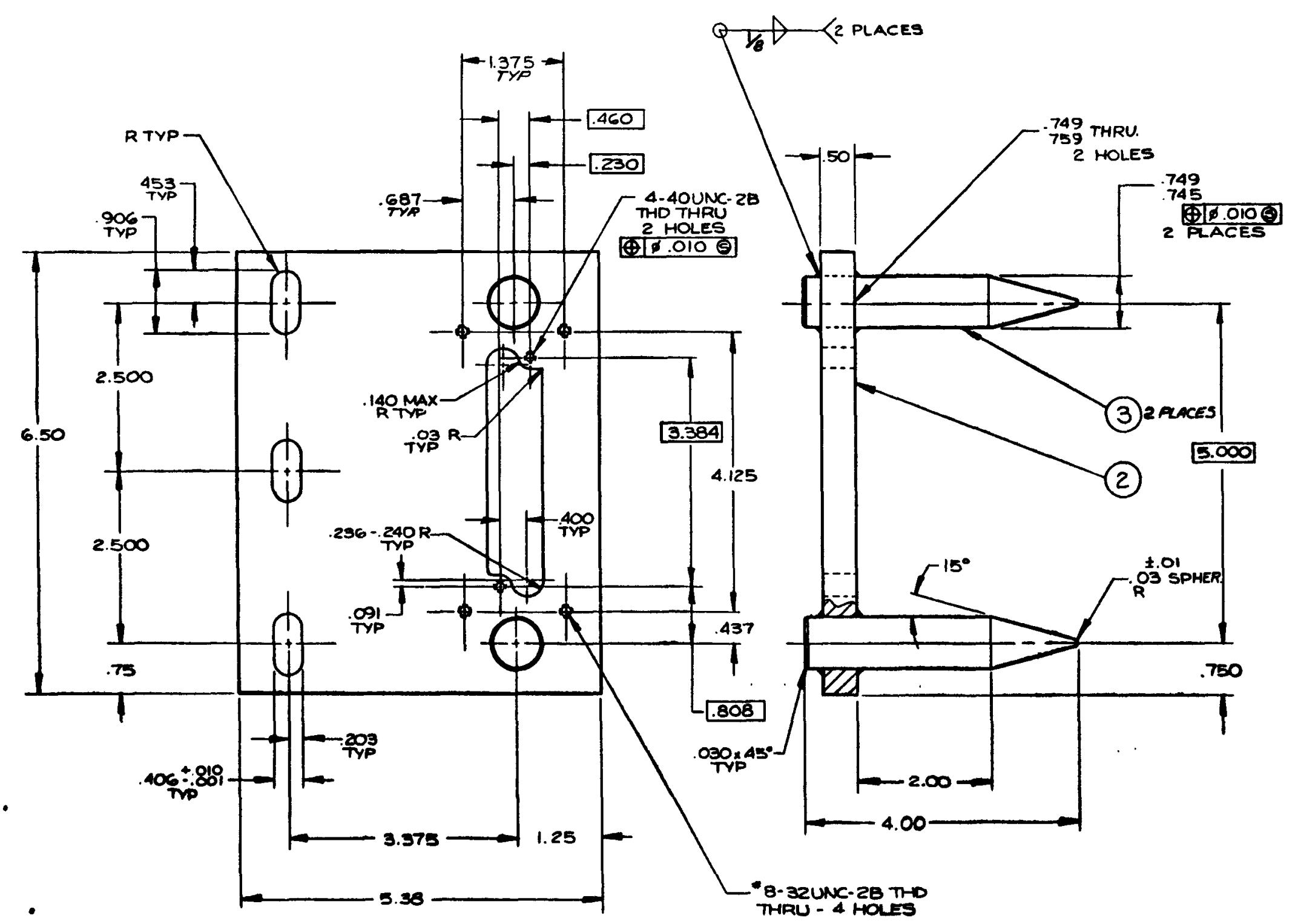

DIMENSIONS * TOLERANCES DER ANSI Y14.5.

PEMOVE ALL BUPRS * SHARP EDGES.

3. WELD BY MANUAL AFC, gTA OR GMa pRocess

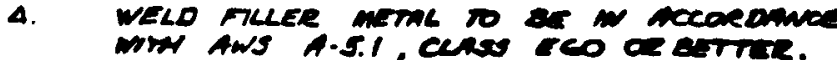

(1) Platerpinassy

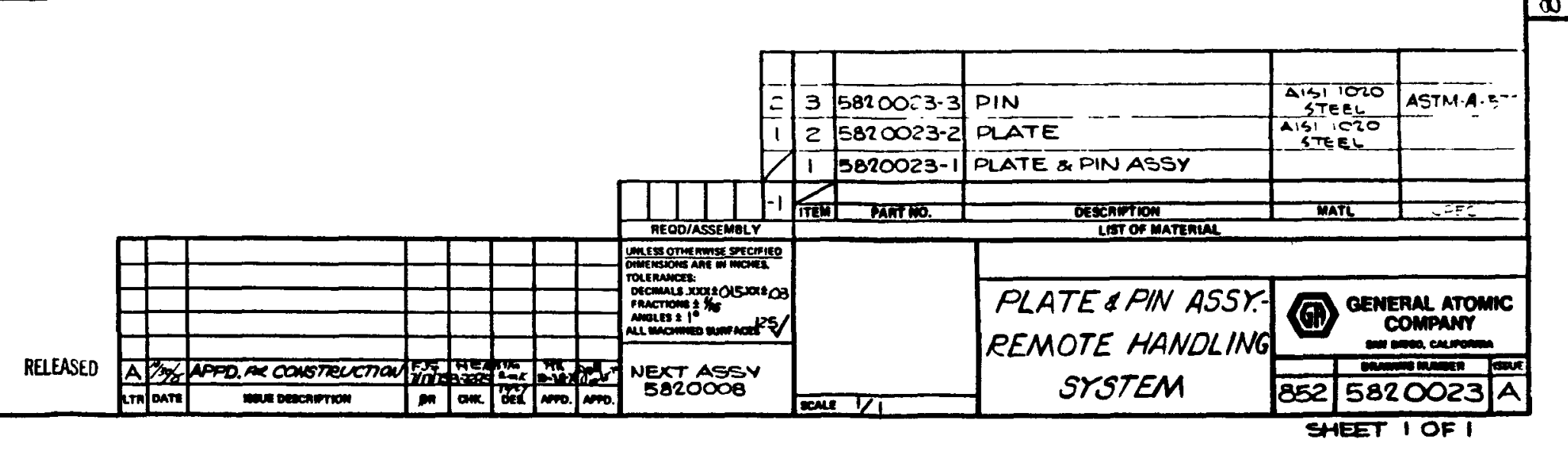


○. . . . 


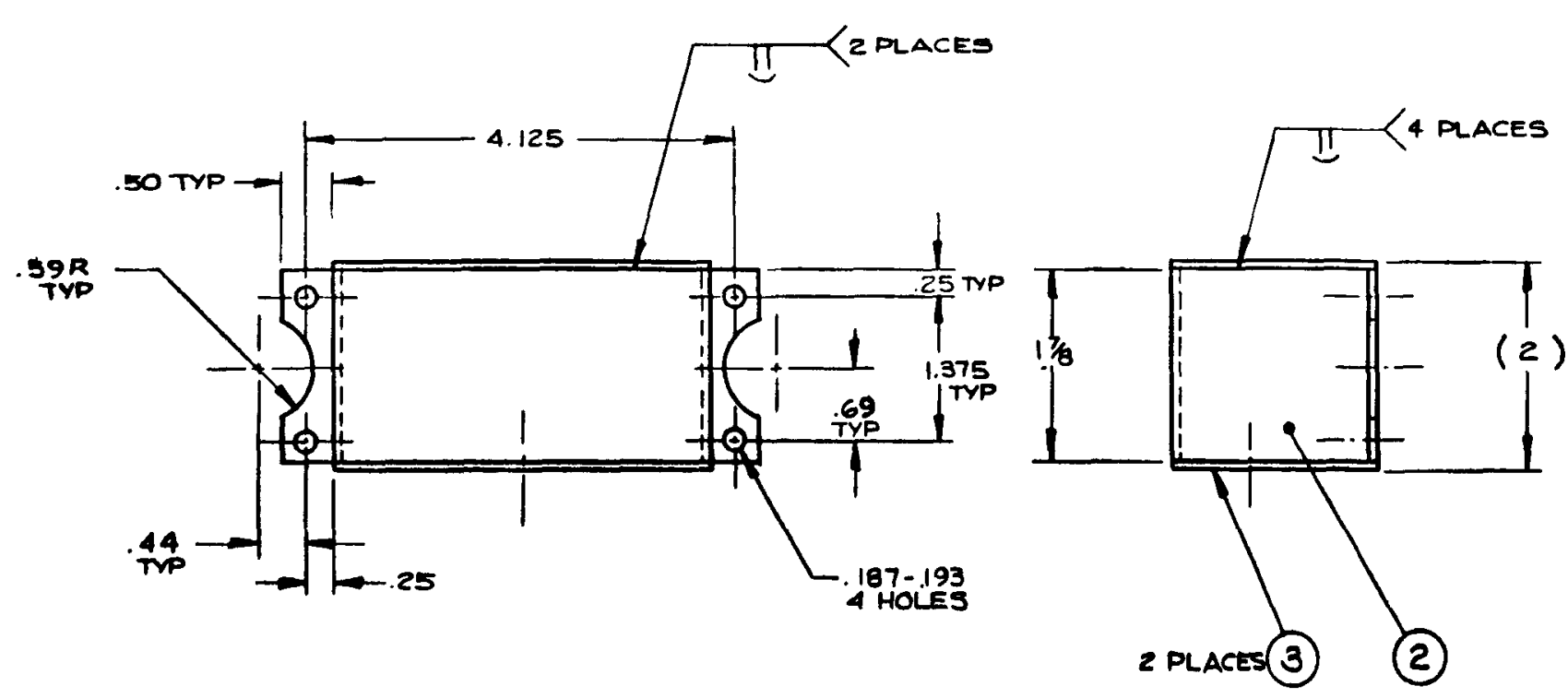

1. DIMENSIONS \& TOLERANCES PER ANSI YIA.5.

2. REMOVE ALL BURRS 2 SHARP EDGES.

3. WELD BV MANUAL ARC, gTA OR GMA DROCESS.

4. WELD FIULR METAL TOBE AWS TUPE 5356.

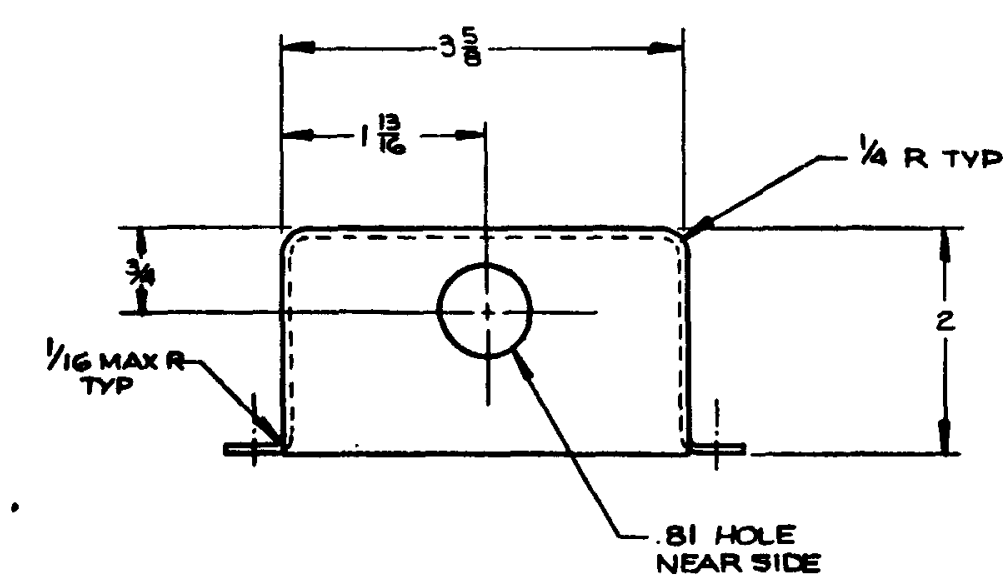

(1) CONNECTOR BOX

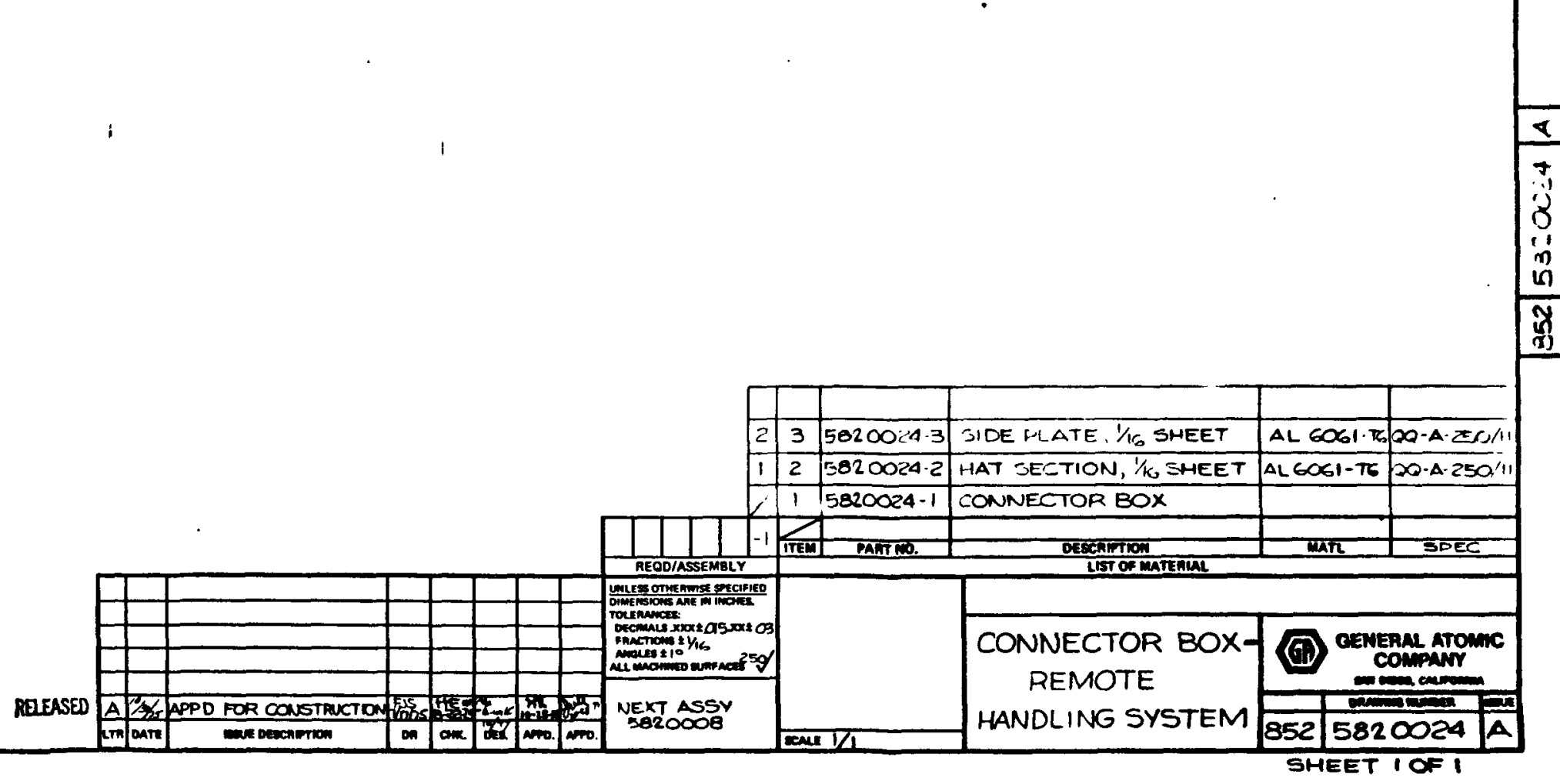


○. . 0 


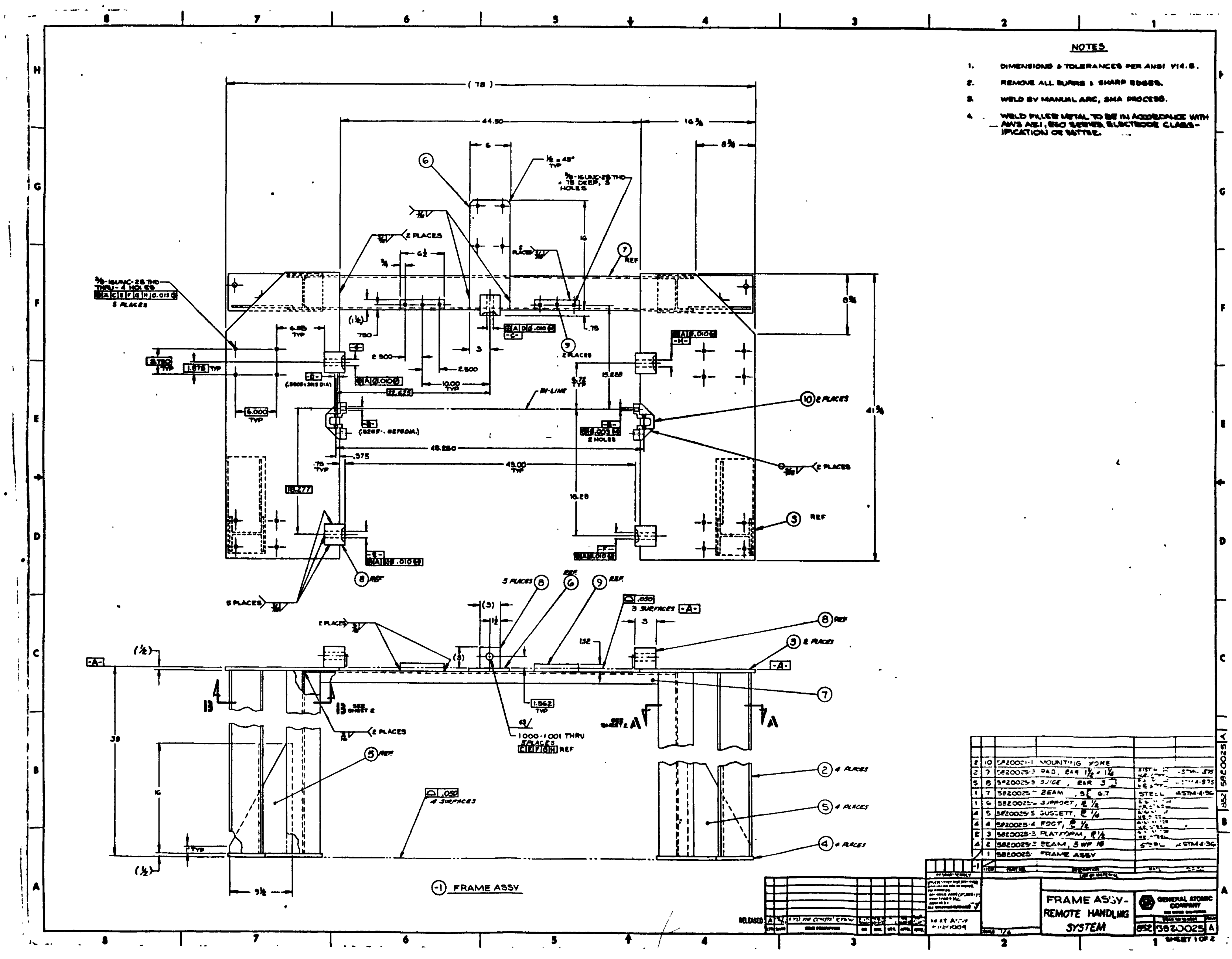





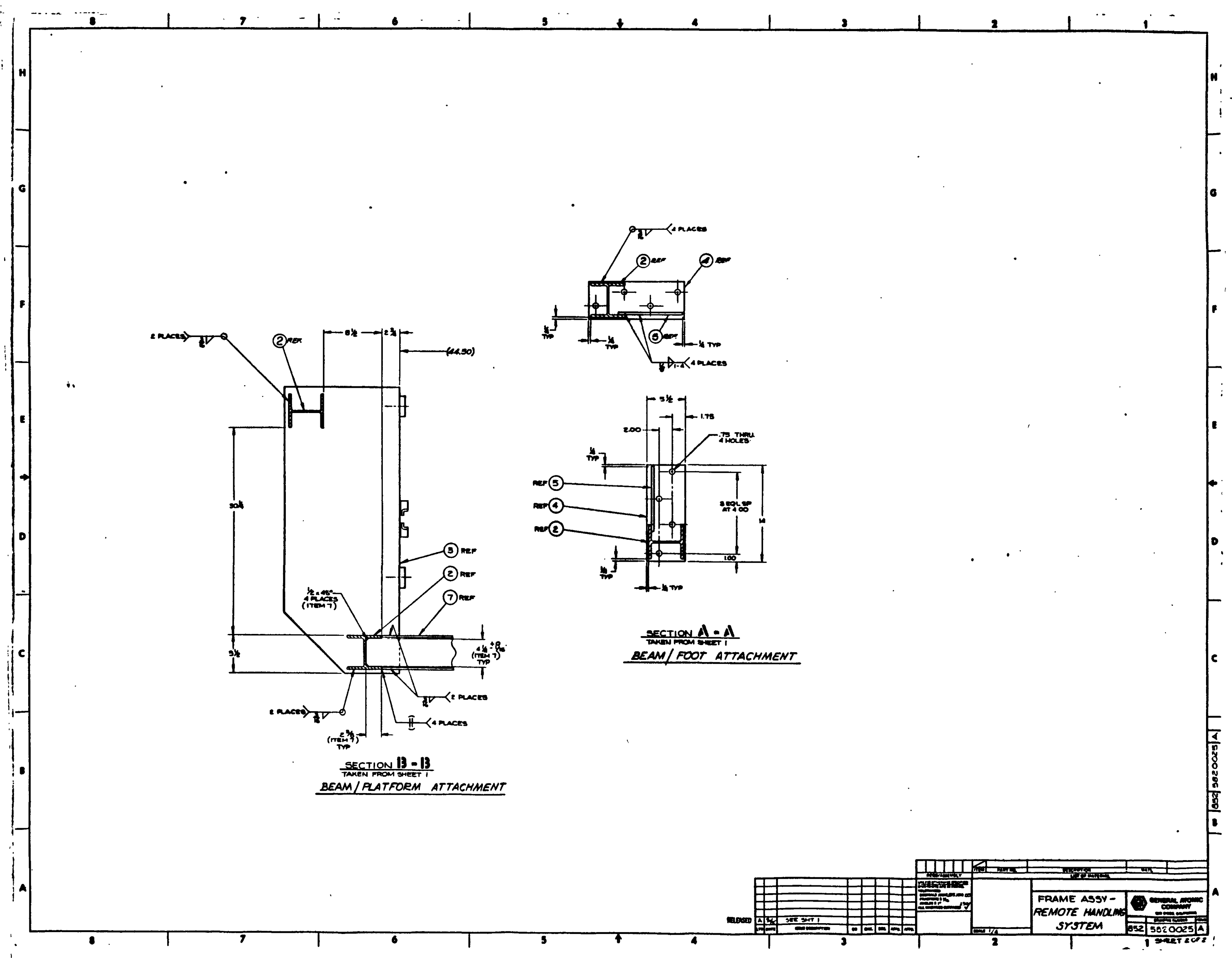


. . . . . . 


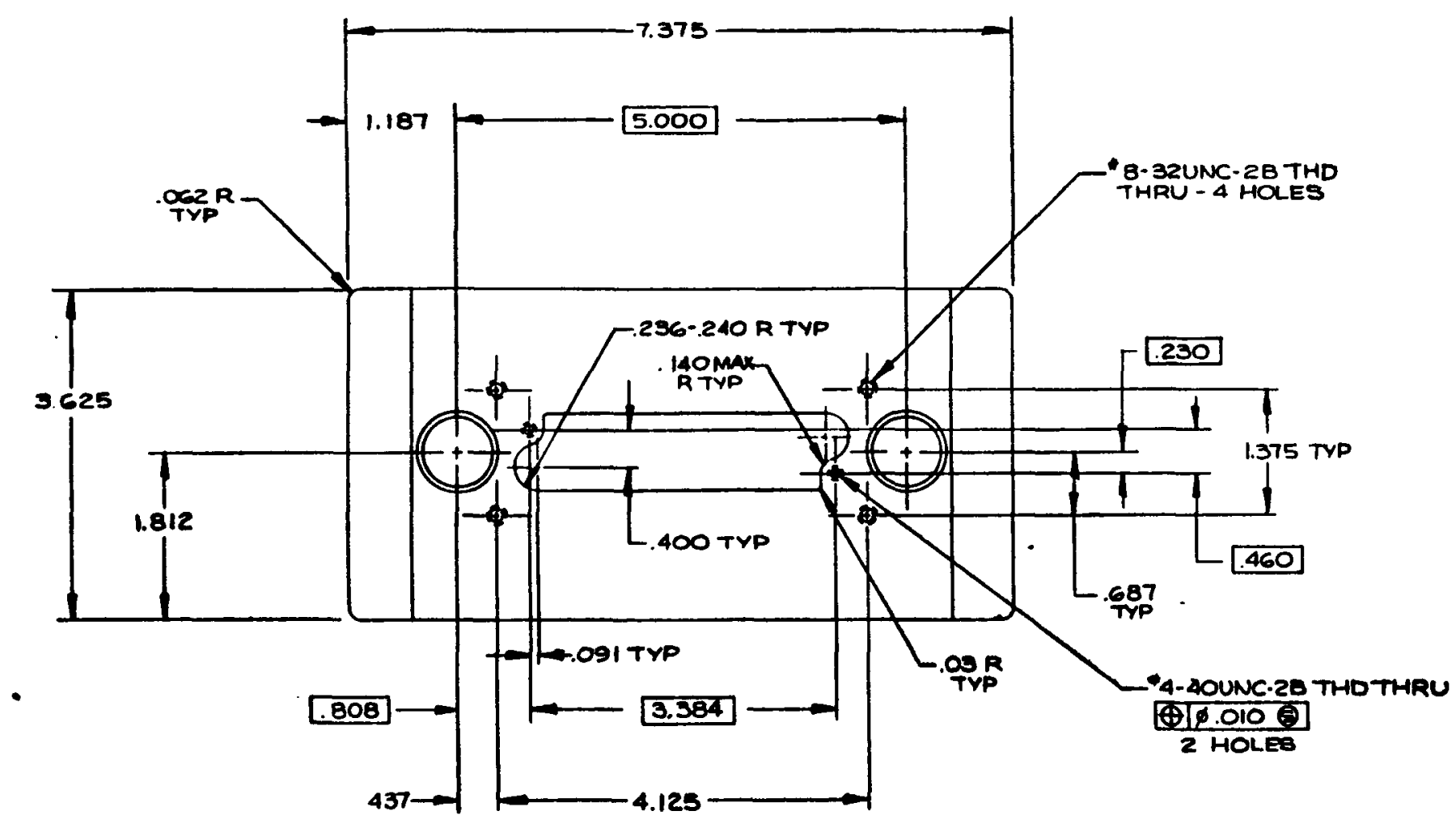

1. DIMENSIONS \& TOLERANCES PER ANSI Y14.5.

2. REMOVE AU EURPS a SMRP EDOES.

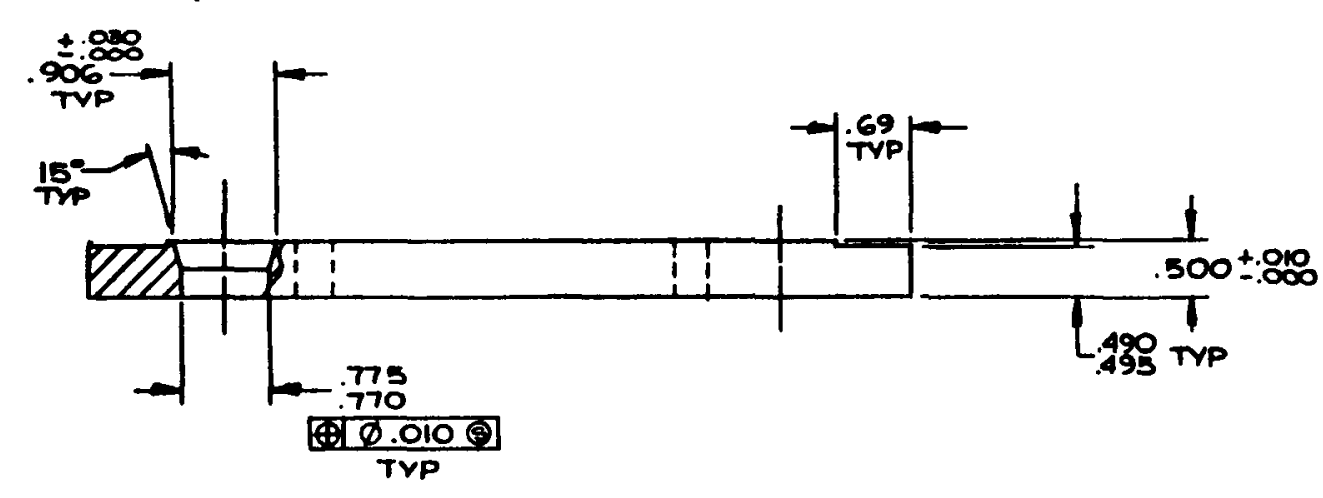

(1) MOVABLE PLATE

$15820026-1 \mid$ MOVABLE PLATE

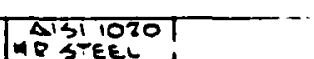

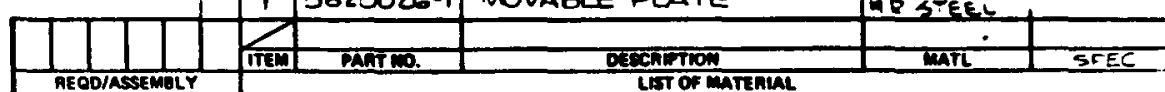


- . 0 

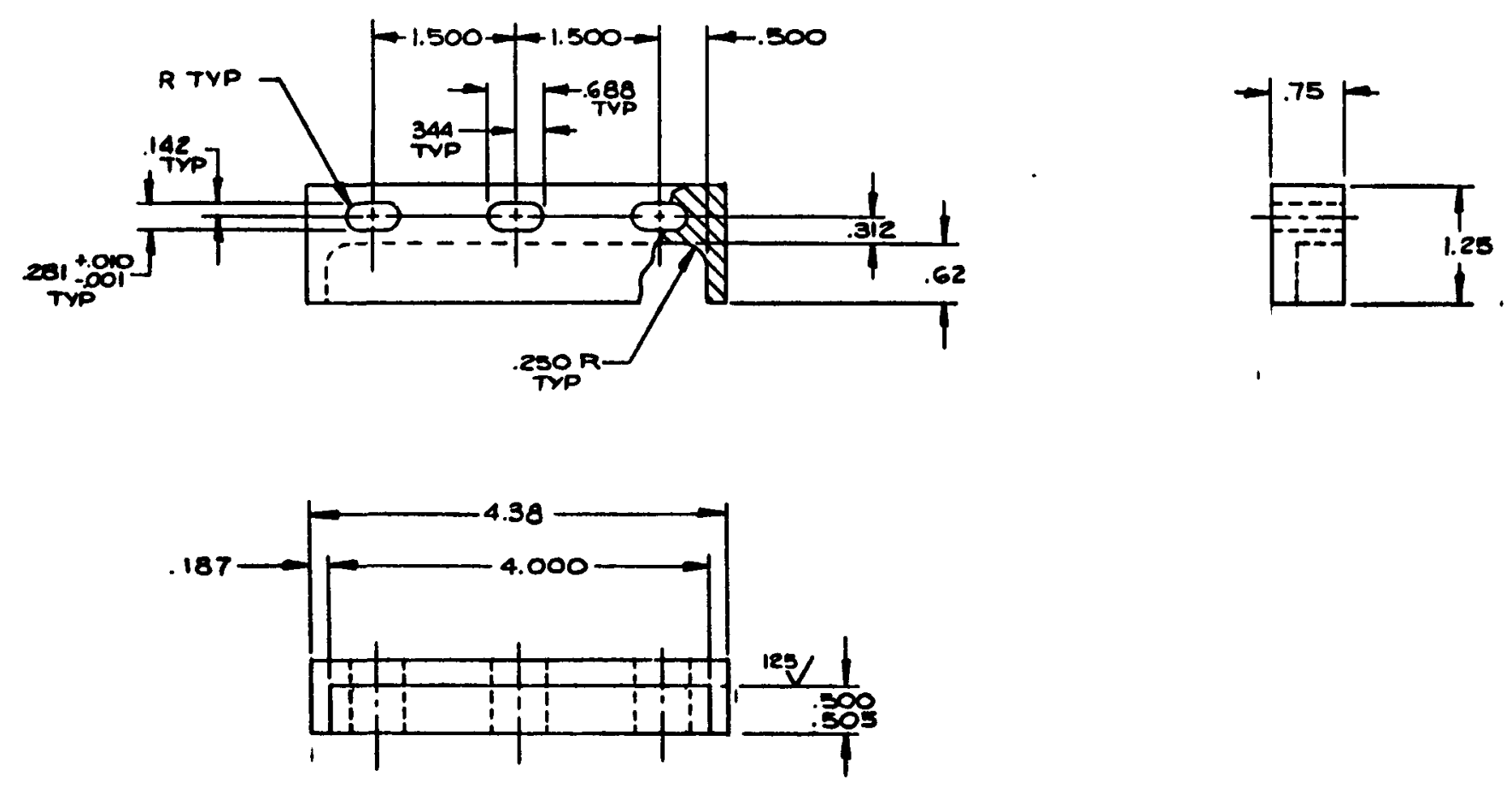

(1) RETAINER BLOCK

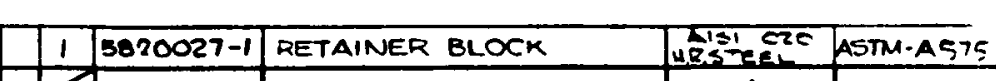

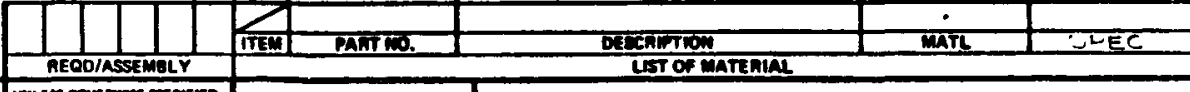

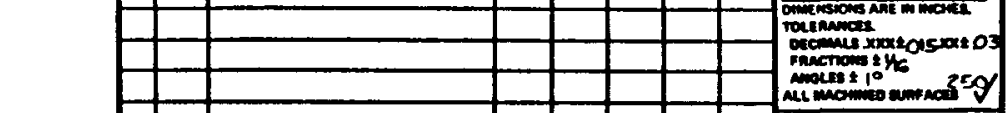


. . . . . . . O 


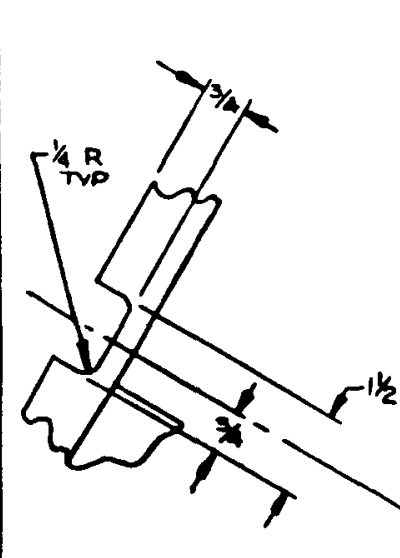

3/4.16UNF-2B THO THRU
TTEM $2-3$ PACES

(5)

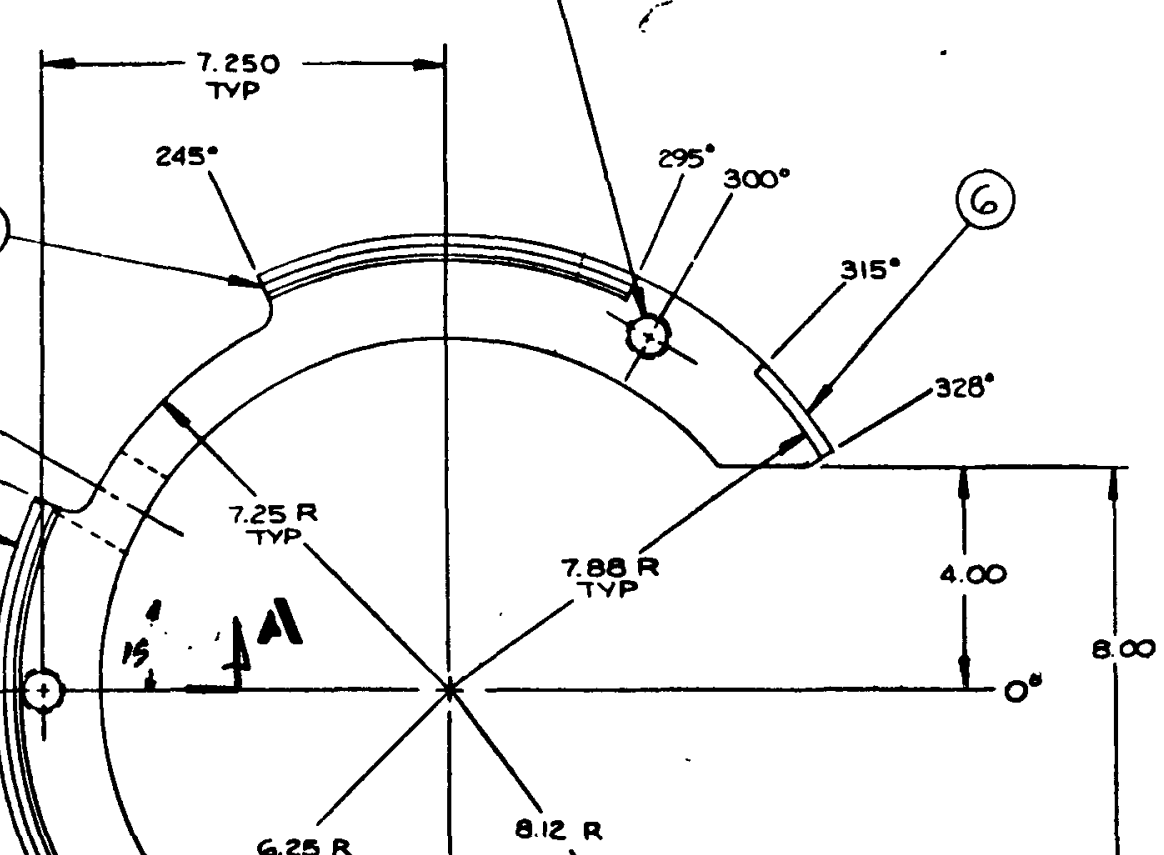

4 4
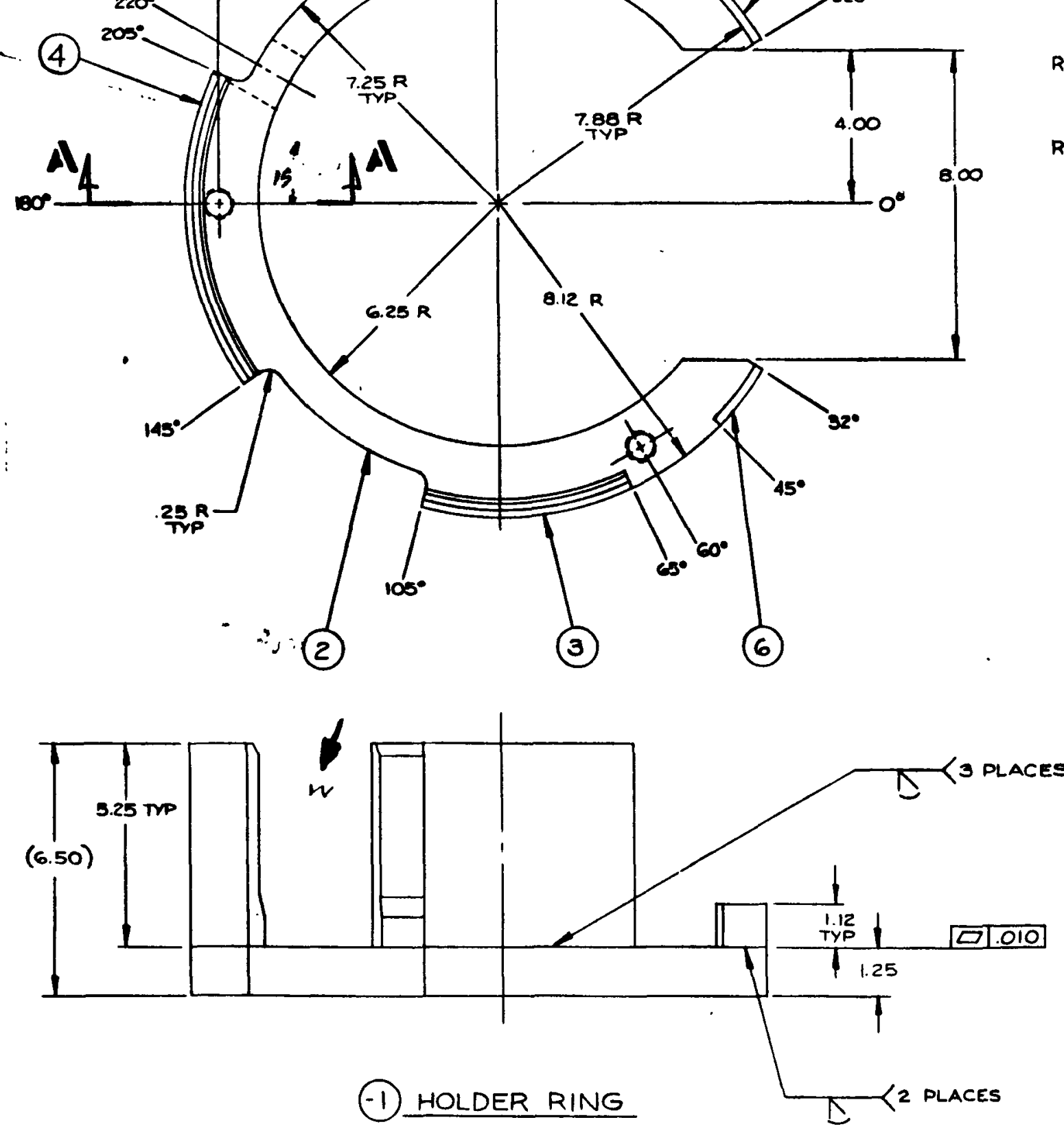

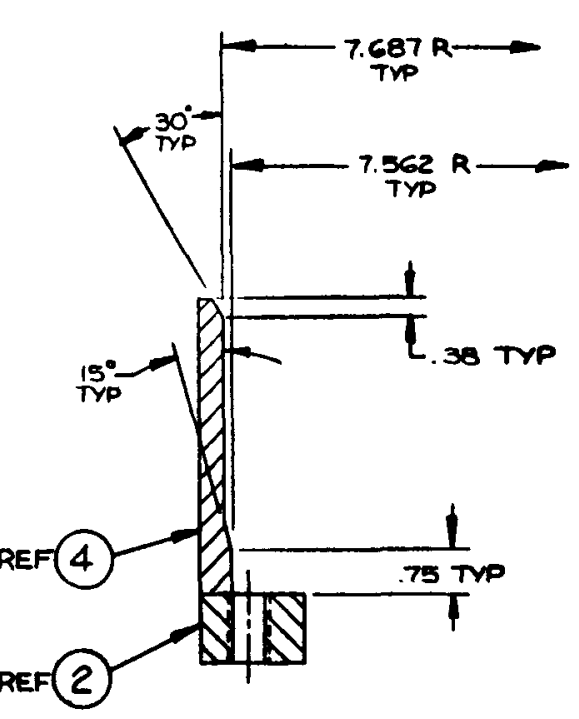

SECTION A-A

5
DIMENSICNO \& TOLERANCES PER ANSI YIA.5.

remove all burRs \& sharp edoges.

3. Weld bY manUAL ARC, gTA OR GMa PRocess

4 WELD FILLER METAL to Be IN ACCOEDance

5. WQUID PENETRANT INSPECT WELOS DER ASTM EIGE SECTION YII OF MSME BOU

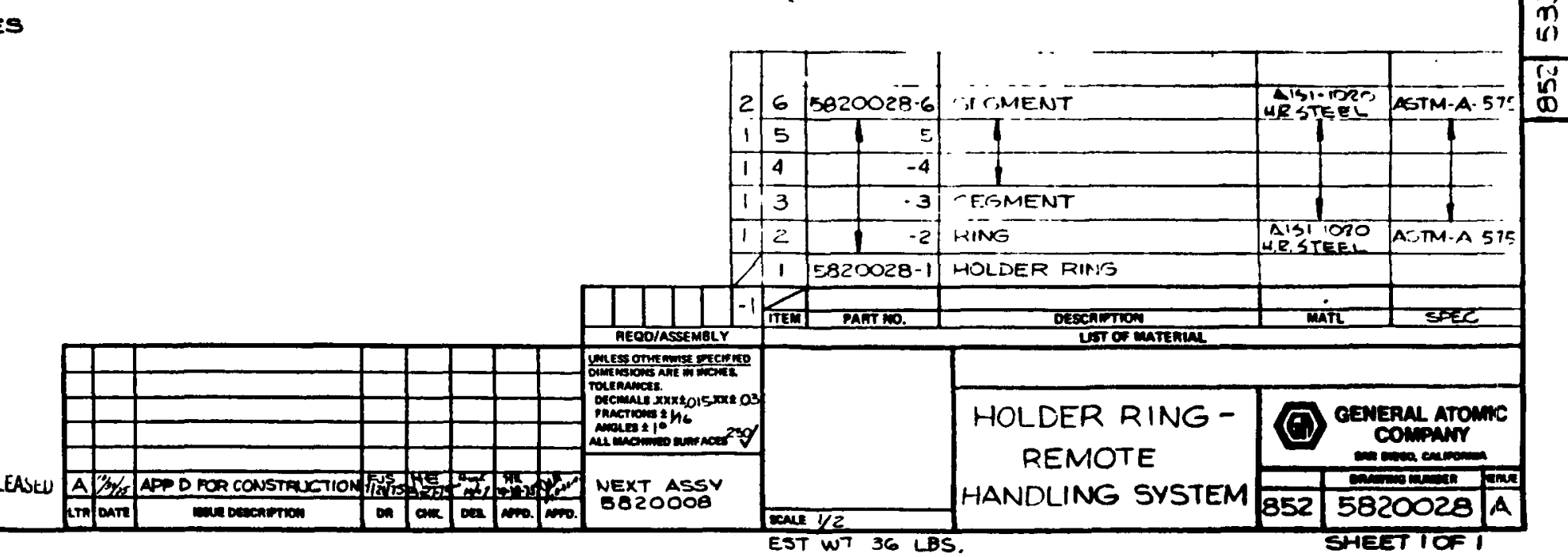


○. . . . . 0 


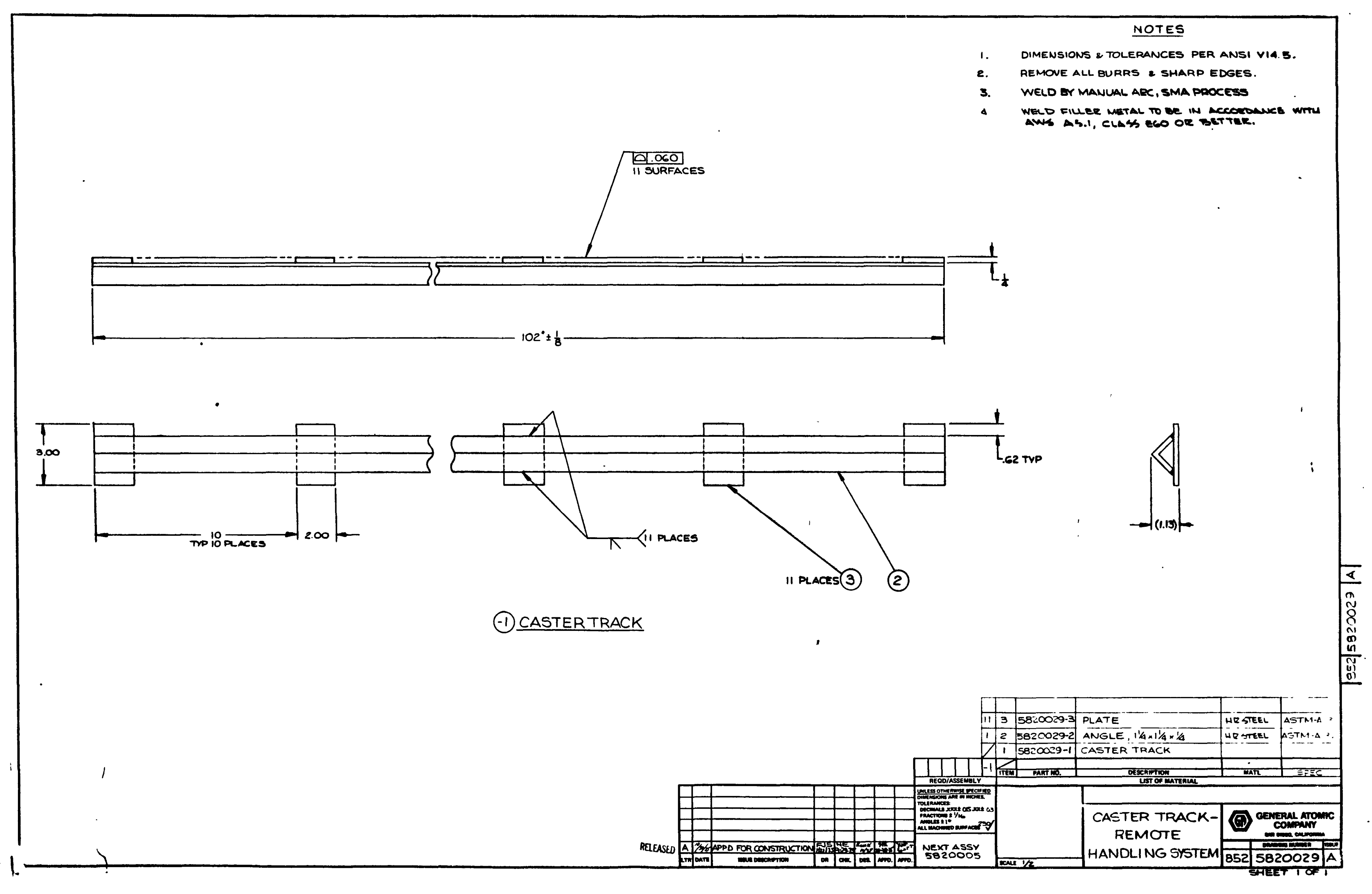


0

0 


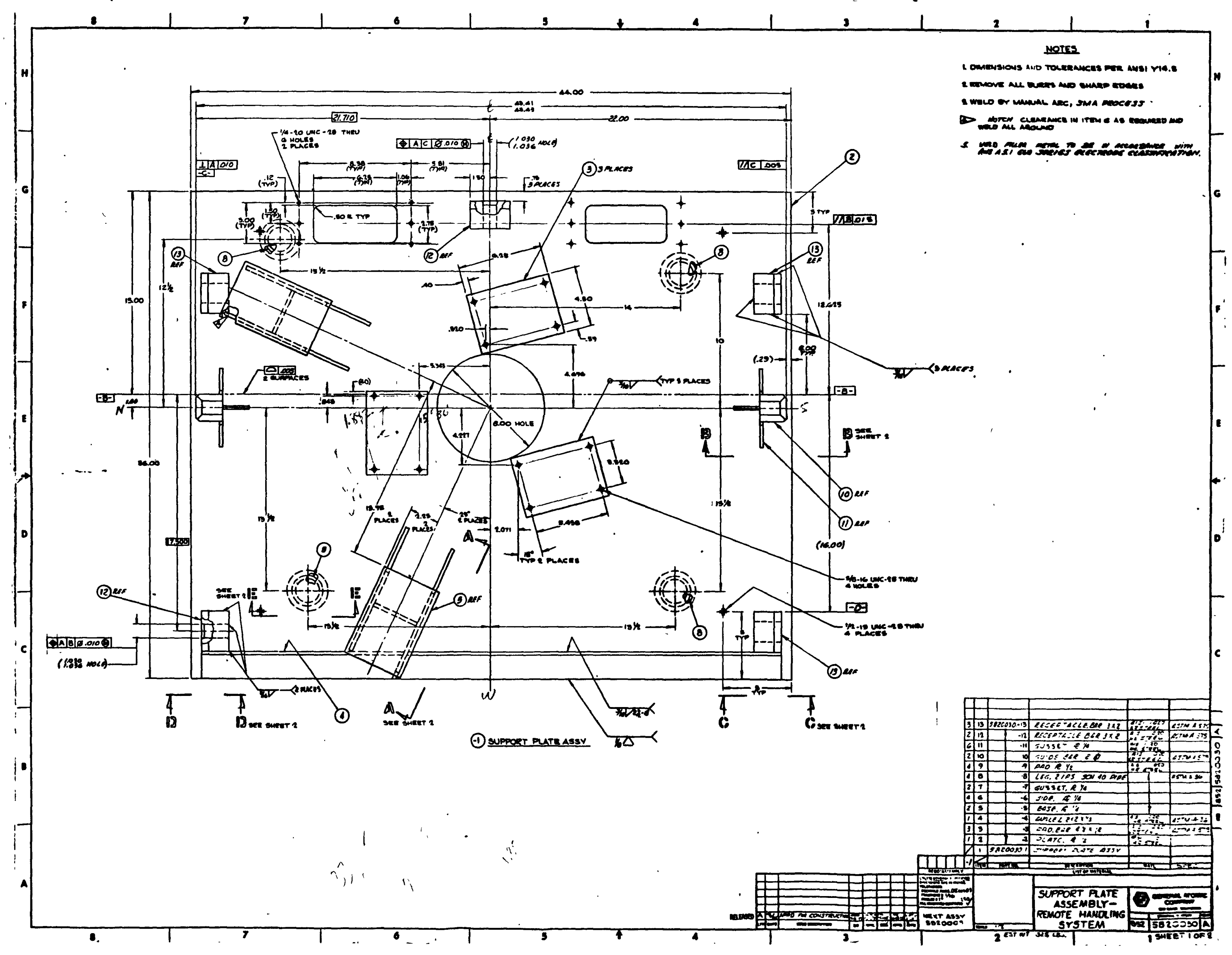


O. . . . . 0 


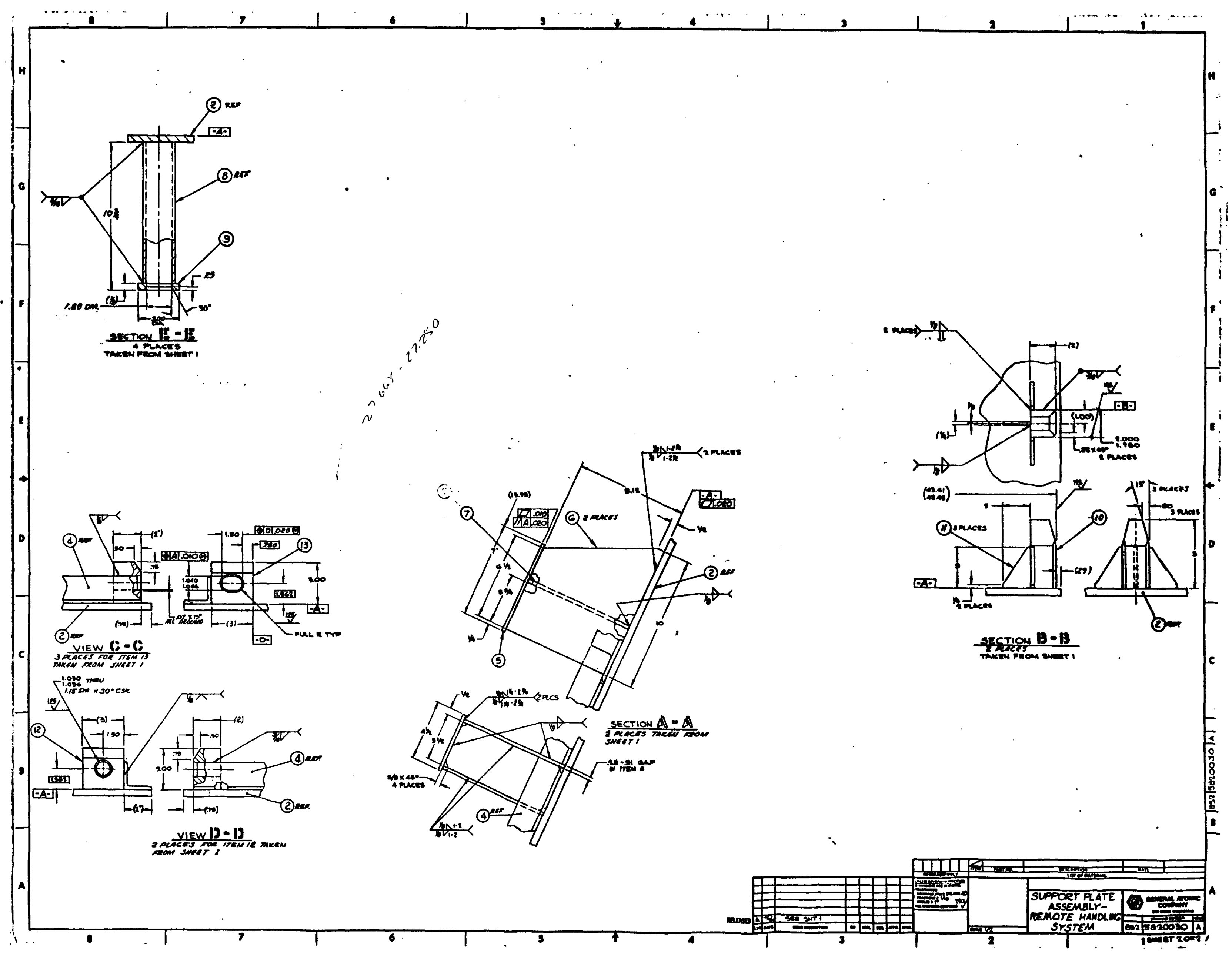


O. . . . . . 


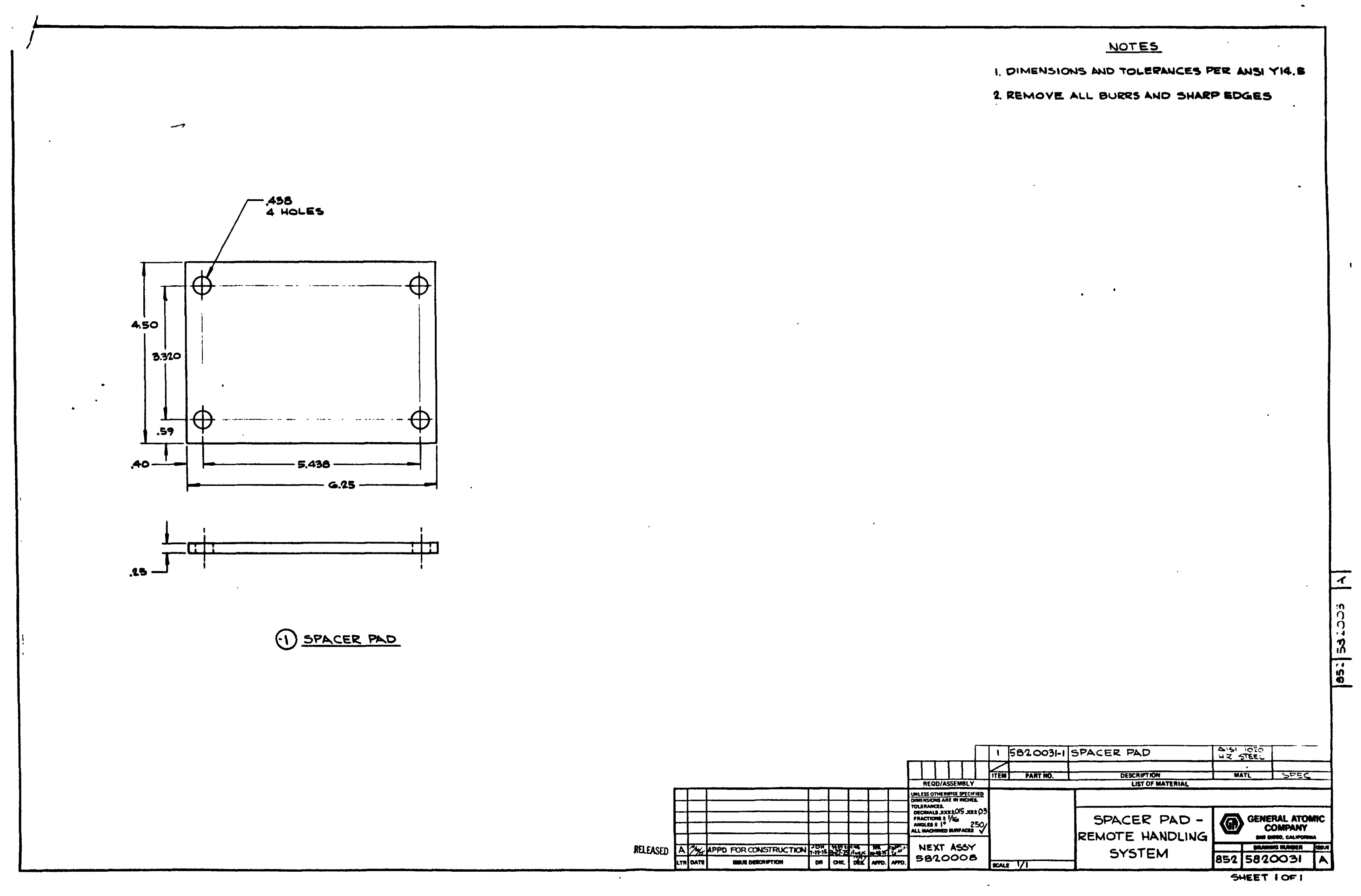


O. . . . . 


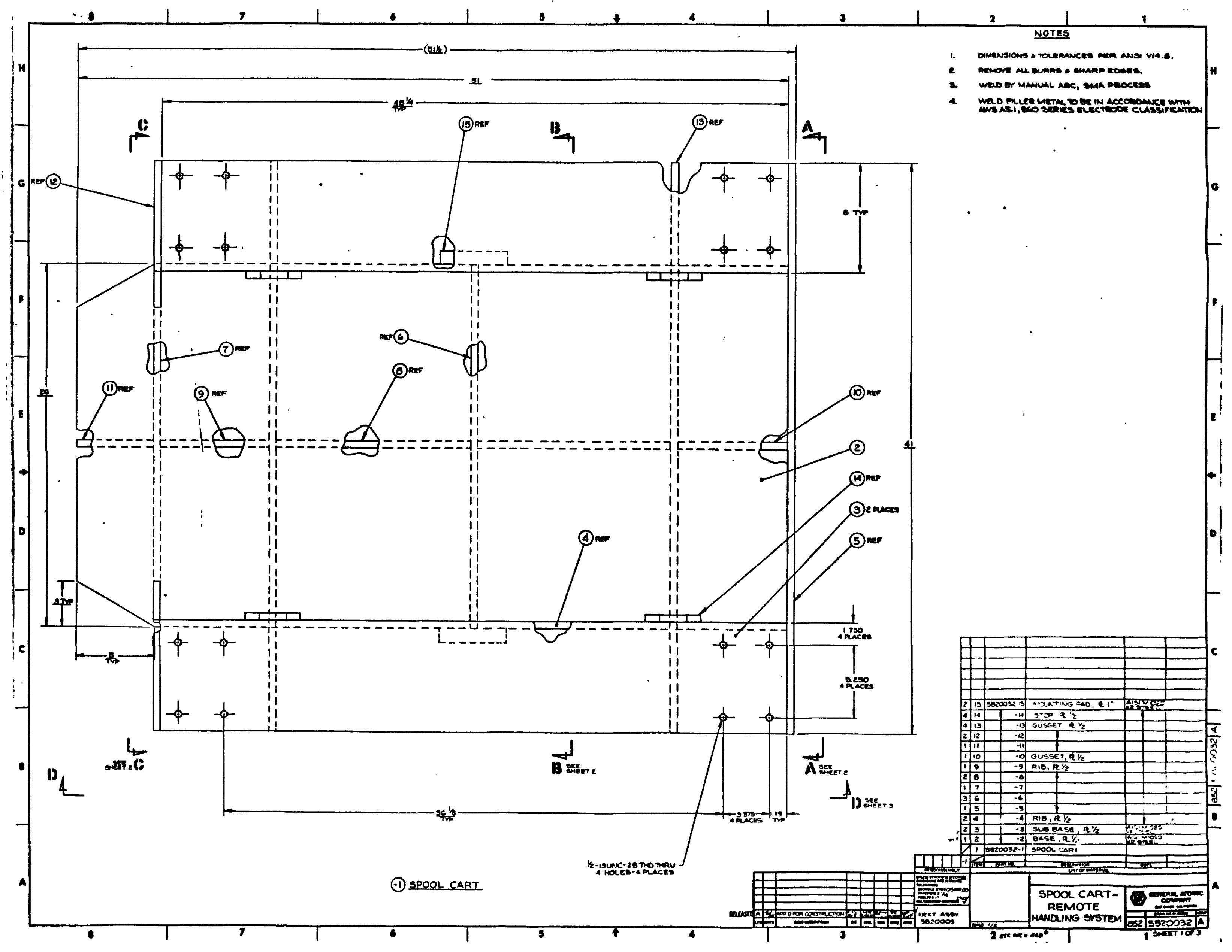


○. . . . . 


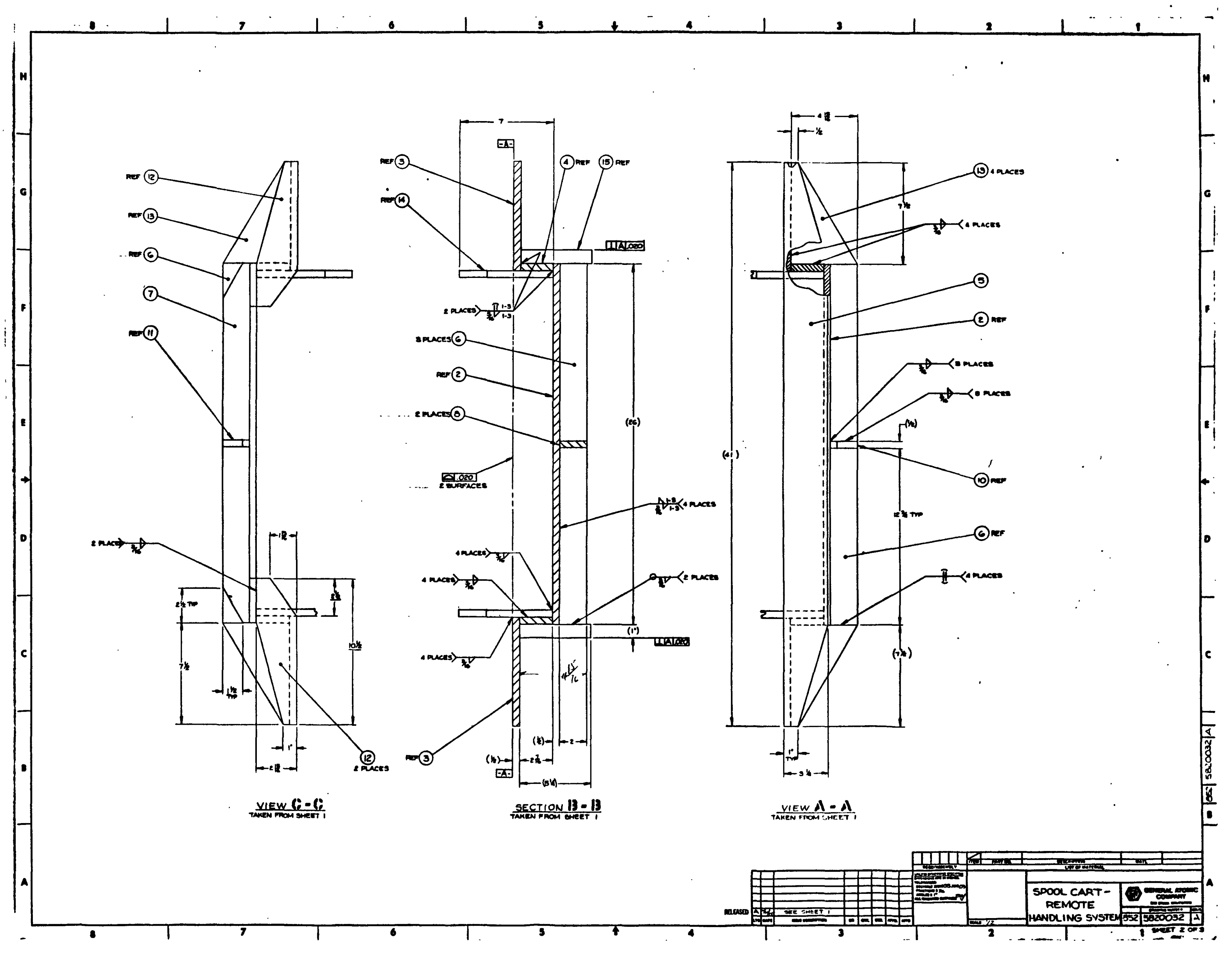


O. . . . . . 


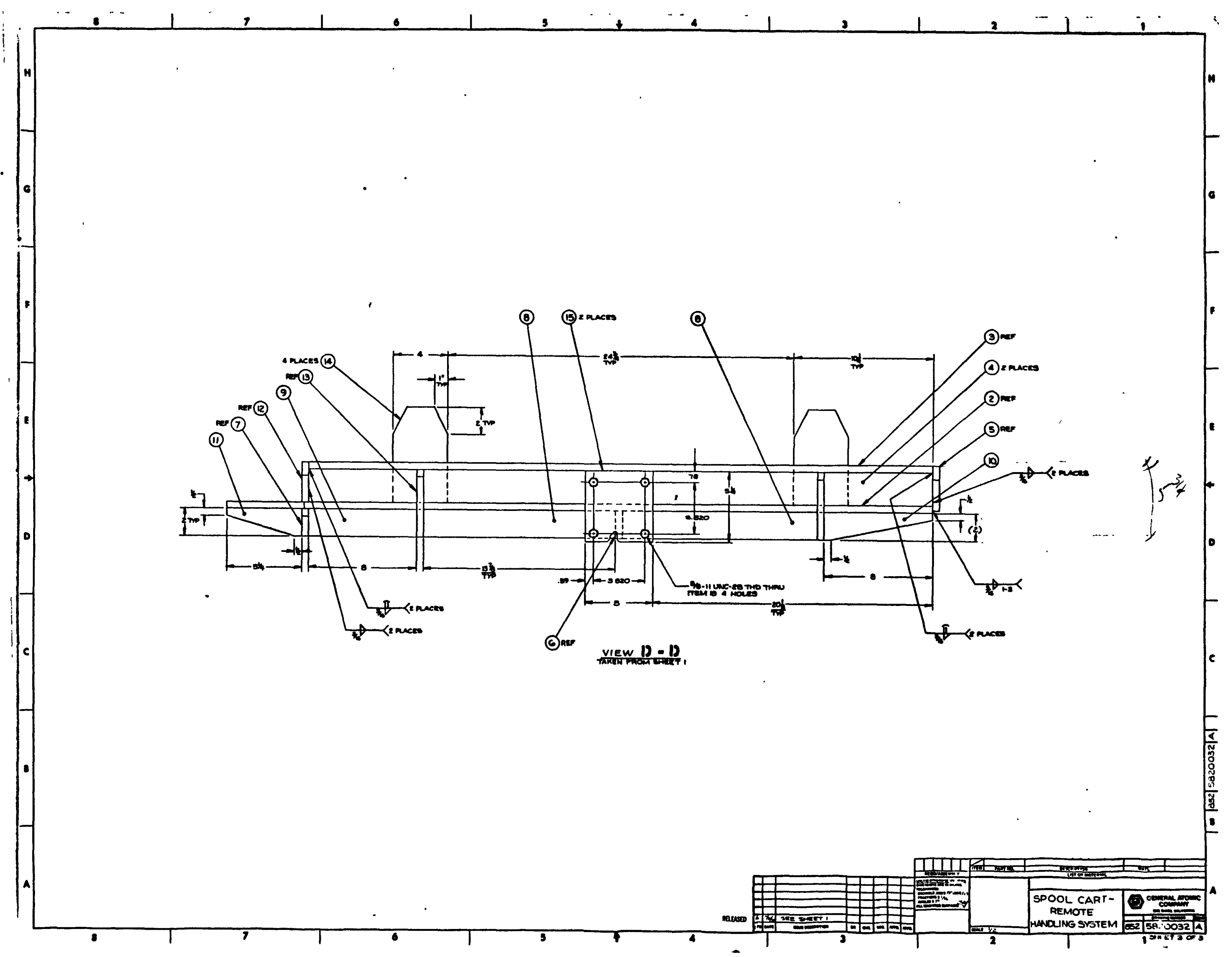


-

0 


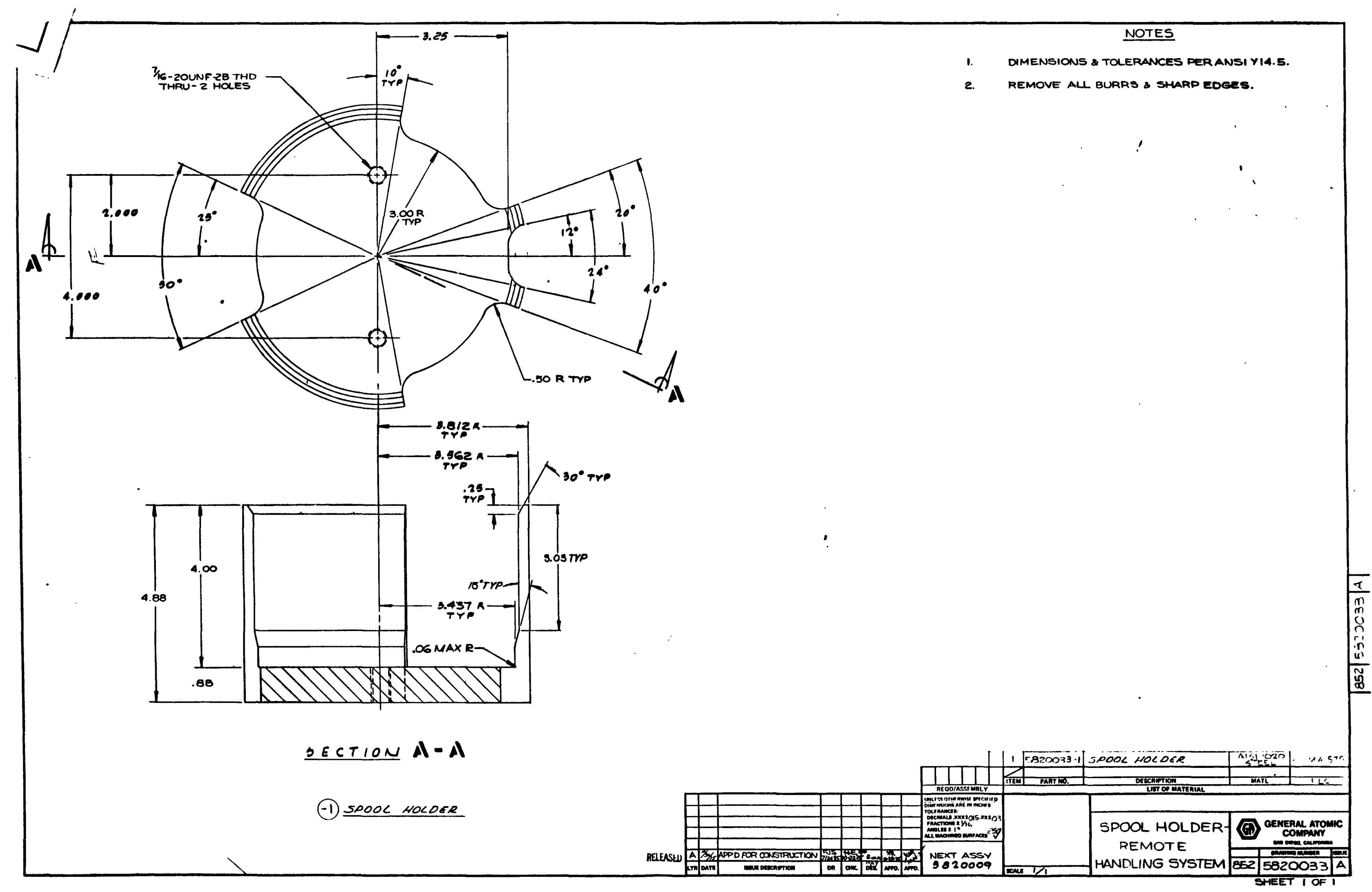




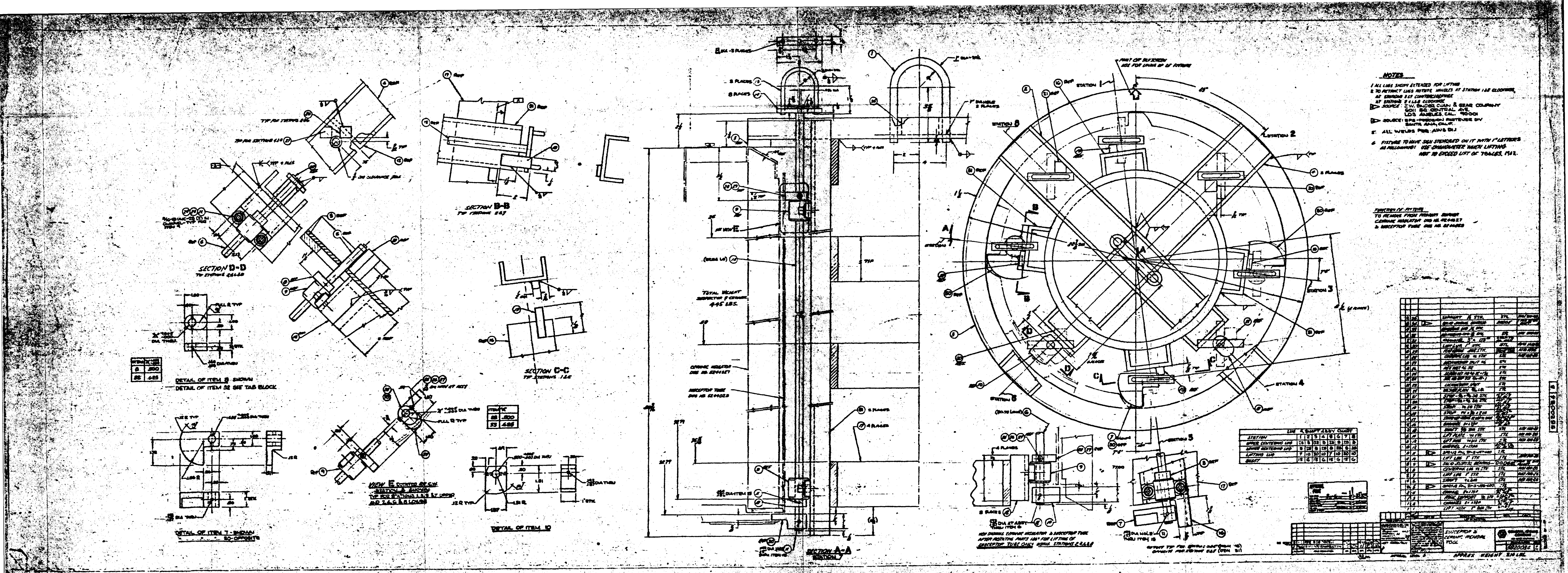


O. . . . . . . . O 


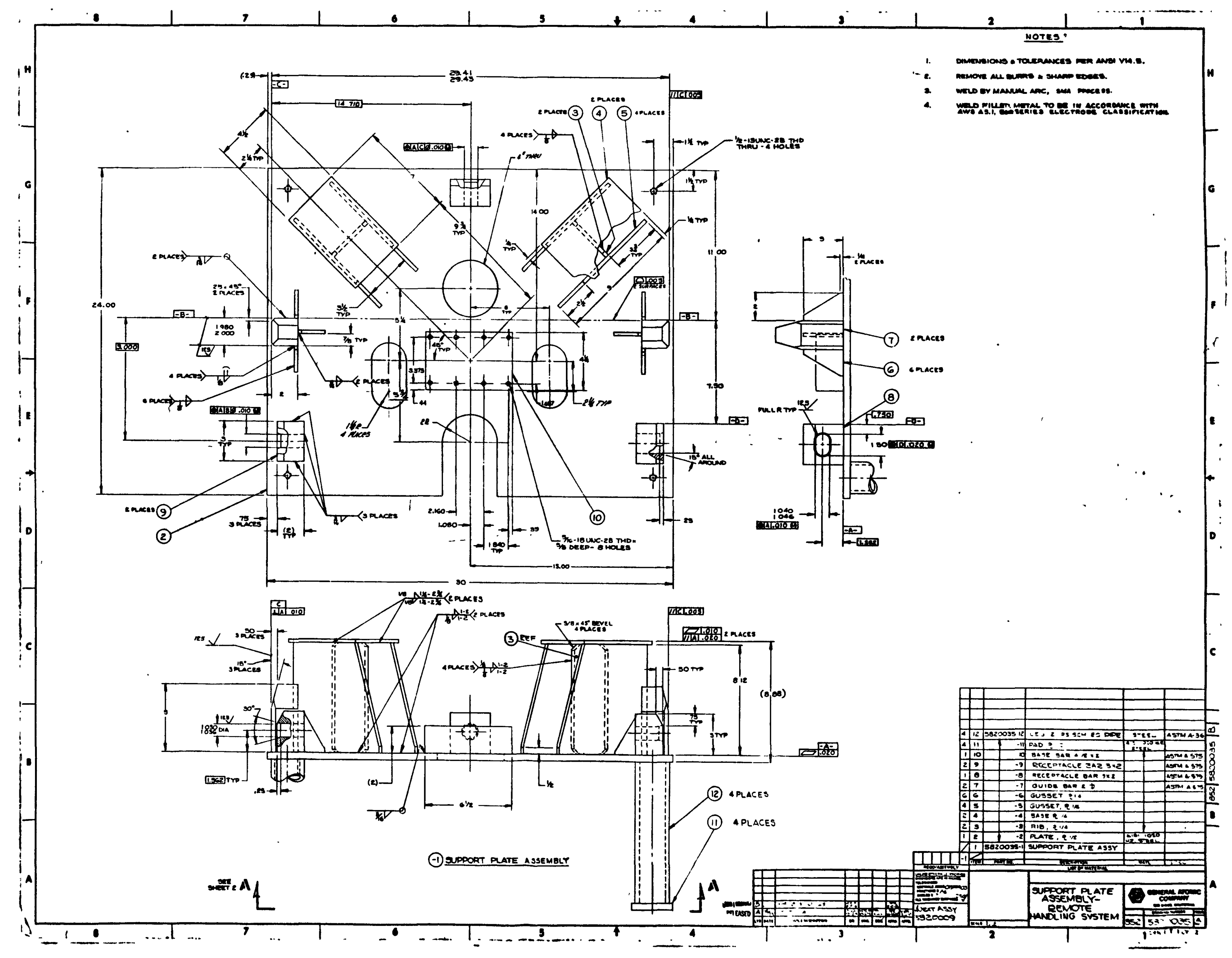


- . . 0 


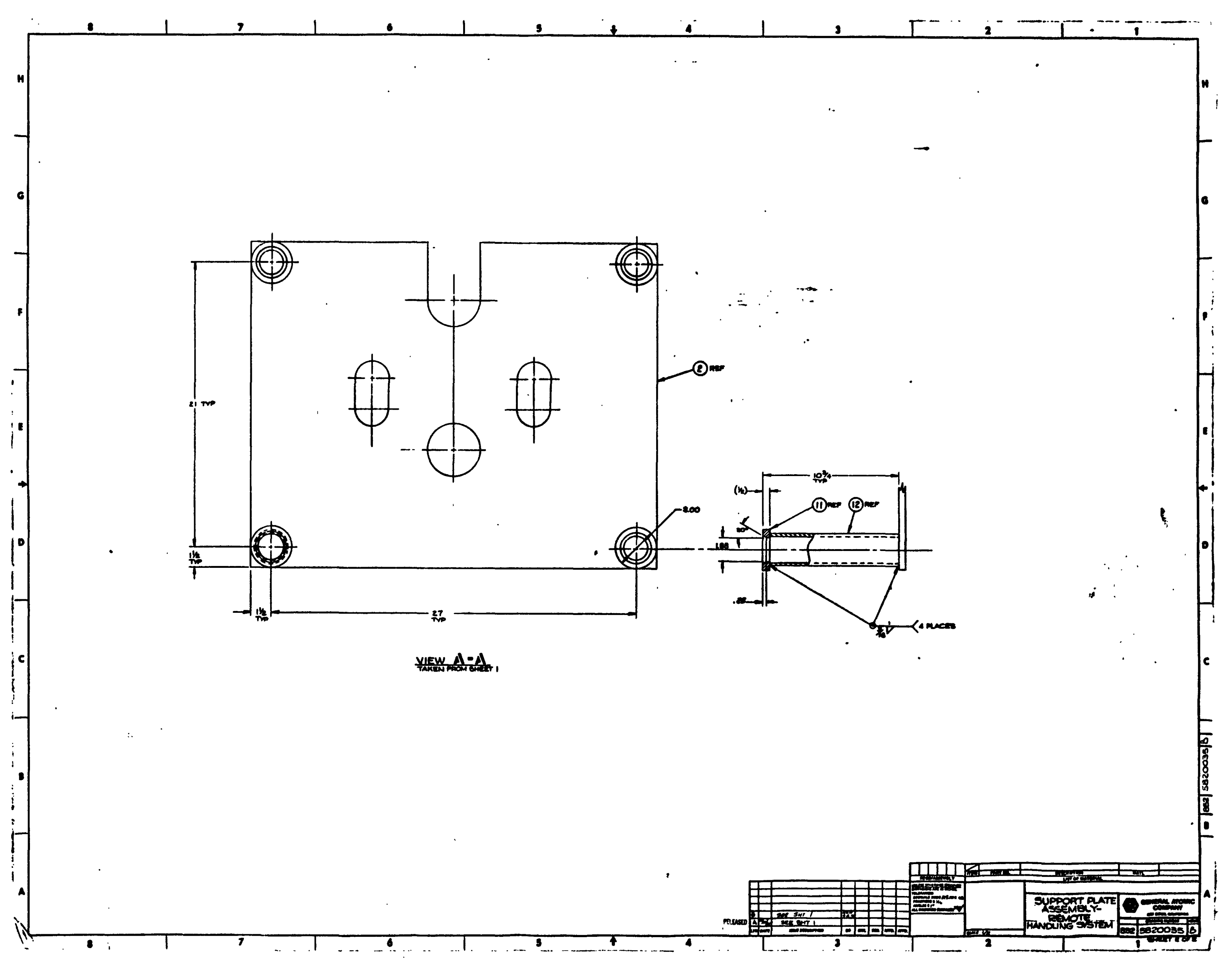



1. DIMENSIONS \& TOLERANCES PER ANSIYIA.S

2. REMOVE ALL BURRS 2 SMARP EDGES.

DV NEXT ASSENBLES wTO 5820009.1

(1) WEXT ASSEMOLES WTO SO20005.1

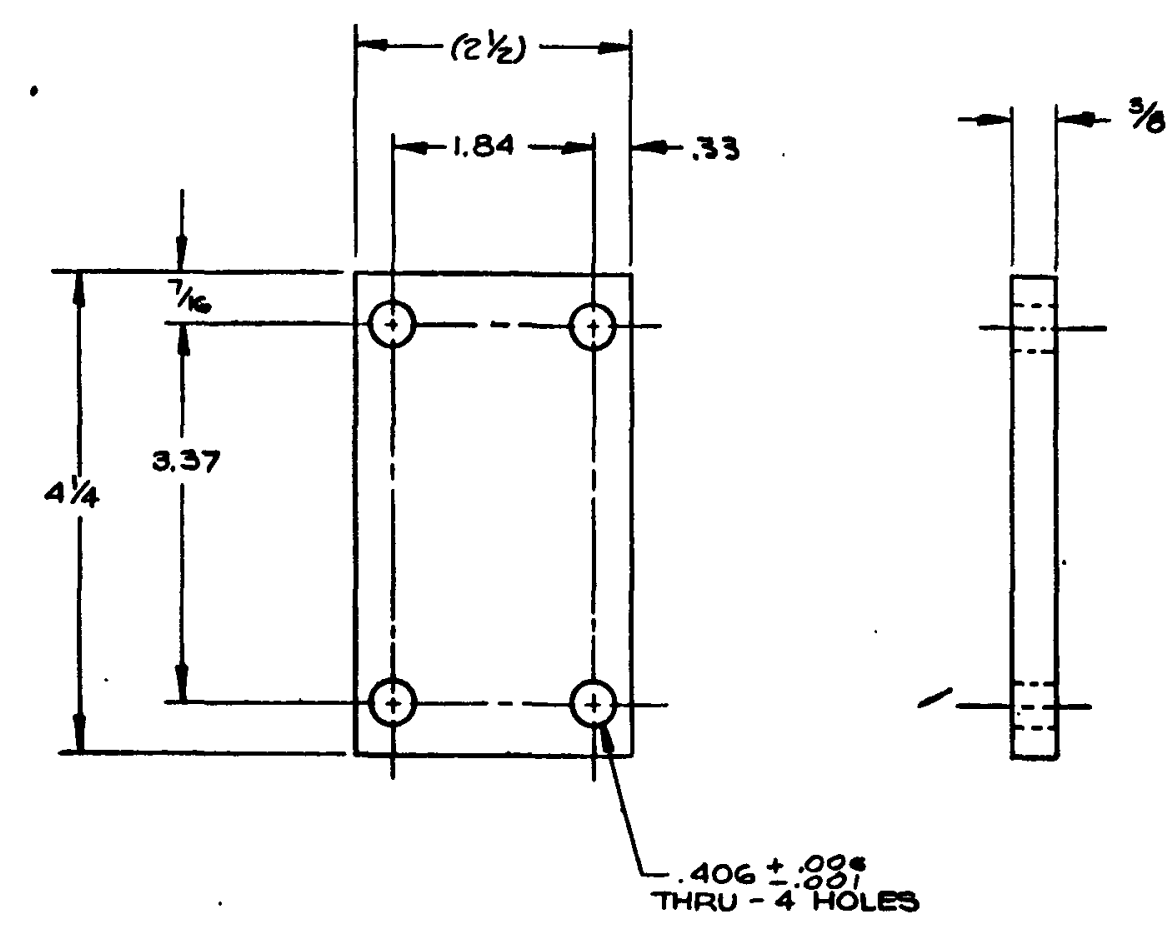
(2) (1) $\frac{\text { SPACER PAD }}{\text { SCALE: } 1 / 1}$

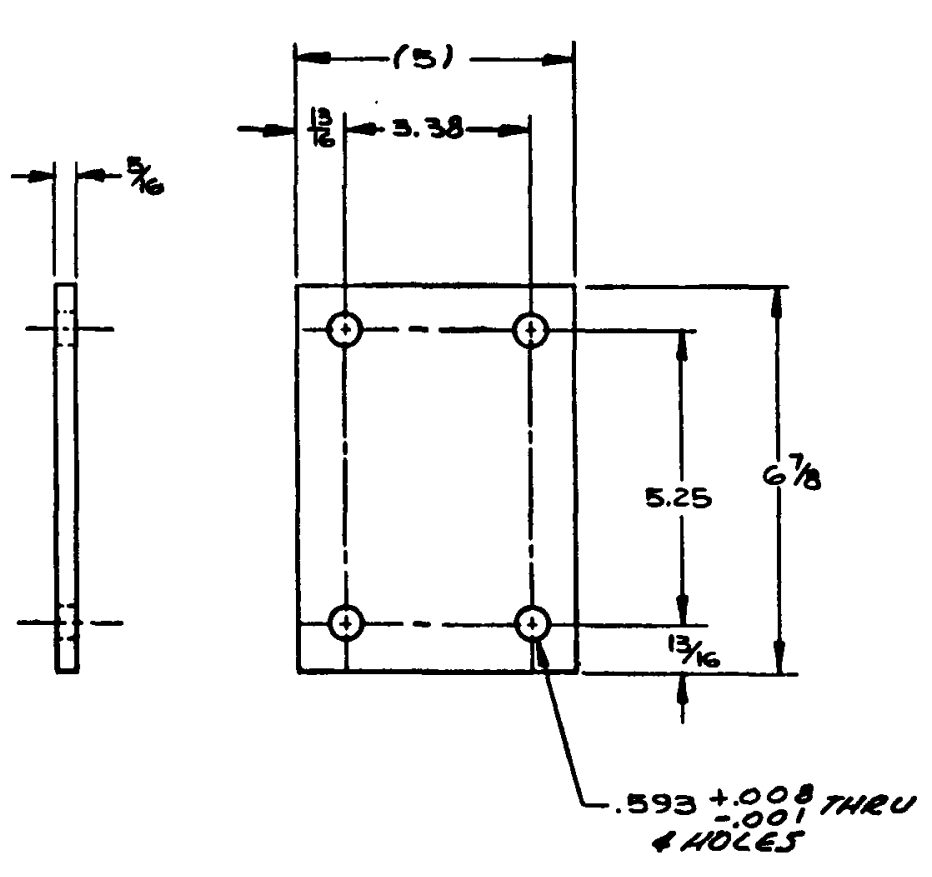

(4) $\frac{\text { SPACER PAD }}{\text { SCALE: } 1 / 2}$

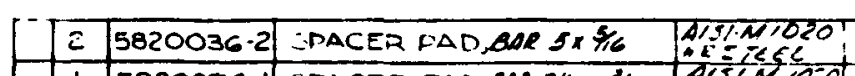

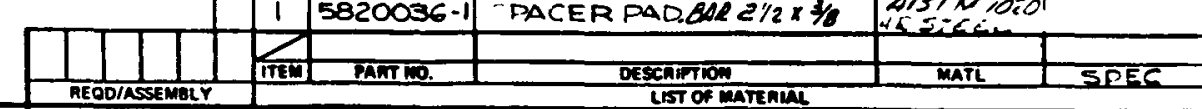




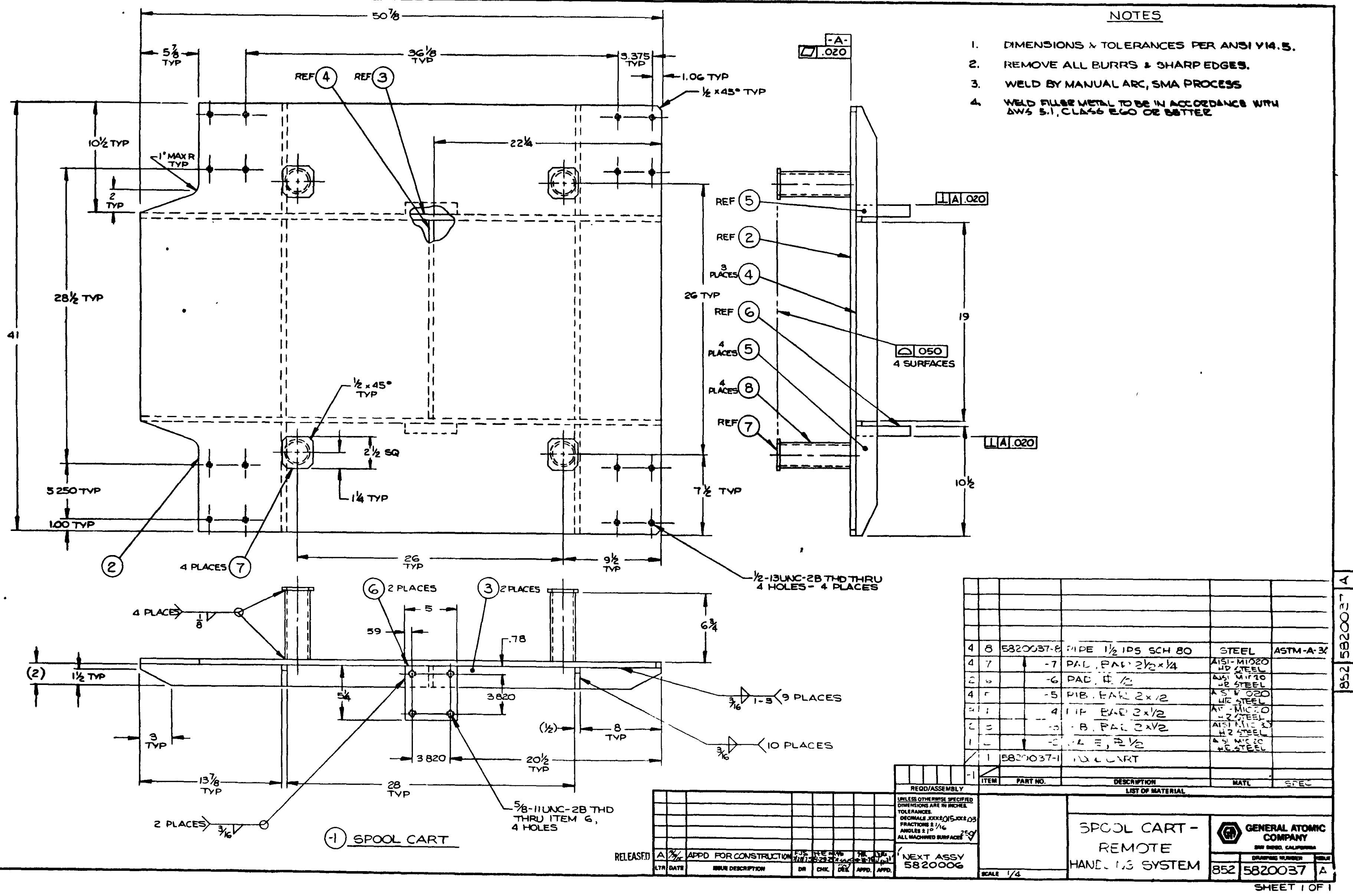


○ $\quad$. 


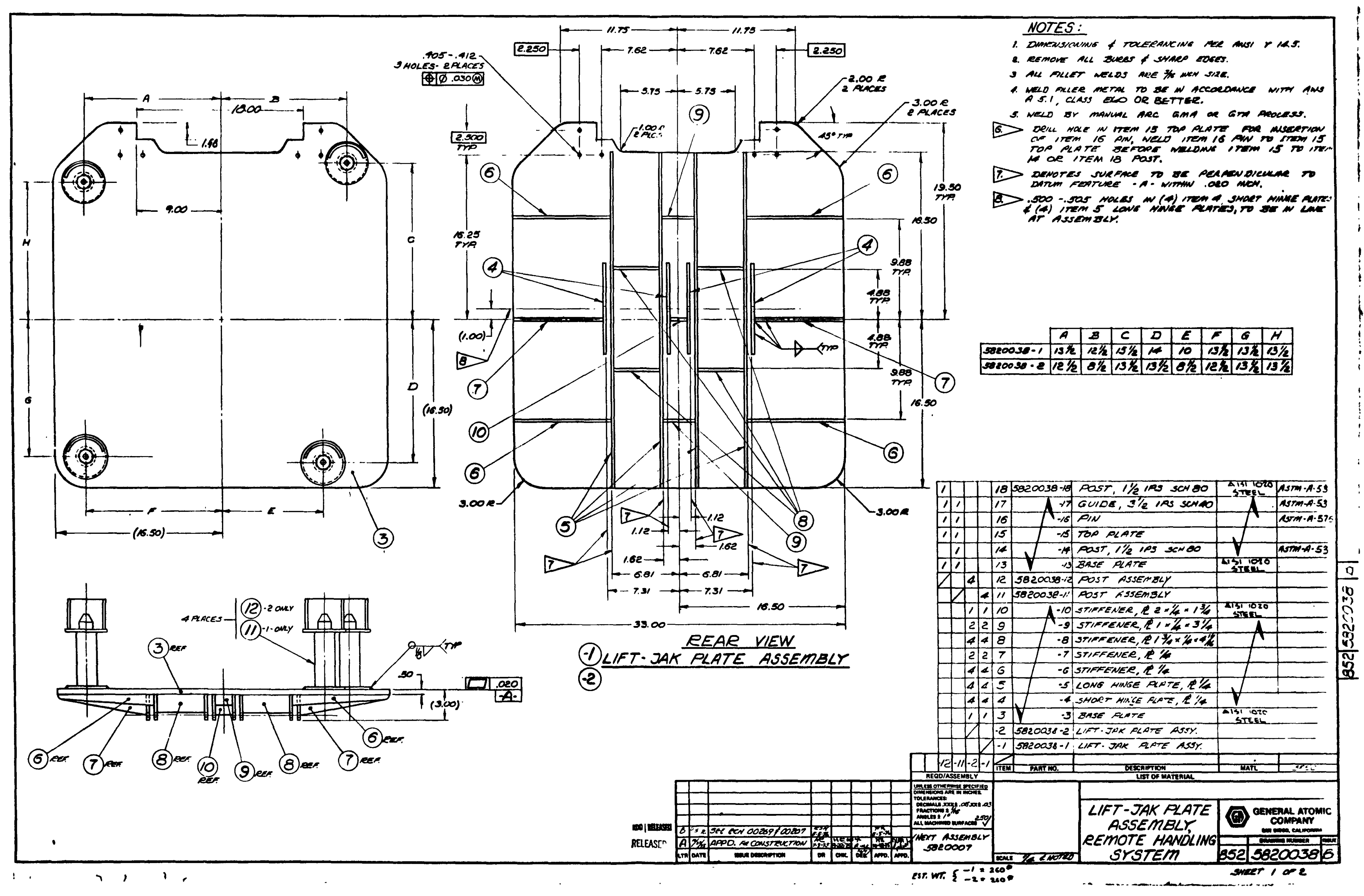


0

. 


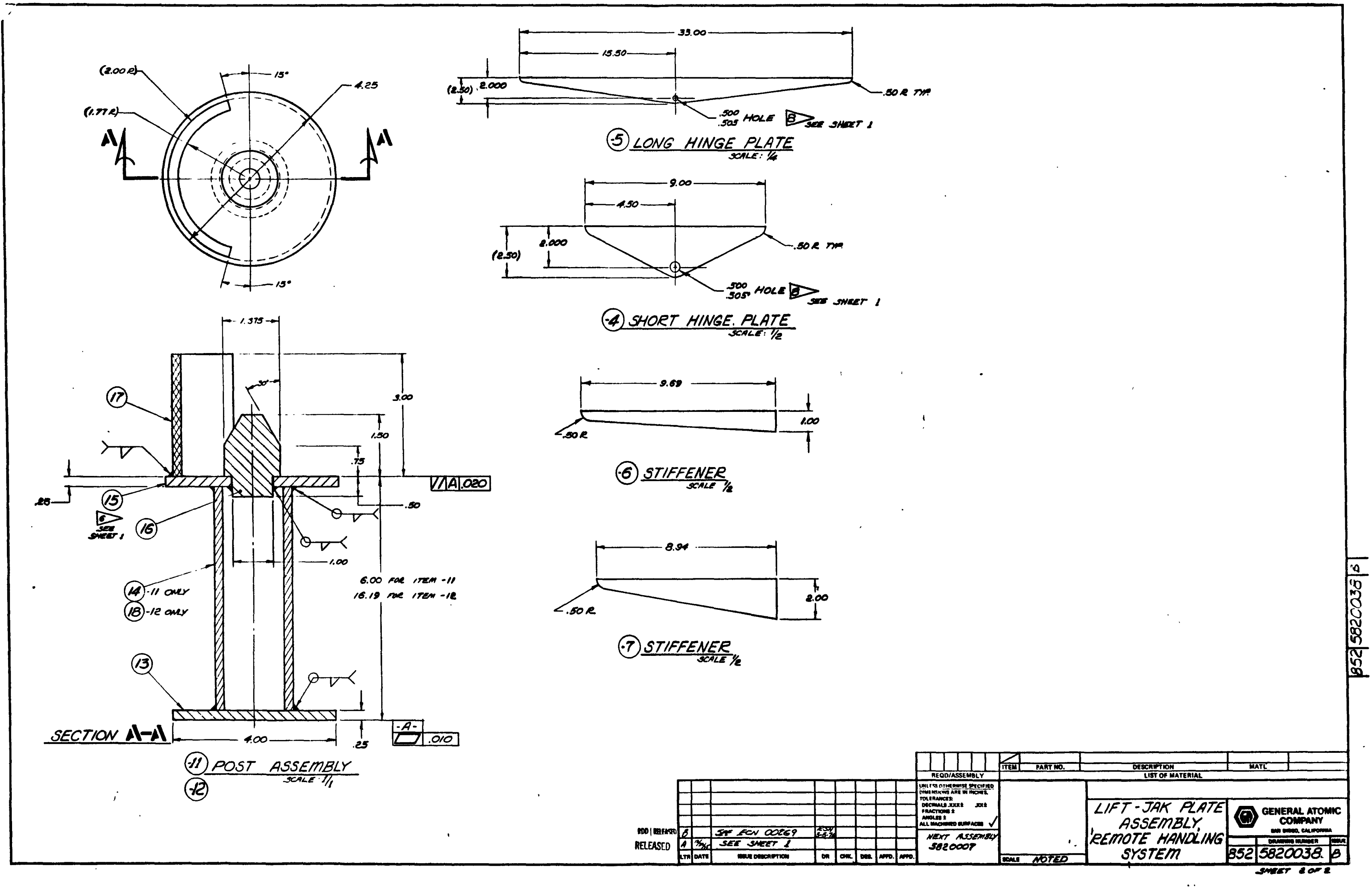


-

- 

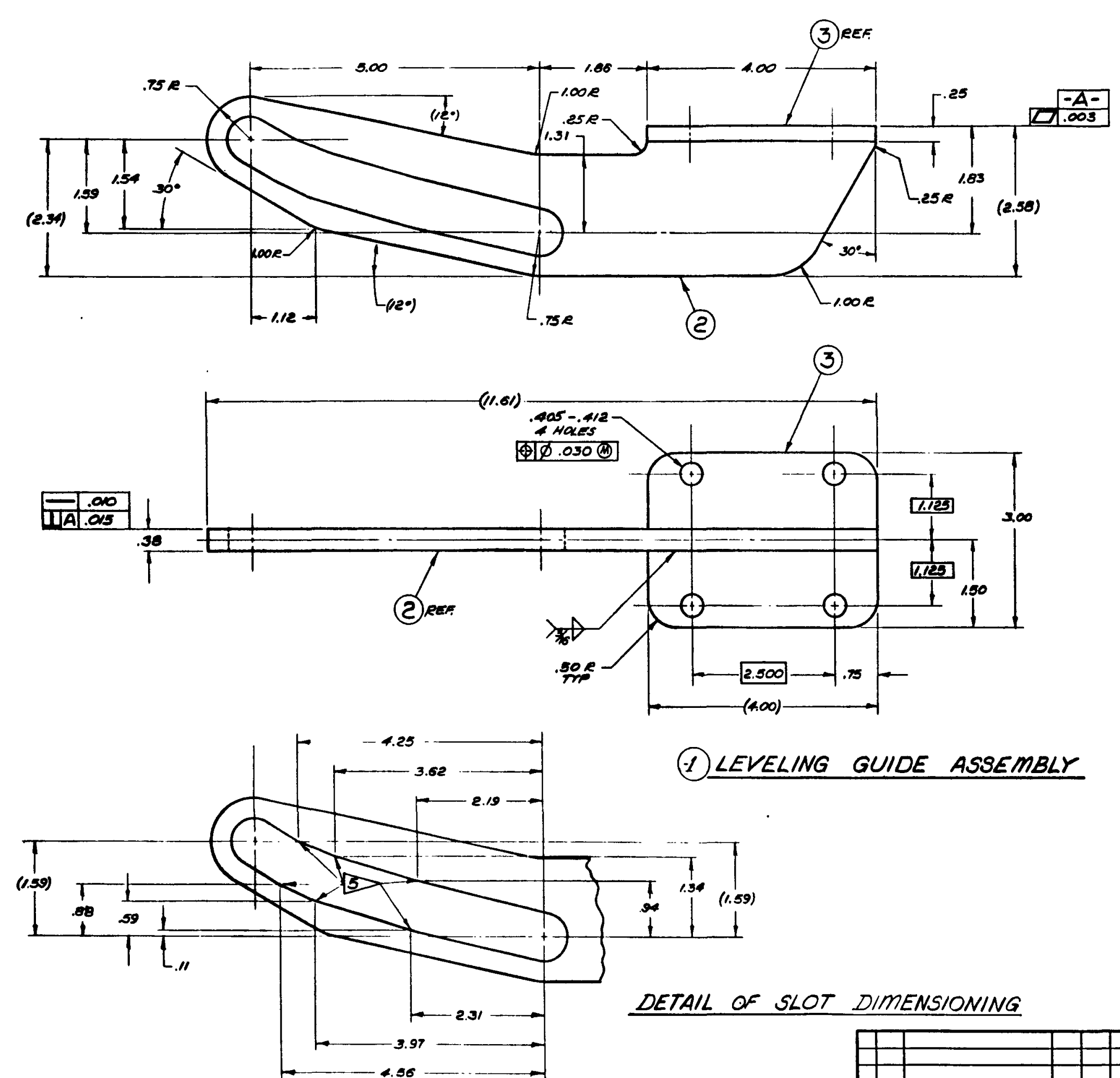

(1) LEVELING GUIDE ASSEMBLY

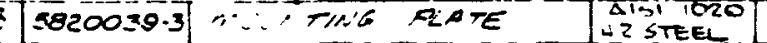

12 5820039-2 LEVELING PLATE W'STIETL

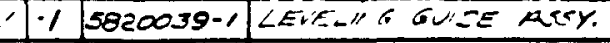

DETAIL OF SLOT DIMENSIONING 
O. . . . 


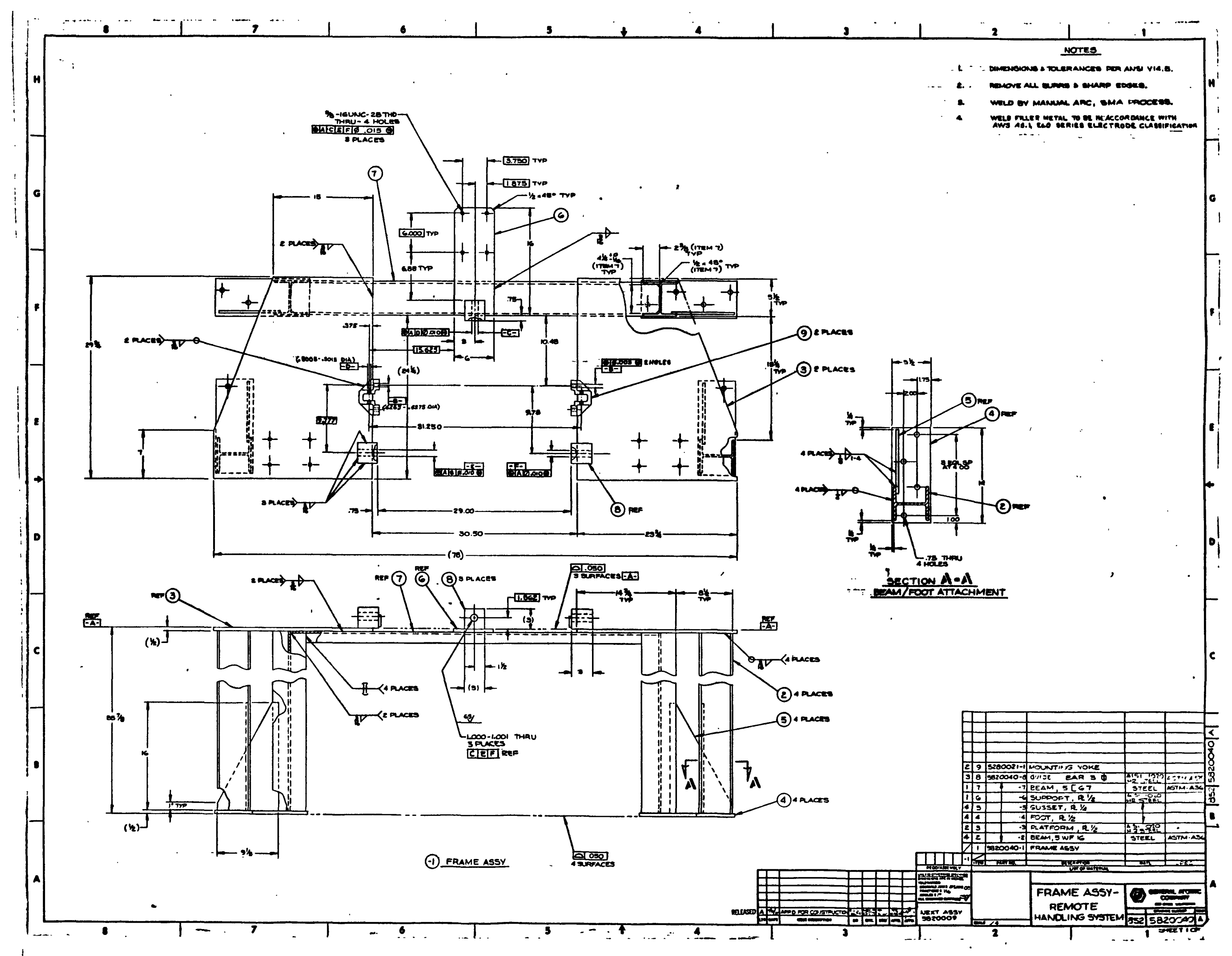


O. . . . 


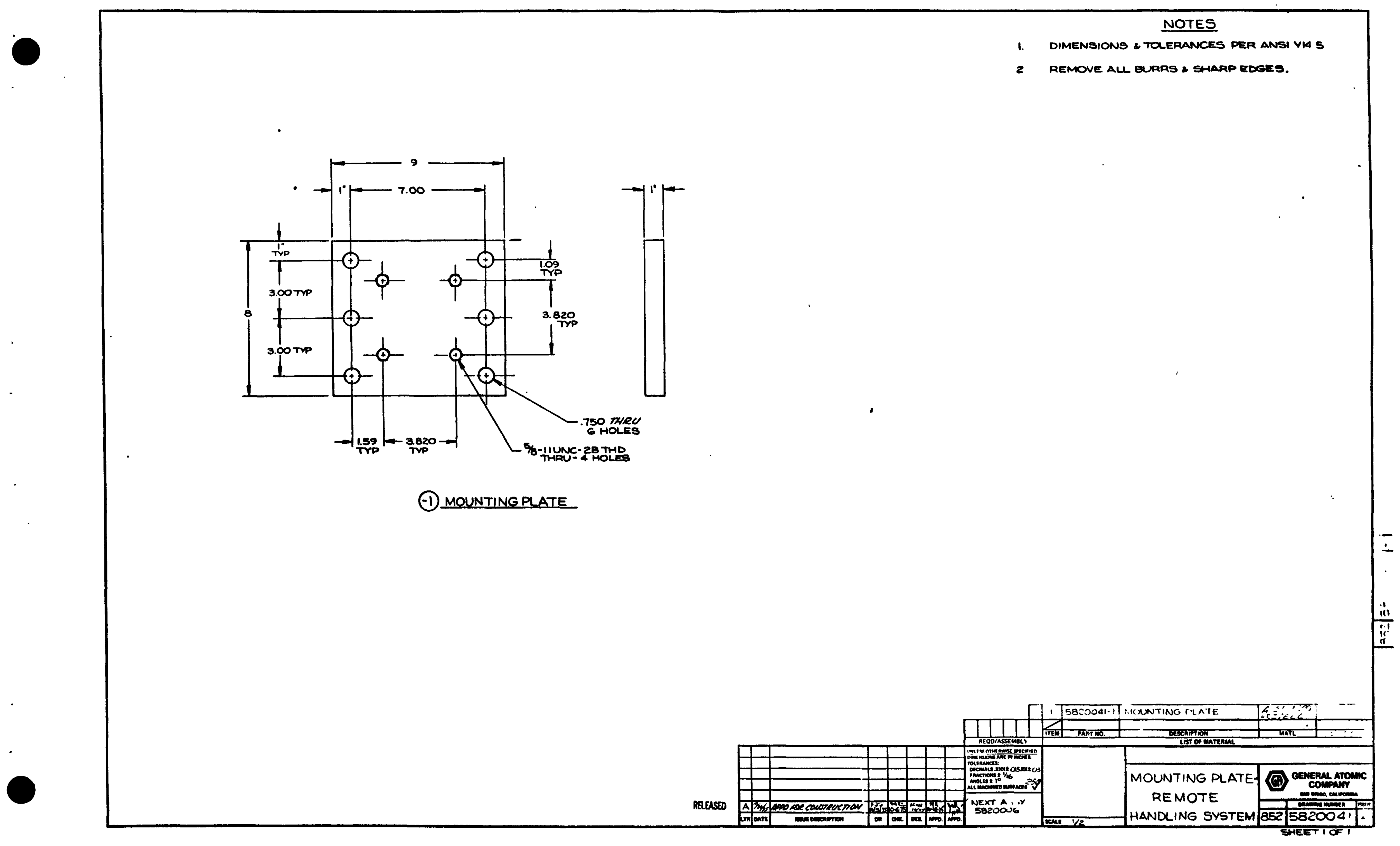


O. . . . . . . . 



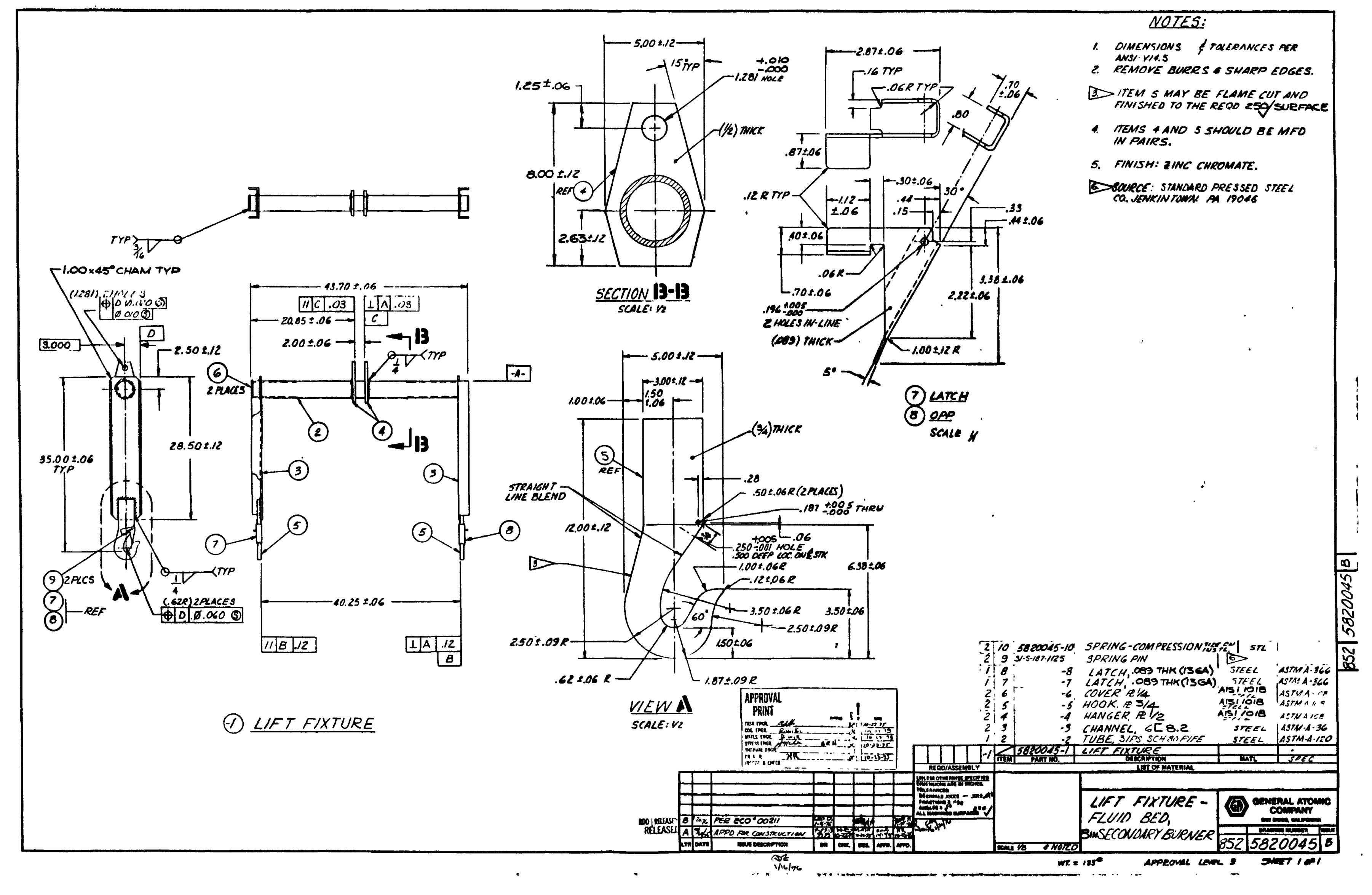


-

- 


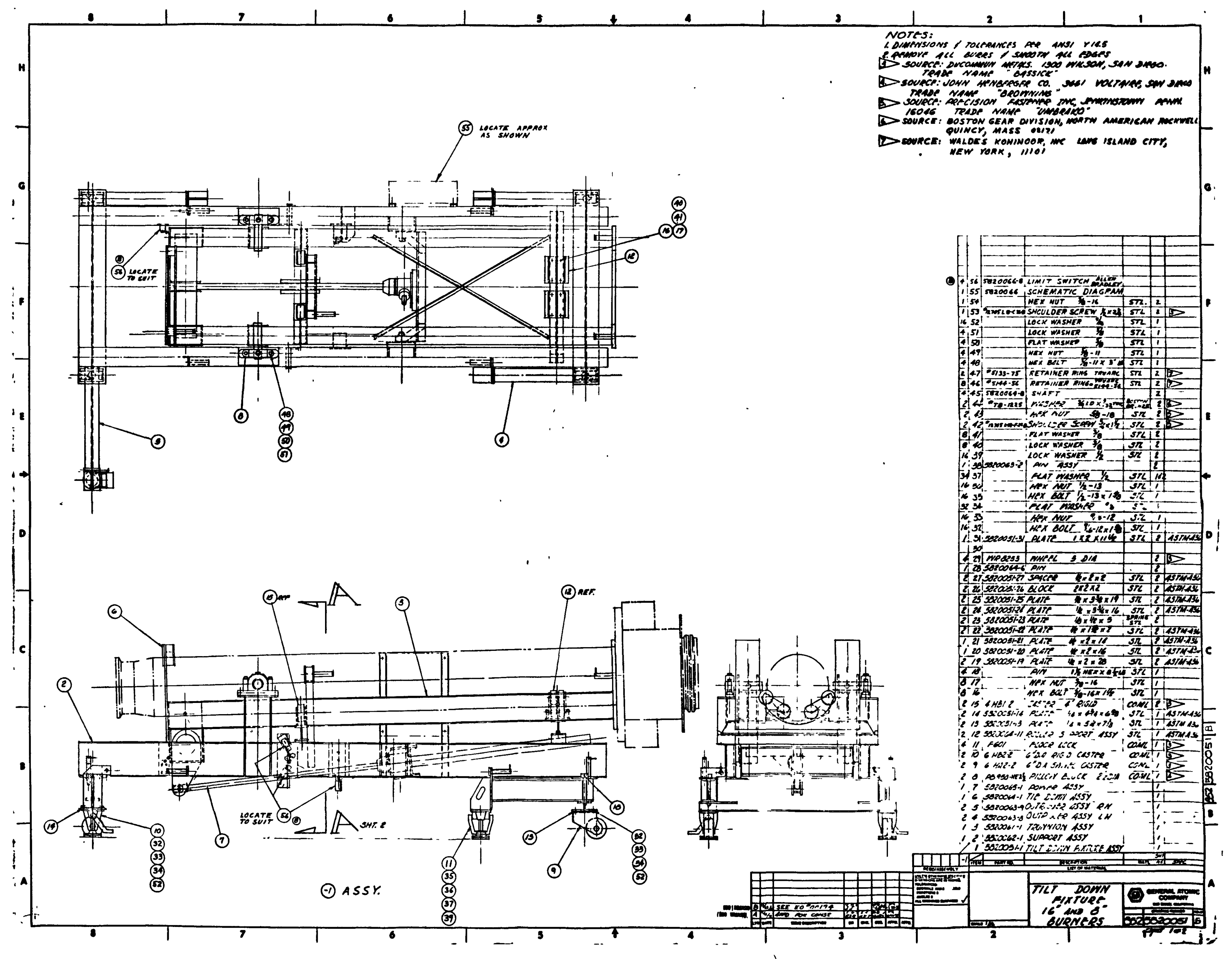


O. . . . . . . 


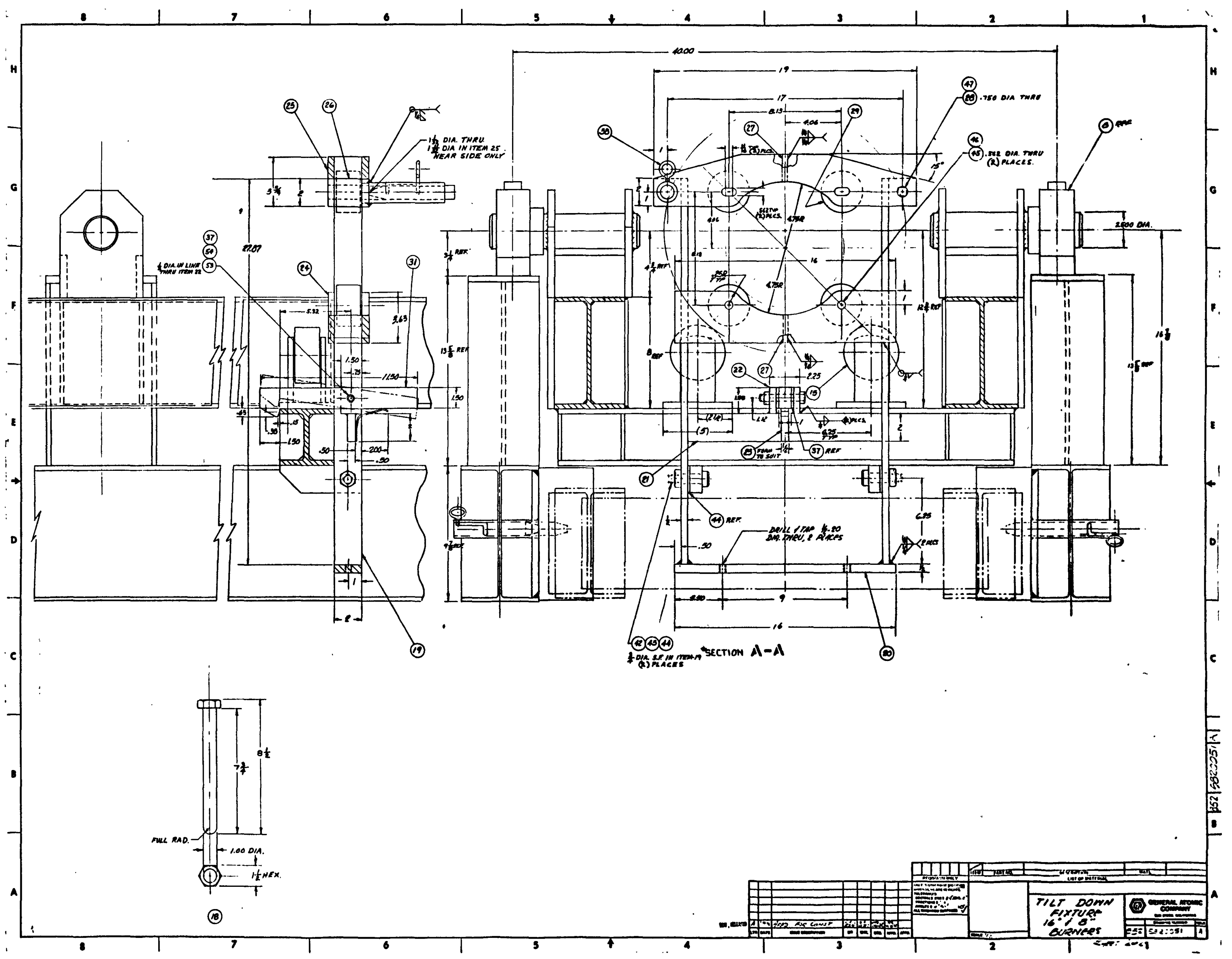


O. . . . . . . . 


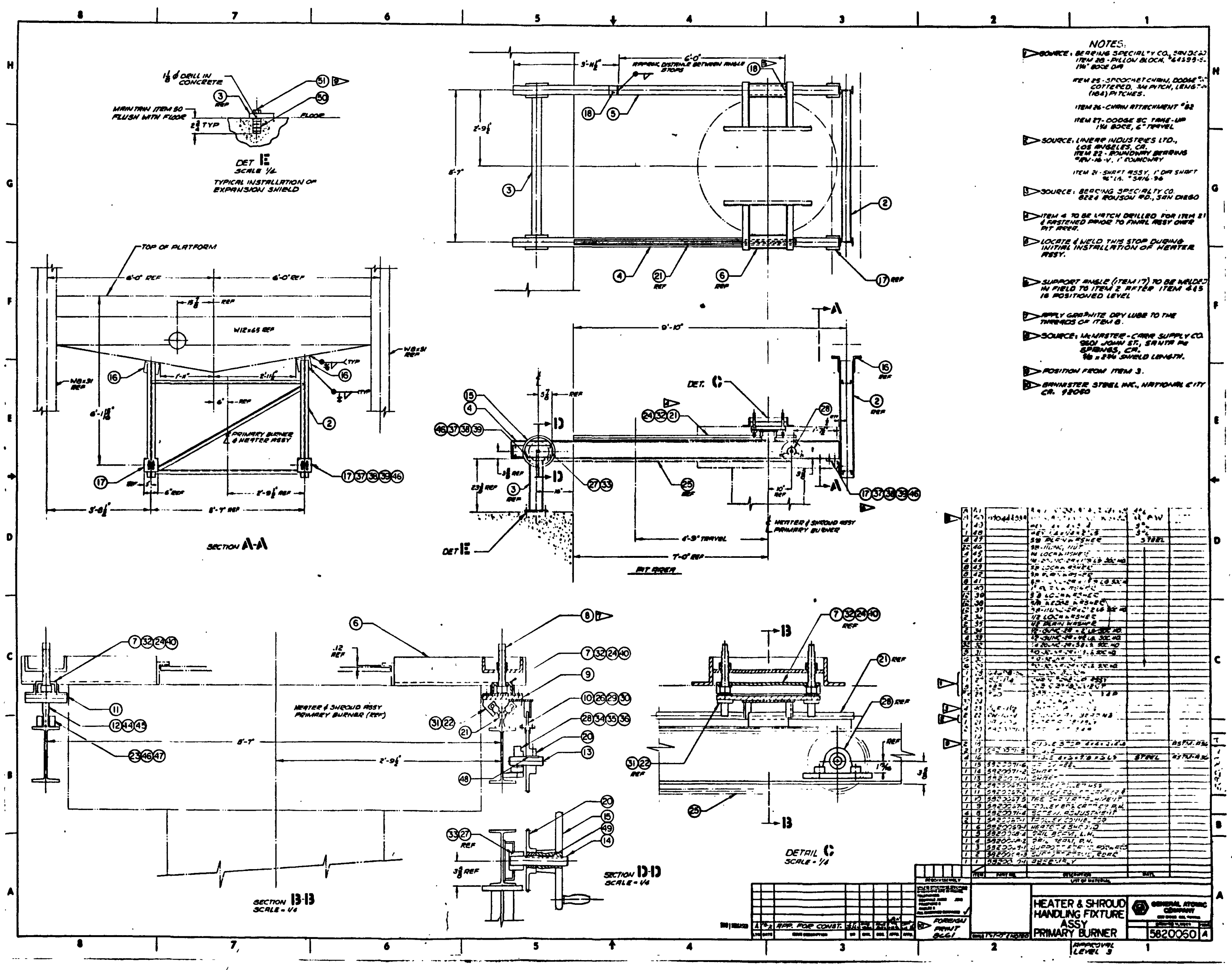


○. . . . 


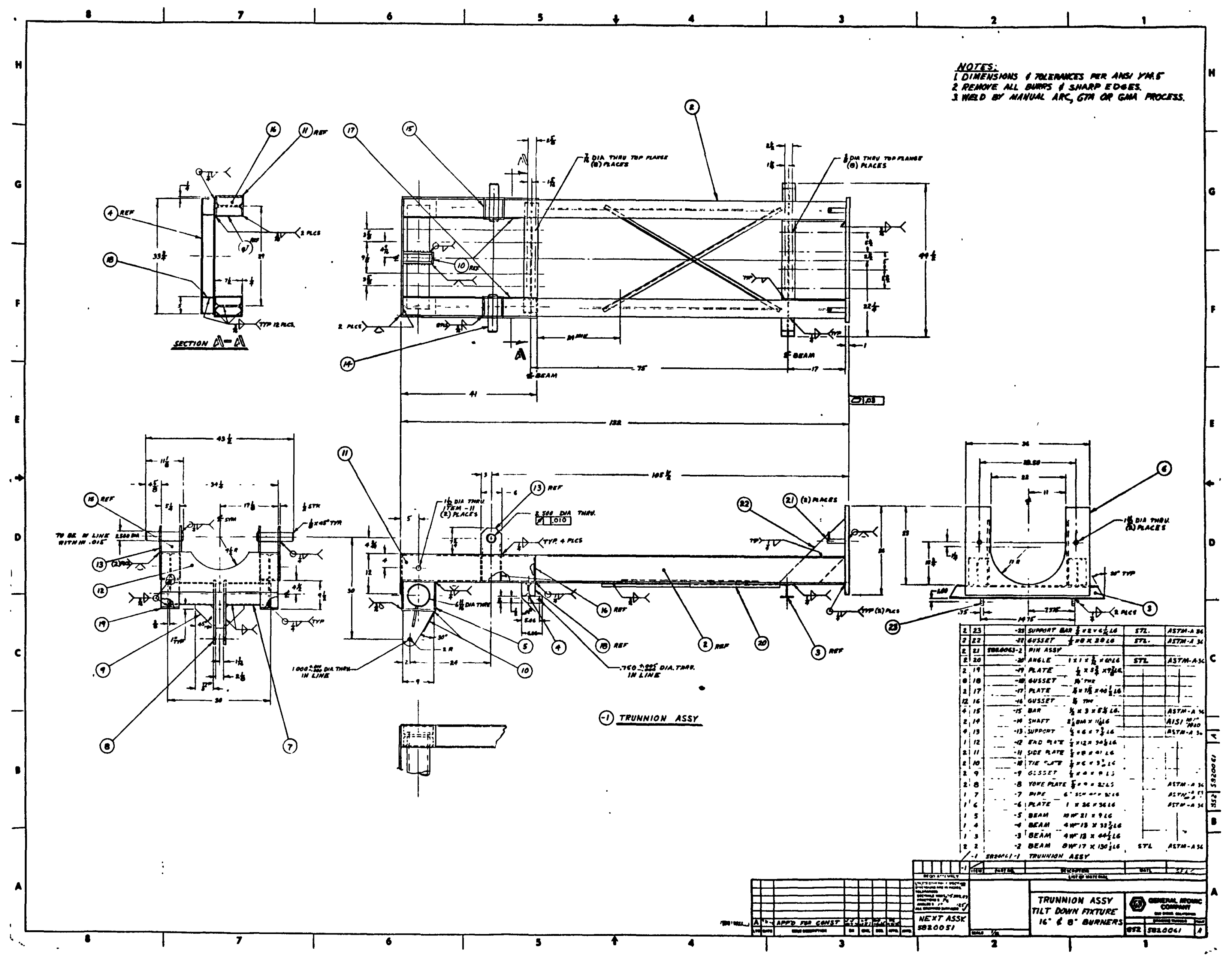


○. . . . . . . 


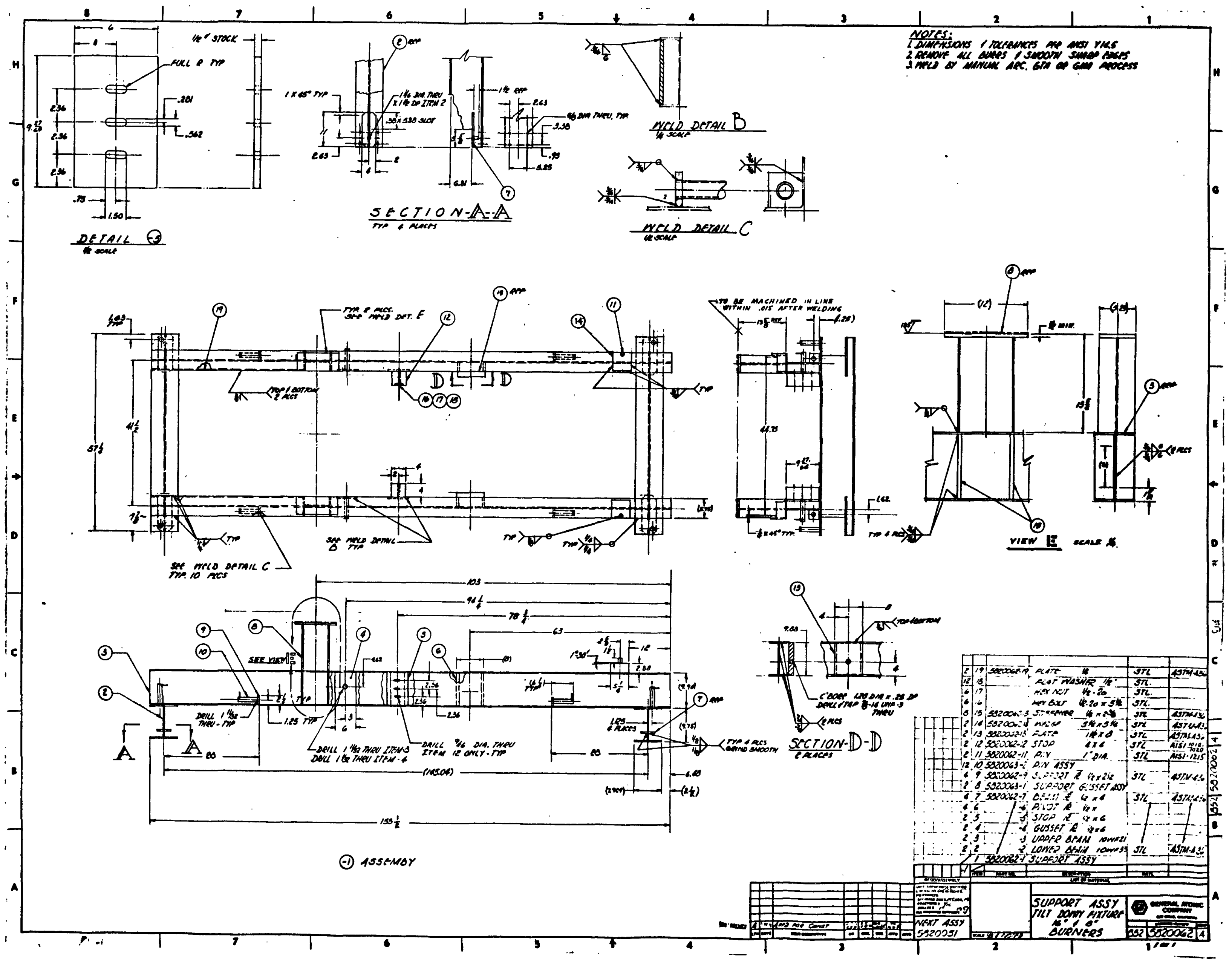


○. . . . 


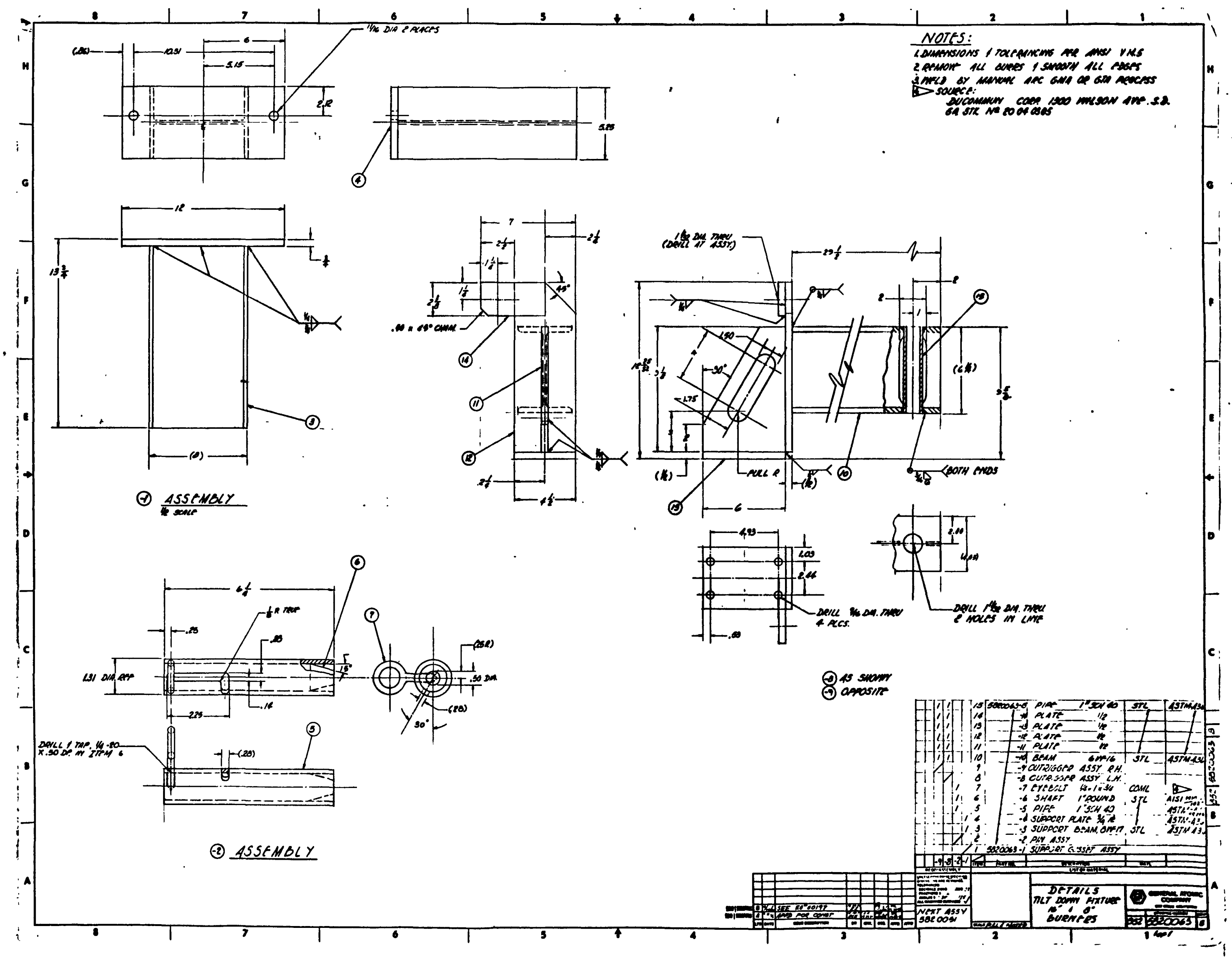


O. . . . . . . 


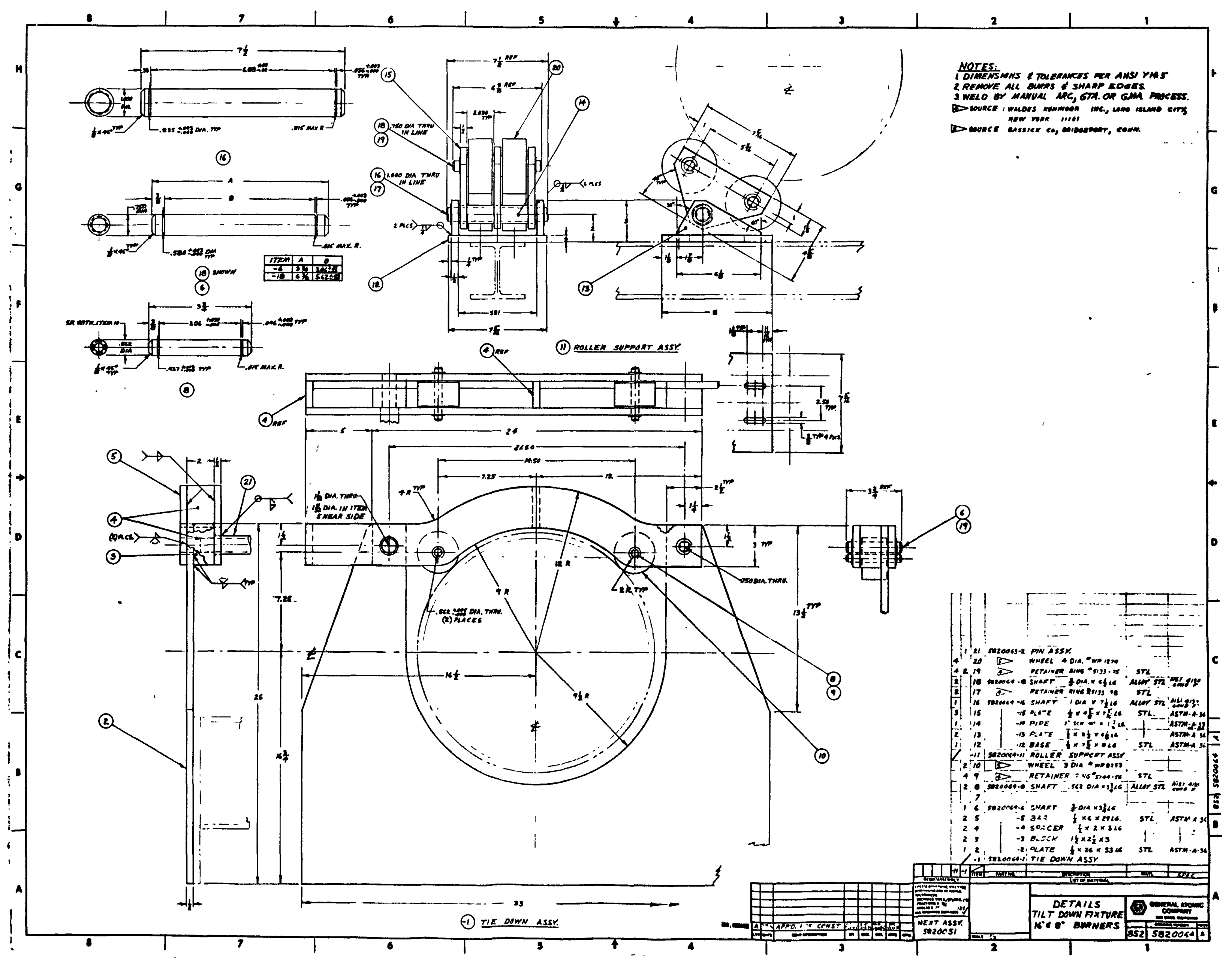


O 


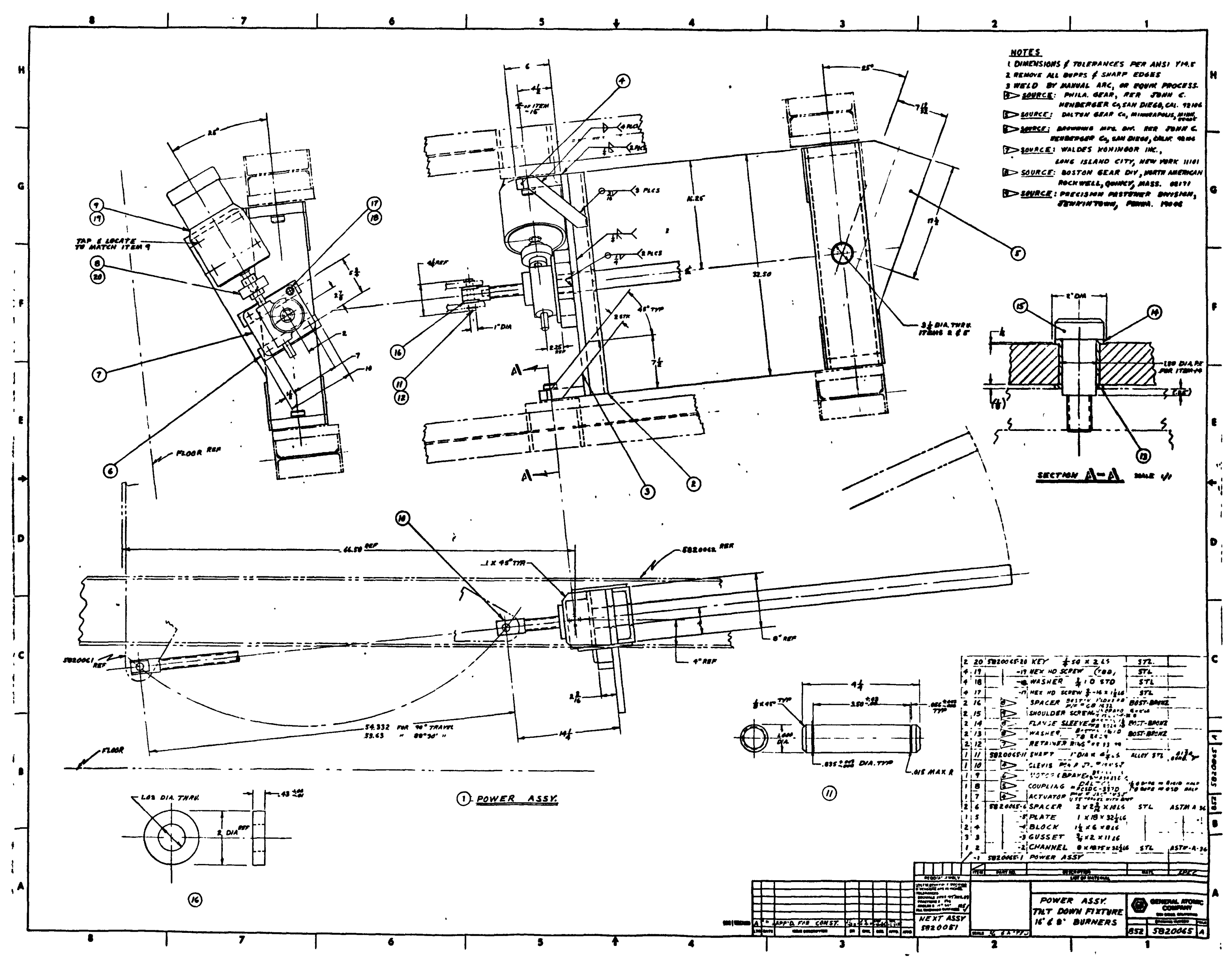


$0 . \quad 0$ 


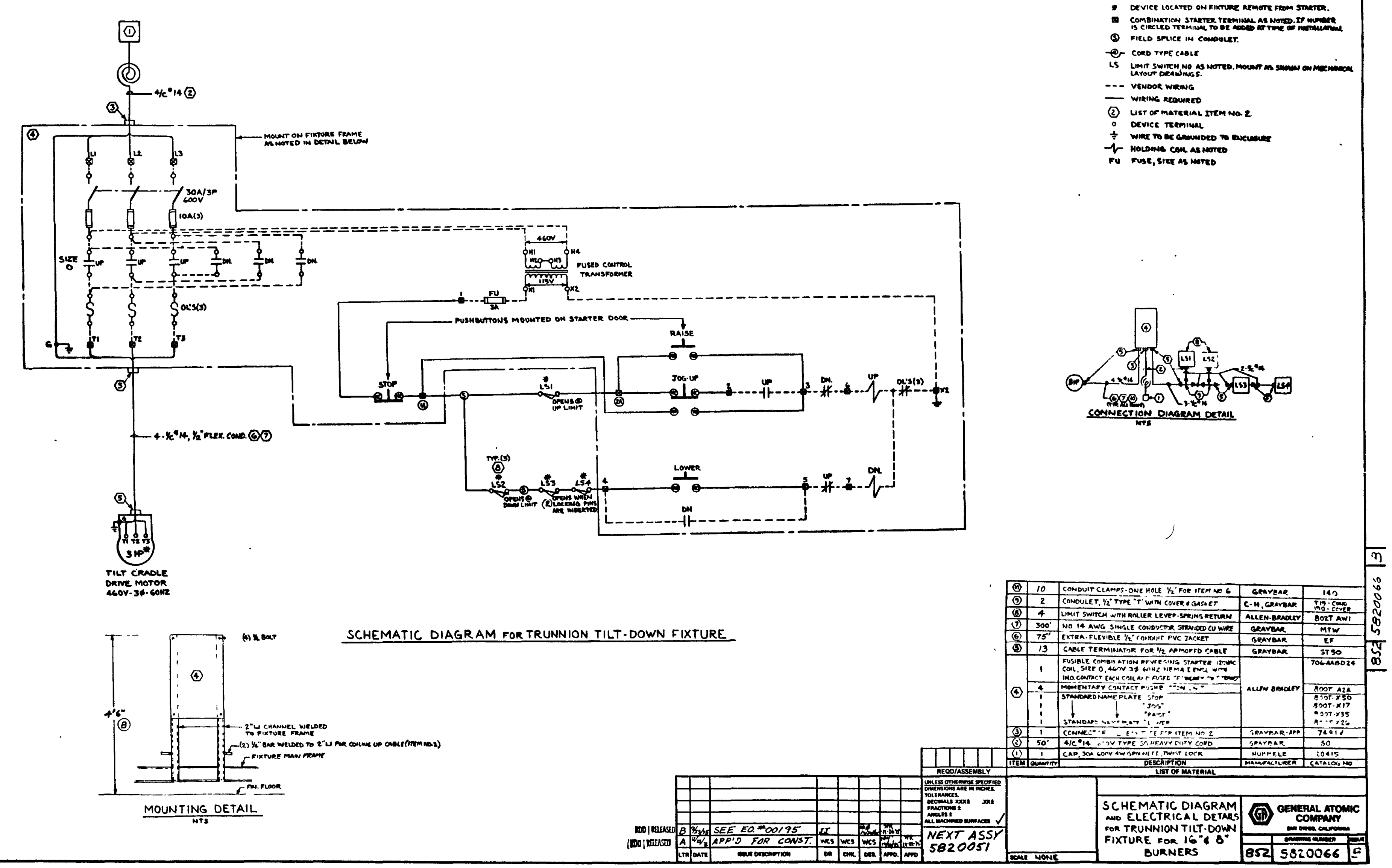


O. . . . . 


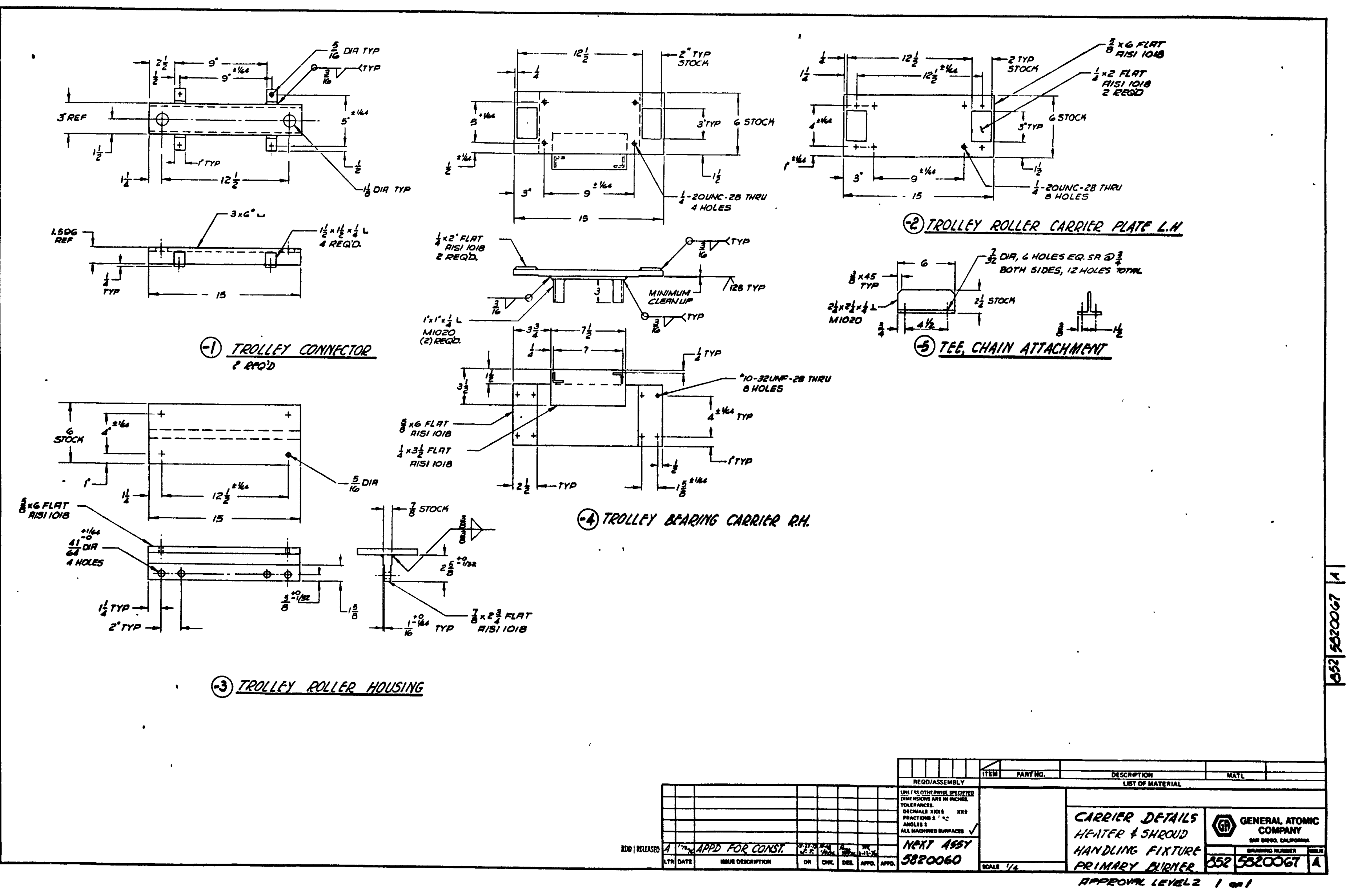


○. . . 0 


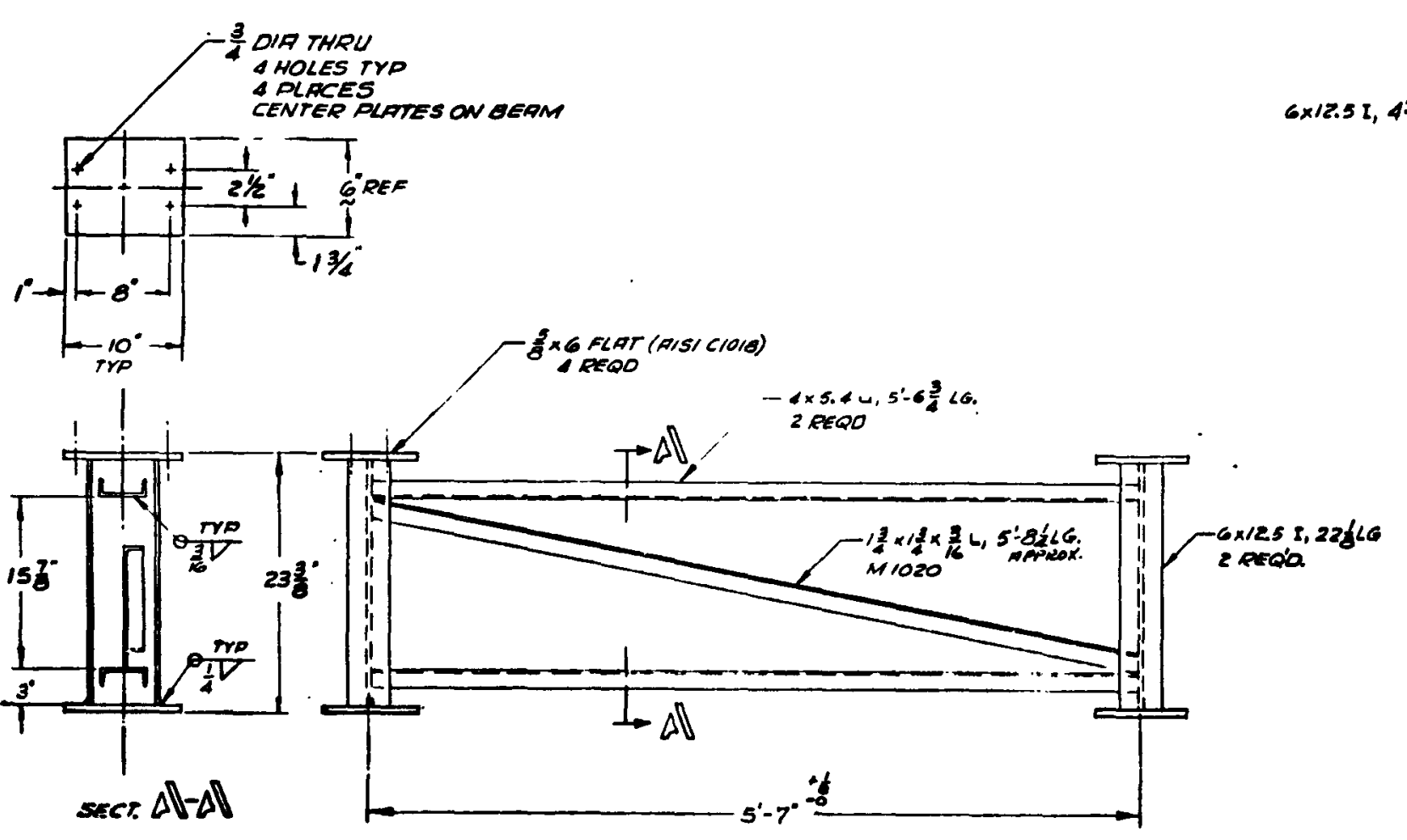

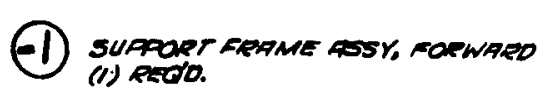
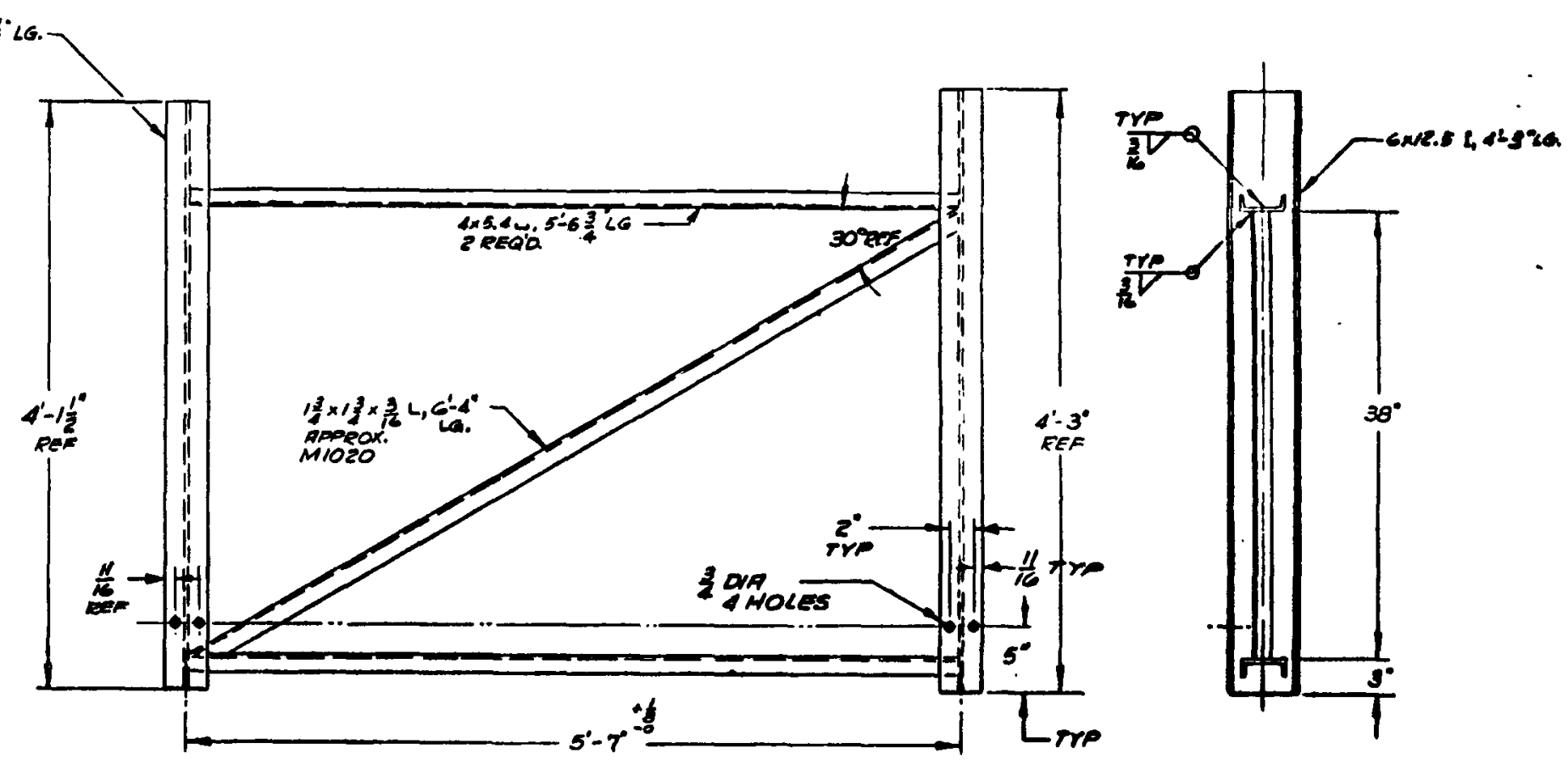

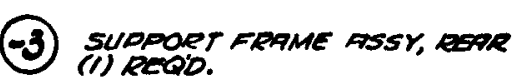

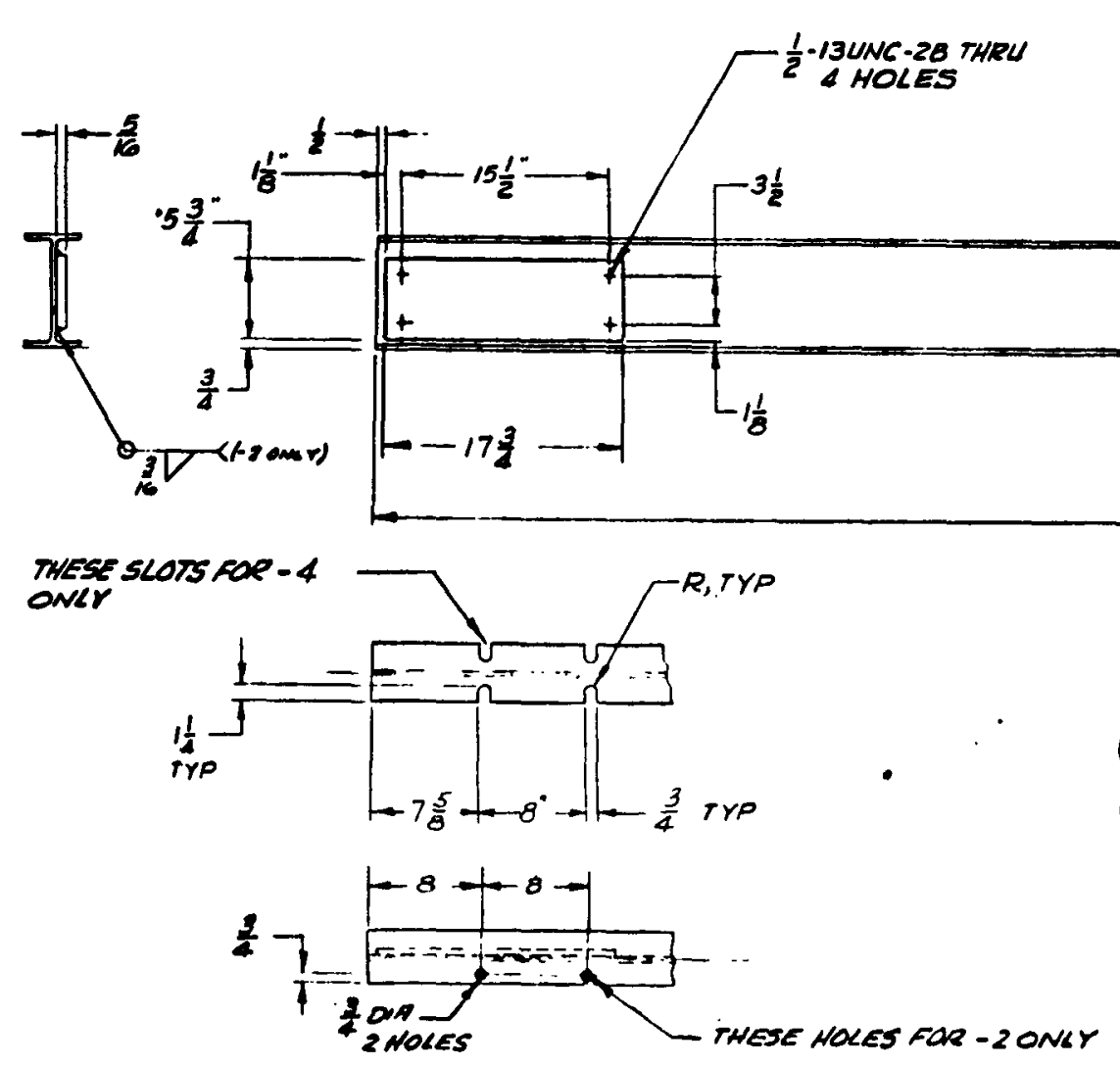

(-2) RAIL ASSY

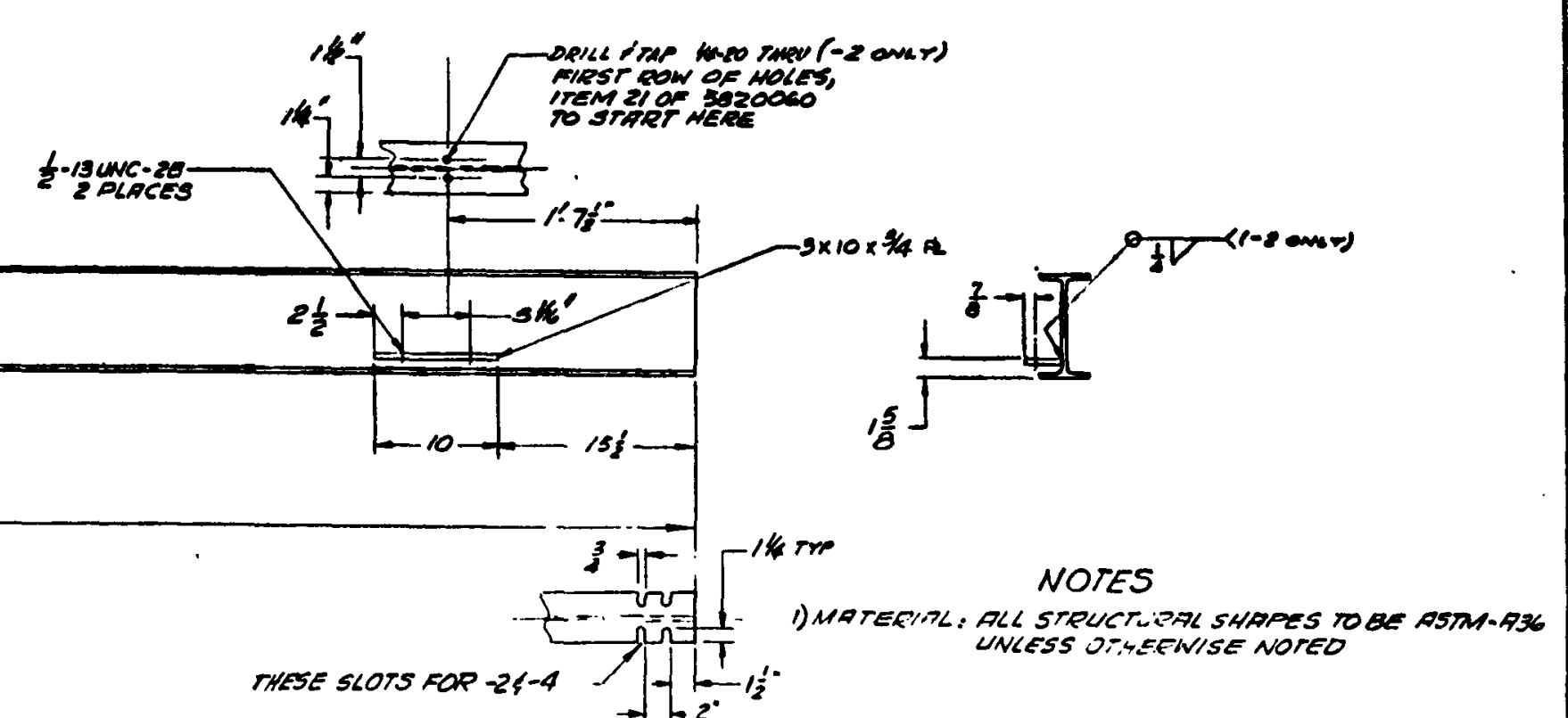

$(-4$

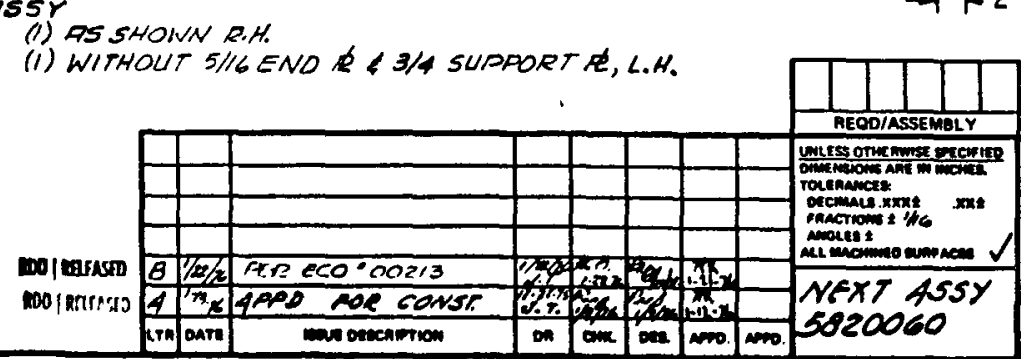

IIII

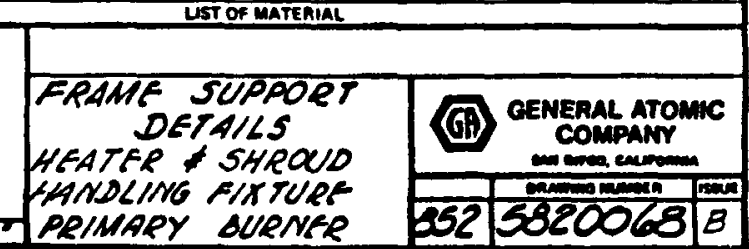

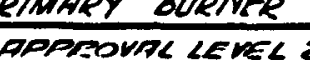



○. 


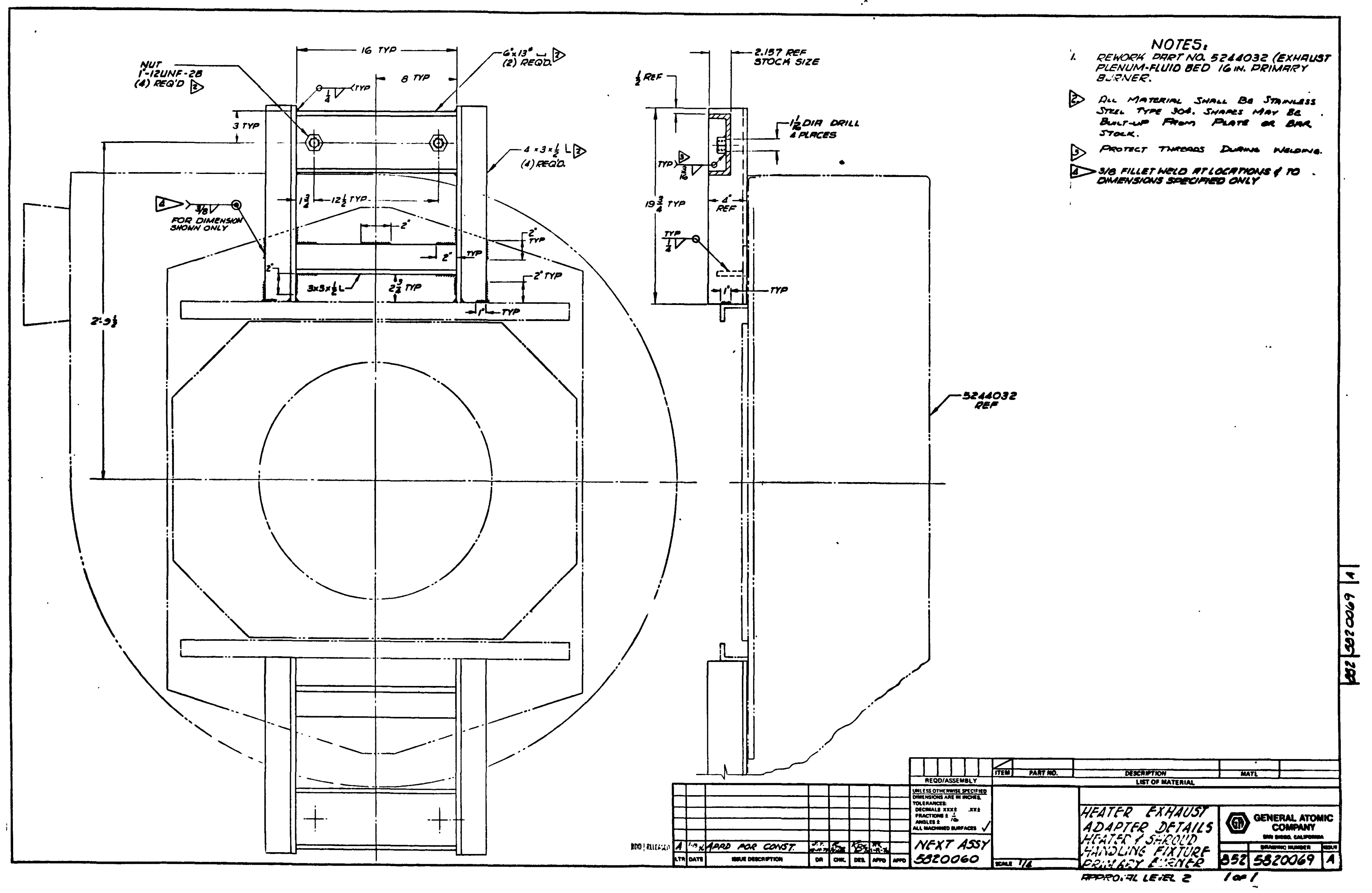


O. . O 
